\title{
Low Cost Processing of Commingled Thermoplastic Composites
}

\author{
By

\section{Matthew Lee Chiasson} \\ A thesis submitted to \\ The Faculty of Graduate Studies and Research \\ in partial fulfillment of \\ the degree requirements of \\ Master of Applied Science \\ Ottawa-Carleton Institute for \\ Mechanical and Aerospace Engineering \\ Department of Mechanical and Aerospace Engineering \\ Carleton University \\ Ottawa, Ontario, Canada \\ January 2012@
}


Library and Archives

Canada

Published Heritage

Branch

395 Wellington Street

Ottawa ON K1A ON4

Canada
Bibliothèque et

Archives Canada

Direction du

Patrimoine de l'édition

395 , rue Wellington

Ottawa ON K1A ON4

Canada
Your file Votre référence

ISBN: 978-0-494-91576-9

Our file Notre référence

ISBN: 978-0-494-91576-9
NOTICE:

The author has granted a nonexclusive license allowing Library and Archives Canada to reproduce, publish, archive, preserve, conserve, communicate to the public by telecommunication or on the Internet, loan, distrbute and sell theses worldwide, for commercial or noncommercial purposes, in microform, paper, electronic and/or any other formats.

The author retains copyright ownership and moral rights in this thesis. Neither the thesis nor substantial extracts from it may be printed or otherwise reproduced without the author's permission.
AVIS:

L'auteur a accordé une licence non exclusive permettant à la Bibliothèque et Archives Canada de reproduire, publier, archiver, sauvegarder, conserver, transmettre au public par télécommunication ou par l'Internet, prêter, distribuer et vendre des thèses partout dans le monde, à des fins commerciales ou autres, sur support microforme, papier, électronique et/ou autres formats.

L'auteur conserve la propriété du droit d'auteur et des droits moraux qui protege cette thèse. $\mathrm{Ni}$ la thèse ni des extraits substantiels de celle-ci ne doivent être imprimés ou autrement reproduits sans son autorisation.
In compliance with the Canadian Privacy Act some supporting forms may have been removed from this thesis.

While these forms may be included in the document page count, their removal does not represent any loss of content from the thesis.
Conformément à la loi canadienne sur la protection de la vie privée, quelques formulaires secondaires ont été enlevés de cette thèse.

Bien que ces formulaires aient inclus dans la pagination, il n'y aura aucun contenu manquant. 
The undersigned recommend to

The Faculty of Graduate Studies and Research

Acceptance of the thesis

\title{
Low Cost Processing of Commingled Thermoplastic Composites
}

\author{
Submitted by Matthew Lee Chiasson \\ in partial fulfillment of the requirements for the degree of \\ Master of Applied Science
}

Dr. Jeremy Laliberté, Thesis Supervisor

Dr. Metin Yaras, Chair, Department of Mechanical and Aerospace Engineering

Carleton University

2012 


\section{Abstract}

A low cost vacuum consolidation process has been investigated for use with commingled thermoplastic matrix composites. In particular, the vacuum consolidation behaviour of commingled polypropylene/glass fibre and commingled nylon/carbon fibre precursors were studied. Laminates were consolidated in a convection oven under vacuum pressure. During processing, the consolidation of the laminate packs was measured by use of noncontact eddy current sensors. The consolidation curves are then used to tune an empirical consolidation model. The overall quality of the resulting laminates is also discussed.

Dynamic mechanical analysis, differential scanning calorimetry and mechanical tensile testing were also performed in order to determine the effects of varying processing parameters on the physical and mechanical properties of the laminates. Through this analysis, it was determined that the nylon/carbon fibre blend was not suitable for vacuum consolidation, while the polypropylene/glass fibre blend is a viable option for vacuum consolidation.

The ultimate goal of this work is to provide a foundation from which low cost unmanned aerial vehicle (UAV) components can be designed and manufactured from thermoplastic matrix composites using a low cost processing technique as an alternative to traditional thermoset composite materials. 


\section{Acknowledgements}

A great many people contributed to this work, both directly and indirectly, all very deserving of my thanks.

Firstly, I need to thank Dr. Jeremy Laliberté for accepting me as his student, and giving me the freedom to determine my own path through this degree. Drawing on his experiences as graduate student, Research Officer at the National Research Council, and assistant professor at Carleton University have been invaluable throughout my research. Furthermore, his understanding of the trials and tribulations experienced by a graduate student have made my research progress much more smoothly than it would have otherwise, and for this I am very thankful.

I would like to thank the researchers at the National Research Council Industrial Materials Institute for donating the commingled material used for this research.

I was provided a great deal of support from Research Officers Drazen Djokic and Dr. Chun Li at the National Research Council Institute for Aerospace Research. The time they spent improving my understanding of composites processing and guiding me through the ups and downs of experimental research was extremely helpful. Also Technical Officers Brian Moyes and Mathieu Harrison provided me a great deal of their time, and facilities. Without their support, the quality of this research would have suffered.

My colleagues Kurtis Kraemer and André Couture deserve mention. Both provided a great deal of help and moral support throughout both my degrees are Carleton University, making them both more enjoyable than they would have been otherwise. 
Finally, my wonderful parents Nicola and Jerome, and my lovely girlfriend Maura deserve a great deal of credit for always believing in me, and providing me the motivation and emotional support required to complete this degree. Thank you. 


\section{Table of Contents}

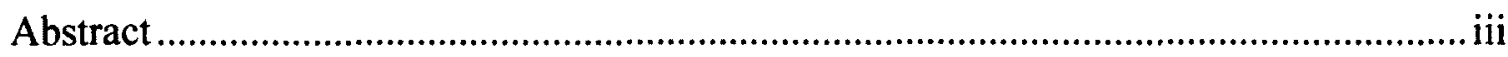

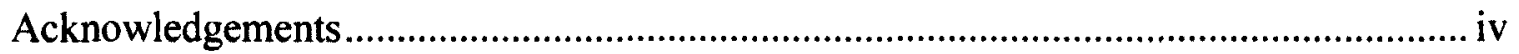

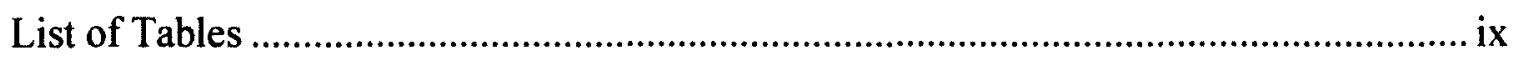

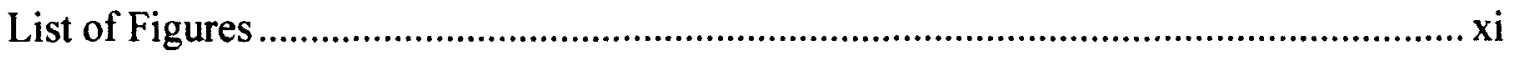

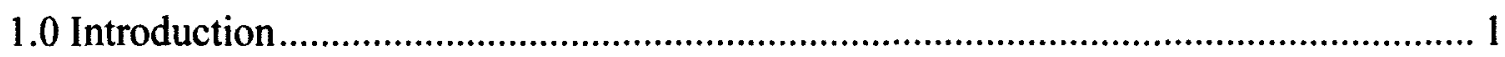

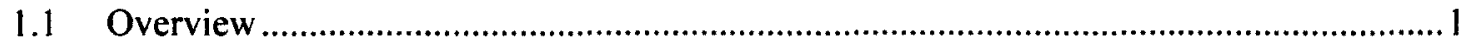

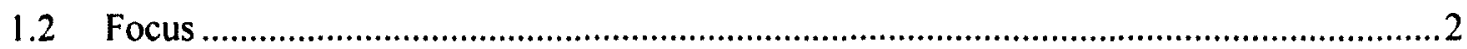

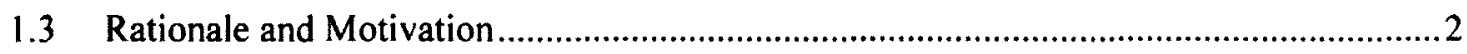

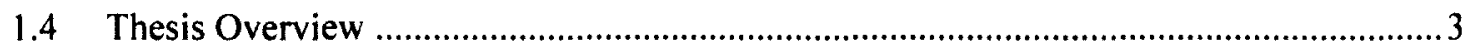

1.5 Objective ....................................................................................................

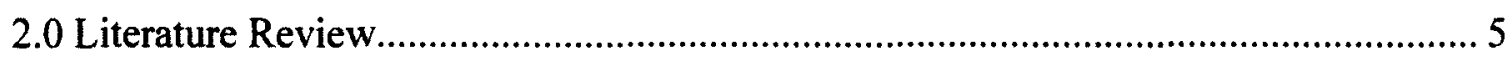

2.1 Thermoplastic vs. Thermosetting Polymers..................................................................

2.1.1 Thermosetting Polymers ......................................................................................

2.1.2 Thermoplastic Polymers ........................................................................................ 8

2.2 Processing of Thermoplastic Composites .....................................................................11

2.2.1 Pre-Impregnation Processing ............................................................................12

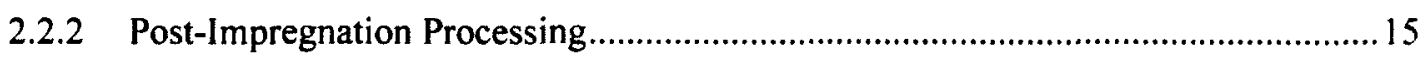

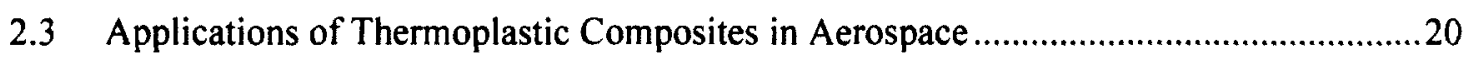

2.4 Discussion and Conclusions .......................................................................................23

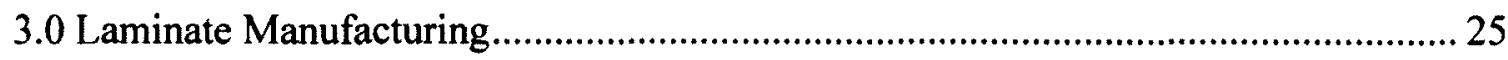

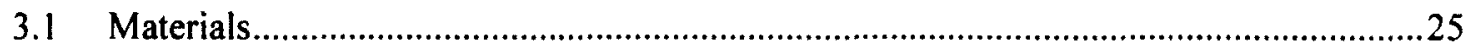

3.1.1 Commingled Polypropylene/E-glass....................................................................26 


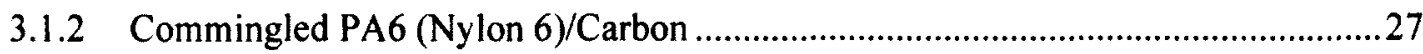

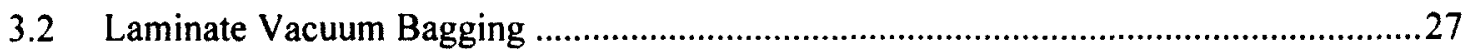

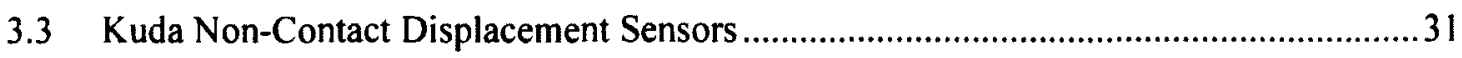

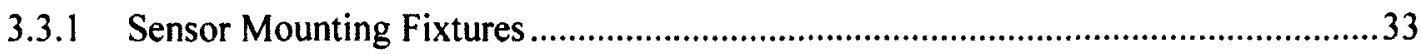

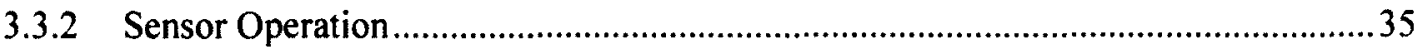

3.4 Vacuum Consolidation Process Development …............................................................ 37

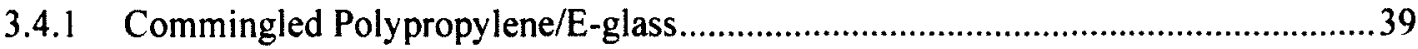

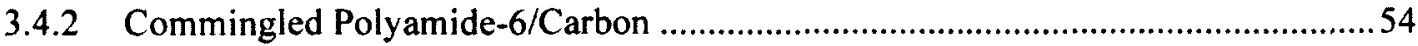

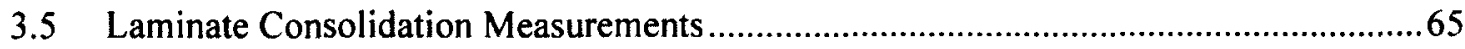

3.5.1 Thermal Effects on the Kuda Displacement Sensors .........................................69

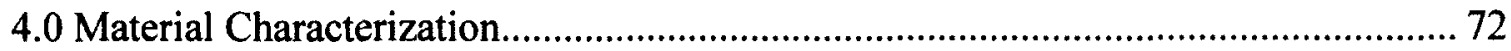

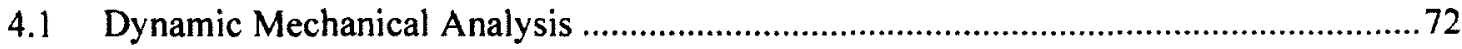

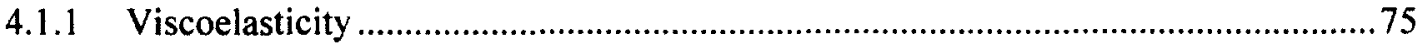

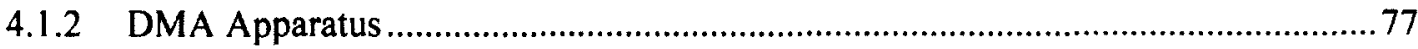

4.1.3 Dynamic Mechanical Analysis Coupon Preparation .............................................80

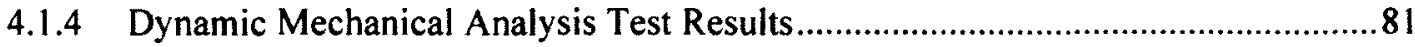

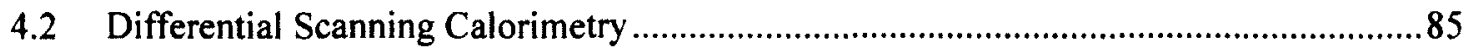

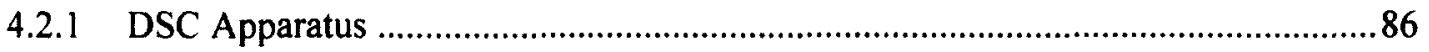

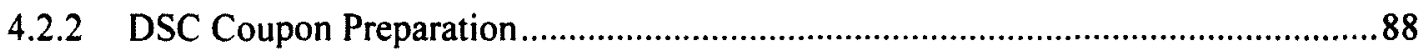

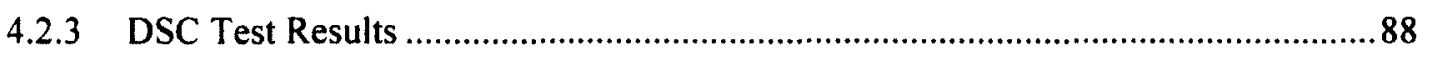

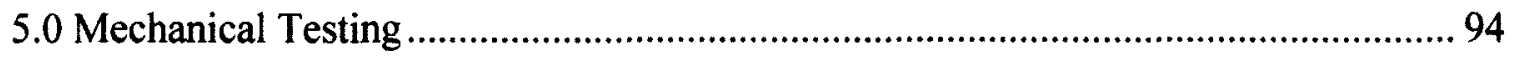

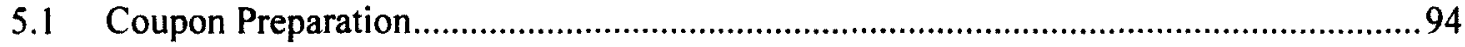

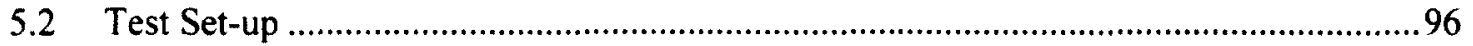

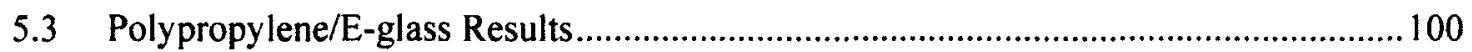

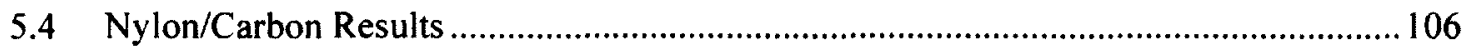


6.0 Consolidation Modelling …………..................................................................... 111

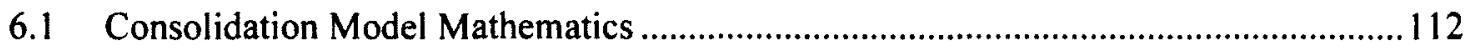

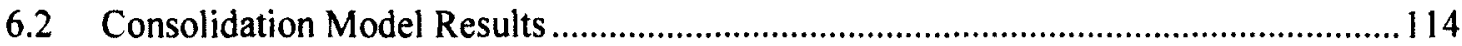

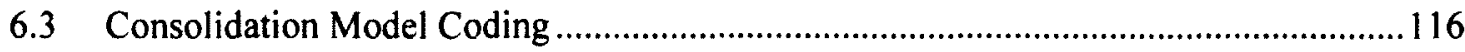

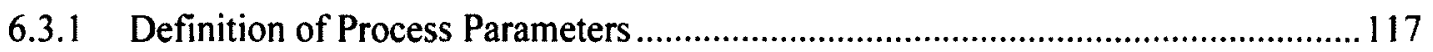

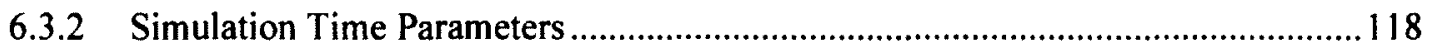

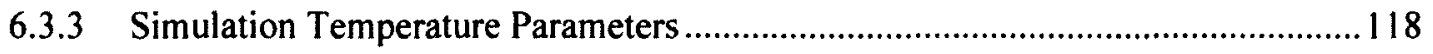

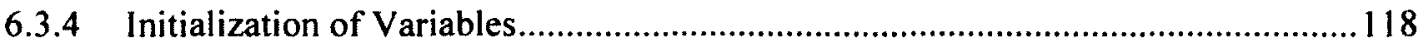

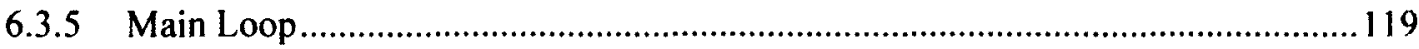

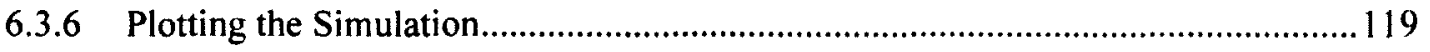

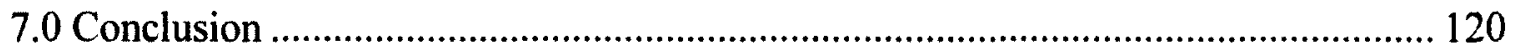

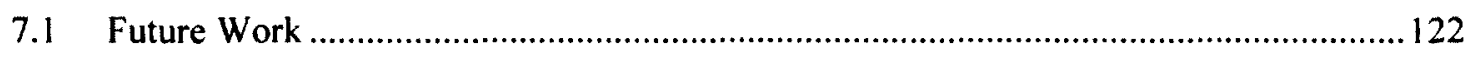

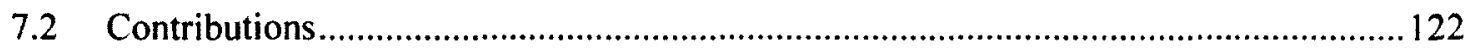

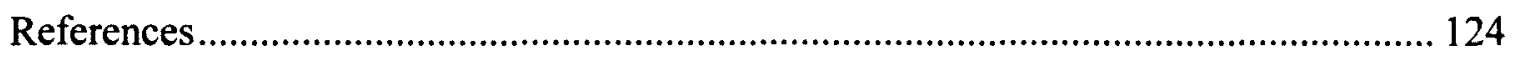

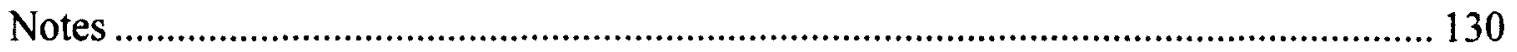

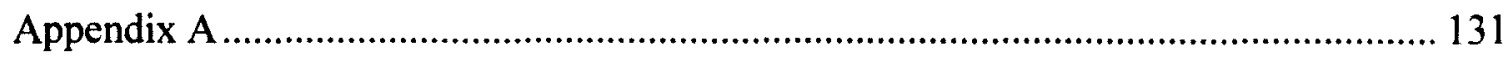

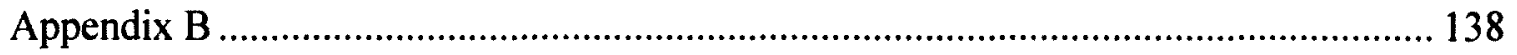

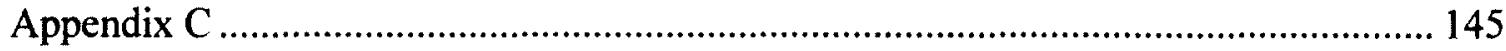

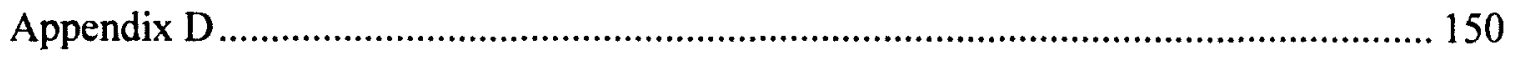




\section{List of Tables}

Table 1: Material information for common thermoplastic polymers used in structural aerospace composites. Epoxy included for comparison to a common thermoset polymer (NRC Material Data Sheet [date unknown]) ......................................... 10

Table 2: Material information for common reinforcing fibres used in structural aerospace (Hexcell Corporation, 2007) (Toray Carbon Fibers America, 2008) (Chalwa, 1998). 10

Table 3: Post-impregnation process comparison (Vaidya, 2008) …................................ 15

Table 4: Summary of reinforced thermoplastic applications on aerospace vehicles........ 23

Table 5: Vacuum bag material information ................................................................. 28

Table 6: Specifications of the Kaman Instruments Kuda non-contact displacement sensor 32

Table 7: Processing parameters for PPG processing trials ............................................... 40

Table 8: Processing parameters and thickness data for PPG T1 .................................... 40

Table 9: Processing parameters and thickness data for PPG T2 ..................................... 43

Table 10: Processing parameters and thickness data for PPG T3 ………......................... 45

Table 11: Processing parameters and thickness data for PPG T4 ……………………... 47

Table 12: Processing parameters and thickness data for PPG T5 ………………............ 49

Table 13: Processing parameters and thickness data for PPG B1 …............................... 50

Table 14: Processing parameters and thickness data for PPG B2 ………………...........53

Table 15: Processing parameters for NC manufacturing trials .......................................55

Table 16: Processing parameters and thickness data for NC T1 ....................................55

Table 17: Processing parameters and thickness data for NC T2 .....................................58 
Table 18: Processing parameters and thickness data for NC T3

Table 19: Processing parameters and thickness data for NC T4 ……………………....61

Table 20: Processing parameters and thickness data for NC B1 ......................................63 63

Table 21: Processing parameters and thickness data for NC B2 ....................................... 64

Table 22: Specifications for the TA Instruments Q800 Dynamic Mechanical Analyzer

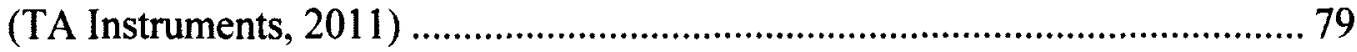

Table 23: Dynamic mechanical analysis test parameters ................................................. 79

Table 24: Processing parameters for PPG processing trials ............................................ 82

Table 25: Processing parameters for NC processing trials ............................................ 83

Table 26: Specifications for the TA Instruments Q2000 Dynamic Scanning Calorimeter ㄴ.

Table 27: Differential scanning calorimetry test parameters............................................ 88

Table 28: PPG tensile coupon thickness data ……………......................................... 96

Table 29: NC tensile coupon thickness data .................................................................. 96

Table 30: Number of tensile coupons tested from each panel ...................................... 102

Table 31: Average coupon thickness and heat of crystallization for each PPG panel.... 102

Table 32: Coupon thickness measurements for PPG B2 ............................................ 105

Table 33: Number of tensile coupons tested from each NC panel ................................. 106

Table 34: Average coupon thickness and heat of crystallization for each NC panel ..... 107

Table 35: Tensile modulus of each coupon from T2 ………………………………. 107

Table 36: Effect of varying each constant in the consolidation model........................... 114

Table 37: Consolidation model parameters for PPG, NC, and PET/Glass (Ijaz, 2006) . 114 


\section{List of Figures}

Figure 1: GeoSurv II UAV showing the location of the payload bay hatches on the

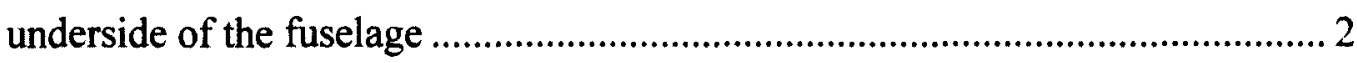

Figure 2: Schematic of a cross-linked thermoset polymer................................................... 8

Figure 3: Schematic of a commingled fibre tow (bundle) …………….......................... 15

Figure 4: Schematic of the filament winding process.................................................. 19

Figure 5: "J-nose" component of the Airbus A380 being prepared for resistance welding of ribs to skin (Beauclaire, 2001) ........................................................................ 21

Figure 6: Commingled polypropylene/E-glass precursor material, as received from NRC-

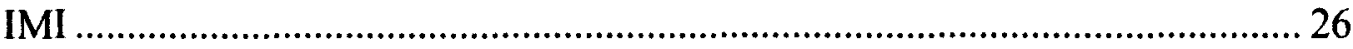

Figure 7: Commingled polyamide 6/carbon precursor material, as received from NRC-

AMTC 27

Figure 8: Vacuum bag arrangement for laminate consolidation trials 28

Figure 9: Vacuum bag preparation (a) Tool plate preparation, (b) Laying up dry fabric on the tool plate, (c) Placing the caul plate over the laid up material, and (d) Covering the assembly with breather cloth and a vacuum bag. 30

Figure 10: A non-contact eddy current sensor mounted within an aluminum fixture ...... 32

Figure 11: Schematic of eddy current position sensor operation (Kaman Instrumentation, 2001) 32

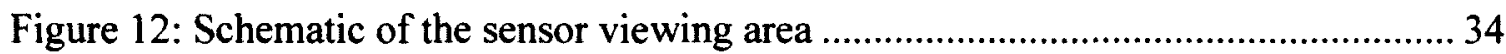

Figure 13: Non-contact displacement sensor mounting fixture ......................................35

Figure 14: Non-contact displacement sensor mounting fixture as configured by Laliberté et al. (2007) 35 
Figure 15: Non-contact displacement sensor mounting fixture 36

Figure 16: A cutout in the breather cloth at the sensor measurement location. .36

Figure 17: Vacuum bag assembly thickness measurement to determine the consolidation distance achieved during processing 38

Figure 18: A typical vacuum consolidation process cycle........ 39

Figure 19: Location where breather cloth wedged under the caul plate during processing

Figure 20: Temperature profile for PPG T1 showing significant laminate temperature lag

Figure 21: Cross section images of PPG T1 43

Figure 22: Cross section images of PPG T2 ………................................................. 44

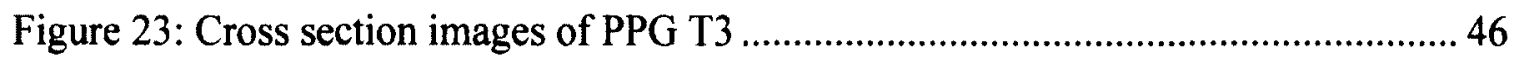

Figure 24: PPG T4 laminate showing significant white areas (due to the E-glass fibres).47

Figure 25: Cross section images of PPG T4 ………................................................ 48

Figure 26: Cross section images of PPG T5 ............................................................. 49

Figure 27: An example of vacuum bag degradation occurring during processing ........... 51

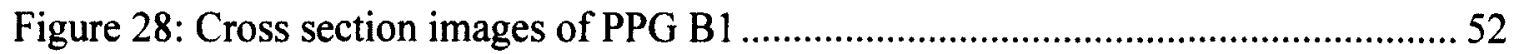

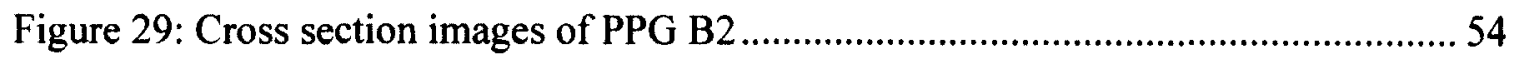

Figure 30: Raw consolidation data for $\mathrm{NC} \mathrm{T} 1$ showing the onset of the resin melt at approximately $180^{\circ} \mathrm{C}$

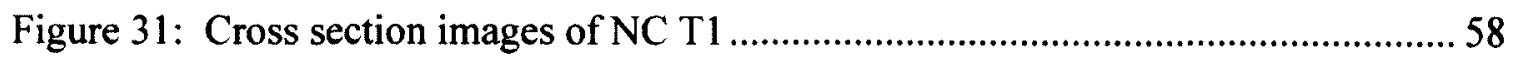

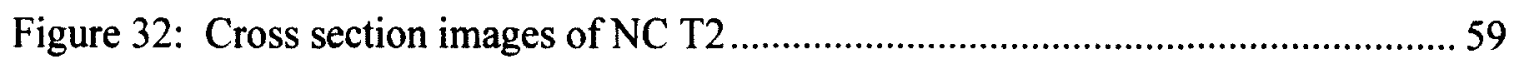

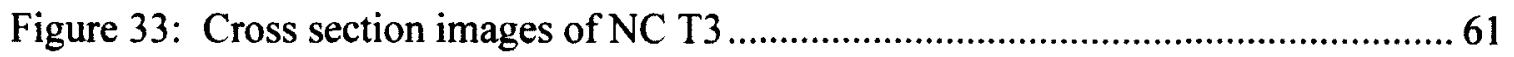




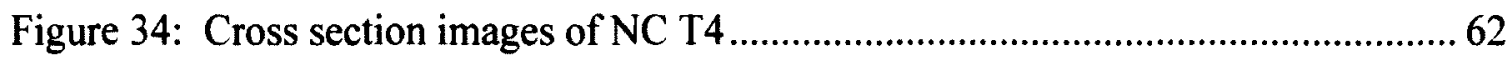

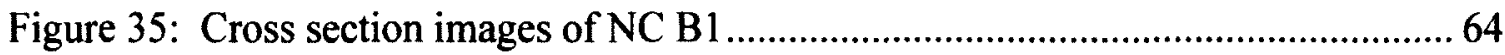

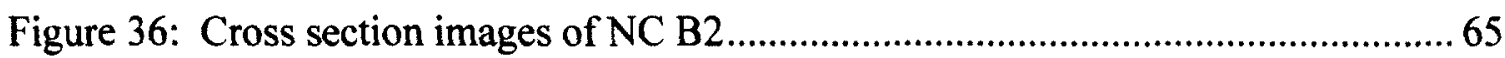

Figure 37: A typical consolidation plot for a PPG laminate ..............................................68

Figure 38: A typical consolidation plot for a NC laminate................................................6 68

Figure 39: Schematic of a non-contact displacement sensor with a fixed target and offset

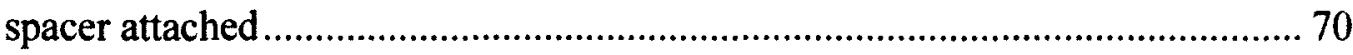

Figure 40: Dry run displacement measurements taken with a fixed target attached to the

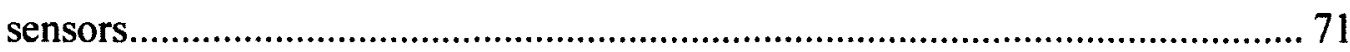

Figure 41: Kuda displacement sensor correction factors ................................................ 71

Figure 42: An example DMA plot demonstrating three methods of determining $T_{g} \ldots \ldots . .74$

Figure 43: TA Instruments Q800 Dynamic Mechanical Analyzer (located at McGill University, Montreal Canada) with a test coupon installed in the three-point bend fixture

Figure 44: Schematic of the TA Instruments Q800 DMA with a three point bend fixture 78

Figure 45: DMA results for the polypropylene/glass (PPG) blend.................................. 82

Figure 46: DMA results for the nylon/carbon (NC) blend ............................................83 83

Figure 47: An example of a DSC plot for the PPG blend with the heat of melt and

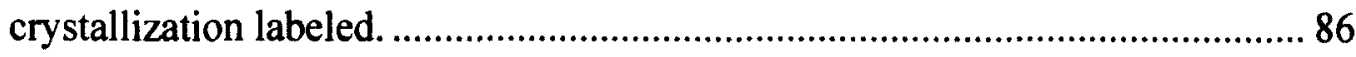

Figure 48: TA Instruments Q2000 Dynamic Scanning Calorimeter (located at McGill

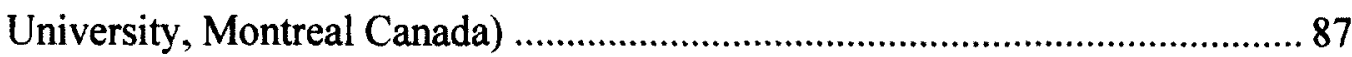

Figure 49: Schematic of a dynamic scanning calorimeter ................................................ 87 


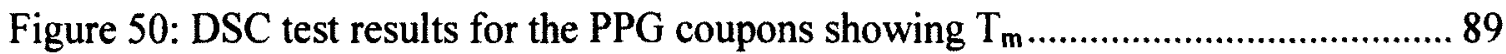

Figure 51: DSC test results for the PPG coupons showing heat of crystallization............89

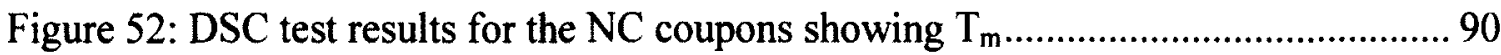

Figure 53: DSC test results for the NC coupons showing heat of crystallization.............. 90

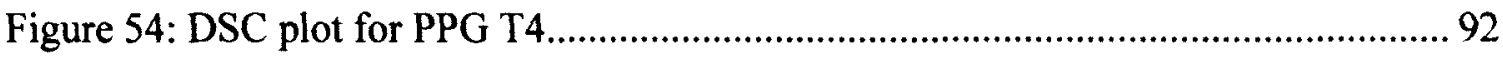

Figure 55: An example of a water jet cut edge of a tensile coupon................................. 95

Figure 56: Cutting template used to cut test coupons from the laminates manufactured in this work. Tensile coupons (10 in $\times 1$ in), DMA coupons (2.2 in $\times 0.4$ in) and optical microscopy coupons $(1$ in $\mathrm{x} 1$ in) are shown .......................................... 95

Figure 57: MTS test frame with a tensile coupon installed in the grips ........................... 97

Figure 58: A tensile test coupon failed at the grips ...................................................... 98

Figure 59: Strain vs. time plot of an initial tensile test showing a variable strain rate due to accumulator saturation in the MTS test frame.................................................. 99

Figure 60: Tensile modulus results for the PPG coupons (processing group of each trial is shown in brackets) 101

Figure 61: Tensile modulus vs. heat of crystallization for the PPG material showing a weak correlation between the two properties 103

Figure 62: Schematic of the caul plate bending under pressure applied during autoclave processing 104

Figure 63: Schematic of a tensile test coupon showing the location of each thickness measurement 105

Figure 64: Tensile modulus results for the NC coupons.............................................. 106

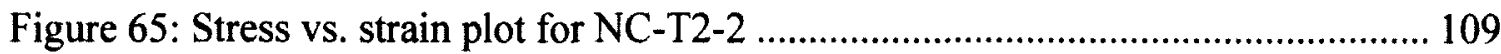


Figure 66: Stress vs. strain plot for NC-T2-4 …......................................................... 109

Figure 67: Consolidation model output compared to experimental consolidation data for

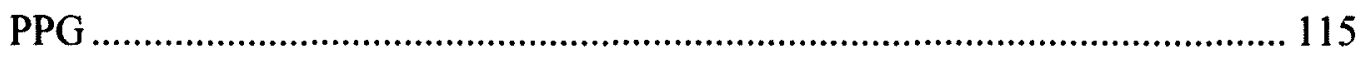

Figure 68: Consolidation model output compared to experimental consolidation data for $\mathrm{NC}$

Figure 69: Block diagram of the consolidation model code execution ........................ 117 


\subsection{Introduction}

This chapter will provide an overview of the research, give details on the focus and rationale for this work, and conclude with some notes on the research objectives.

\subsection{Overview}

Unmanned aerial vehicles (UAVs) have been a topic of research at Carleton University throughout the past ten years. One of the main areas of research has been low cost manufacturing of composite structures for UAV applications. One of the UAVs currently under development at Carleton University is the GeoSurv II, designed to perform geophysical surveys for Sander Geophysics Limited (SGL). Due to the sensitivity of the magnetometer payload of this aircraft to any metallic materials in the airframe, an allcomposite airframe has been developed. Currently, the structure of the aircraft is manufactured using carbon fibre reinforced epoxy.

An opportunity to improve the payload bay hatches (located on the underbelly of the fuselage, shown in Figure 1) by using thermoplastic matrix composites has been identified. Since these components are located on the bottom side of the fuselage, they are susceptible to impact damage from loose rocks or debris that may be present on the remote airfields where this aircraft is intended to operate. By taking advantage of the impact damage resistance properties of thermoplastic matrix composites, a more durable component may be feasible. In addition of the impact damage resistance, the potential for low cost, integrated manufacturing is attractive, and is in line with the more broad research interests at Carleton University. 


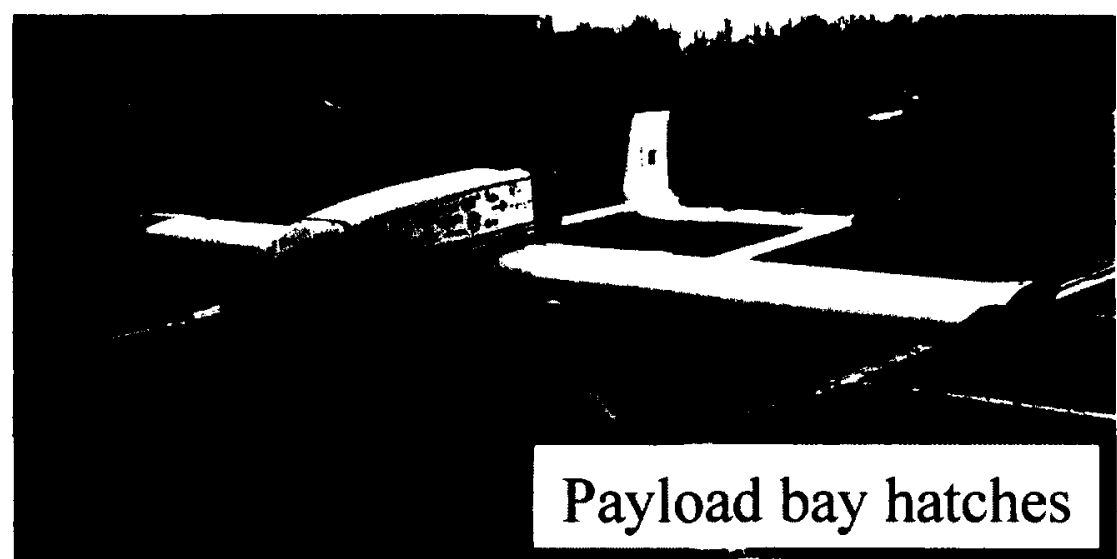

Figure 1: GeoSurv II UAV showing the location of the payload bay hatches on the underside of the fuselage

\subsection{Focus}

The focus of this research is on low cost manufacturing techniques for thermoplastic matrix composites. More specifically, determining a suitable low-cost manufacturing process for small manufacturing runs is the main focus.

\subsection{Rationale and Motivation}

Although the use of composite materials in aerospace applications has become more commonplace in recent years, the large majority of materials selected for these applications have been of the thermosetting matrix type. Despite a number of advantages associated with thermoplastic matrix composites including increased damage resistance, integrated manufacturing techniques and recyclability, difficulty in material processing has been a limiting factor. The main reason for this difficulty is their relatively high viscosities when in their molten form when compared to thermosets. This makes the impregnation of reinforcing fibres significantly more difficult and costly. 
This present research attempts to overcome these challenges and produce high quality thermoplastic matrix composites at a low cost. By achieving this, the advantages of these materials can be exploited to produce better aerospace components in terms of durability, part count, labour, and cost. Additionally, exploring the possibilities associated with a relatively new material type with a vision to improving the current UAV structures being manufactured at Carleton University provided the required motivation to pursue this work.

\subsection{Thesis Overview}

The first step in this research was to identify the current thermoplastic materials and processes being used in the aerospace, automotive, and marine industries. By exploring the current state of the art in terms of thermoplastic composites, potential materials and processes were identified that fit within the low-cost category.

Once a feasible material and manufacturing process combination was identified, laminate manufacturing trials were conducted to gain experience with thermoplastic processing techniques. A number of processing parameters were investigated, based on published manufacturing recommendations from various sources. During laminate manufacturing, the consolidation (or through thickness compaction) was measured to better understand the manufacturing process. From the resulting laminates, a number of test coupons were cut in order to further evaluate the effect of various processing parameters on the physical and mechanical properties of the materials.

Finally, an empirical model was implemented to reproduce the consolidation behaviour of the laminates during processing. The purpose of this model was to provide 
a first estimate of laminate consolidation behaviour to more efficiently design manufacturing processes in the future.

\subsection{Objective}

The objective of this thesis is to provide a foundation of knowledge on thermoplastic matrix composites from which future research can be based. Specifically, determining an efficient and low-cost manufacturing process to produce thermoplastic matrix composite components was the primary objective. The high level objective of this work is to improve on current UAV component design at Carleton University. 


\subsection{Literature Review}

In recent years, composite materials have been increasingly used in automotive and aerospace applications due to a larger emphasis on both manufacturing efficiency (manufacturing time, labour, cost) and vehicle operating efficiency (mainly fuel consumption) (Total Plastics Inc, 2010 and Michaels, 2007). The high specific strength of composite material allows designers to reduce weight while maintaining adequate strength and stiffness. In particular, fibre reinforced epoxy matrix (thermoset) composites have traditionally dominated the high performance composite landscape. However, the use of thermoplastic matrix composites has been increasing. Until recently, the use of thermoplastic composites has been limited to secondary and tertiary aircraft structures such as vehicle flooring and rudder trailing edges. Now, thermoplastic composites have reached a level of maturity where they have been used to manufacture primary aircraft structure (High Performance Composites, 2006).

Although many thermoplastic matrices are commercially available, only a small number have been used in aerospace applications due to the stringent material requirements found in this industry. High strength, toughness and resistance to moisture and various chemicals are among some of material properties sought by aerospace engineers. Adding to the difficulty of material selection are the processing requirements of these materials. The matrix material of a composite must be compatible with the reinforcing fibres, and it must be economical to manufacture components using this material.

When compared with thermosetting matrix composites, thermoplastics typically require higher processing temperatures, leading to higher capital costs, due to their higher 
melt viscosities that are typically 500-1000 times that of thermosets (Eire Composites, [date unknown]). This significantly increases the final cost of components, and is a good indication of why thermoplastics have traditionally taken a back seat to thermosets in aerospace applications. Another factor that has made thermosets a more attractive choice than thermoplastics is the extensive material databases available for thermosets as a result of their extensive use. More recently, advances in thermoplastic chemistry have produced less costly raw materials making them more attractive. Advances in processing technology have also made the use of thermoplastics significantly more economical. By taking advantage of novel processing technologies such as fusion bonding, a number of cost savings are possible. For example, consider a wing rib being joined to a wing skin. Traditionally, a metallic wing rib would be fastened to the wing skin with rivets, requiring a technician to perform the riveting. More recently, thermosetting matrix composite parts would be secondarily bonded together to form the joint. In both of these examples, two distinct components have been joined, and therefore that joint would have to be certified in order to enter into service. Now consider the same assembly made from thermoplastic matrix composite components. Fusion bonding could be used to join the components, resulting in a continuous structure with no mechanical fastening. Additionally, the process could be automated to further reduce labour costs. Since the resulting assembly is one continuous part, the certification of that joint has been eliminated. Add to this the fact the material waste is reduced since unlike thermosetting polymers, thermoplastics have near unlimited shelf life, and do not require refrigeration for storage. All of these cost saving features have lead to increase in interest and application of thermoplastic matrix composites. 
The following sections provide an overview of the state of thermoplastic composites in the aerospace industry. First, there is a discussion on the distinctions between thermoset and thermoplastic polymers, and some characteristics of each type are discussed. Next, the most common matrix and fibre materials used in aerospace thermoplastic composites are outlined. The processes that transform the raw matrix and fibres into final aerospace components are then discussed. To put the materials and processes into context, a discussion of specific aircraft components and the corresponding processing techniques is provided.

\subsection{Thermoplastic vs. Thermosetting Polymers}

The matrices found in modern fibre reinforced polymer composite materials can be divided into two distinct groups: thermosetting polymers (TSPs) and thermoplastic polymers (TPPs). The manner in which the molecules of each type of polymer interact is what governs their various physical, chemical and mechanical properties.

\subsubsection{Thermosetting Polymers}

Thermosetting polymers (e.g. epoxy, phenolic, polyimide) exhibit a three dimensional cross-linked molecular structure as shown in Figure 2 (Baker, 2004). This structure is formed when the polymer is cured (e.g. by the addition of a catalyst, or heat). The curing of TSP typically takes a number of hours to complete. During the curing process, TSPs generally experience a period of low viscosity that facilitates the addition of reinforcement. TSPs are amorphous materials, meaning there is no local order to their arrangement of molecules. Once cured, TSPs cannot be melted or reformed. 


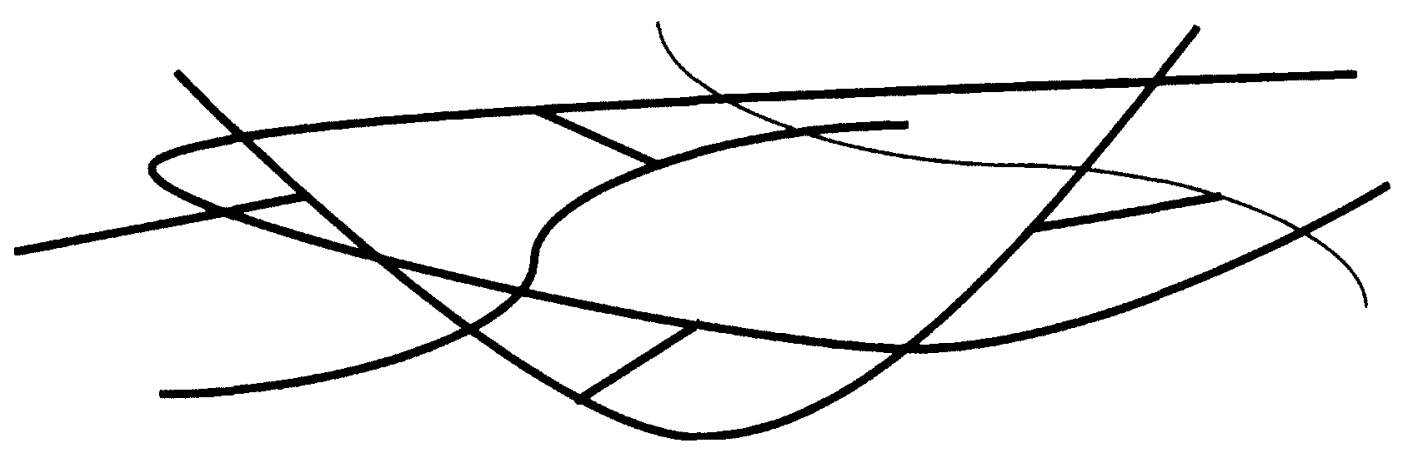

Figure 2: Schematic of a cross-linked thermoset polymer

The rigidity of the three dimensional, cross-linked nature of TSPs results in relatively low strain-to-failure and low impact energy absorption. In addition, the crosslinked structure produces a matrix that is highly resistant to solvents.

\subsubsection{Thermoplastic Polymers}

Thermoplastic polymers do not undergo a chemical change when heated; therefore no additional cross-linking occurs (Vaidya, 2008). However partial crystallinity, or local alignment of polymers, is possible in TPPs. Due to the lack of a curing reaction in TPPs, processing times can be much quicker relative to TSPs (on the order of minutes). The degree of crystallinity in a TPP is a function of its processing history. One of the most important parameters governing crystallinity is the cooling rate of the polymer from a liquid to solid state. Salek (2005) noted that by varying the cooling rate of poly-etherketone-ketone (PEKK) from $7^{\circ} \mathrm{C} /$ minute to $10^{\circ} \mathrm{C}$ /minute, the degree of crystallinity in the TPP decreased from $16 \%$ to $8 \%$. TPPs that are not $100 \%$ amorphous are classified as semi-crystalline. This implies that the structure of the matrix is generally amorphous, however segments of crystalline polymer can be found throughout. 
The mechanical properties of TPPs are affected by the degree of crystallinity. El Kadi et al. (2001) showed that carbon fibre reinforced poly-ether-ether ketone (PEEK) coupons manufactured with slower cooling rates and therefore higher crystallinity exhibited increased mechanical properties such as shear strength, tensile strength and flexural strength. In addition, as the degree of crystallinity increases, so too does the high temperature performance of the matrix (Muzzy, 2000).

At temperatures above the glass transition temperature $\left(T_{g}\right)$, an amorphous TPP will lose its stiffness and become rubbery. In contrast, a semi-crystalline TPP will retain a portion of its stiffness proportional to its degree of crystallinity. TPPs have very low water absorption, typically in the range of $0.01-0.30 \%$ (Muzzy, 2000).

One of the primary disadvantages of TPPs is their generally high melt viscosity. This makes fibre impregnation extremely difficult by traditional means (i.e. resin transfer moulding).

\subsubsection{Thermoplastic Matrices used in Structural Aerospace}

\section{Composites}

Table 1 presents information on the set of thermoplastic materials that are most commonly found in aerospace composite materials used in structural applications. 
Table 1: Material information for common thermoplastic polymers used in structural aerospace composites. Epoxy included for comparison to a common thermoset polymer (NRC Material Data Sheet [date unknown])

\begin{tabular}{|c|c|c|c|c|c|c|c|}
\hline Matrix & $\begin{array}{c}\text { Semi- } \\
\text { Crystalline/ } \\
\text { Amorphous }\end{array}$ & Density & $\begin{array}{c}\mathrm{T}^{\circ} \text { max } \\
(\text { Continuous })\end{array}$ & $\mathrm{Tg}$ & Tmelt & $\begin{array}{c}\text { Tensile } \\
\text { Modulus }\end{array}$ & $\begin{array}{c}\text { Price } \\
\text { Polymers }\end{array}$ \\
\hline PEEK & $\mathrm{SC}$ & $1.3-1.44$ & 250 & 150 & 330 & 4.5 & High \\
PEI & $\mathrm{A}$ & $1.26-1.7$ & 170 & 215 & 300 & 3.7 & Medium \\
PPS & $\mathrm{SC}$ & $0.35-1.43$ & 200 & 88 & 288 & 3.6 & High \\
PEKK & $\mathrm{SC}$ & 1.31 & 250 & 155 & 305 & 4.4 & High \\
Pl & $\mathrm{A}$ & $1.31-1.43$ & 260 & 250 & 388 & 2.5 & Very High \\
Epoxy & - & $0.96-1.40$ & 300 & $60-300$ & - & $0.007-3.4$ & Low-High \\
\hline
\end{tabular}

\subsubsection{Reinforcing Fibres Used in Structural Aerospace}

\section{Composites}

As with thermoplastic polymer matrices, the number of fibre types used in structural aerospace composites is fairly limited. In aerospace structural applications, carbon fibre is most abundantly used, with glass fibre being the second most common fibre type. Due to the low elastic modulus of glass fibres, they are more commonly used on interior, nonstructural components (Chalwa, 1998). A comparison of density, tensile strength, and tensile modulus of some of the most common reinforcing fibres in aerospace structures is shown in Table 2.

Table 2: Material information for common reinforcing fibres used in structural aerospace (Hexcell Corporation, 2007) (Toray Carbon Fibers America, 2008) (Chalwa, 1998).

\begin{tabular}{|c|c|c|c|}
\hline Fibre Type & $\begin{array}{c}\text { Density } \\
\left(\mathrm{g} / \mathrm{cm}^{3}\right)\end{array}$ & $\begin{array}{c}\text { Tensile Strength } \\
(\mathrm{GPa})\end{array}$ & $\begin{array}{c}\text { Tensile Modulus } \\
(\mathrm{GPa})\end{array}$ \\
\hline IM-7 (carbon) & 1.78 & 5.48 & 276 \\
IM-6 (carbon) & 1.76 & 5.7 & 279 \\
AS4 (carbon) & 1.79 & 4.48 & 231 \\
T300 (carbon) & 1.76 & 3.53 & 230 \\
E-Glass & 2.54 & $1.7-3.5$ & $69-72$ \\
\hline
\end{tabular}


High modulus polypropylene fibres (HMPP), such as those produced under the trade name Innegra, have recently become available commercially. These fibres boast high toughness and low weight, and are commonly mixed with carbon or glass fibres in hybrid composite materials to increase their ballistic properties (Moran, 2009).

Similar to HMPP, Spectra (polyethylene) and Kevlar fibres are also commonly used in ballistic applications, and applications requiring high toughness and wear resistance. A major shortcoming of these fibres is their poor compressive strength (Chalwa, 1998), which limits their use to structural applications where impact resistance is the main design driver (e.g. armour, ballistic clothing, etc.).

\subsection{Processing of Thermoplastic Composites}

One of the main drawbacks of thermoplastic composites is their increased processing difficulty when compared to thermosetting composites. This difficulty arises from generally higher melt viscosities of thermoplastic polymer resins that complicate fibre wetting and impregnation. Vaidya et al. (2008) have summarized the most common means of processing thermoplastic composites, those include:

- Hand lay-up

- Powder impregnation

- Solution impregnation

- Melt impregnation

- Commingling

- Injection moulding
- Automated fibre/tow placement

(ATP/AFP)

- Filament Winding

- Compression Moulding

- Thermoforming

- Pultrusion 
Numerous variations of each process are available, depending on the desired constituent materials, budget limitations and required component properties. These processes can be divided into two groups: pre-impregnation processes, and postimpregnation processes.

\subsubsection{Pre-Impregnation Processing}

In pre-impregnated thermoplastic processing, the fibres are wetted with the matrix material in a process separate from actual part manufacture. Pre-impregnated thermoplastic composites, or prepregs, can be made in sheets, tapes, or films. These prepregs are typically stacked together to form multi-ply laminates that are consolidated with the application of heat and pressure. Thermoplastic prepregs offer many advantages over thermoset prepregs such as unlimited shelf life, short part manufacturing time, and recyclability (Peltonen, 1992).

The following sections discuss the various methods of processing thermoplastic composites.

\subsubsection{Powder Impregnated Tows}

The powder impregnated tow process involves passing reinforcing fibres through a bath of thermoplastic polymer powder (either suspended in a liquid or loosely packed) (lyer, 1990). An electrostatic force between the fibres and the powder cause the particles to adhere to the fibres. After the powder has been deposited on the fibre, it is heated above the thermoplastic's melting temperature and passed through a die to consolidate the 
composite into a prepreg tape. Studies carried out by Vodermayer et al. (1993) have shown that with constant tool and process parameters, the critical factors to consider in this process are particle size and concentration in the impregnation chamber. This group reported that up to $70 \%$ fibre volume fraction is achievable using this impregnation method.

\subsubsection{Solution Impregnated Tows}

One of the main difficulties with wetting reinforcing fibres with thermoplastic matrices is their generally high viscosity. This problem can be circumvented by dissolving the polymer in a solvent to produce a low viscosity solution, which is more easily combined with fibres (Vaidya, 2008). In this process, the reinforcing fibres are passed through a bath of polymer solution before entering a solvent recovery system. A major drawback of this process is that it is difficult to fully recover the solvent deposited on the fibres, which can lead to void formation within the polymer especially upon heating. In addition, since the thermoplastic matrix must be soluble in order to employ this technique, the resultant composite will be susceptible to solvent attack.

\subsubsection{Melt Impregnation}

Melt impregnation is the process of introducing the polymer matrix into the reinforcing fibres while in its molten state (Peltonen, 1992). Typically the fibres are heated and passed through a heated die where molten polymer is extruded into the fibre bundles. This process is compatible with many types of polymers and fibres, and can create high 
quality prepregs with fibre volume fractions typically around 60\% (Vaidya, 2008). Controlling the fibre volume fraction is critical in aerospace applications due to the need to reduce weight. Considering that fibre reinforcement are typically capable of carrying much higher loads than polymer matrices, maximizing the fibre content leads to more efficient composite materials in terms of specific strength.

Recent advances in melt impregnation have resulted in the development of the DRIFT (direct reinforcement fabrication technology) process (Harntess, 2001). This specific variation of hot melt impregnation allows for production rates of up to $60 \mathrm{~m}$ per minute, which makes the process highly economical.

\subsubsection{Commingling Fibres}

Commingling (mixing in a single tow/bundle) of polymer matrix fibres with reinforcing fibres (as shown in Figure 3) addresses the problem of fibre impregnation by reducing the required flow distance of the molten matrix to the order of nanometres (Svensson, 1998). By introducing polymer fibres at the filament level, highly drapable fabrics are possible, which lend well to the manufacture of components with complex geometries. Many problems have been identified with this processing method including uneven matrix distribution and insufficient fibre wetting. In addition, the commingling process is relatively expensive due to the high cost of spinning fine polymer fibres. This cost is partially recovered, however, by using a low cost processing method such as vacuum consolidation in an oven that eliminates the need for expensive processing hardware (such as an autoclave or hot press). 
Twintex is a commercially available brand of commingled fibres (polypropylene and $60 \%$ e-glass by weight) manufactured by Owens Corning.

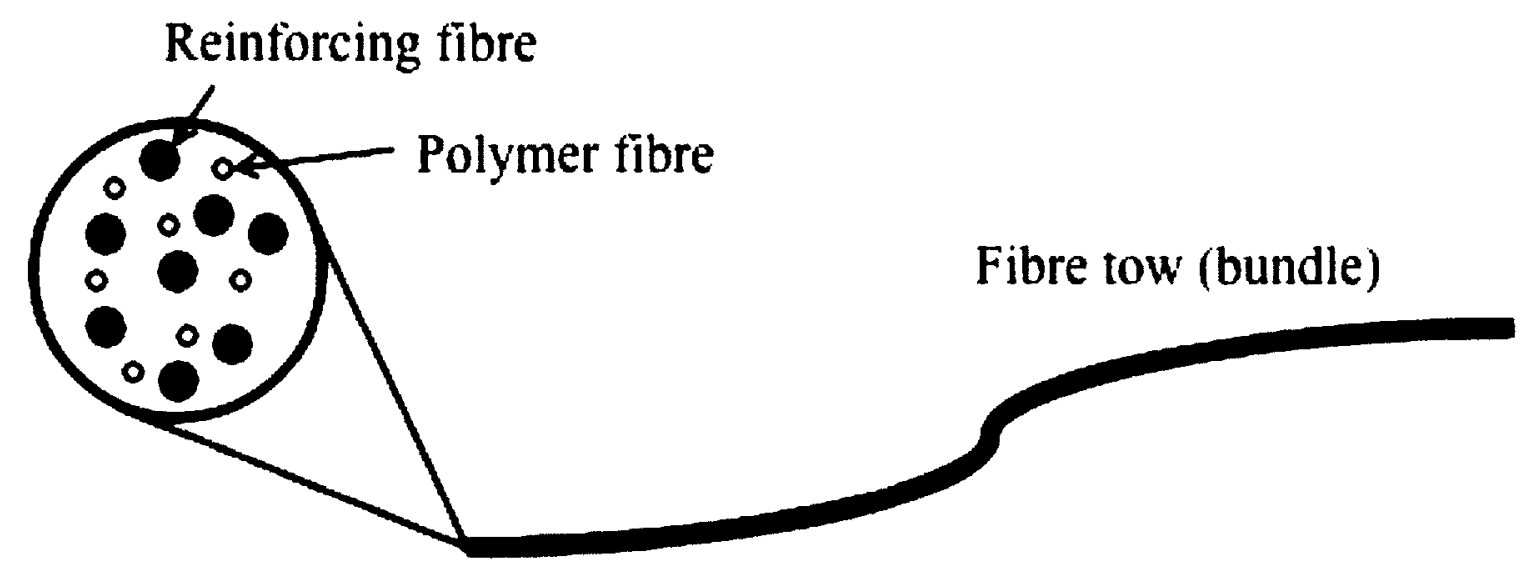

Figure 3: Schematic of a commingled fibre tow (bundle)

\subsubsection{Post-Impregnation Processing}

Post-impregnation processing comprises the processing of prepreg materials into final components in addition to processes that wet out the reinforcing fibres with the matrix material online.

Table 3 presents a qualitative comparison of common processing techniques used to produce thermoplastic and thermoset composite aerospace structures.

Table 3: Post-impregnation process comparison (Vaidya, 2008)

\begin{tabular}{|c|c|c|c|}
\hline Process & Capital Cost & Throughput & Part Complexity \\
\hline Hand lay-up & Low-Very high & Low & Low-High \\
Automated fibre/tow placement & Very high & Moderate-high & Moderate \\
Filament Winding & High & Moderate & Low \\
Thermoforming & Moderate & High & Moderate \\
Pultrusion & Moderate & High & Low \\
Compression Moulding & Moderate & High & Moderate \\
\hline
\end{tabular}

These processes are discussed in further detail in the following sections. 


\subsubsection{Hand Lay-Up}

Hand lay-up is a process in which layers of prepreg are stacked together by hand to form a multi-ply laminate that is cured in an autoclave. The prepreg material is first cut into plies of the desired shape with a cutting tool, or by an automated machine. These plies are then stacked together by hand and debulked to remove excess gasses trapped between plies and to create intimate contact between layers. Debulking can either take place on the complete laminate, or more commonly on smaller groups of lamina. The laminate is then placed on a carefully prepared tool (commonly made of aluminum or steel). The laminate is then bagged and sealed using high temperature materials. Vacuum pressure is applied to the bagged laminate and it is consolidated in an autoclave.

\subsubsection{Pultrusion}

Pultrusion is the process of pulling matrix and reinforcing fibres through a die to create a component of constant cross section (Larock, 1989). This process can be applied to prepreg materials, or the fibres can be wet out online. Online wetting of fibres refers to the process of adding polymer matrix in its molten form to the reinforcing fibres in the same process as the pultrusion. Similar to an assembly line, the reinforcing fibres are drawn through a serious of stages, including (but not limited to) fibre treatment (to improve adhesion to the polymer matrix), fibre wetting, and pultrusion through a die. Devlin et al. (1991) have developed a pultrusion process capable of producing high quality components made from nylon/glass fibres as well as PEEK/carbon prepreg (APC2). They produced components with slightly reduced flexural and inter-laminar shear strength (ILSS) performance comparable to that of unidirectional compressed plaques of 
the same material (10-15\% reduction). Pultrusion has also been studied using commingled thermoplastic fibres (Larock, 1989). It was found that many problems arose when pultruding this material, mostly due to clogging of the pultrusion die by the thermoplastic fibres.

\subsubsection{Thermoforming}

Thermoforming is the process of heating a pre-impregnated thermoplastic sheet to its processing temperature, and forming it to a mould using one of various methods such as hydraulic pressure, gas pressure, or a matched male/female mould (Vaidya, 2008). This process has proven successful for producing single curvature components by Dutta et al. (1991) for APC-2 prepreg, however various other prepregs studied by this group produced parts containing voids and delaminations. This has been attributed to the excellent fibre/matrix distribution and adhesion of APC-2. In an extension of their study, Dutta $e t$ al. were unsuccessful in producing parts containing double curvature due to severe folding and wrinkling of the prepreg (Cakmak, 1991). Despite these problems, the feasibility of this process technique is promising for the manufacture of high quality parts.

\subsubsection{Automated Tape/Tow Placement}

Automated tape placement (ATP) is a process in which a prepreg tape is laid on a tool by a robotic arm. The prepreg is heated online, and consolidated in situ which avoids the need for expensive autoclave post-placement operations (although they are sometimes performed anyway) (Ahrens, 1998). Automated fibre placement machines typically 
have the capability to cut the prepreg tape and add multiple plies in different orientations to create components with complex geometries. A research group from the NASA Langley Research Center have found that laminates manufactured using ATP technology retained about $85-93 \%$ of the strength of hand lay-up/autoclave processed laminates (Shuart et al., 1998)

One of the main drawbacks of this technology is the extremely high capital cost of an ATP machine. Due to the high capital investment required for these robots, relatively few machines are in service worldwide.

\subsubsection{Compression Moulding}

Compression moulding is a process in which a thermoplastic composite sheet is preheated to above the polymer matrices melting temperature, and then placed in a tool that applies pressure and forces the composite charge to flow into its final form. This process is designed so that the final components require little or no trimming, and it is compatible with a wide range of polymers and fibres (Vaidya, 2008). Wakeman et al. (2000) determined an optimized compression moulding cycle for PP/glass composites and concluded that this process is suitable for high volume production of structural components (cycle times of $<1$ minute).

\subsubsection{Filament Winding}

Filament winding is the process of robotically winding prepregs around a tool or mandrel to create a closed geometry part (shown in Figure 4). The prepreg is preheated as it is 
placed on the tool, and it is consolidated by tension applied to the prepreg tape and/or a compaction roller (Lauke, 1993). This process is similar to ATP; however the robotic head does not touch the tool in filament winding. One shortcoming of this process is that fibres cannot be oriented parallel to the winding axis.

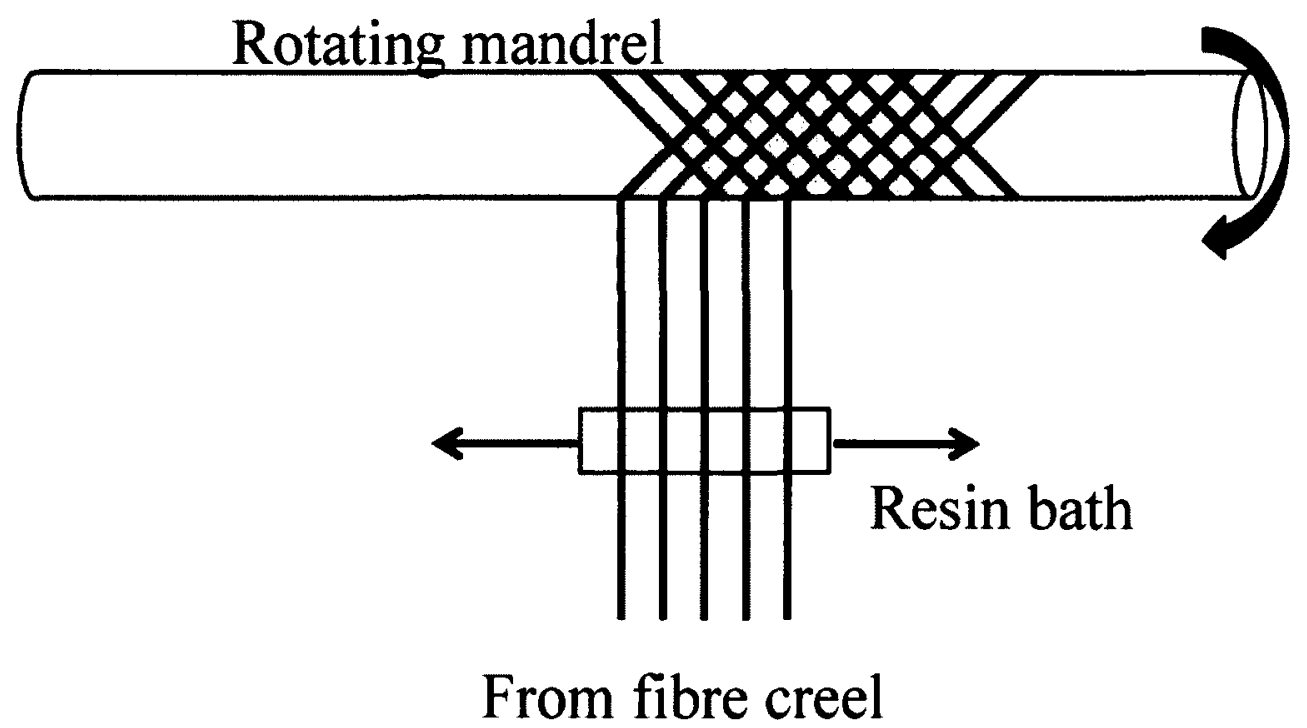

Figure 4: Schematic of the filament winding process

\subsubsection{Fusion Bonding}

In addition to the processing options described above, thermoplastic matrices allow further processing flexibility due to their weldability. Fusion bonding (or welding) of thermoplastics has been studied by Yousefpour et al. (2004). These techniques have significant implications in terms of certification since previously bonded or fastened joints can be replaced by continuous structures via fusion bonding, thus eliminating secondary bonded joints. Specific applications of this technology are further discussed in Section 2.3. 


\subsection{Applications of Thermoplastic Composites in Aerospace}

The prospect of reducing weight, part count and labour costs has been the primary driver responsible for the integration of thermoplastic matrix composites into aerospace vehicles. Stork Fokker introduced carbon and glass fibre reinforced thermoplastics into series production in the late 1980's in the form of cargo floor panels. Taking advantage of the improved toughness of thermoplastics and the emerging thermo-folding processing techniques, floor panels were designed that showed significant improvements in terms of impact damage (Offringa, 2005). Following this, Gulfstream Aerospace and Airbus incorporated similar components into their production aircraft (Offringa, 1996).

The advent of these first thermoplastic composite components proved that thermoplastics were a viable solution for cost and weight savings. The introduction of welding technologies improved the economics of thermoplastic composites by further reducing part counts and labour requirements. By eliminating the need for fasteners and reducing labour costs, the higher material cost of thermoplastics relative to metals or thermosets is offset (Offringa, 1996). When the other advantages of thermoplastics are considered (i.e. infinite shelf life, improved moisture uptake, better reparability, recyclability etc.), it is easy to see why thermoplastic use in aircraft is desirable.

Over the past decade, Airbus has continued to implement thermoplastic composites into their products, namely the fixed leading edges (so called "J-nose", shown in Figure 5) of the A340 500/600, and more recently on the same component of the super-jumbo A380 (Beauclaire, 2001). These components, the fixed portion of the leading edge under the slats, take advantage of automated resistance welding technology to weld compression-moulded ribs to the hand laid leading edge skin. A weight savings 
of $20 \%$ was realized by replacing the older aluminum leading edges, in addition to an improvement in impact resistance, reduced fabrication time and tighter tolerances in the components operating temperature range (Bokulich, 2001).

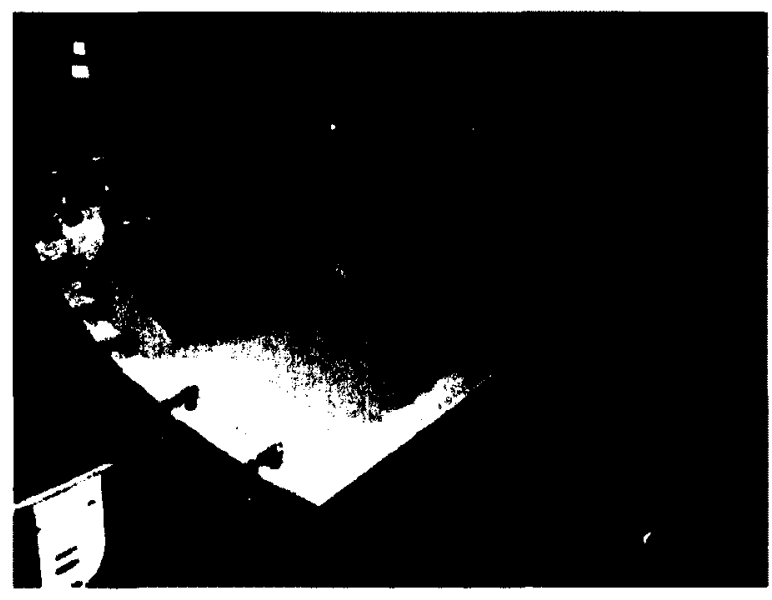

Figure 5: "J-nose" component of the Airbus A380 being prepared for resistance welding of ribs to skin (Beauclaire, 2001)

Thermoplastics have been limited to a narrow range of aircraft components to date. The most common uses have been lightly loaded parts that are susceptible to impact damage, such as floor panels, various skin panels and control surface components. In addition, many non-structural components comprising aircraft interiors exploit the fireresistant properties of thermoplastics.

Table 4 summarizes some of applications where reinforced thermoplastics have been used on aerospace vehicles.

One of the most high profile uses of thermoplastic composites in the Canadian aerospace industry to date is on the Space Station Remote Manipulator System (SSRMS), or the Canadarm 2 installed on the International Space Station. The primary structure of this system consists of four filament wound carbon reinforced poly-ether-ether-ketone 
(PEEK) tubes (Desbiens, 2003). One of the main design requirements of this component was a 30 year service life in the harsh environment of space. This environment presents many challenges to the structure and materials of the Canadarm 2, such as space debris, significant thermal cycling (day-night cycles), and the vacuum effects of space. Carbon fibre/PEEK composite was selected for this application based on its excellent resistance to impact damage, its operational temperature range and its low moisture absorption.

The extent of thermoplastic composite usage on military aircraft is largely unknown. Aircraft such as the F-117, F-22 and B-2 all incorporate reinforced thermoplastic into components that experience relatively light loading, but are susceptible to impact damage such as exterior panels, doors, and trailing edges (Younossi, 2001). Bell Helicopter Textron has designed and flown reinforced thermoplastic wing ribs for the V-22 Osprey tiltrotor, in addition to various other secondary structures on the V-22 and their Model 412 helicopter (Hutchins, 1992). McDonnell-Douglas (now Boeing) designed, manufactured and tested a complete horizontal stabilizer for the AH-64A Apache, however the extent of this components use in service is unknown (Vitlip, 1991).

When dealing with military aircraft, Younossi et al. (2001) noted that it is common for the percentage of composites in the design to decrease as the design process progresses because designers tend to be overly optimistic at the outset of the design phase. An example of this phenomenon is the F-35 Joint Strike Fighter (JSF). Originally, designers intended to extensively use thermoplastic composites on the JSF (e.g. wing skins) however this concept was eventually discarded in favour of more established materials (Younossi, 2001). 
Table 4: Summary of reinforced thermoplastic applications on aerospace vehicles

\begin{tabular}{|c|c|c|c|c|c|}
\hline Vehicle & Component & Manufacturer & Matrix & Fibre & Manufacturing Process \\
\hline SSRMS (Canadarm 2) & Main structure (4 booms) & FRE Composites & PEEK (APC-2) & IM-7 & Filament Winding + Autoclase \\
\hline A380 & $\begin{array}{l}\text { Fixed Wing leading edges } \\
\text { Leading edge ribs } \\
\text { Assoned Brackets }\end{array}$ & $\begin{array}{l}\text { Stork Folker AESP } \\
\text { Stork Folker AESP } \\
\text { Stork Folker AESP }\end{array}$ & $\begin{array}{l}\text { PPS (Ten Cale) } \\
\text { PPS (Ten Cale) } \\
\text { PPS (Ten Cale) }\end{array}$ & $\begin{array}{l}\text { E-Glass (Cetex - 8H Satin) } \\
\text { E-Glass (Cetex - 8H Satin) } \\
\text { E-Glass (Celex - RH Satin) }\end{array}$ & $\begin{array}{l}\text { Semipreg Hand Lay-Up + Autoclate } \\
\text { + Resistance Welded } \\
\text { Semipreg + Compression Moulded + } \\
\text { Machined + Resistance Welded }\end{array}$ \\
\hline A3410 & $\begin{array}{l}\text { Fixed Inboard leading edges } \\
\text { Leading edge ribs } \\
\text { Keel Beam } \\
\text { Ailerons }\end{array}$ & $\begin{array}{c}\text { Stork Folker AESP } \\
\text { Storh Folker AESP } \\
\text { Aerospatiale } \\
\text { Aerospatiale }\end{array}$ & $\begin{array}{l}\text { PPS (Ten Cate) } \\
\text { PPS (Ten Cate) } \\
\text { PPS (Ten Cate) } \\
\text { PPS (Ten Cate) }\end{array}$ & $\begin{array}{c}\text { E-Glass (Celex - 8H Satin) } \\
\text { E-Glass (Celex - KH Satin) } \\
\text { Carbon } \\
\text { Carbon }\end{array}$ & $\begin{array}{l}\text { Semipreg Hand Lay-Up + Auloclas e } \\
\text { + Resistance Welded } \\
\text { Semipreg + Compression Moulded + } \\
\text { Machined + Resistance Welded }\end{array}$ \\
\hline Airtus Beluga & Floor Panels & Storl Follier AESP & PEI & Carbon & Thermofolding \\
\hline Gulfstream $G 4(x) / G 500$ & $\begin{array}{c}\text { Floor Panels } \\
\text { Rudder Trailing Edge } \\
\text { Over-uing Pressure Bulkhead }\end{array}$ & $\begin{array}{l}\text { Storh Folker AESP } \\
\text { Stork Folker AESP } \\
\text { Stork Folker AESP }\end{array}$ & $\begin{array}{l}\text { PEI } \\
\text { PEI } \\
\text { PEI }\end{array}$ & $\begin{array}{l}\text { Carbon } \\
\text { Carbon } \\
\text { Carbon }\end{array}$ & $\begin{array}{l}\text { Thermofolding } \\
\text { Hand lay -up + Autoclave } \\
\text { + Thermofolding }\end{array}$ \\
\hline Folker tolo & Cargo Flooring & Stork Folkier AESP & PEI & Glass & Thermofolding \\
\hline Fohker 50 & $\begin{array}{c}\text { Matn Landing Gear Door } \\
\text { Outer Wing Skin (Shroud Stin) }\end{array}$ & $\begin{array}{l}\text { Stork Folker AESP } \\
\text { Storl Folker AESP }\end{array}$ & PPS (Ten Cate) & Carbon & $\begin{array}{l}\text { Compression Moulding + Resistance } \\
\text { Welding }\end{array}$ \\
\hline F.117 & V-Stab Panels & & & & \\
\hline F-22 & Doors/Panels & & & & \\
\hline B-2 & Fixed Trailing Edge & & PI & Glass & \\
\hline Boeing Apache & Modular Avionics Bay s & Stork Fokker AESP/Boeing & PEI & Carbon & Press Forming \\
\hline Dornier 328 & Flap Ribs & Dornier Luffrahn & PEI (Ultem) & Carbon & Press forming \\
\hline$v-22$ & Wing Ribs & Bell Helicopters & PEEK (APC-2) / PEKK & Carbon (AS-4) & $\begin{array}{l}\text { Malched Die Press Forming } \\
\text { Diaphragm Forming }\end{array}$ \\
\hline Bell 412 & Bagagge Door & Bell Helicopters & PES & Carbon (T301) & Press Forming \\
\hline
\end{tabular}

\subsection{Discussion and Conclusions}

Based on the reviewed literature, and the apparent trend of increasing thermoplastics use in the aerospace industry, it was decided that research in this area would be pursued. In keeping with the research theme of low-cost composites processing at Carleton University, vacuum consolidation of commingled thermoplastic composites was selected as the topic for this work.

In conforming to the low-cost segment of composites processing, many processes were eliminated as candidates very early on based on the requirement for processing equipment requiring a large capital investment. These processes included automated fibre placement, filament winding, pultrusion and compression moulding. Of the remaining options, vacuum consolidation was identified as the leading candidate due to 
the overlap of required equipment with the hand lay-up processes currently used at Carleton University. In terms of processing hardware, only a convection oven and vacuum pump are required, both of which were available at Carleton University, and also at NRC-IAR.

The choice of commingled polypropylene/glass and nylon/carbon was made based on material availability. The National Research Council Industrial Materials Institute (NRC-IMI) donated both material types. Purchasing these materials from suppliers was investigated, however the large minimum orders required to purchase from these sources did not make sense for the scope of this research. Despite this, polypropylene/glass and nylon/carbon blends do represent typical aerospace grade materials.

An in-depth discussion on these material types and the vacuum consolidation processing techniques employed in this work are provided in the next chapter. 


\subsection{Laminate Manufacturing}

Laminated panels made up of four plies, all oriented at $0^{\circ}$, were manufactured using the hand lay-up/vacuum consolidation process to assess quality, mechanical performance and consolidation behaviour of commingled polypropylene/e-glass and commingled polyamide 6/carbon material precursors (to be discussed further in the next section). During processing, the consolidation (or through thickness compaction) of the laminates was measured using a set of two non-contact displacement sensors manufactured by Kaman Measuring Systems. The following sections outline the experimental set-up that was used for these experiments.

The goal of the process development exercise is to determine the most economical approach to processing, while balancing satisfactory mechanical performance. This can be achieved by minimizing void content in the laminates, while ensuring no thermal degradation of the polymer occurs. Additionally, determining an appropriate vacuum bagging arrangement was a goal of this work.

\subsection{Materials}

Two commingled material types were studied for this work, commingled polypropylene/E-glass (PPG) and commingled polyamide 6/carbon (NC). Both material types were donated by the National Research Council Industrial Materials Institute (NRC-IMI). Unfortunately, accompanying documentation for these materials was not available, so some uncertainty remains about the detailed material specifications.

As a general observation about both material types studied here, some degree of variability was observed in the dry material. Waviness in the fibre tows, uneven 
fibre/matrix distribution and defects in the material weave were present in both material types. These variables in the materials likely contributed to the variability in the material characterization and mechanical testing results reported in section 4.0 and section 5.0 respectively.

\subsubsection{Commingled Polypropylene/E-glass}

The PPG material, manufactured by Twintex, is a $2 / 2$ twill weave as shown in Figure 6 . The specifications for various blends of commingled PPG are available online (Twintex, 2011). Although the exact material type is unknown, it was determined from the manufacturers information that the material contains $60 \%$ E-glass by weight. This fibre content has not been verified independently; therefore the reliability of this data is unknown.

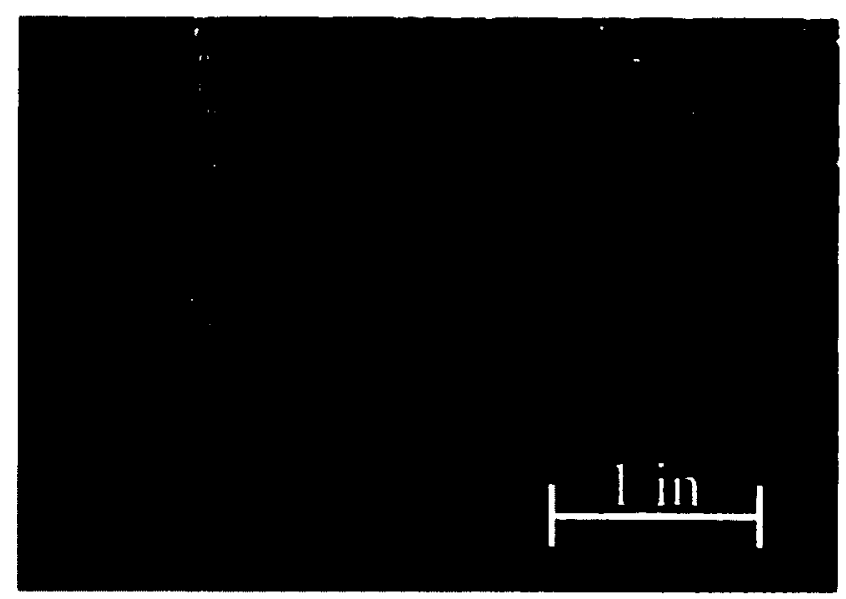

Figure 6: Commingled polypropylene/E-glass precursor material, as received from NRC-IMI 


\subsubsection{Commingled PA6 (Nylon 6)/Carbon}

Very little is known about the NC commingled material studied in this work, including the original manufacturer. It is believed that it is a custom woven blend intended for research purposes. When received, the exact type of nylon was unknown, however through consolidation experiments and differential scanning calorimetry analysis to be discussed later, most likely polyamide 6 (nylon 6) is the thermoplastic filament commingled with reinforcing carbon fibre. This observation was based on the melting temperature of the thermoplastic matrix measured during experiments. In addition, it was determined that a satin weave was used for this material, the dimensions of which are unclear. Figure 7 shows the as-received material.

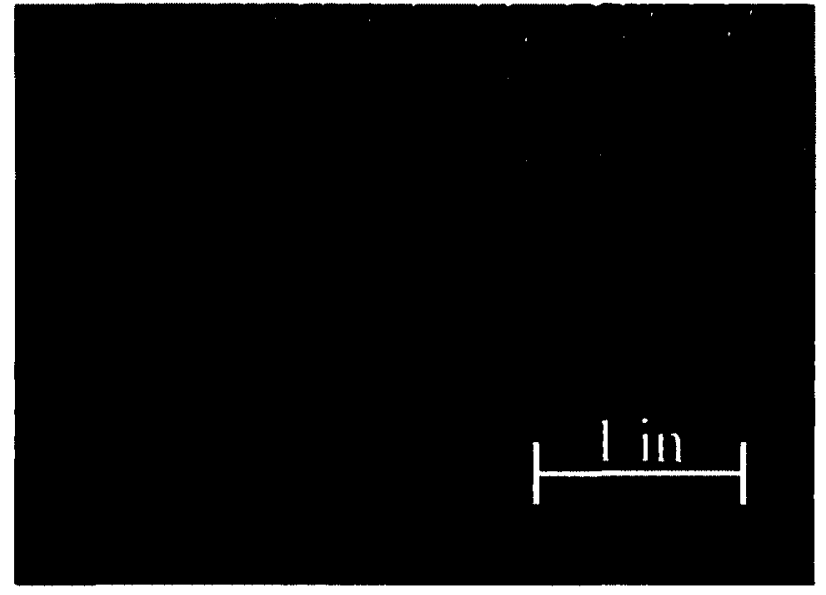

Figure 7: Commingled polyamide 6/carbon precursor material, as received from NRC-AMTC

\subsection{Laminate Vacuum Bagging}

In order to apply vacuum pressure to the laminates during the consolidation cycle, they must be first prepared in a vacuum-sealed bag to ensure that negative pressure can be maintained throughout the consolidation process. The vacuum bagging arrangement 
consists of a tool plate, laminate thickness control shims, Teflon film (solid and perforated), breather cloth, vacuum bag film, a caul plate, tacky tape, and finally a vacuum hose attachment fixture. Further information on these materials can be found in Table 5. The vacuum bag arrangement is shown schematically in Figure 8. The laminate lay-up and vacuum bagging was conducted in the class 10000 clean room located at NRC-IAR in Ottawa, Canada.

Table 5: Vacuum bag material information

\begin{tabular}{|l|l|}
\hline Material & Details \\
\hline Tool plate/Caul plate & Aluminum, stress relieved, 3/8 in thickness \\
\hline Thickness control shims & Aluminum, 0.050 in thick \\
\hline Teflon film & $\begin{array}{l}\text { A5000 release film, supplied by Richmond } \\
\text { Aircraft Products, 0.002 in thickness }\end{array}$ \\
\hline Breather cloth & $\begin{array}{l}\text { RC3000-4/10 polyester breather clothe, } \\
\text { supplied by Richmond Aircraft Products. } \\
\text { 4 oz/yard }{ }^{2} \text { and 10 oz/ yard }\end{array}$ \\
\hline Vacuum bag film & $\begin{array}{l}\text { Vac-Pak HS 8171-6/66 Nylon Film, supplied } \\
\text { by Richmond Aircraft products }\end{array}$ \\
\hline Tacky tape & $\begin{array}{l}\text { SM5126 vacuum bag sealant tape, supplied by } \\
\text { Schnee-Morehead Inc. }\end{array}$ \\
\hline
\end{tabular}

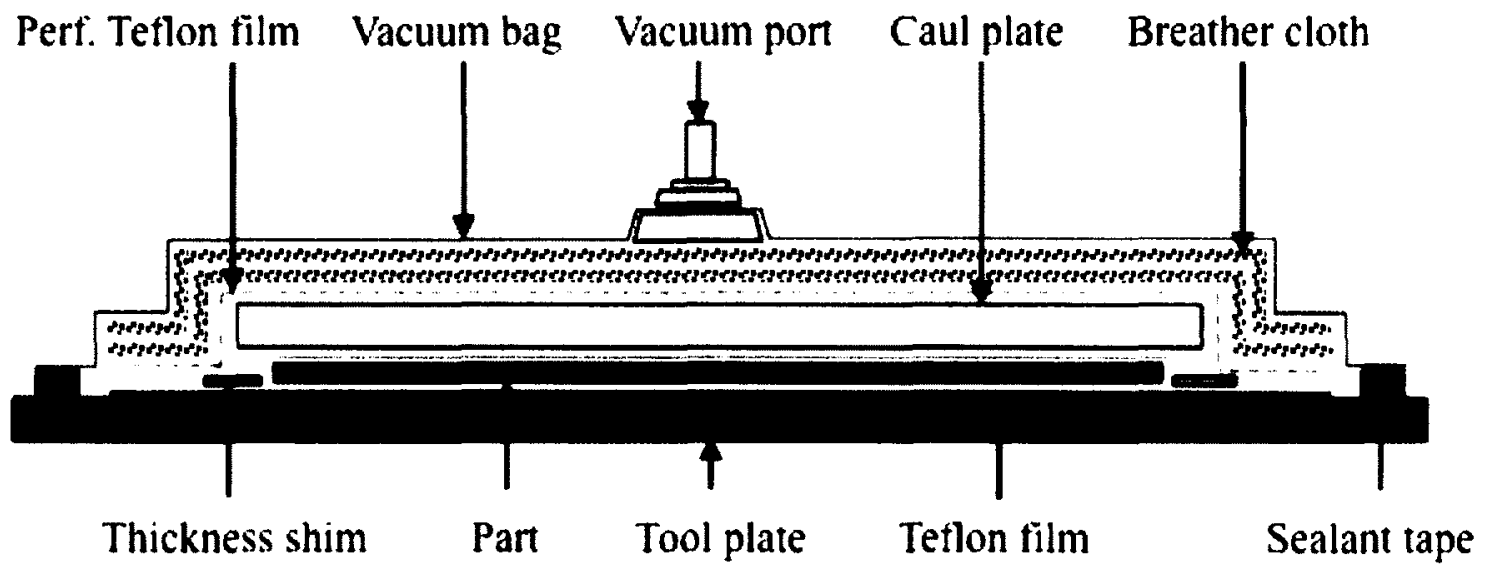

Figure 8: Vacuum bag arrangement for laminate consolidation trials

The vacuum bagging procedure is shown in Figure 9. The following procedure was used for vacuum bagging for this work: 
1. The tool plate was cleaned using isopropyl alcohol.

2. A layer of solid Teflon film was placed on the tool plate, leaving approximately 0.5 in exposed along each edge.

3. Tacky tape was placed down along the exposed edges of the tool plate, leaving the backing paper attached.

4. Thickness shims were placed on the tool plate, and taped down as shown in Figure 9 (a), ensuring sufficient space for the dry material.

5. The dry material was laid up within the thickness shims as shown in Figure 9 (b). Care was taken to align the fibres of the material as orthogonally as possible.

6. The caul plate was placed over the dry material as shown in Figure 9 (c).

7. A layer of perforated Teflon film was placed over the caul plate to provide a buffer between the laid up material and the fibres of the breather cloth.

8. Breather cloth was placed over the perforated Teflon film.

9. Vacuum bag (with an installed vacuum port) was placed over the breather cloth. At this point, the backing of the previously laid Tacky Tape was removed and the vacuum bag was sealed along the edges of the tool plate as shown in Figure 9 (d).

10. Vacuum was applied through the vacuum port, and the vacuum bag was inspected for any leaks. If leaks were found, additional Tacky Tape was used to seal the holes. 


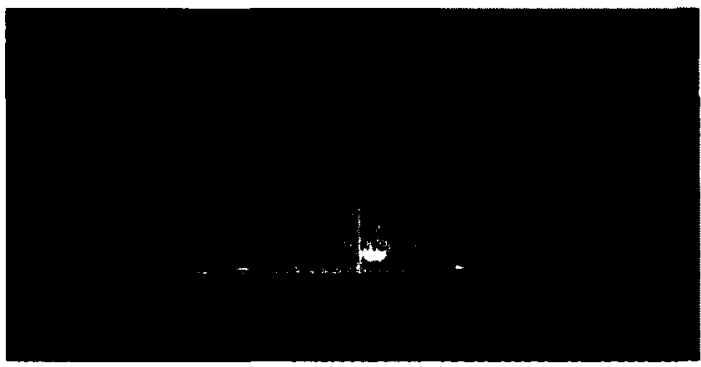

(a)

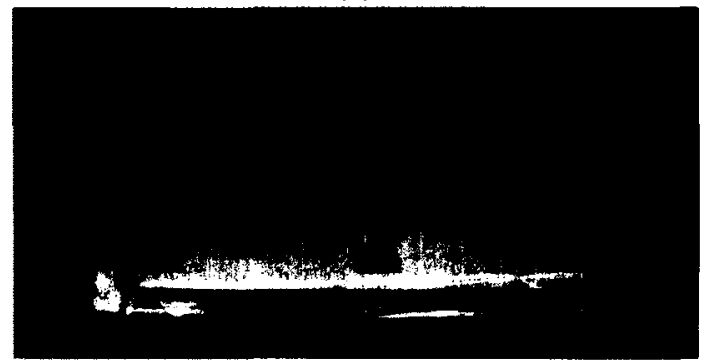

(c)

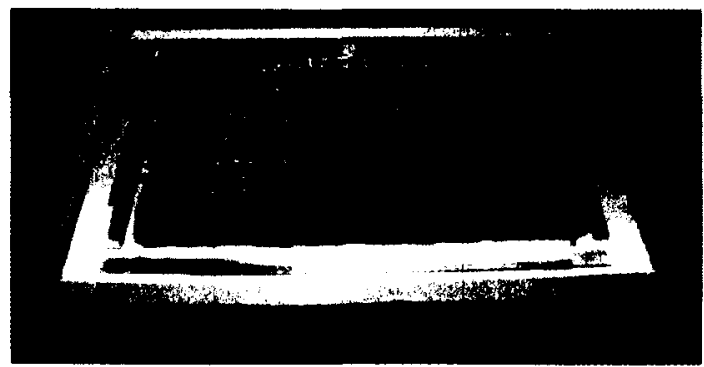

(b)

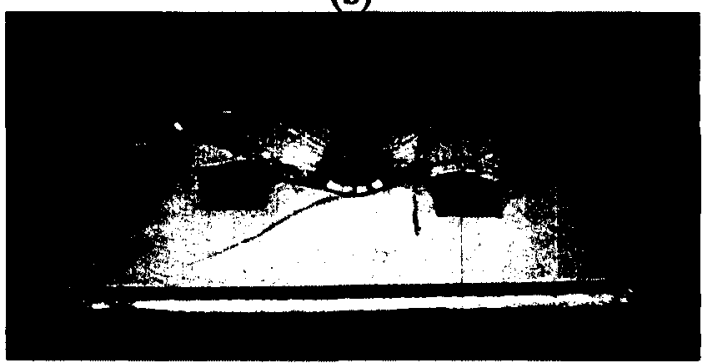

(d)

Figure 9: Vacuum bag preparation (a) Tool plate preparation, (b) Laying up dry fabric on the tool plate, (c) Placing the caul plate over the laid up material, and (d) Covering the assembly with breather cloth and a vacuum bag.

The tool plate and caul plate used for the manufacturing trials is made of stress free cast aluminum. This material is typically chosen as a tooling material due to its low cost, machinability/reparability, and low weight, however its coefficient of thermal expansion (CTE) is not ideal for this application. An ideal choice for tooling material would have a CTE that closely matches that of the composite material being manufactured. With the addition of heat, both the tooling material and the part will expand to some degree. If there is a significant mismatch between the CTE of the tool and the CTE of the part, undesirable interaction between the two could result, with the consequences being residual stresses forming in the part - possibly causing part warpage. To reduce the effect of this CTE mismatch, Teflon release film is used to reduce friction between the part and the tool.

The tool plate used for this work measured $38 \mathrm{~cm} \times 23 \mathrm{~cm} \mathrm{x} 1 \mathrm{~cm}(15$ in $\times 9$ in $\times$ $0.375 \mathrm{in})$. The size of the tool plate used for this work was limited by the displacement 
sensor mounting fixtures, and also by the internal dimensions of the convection oven. Ideally the tool plate would be significantly larger than the one described here. This limitation created some challenges when vacuum bagging the laminates. This will be discussed further in section 3.4 .

\subsection{Kuda Non-Contact Displacement Sensors}

The consolidation of the thermoplastic composite laminates was measured using two Kaman Instrumentation Kuda 16U non-contact sensors (one sensor shown in Figure 10). These sensors create an electromagnetic field near the sensor head by energizing the sensor coil with alternating current (AC). The energized coil induces an eddy current in the measurement target. The current in the measurement target then creates a secondary electromagnetic field that has amplitude proportional to its distance from the sensor head. This secondary electromagnetic field acts destructively on the original sensor's field. The variation in field strength is then captured by the sensor as a change in impedance (Kaman Aerospace Corporation, 2001). A schematic of the eddy current position sensor operation is shown in Figure 11. The specifications of the Kuda non-contact displacement sensor are shown in Table 6. 


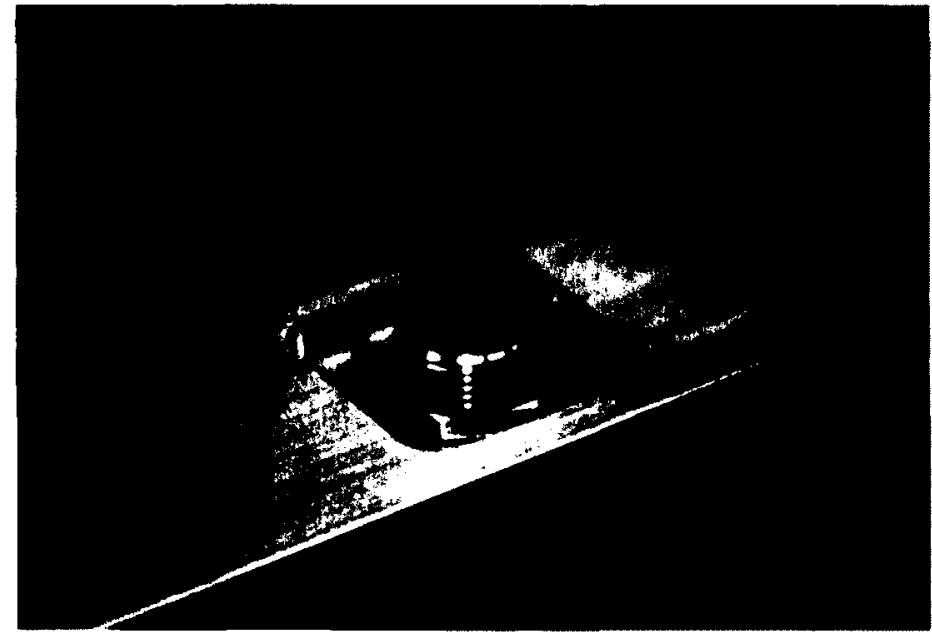

Figure 10: A non-contact eddy current sensor mounted within an aluminum fixture

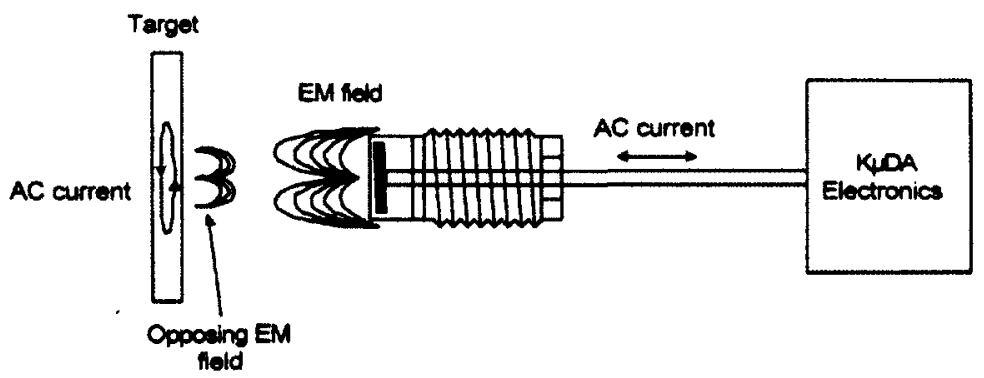

Figure 11: Schematic of eddy current position sensor operation (Kaman Instrumentation, 2001)

Table 6: Specifications of the Kaman Instruments Kuda non-contact displacement sensor

\begin{tabular}{|r|l|}
\hline Measuring range, $\mathbf{m m}$ (in) & $5(0.200)$ \\
\hline Offset, $\mathbf{m m}$ (in) & $0.5(0.02)$ \\
\hline Resolution, $\mathbf{m m}$ (in) & $0.0015\left(60 \times 10^{-6}\right)$ \\
\hline Temperature Compensation (10 $\left.0^{\circ} \mathbf{C}-50^{\circ} \mathrm{C}\right)$ & $\pm 20 \times 10^{-6}$ \\
\hline
\end{tabular}

Using non-contact eddy current sensors in this application has many benefits when compared to sensors that require contact with a target (i.e. linear variable differential transducer (LVDT)). The main benefit is that the non-contact sensor measurements will not be affected by the vacuum bagging materials when measuring 
consolidation like a LVDT would be since non-conductive materials have no effect on the sensor output. This is extremely useful for a vacuum bag consolidation measurement scenario. By measuring the movement of the caul plate during consolidation without interference from the otherwise obstructive bagging materials, accurate measurements of the laminate consolidation can be collected since the composite material and caul plate are in direct, intimate contact.

Although a temperature compensation feature is available for the Kuda sensors, which is claimed to reduce temperature induced measurement errors by $\pm 20 \times 10^{-6}$ in in the temperature range of $10^{\circ} \mathrm{C}-50^{\circ} \mathrm{C}$, it was found that significant thermal drift occurred during laminate processing since processing temperatures reached as high as $230^{\circ} \mathrm{C}$ $\left(450^{\circ} \mathrm{F}\right)$. This was confirmed by performing a 'dry run' in which a measurement target was fixed to the end of the sensor head. By fixing targets to the ends of the sensors, any measured variation in the sensor outputs when exposed to elevated temperatures could be considered 'thermal drift'. By measuring the thermal drift, a correction factor as a function of temperature was determined. Hysteresis behaviour was observed when exposing the sensors to thermal cycling; this behaviour and the accommodation of this behaviour is discussed in section 3.5.1.

\subsubsection{Sensor Mounting Fixtures}

The mounting of the non-contact displacement sensors is a critical component of the experimental set-up. Due to potential interference of metallic fixtures, the design of the fixtures must be such that no metallic interference is present within the sensor viewing area, as shown in Figure 12. One of the two sensor-mounting fixtures used for this work 
is shown in Figure 13. The sensor head is mounted within a milled cavity in the fixture to ensure no interference is present. Figure 10 shows the details of the sensor mounting within the fixture.

These mounting fixtures were adapted from a previous research project conducted at NRC-IAR by Djokic et al. (2001) in which residual stresses in bonded composite patches was studied. The fixture, a custom design, was intended to support a bonded patch between two cantilever beams that indirectly measured patch warpage during thermal cycling. Later, the sensor mounting fixture was adapted to incorporate the noncontact eddy current sensors, and used for a research project conducted by Laliberté et al. (2007) in which residual stresses in fibre metal laminates (FMLs) was measured. The fixture configuration as used by Laliberté et al. is shown in Figure 14. In this configuration, two sensors were positioned above and below a horizontally supported FML laminate. During processing, the warpage of the FML was measured be the sensors.

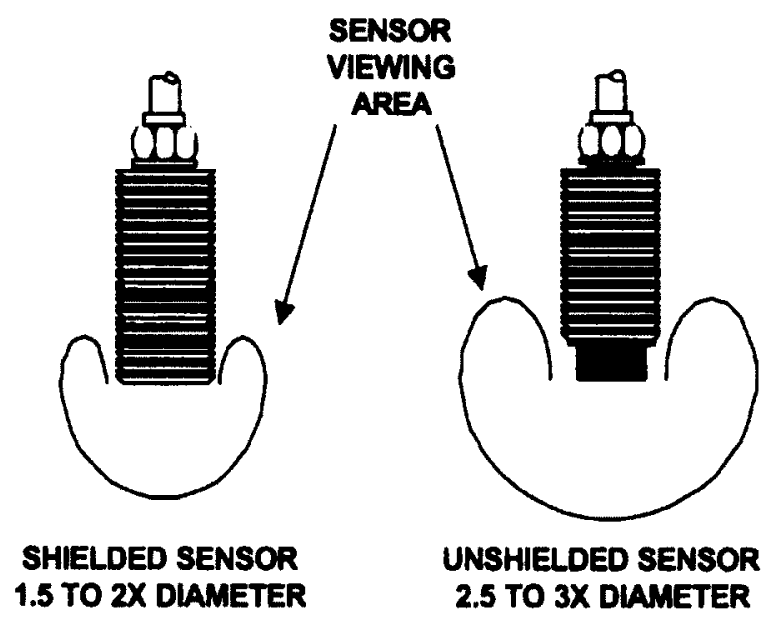

Figure 12: Schematic of the sensor viewing area 


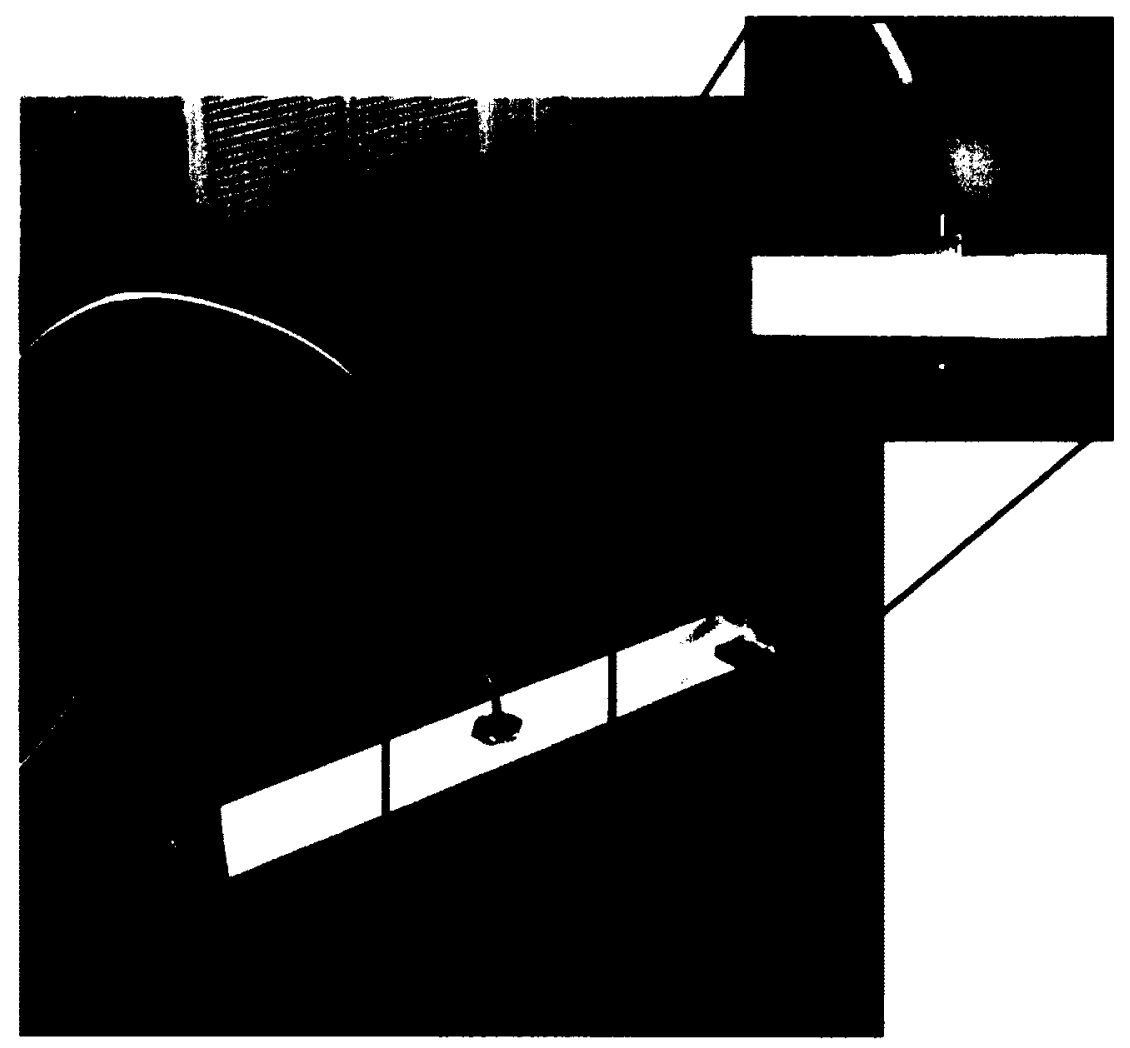

Figure 13: Non-contact displacement sensor mounting fixture

Non-contact eddy current sensor $(\times 2)$

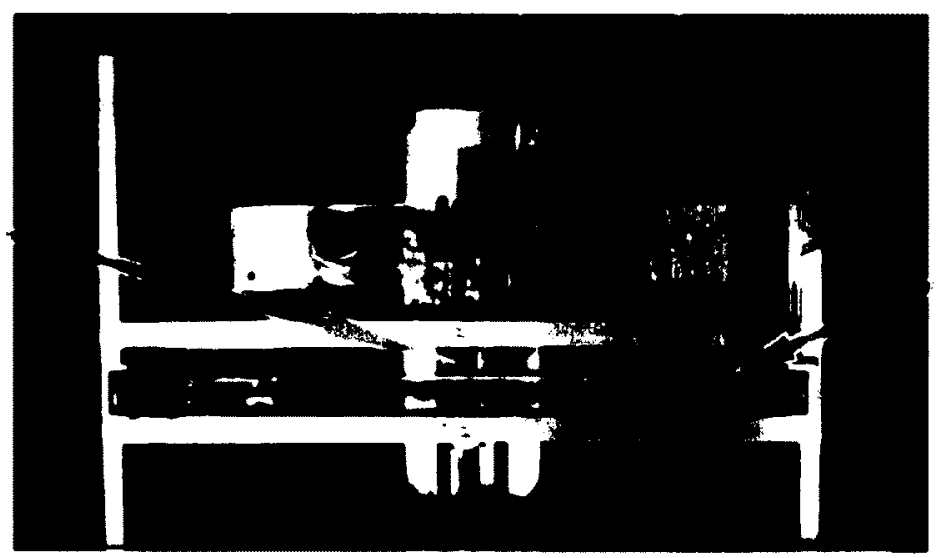

FML

Specimen

Figure 14: Non-contact displacement sensor mounting fixture as configured by Laliberté et al. (2007)

\subsubsection{Sensor Operation}

The sensor mounting fixtures are placed over the vacuum bagged part such that the sensors are positioned $0.8 \mathrm{~mm}(0.030 \mathrm{in})$ above the caul plate as shown in Figure 15. 
Small cut-outs were made in the breather cloth (within the vacuum bag) at the locations where the sensors targeted, as seen in Figure 16. This ensured that the sensors could be placed at the desired offset distance from the caul plate without interference from the vacuum bag arrangement. The sensors were positioned at one quarter and three quarters along the length of the caul plate, and centered along the width.

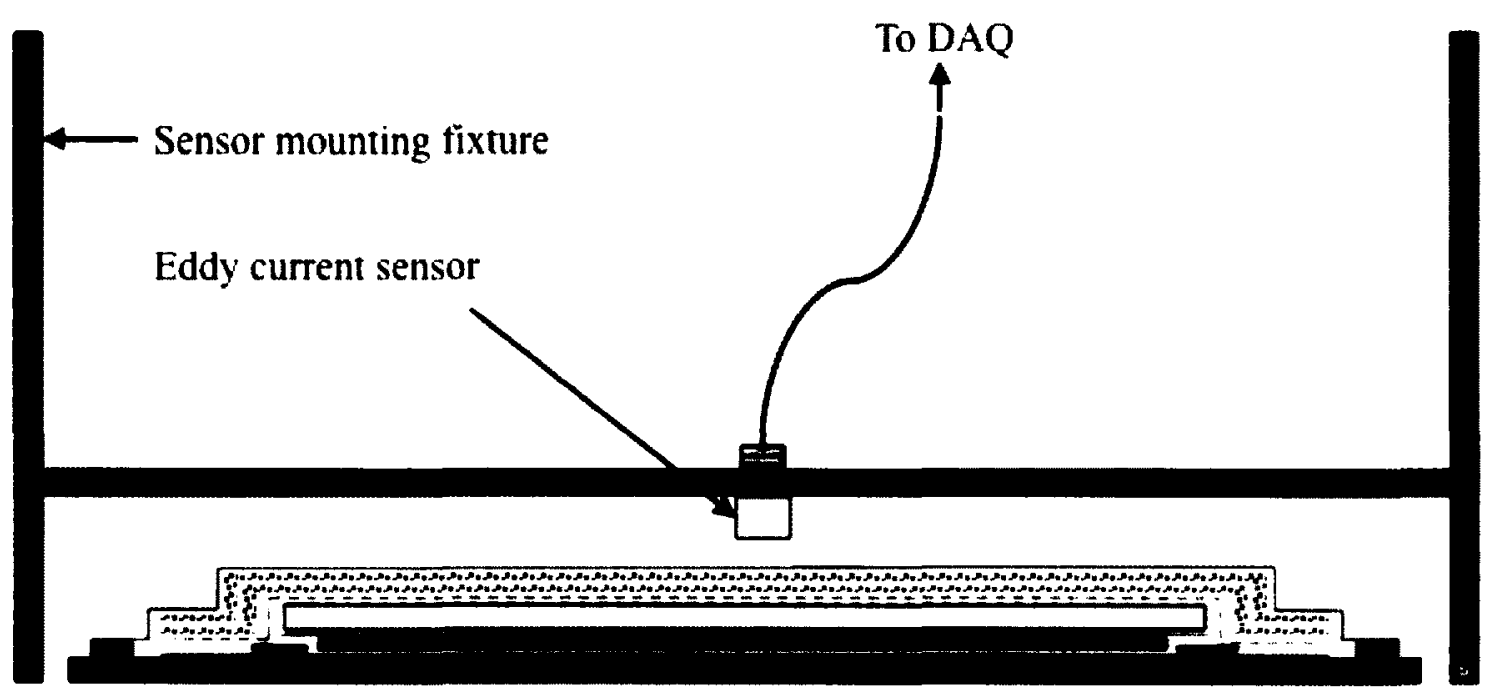

Figure 15: Non-contact displacement sensor mounting fixture

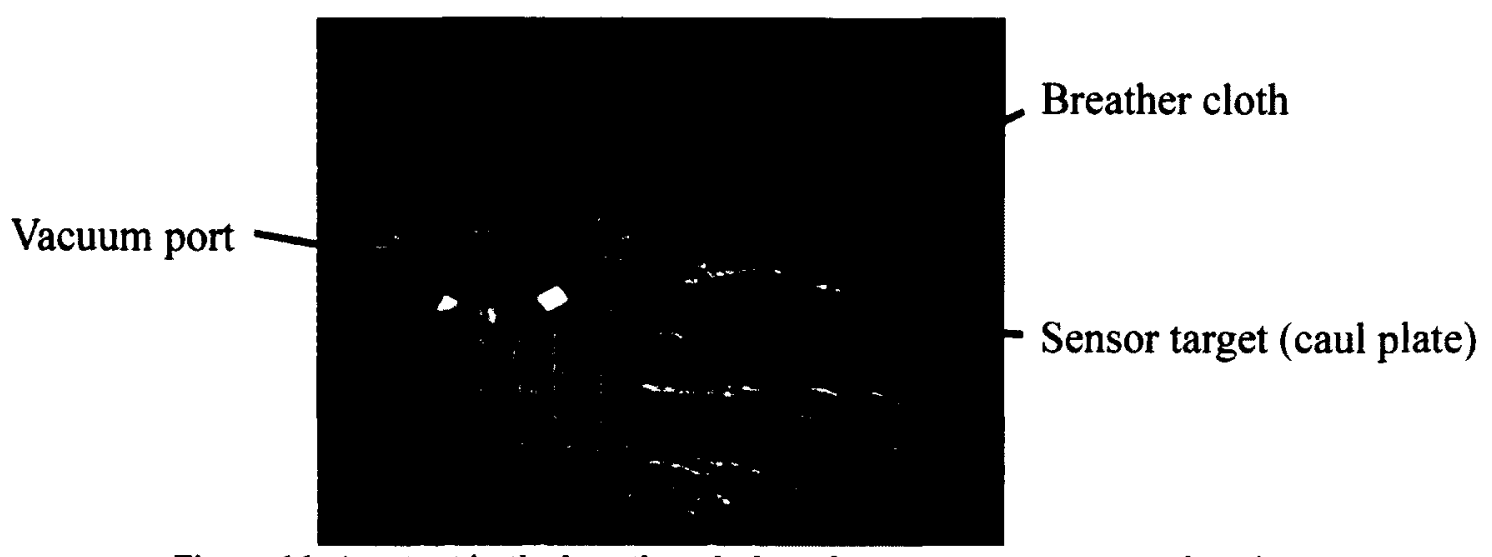

Figure 16: $A$ cutout in the breather cloth at the sensor measurement location. 


\subsection{Vacuum Consolidation Process Development}

The primary processing parameters of interest during vacuum consolidation are time and temperature. Typically pressure is of interest in similar processing methods (i.e. autoclave processing), however the vacuum consolidation process requires that full vacuum pressure (approximately $-95 \mathrm{kPa}(14 \mathrm{psi})$ ) be maintained throughout consolidation.

For each manufacturing trial described in the following sections, a table is provided outlining the processing parameters and laminate thickness information. The "Consolidation" row in each table refers to the difference between the initial vacuum bagged laminate thickness (dry material, pre-processing), and the final laminate thickness. This value was found by measuring the thickness of the complete vacuum bagged assembly before processing using a deep-throat micrometer as shown in Figure 17, and comparing it to the same measurements taken after processing was completed (this measurement was not taken for PPG trials 1-3). This data could also be extracted from the laminate consolidation data, however to ensure measurement accuracy manual measurements were taken. This measurement error will be discussed further in section 3.5.1. 


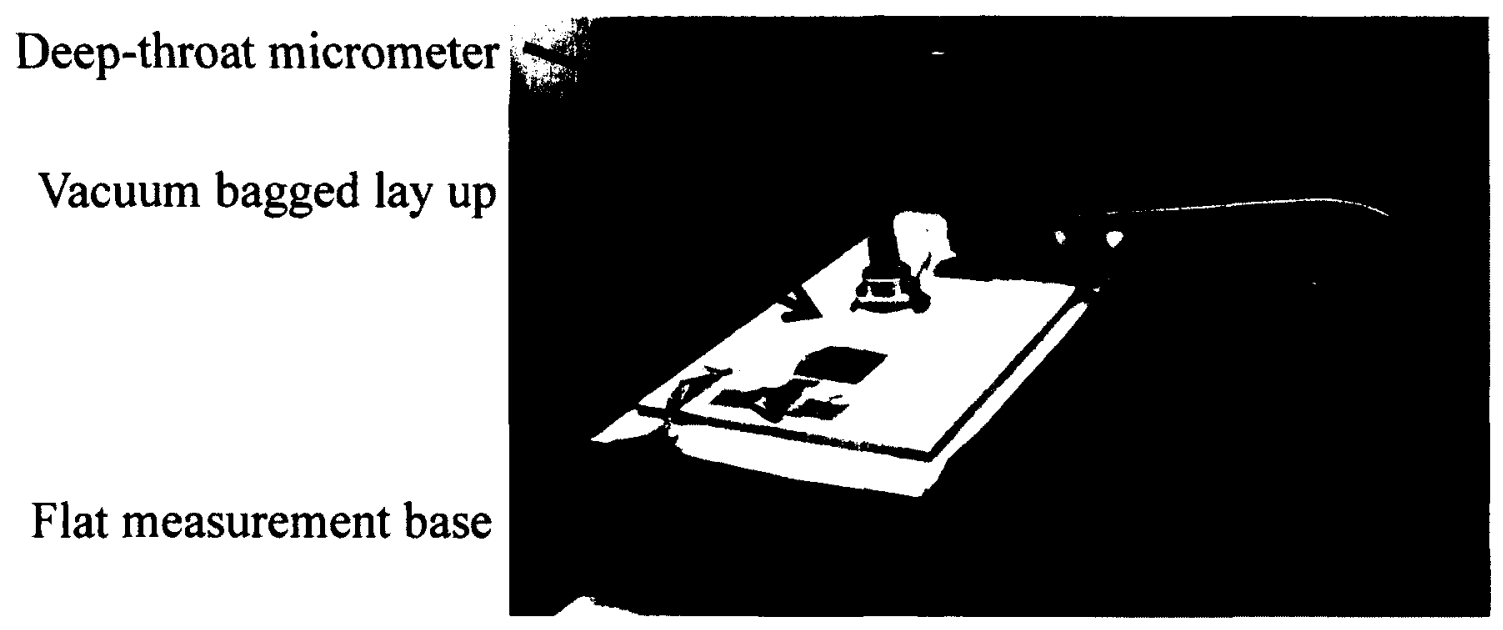

Figure 17: Vacuum bag assembly thickness measurement to determine the consolidation distance achieved during processing

It should also be noted that images of the laminate cross sections were not available until all laminates had been manufactured, so this data could not be used as feedback during process development. It was found that cutting both material types by traditional abrasive methods caused the thermoplastic matrix to soften or melt near the cutting surface. This undesirable local thermal effect resulted in coupon edges that were not suitable for examination with an optical microscope. To resolve this issue, coupons were water-jet cut by Hydrotech Cutting Inc. in Ottawa, Canada. To reduce costs, laminates were sent for cutting in large batches (one batch per material type), and therefore the laminate cross sections could not be examined between processing trials.

A typical processing cycle is shown in Figure 18. The laminate temperature data was collected via a thermocouple mounted to the outside of the vacuum bag. A disadvantage of this thermocouple arrangement is that no temperature gradient data (through the laminate thickness) was captured. Since temperature gradients can be a contributing factor to residual stress formation during processing and therefore undesirable laminate curvature/warping, this data should be collected in any future 
experiments that are conducted. Unless otherwise noted, it can be assumed that each processing cycle follows Figure 18, taking into account the parameters listed for each processing trial.

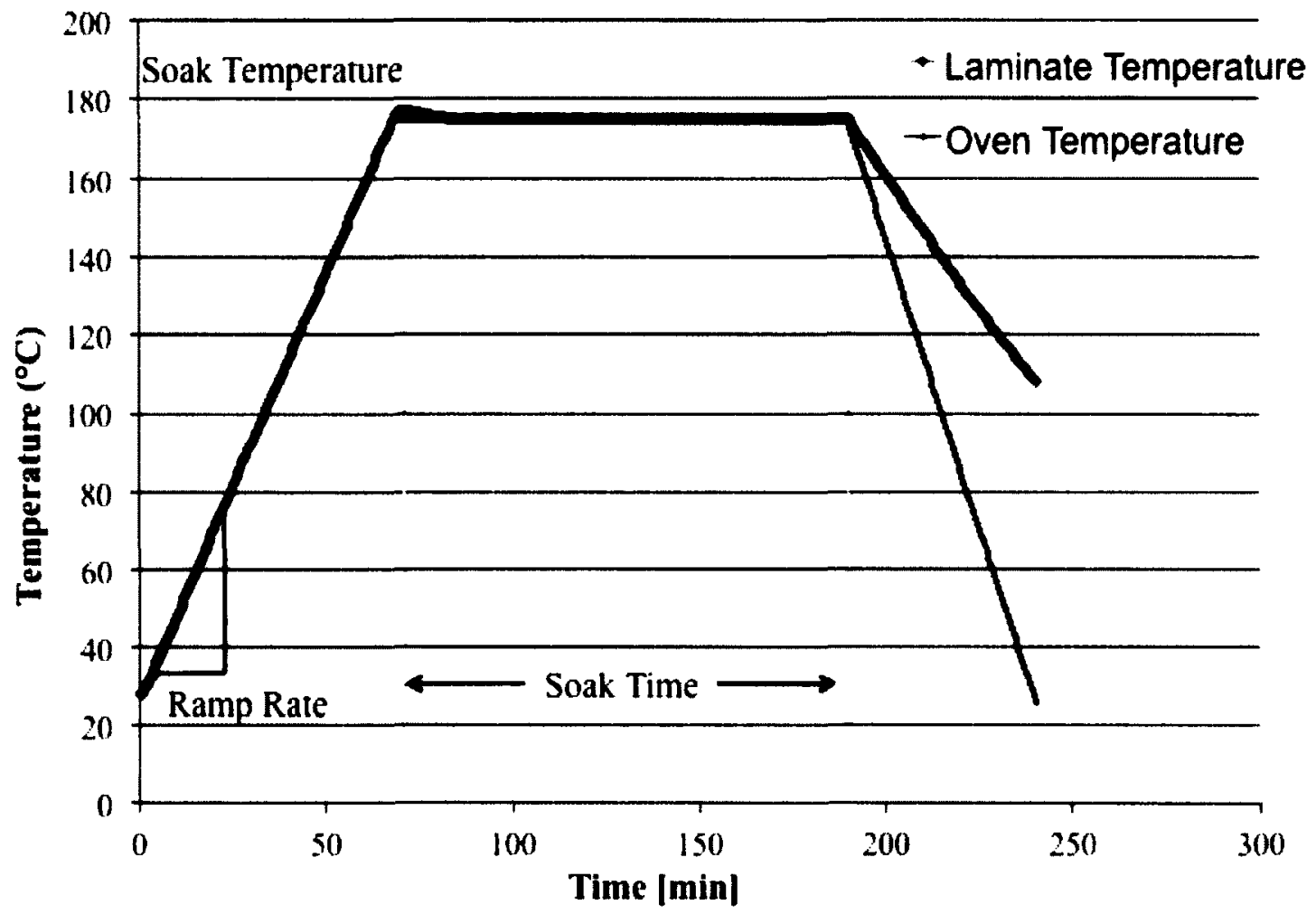

Figure 18: A typical vacuum consolidation process cycle

\subsubsection{Commingled Polypropylene/E-glass}

From literature, the melting point of polypropylene was determined to be $165^{\circ} \mathrm{C}$ $\left(330^{\circ} \mathrm{F}\right)$ (NRC-IAR Thermoplastic Material Datasheet). This value was taken to be the minimum temperature required to achieve laminate consolidation. Also, from preliminary consolidation trials, it was found that 2-ply vacuum consolidated laminates have an approximate thickness of $0.6 \mathrm{~mm}(0.023 \mathrm{in})$. This value was extrapolated to predict a 4-ply laminate thickness of approximately $1.3 \mathrm{~mm}(0.050 \mathrm{in})$; shims of this 
thickness were used to minimize laminate thickness variations (on all trials other than PPG trial 1). The various processing parameters used for the PPG processing trials are shown in Table 7. The consolidation behaviour of the PPG laminates will be discussed in section 3.5 .

Table 7: Processing parameters for PPG processing trials

\begin{tabular}{|c|c|c|c|}
\hline Trial & Oven Ramp Rate, ${ }^{\circ} \mathbf{C} / \mathbf{m i n}$ & $\begin{array}{c}\text { Soak Temperature, } \\
{ }^{\circ} \mathbf{C}\left({ }^{\circ} \mathbf{F}\right)\end{array}$ & $\begin{array}{c}\text { Soak Time } \\
\text { [min] }\end{array}$ \\
\hline T1 & 6.0 & $180(355)$ & 15 \\
\hline T2 & 3.0 & $180(355)$ & 25 \\
\hline T3 & 2.2 & $180(355)$ & 25 \\
\hline T4 & 2.2 & $175(347)$ & 120 \\
\hline T5 & 2.2 & $190(374)$ & 60 \\
\hline BT1 & 5.0 & $190(374)$ & 60 \\
\hline BT2 & 5.0 & $180(355)$ & 15 \\
\hline
\end{tabular}

\subsubsection{PPG T1}

The processing parameters used for PPG trial 1 are shown in Table 8. The soak temperature for this trial was chosen to be $180^{\circ} \mathrm{C}$ to ensure the part reached a processing temperature sufficiently above the melting temperature of the PP matrix. A soak time of 15 minutes was selected based on the recommendations found in the reviewed literature (see section 1.0). As previously noted, no thickness shims were used for this processing trial.

Table 8: Processing parameters and thickness data for PPG T1

\begin{tabular}{|r|l|}
\hline Temperature Ramp Rate & $6^{\circ} \mathrm{C} / \mathrm{min}$ \\
\hline Soak Temperature & $180^{\circ} \mathrm{C}\left(355^{\circ} \mathrm{F}\right)$ \\
\hline Soak Time & $15 \mathrm{~min}$ \\
\hline Laminate Thickness & $2 \mathrm{~mm}(0.081 \mathrm{in})$ \\
\hline Thickness Standard Deviation & $0.05 \mathrm{~mm}(0.002 \mathrm{in})$ \\
\hline
\end{tabular}


When the vacuum bag was removed from the oven, it was found that the vacuum pressure had forced the breather cloth at the edge of the tool plate under the caul plate. This resulted in the breather cloth being pinched between the caul plate and the tool plate during laminate consolidation, at the location shown in Figure 19 (refer to Figure 8 for a schematic of the vacuum bag arrangement). This may have resulted in restricted laminate consolidation due to resistance from the breather cloth. It was also observed that the part temperature lagged the oven set point significantly during processing, as shown in Figure 20.

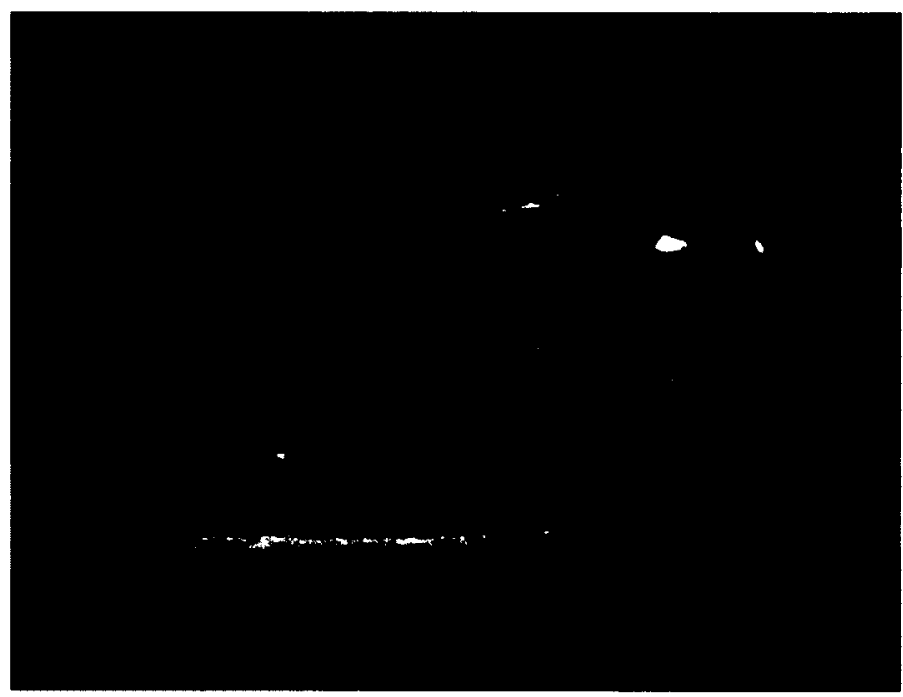

Figure 19: Location where breather cloth wedged under the caul plate during processing 


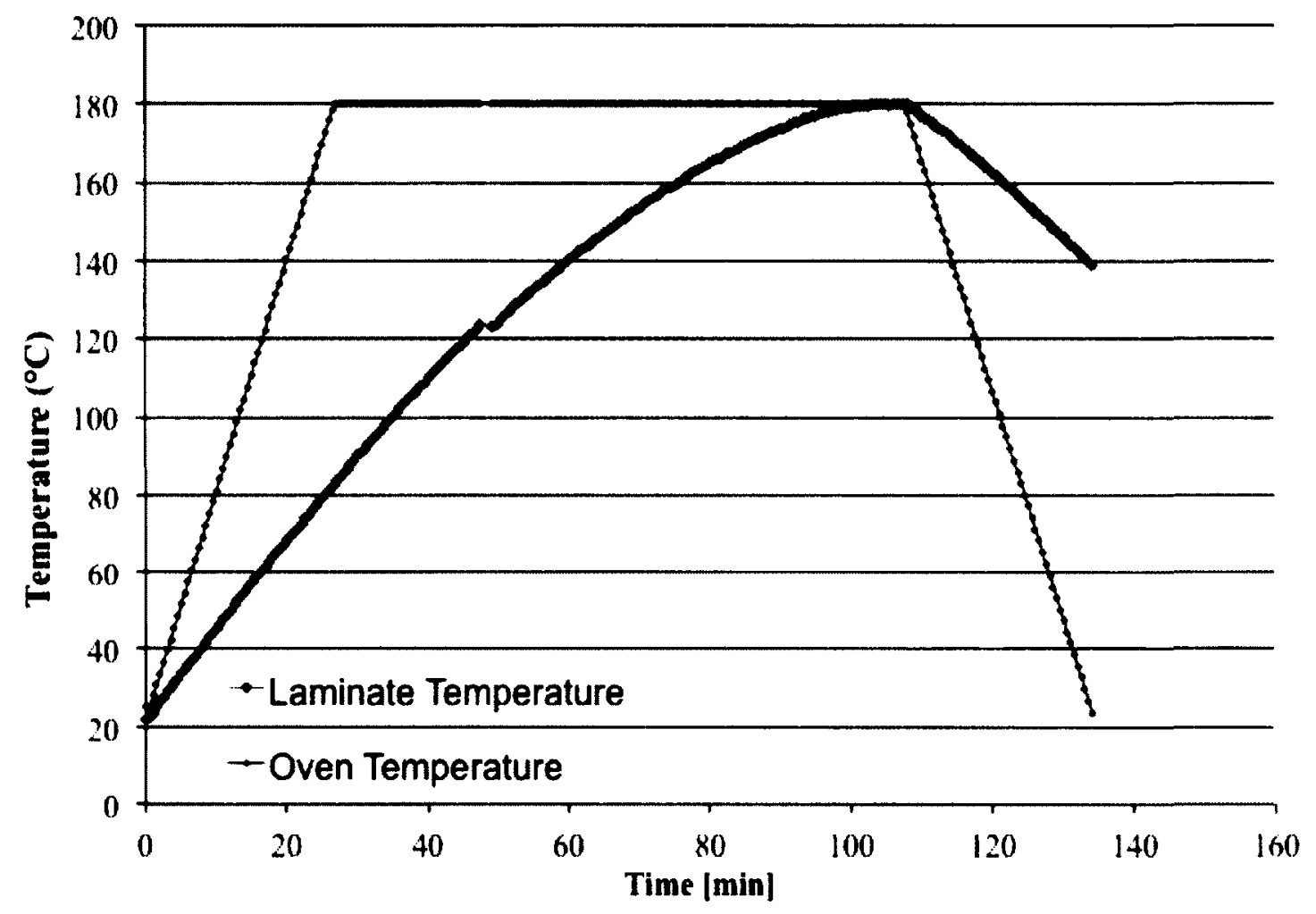

Figure 20: Temperature profile for PPG T1 showing significant laminate temperature lag

The surface finish of the resulting laminate was slightly rough, with visible surface dimples at the locations where perpendicular tows of glass fibres intersect, indicating that further consolidation/impregnation of the laminate would be required to reach an ideal level of consolidation. A small amount of resin bleed (excess resin that was squeezed out during consolidation) accumulated at the perimeter of the laminate.

Images of the cross section of PPG trial 1 are shown in Figure 21. No significant internal void content up to the limit of detection with optical methods used in this study has been observed for this laminate. 


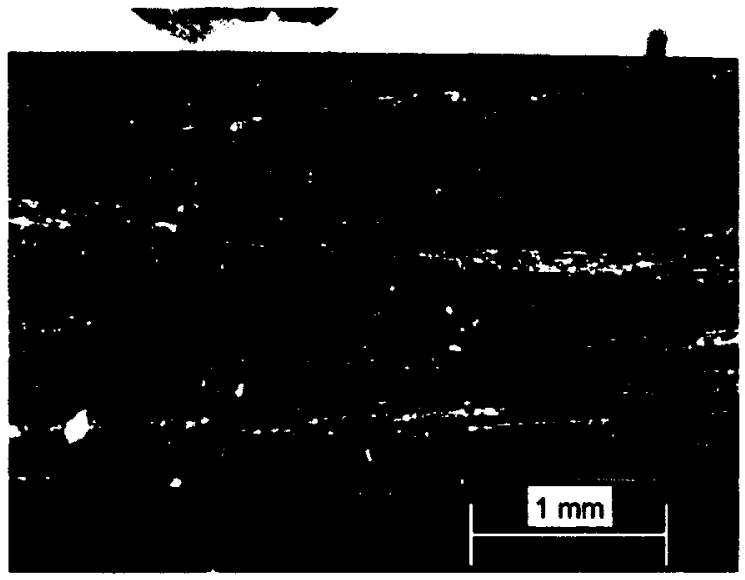

(a)

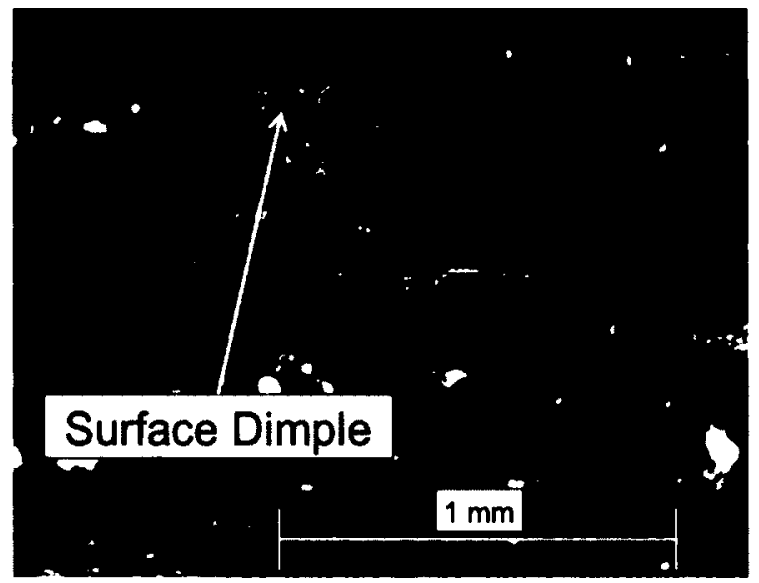

(b)

Figure 21: Cross section images of PPG T1

\subsubsection{PPG T2}

The processing parameters used for PPG trial 2 are shown in Table 9. The soak temperature was unchanged from the previous trial; however the soak time was increased by 10 minutes to 25 minutes to determine if any beneficial increase in laminate quality would result. The temperature ramp rate was reduced to $3^{\circ} \mathrm{C} / \mathrm{min}$ to eliminate the part temperature lag shown in Figure 20.

Table 9: Processing parameters and thickness data for PPG T2

\begin{tabular}{|r|l|}
\hline Temperature Ramp Rate & $3^{\circ} \mathrm{C} / \mathrm{min}$ \\
\hline Soak Temperature & $180^{\circ} \mathrm{C}\left(355^{\circ} \mathrm{F}\right)$ \\
\hline Soak Time & $25 \mathrm{~min}$ \\
\hline Laminate Thickness & $2.2 \mathrm{~mm}(0.085 \mathrm{in})$ \\
\hline Thickness Standard Deviation & $0.03 \mathrm{~mm}(0.001 \mathrm{in})$ \\
\hline
\end{tabular}

Thickness shims were used for this trial in an attempt to prevent the breather cloth from wedging beneath the caul plate. The shims were aligned so that they were partially 
under the caul plate, and partially exposed, as shown in Figure 8. As discussed in section 3.4.1, the shim thickness was $1.3 \mathrm{~mm}(0.050 \mathrm{in})$.

It was found that the wedging of the breather cloth was greatly reduced, but small amounts were still found to be wedged under the caul plate. Despite the reduced wedging effect, the laminate thickness was found to be $0.1 \mathrm{~mm}(0.004 \mathrm{in})$ thicker than the previous trial, possibly indicating that the wedging of the breather cloth was not affecting the final laminate thickness. Also, lag was again observed in the part temperature during processing, although to a greatly reduced degree.

The surface finish of the resulting laminate was very similar to that of PPG trial 1 , however the surface dimples were much more prominent, owing to the reduced laminate consolidation.

Images of the cross section of PPG trial 2 are shown in Figure 22. No significant internal void content has been observed for this laminate.

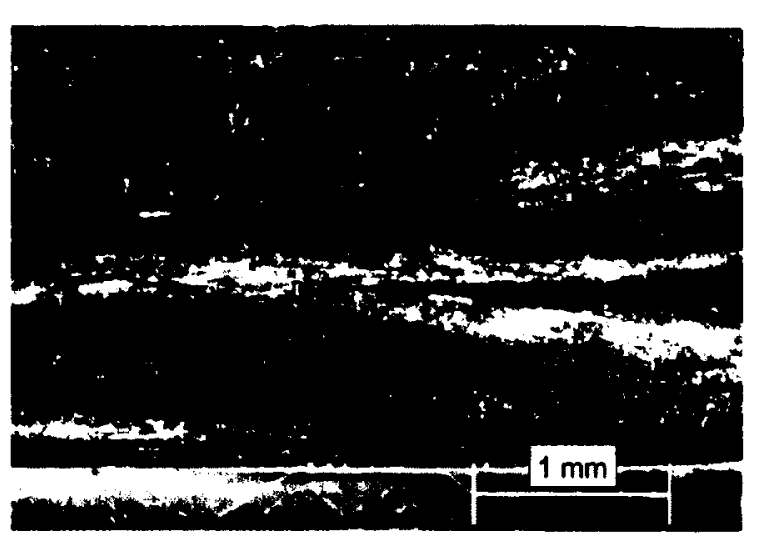

(a)

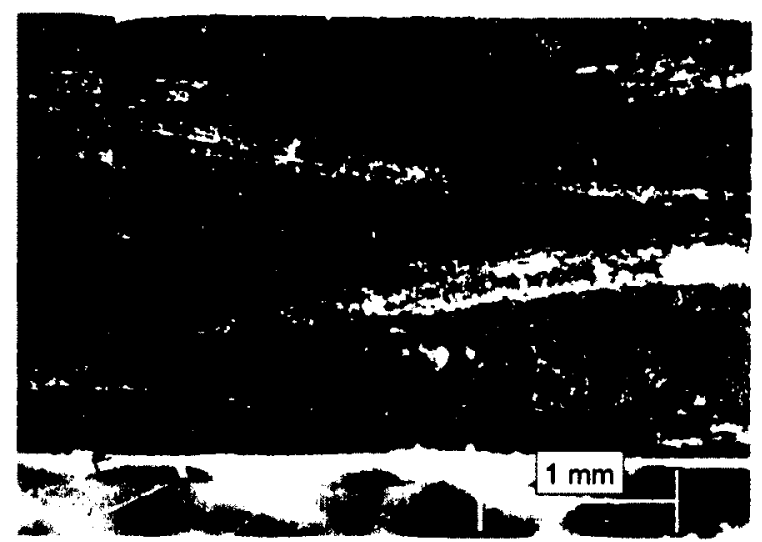

(b)

Figure 22: Cross section images of PPG T2 


\subsubsection{PPG T3}

The processing parameters used for PPG trial 3 are shown in Table 10. The temperature ramp rate for this trial was reduced to $2.2^{\circ} \mathrm{C} / \mathrm{min}$ in an attempt to completely eliminate the part temperature lag that was observed in the previous trials. The soak temperature has remained unchanged from the previous trial.

Table 10: Processing parameters and thickness data for PPG T3
\begin{tabular}{|r|l|}
\hline Temperature Ramp Rate & $2.2^{\circ} \mathrm{C} / \mathrm{min}$ \\
\hline Soak Temperature & $180^{\circ} \mathrm{C}\left(355^{\circ} \mathrm{F}\right)$ \\
\hline Soak Time & $25 \mathrm{~min}$ \\
\hline Laminate Thickness & $2.1 \mathrm{~mm}(0.082 \mathrm{in})$ \\
\hline Thickness Standard Deviation & $0.05 \mathrm{~mm}(0.002 \mathrm{in})$ \\
\hline
\end{tabular}

To address the issue of the breather cloth wedging under the caul plate, two plies of a lighter weight $\left(4 \mathrm{oz} / \mathrm{yd}^{2}\right)$ breather cloth were used instead of a single ply of heavier breather cloth $\left(10 \mathrm{oz} / \mathrm{yd}^{2}\right)$. The lighter weight breather cloth is much less stiff and much thinner. Two plies were used instead of a single ply to ensure no areas of the vacuum bag became choked off, reducing the local vacuum pressure.

It was found that the different breather cloth arrangement did not eliminate the wedging completely. The ideal solution to this problem would have been to increase the size of the tool plate and caul plate, resulting in increased area covered by breather cloth, and an increased distance between the edge of the breather cloth and the laid up laminate. However the size of the convection oven and the size of the sensor mounting fixtures limited the sizes of these components. 
The temperature ramp rate of $2.2^{\circ} \mathrm{C} / \mathrm{min}$ was found to eliminate the part temperature lag, and was used for all subsequent processing trials.

The surface finish of the resulting laminate was very similar to that of PPG trial 1 , however the surface dimples were greatly reduced in both size and quantity.

Images of the cross section of PPG trial 3 are shown in Figure 23. No significant internal void content has been observed for this laminate.

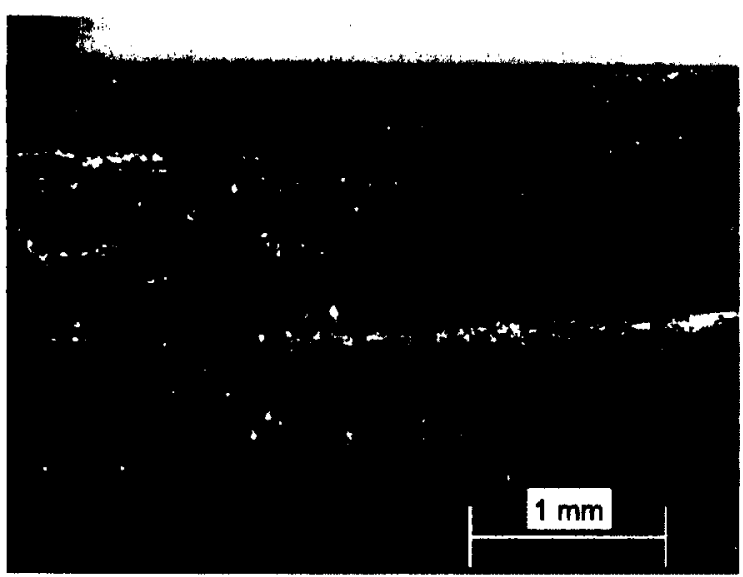

(a)

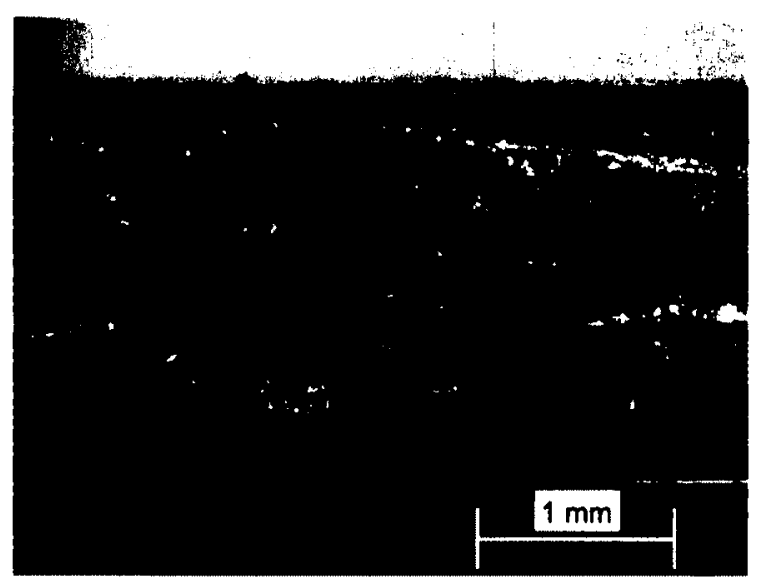

(b)

Figure 23: Cross section images of PPG T3

\subsubsection{PPG T4}

The processing parameters used for PPG trial 4 are shown in Table 11. In an attempt to improve the surface finish quality of the laminate, a long processing cycle was attempted at a slightly reduced temperature of $175^{\circ} \mathrm{C}\left(347^{\circ} \mathrm{F}\right)$. It was assumed that the longer soak time would allow sufficient time for the laminate to achieve a fully consolidated state, reducing the surface roughness (dimples) that had previously been observed. 
Table 11: Processing parameters and thickness data for PPG T4

\begin{tabular}{|r|l|}
\hline Temperature Ramp Rate & $2.2^{\circ} \mathrm{C} / \mathrm{min}$ \\
\hline Soak Temperature & $175^{\circ} \mathrm{C}$ \\
\hline Soak Time & $120 \mathrm{~min}$ \\
\hline Consolidation & $1.45 \mathrm{~mm}(0.057 \mathrm{in})$ \\
\hline Laminate Thickness & $2.13 \mathrm{~mm}(0.084 \mathrm{in})$ \\
\hline Thickness Standard Deviation & $0.05 \mathrm{~mm}(0.002 \mathrm{in})$ \\
\hline
\end{tabular}

Despite the longer processing time, no significant additional consolidation was observed in the resulting laminate. The surface finish was similar to PPG trial 3 (i.e. slight surface roughness and small surface dimples).

The overall appearance of the panel varied significantly from the previous trials, however. The white colour of the glass fibres was very prominent on this panel, as seen in Figure 24. It was believed that some degree of thermal degradation might have occurred during processing. This hypothesis will be discussed further in section 4.0 following differential scanning calorimetry trials.

\section{PPG trial 1}

\section{PPG trial 4}

Figure 24: PPG T4 laminate showing significant white areas (due to the E-glass fibres).

Images of the cross section of PPG trial 4 are shown in Figure 25. No significant internal void content has been observed for this laminate. The cross sections of PPG trial 
4 appear much less homogenous than those of the previous trials. The dark colour of the polypropylene matrix and the white colour of the E-glass fibres are much more distinct, whereas the previous trials showed a more constant grey colour throughout the cross section.

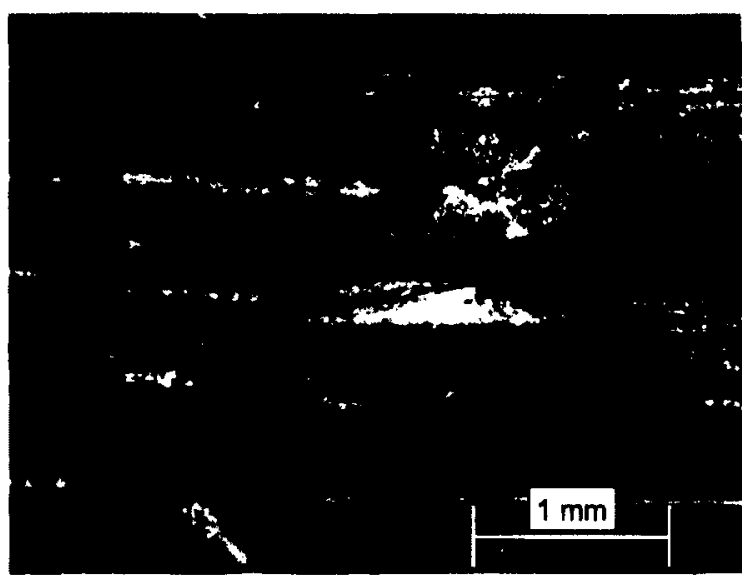

(a)

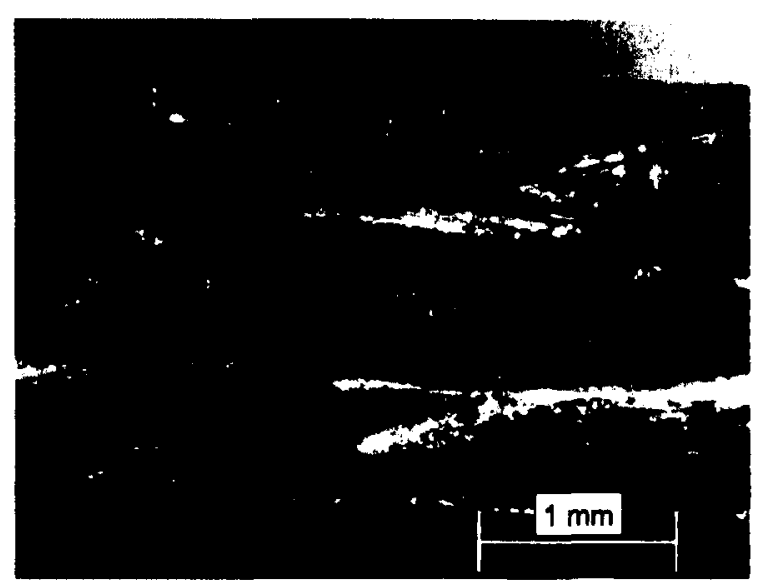

(b)

Figure 25: Cross section images of PPG T4

\subsubsection{PPG T5}

The processing parameters used for PPG trial 5 are shown in Table 12. Similar to the previous trial, an attempt was made to improve the surface finish of the laminate. The soak temperature was increased to $190^{\circ} \mathrm{C}\left(374^{\circ} \mathrm{F}\right)$ from $175^{\circ} \mathrm{C}\left(347^{\circ} \mathrm{F}\right.$, as in the previous trial), the soak time was reduced to 60 minutes from 120 minutes (as in the previous trial). 
Table 12: Processing parameters and thickness data for PPG T5

\begin{tabular}{|r|l|}
\hline Temperature Ramp Rate & $2.2^{\circ} \mathrm{C} / \mathrm{min}$ \\
\hline Soak Temperature & $190^{\circ} \mathrm{C}\left(374^{\circ} \mathrm{F}\right)$ \\
\hline Soak Time & $60 \mathrm{~min}$ \\
\hline Consolidation & $1.52 \mathrm{~mm}(0.060 \mathrm{in})$ \\
\hline Laminate Thickness & $2.06 \mathrm{~mm}(0.081 \mathrm{in})$ \\
\hline Thickness Standard Deviation & $0.05 \mathrm{~mm}(0.002 \mathrm{in})$ \\
\hline
\end{tabular}

No significant improvement in surface finish quality over PPG trial 4 was observed in the resulting laminate. Also, the peculiar appearance of the previous laminate was not observed on this panel, indicating that extended processing cycles may cause undesirable thermal degradation. This will be discussed further in chapter 4.0 and chapter 5.0.

Images of the cross section of PPG trial 5 are shown in Figure 26. No significant internal void content has been observed for this laminate.

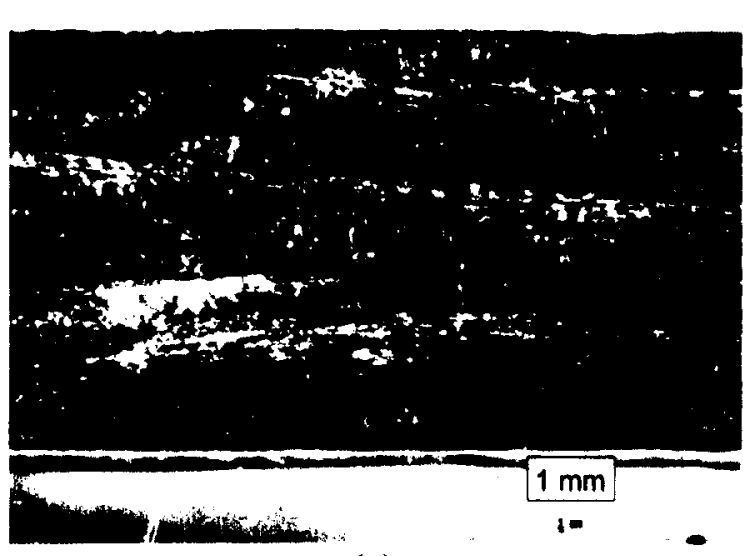

(a)

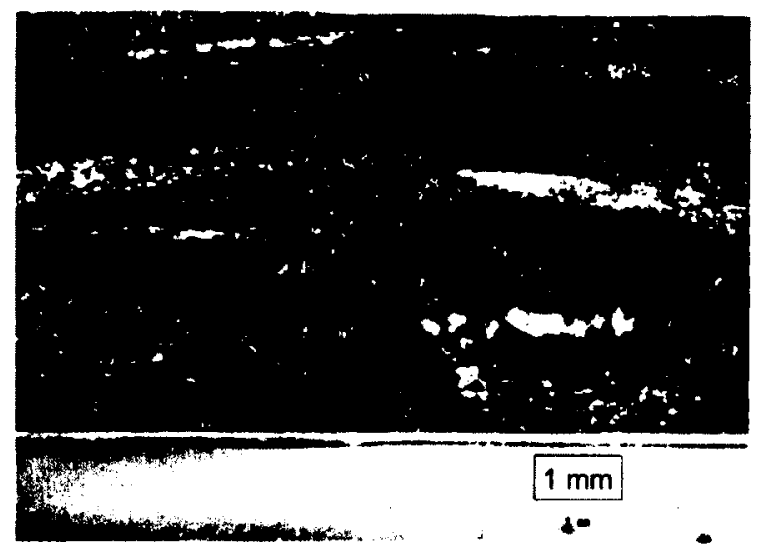

(b)

Figure 26: Cross section images of PPG T5 


\subsubsection{PPG B1}

To determine the ideal manufacturing quality (or the baseline laminate quality) for the PPG material, a 4-ply laminate was manufactured in the autoclave located at the National Research Council Institute for Aerospace Research (NRC-IAR) in Ottawa, Canada. The use of an autoclave permits the addition of external consolidation pressure over and above vacuum pressure alone. In theory, this will result in improved consolidation over using vacuum pressure alone as for the previously described trials. The processing parameters used for this laminate are shown in Table 13. To achieve an 'ideal' manufacturing quality, $190^{\circ} \mathrm{C}\left(374^{\circ} \mathrm{F}\right)$ and 60 min were selected for the soak temperature and soak time, ensuring that sufficient time and temperature were provided to reach $100 \%$ consolidation. An autoclave pressure of $586 \mathrm{kPa}(85 \mathrm{psi})$ and a temperature ramp rate of $5^{\circ} \mathrm{C} / \mathrm{min}$ were selected based on previous experience with thermosetting autoclave cure cycles, and recommendations from NRC Technical Officer Brian Moyes. Although the increased temperature ramp rate may preclude direct comparison between autoclave and oven processed laminates, the reviewed literature indicates that the heating rate does not affect the characteristics of the final part.

Table 13: Processing parameters and thickness data for PPG B1

\begin{tabular}{|r|l|}
\hline Temperature Ramp Rate & $5^{\circ} \mathrm{C} / \mathrm{min}$ \\
\hline Soak Temperature & $190^{\circ} \mathrm{C}\left(374^{\circ} \mathrm{F}\right)$ \\
\hline Soak Time & $60 \mathrm{~min}$ \\
\hline Autoclave Pressure & $586 \mathrm{kPa}(85 \mathrm{psi})$ \\
\hline Consolidation & $1.3 \mathrm{~mm} \mathrm{(0.051} \mathrm{in)}$ \\
\hline Laminate Thickness & $2.3 \mathrm{~mm}(0.089 \mathrm{in})$ \\
\hline Thickness Standard Deviation & $0.08 \mathrm{~mm}(0.003 \mathrm{in})$ \\
\hline
\end{tabular}


When removed from the autoclave, it was found that the vacuum bag had not held vacuum pressure throughout the processing cycle - likely due to a bag puncture or a leak in the tacky tape seal. In addition, it was found that the vacuum bag material had degraded. Instead of the usual green colour, significant areas of orange/brown colour were observed, as shown in Figure 27. These degraded areas of the bag broke away in 'flakes' when the bag was opened. Because of the break in the vacuum bag, the driving consolidation pressure was greatly reduced, resulting in a poorly consolidated laminate.

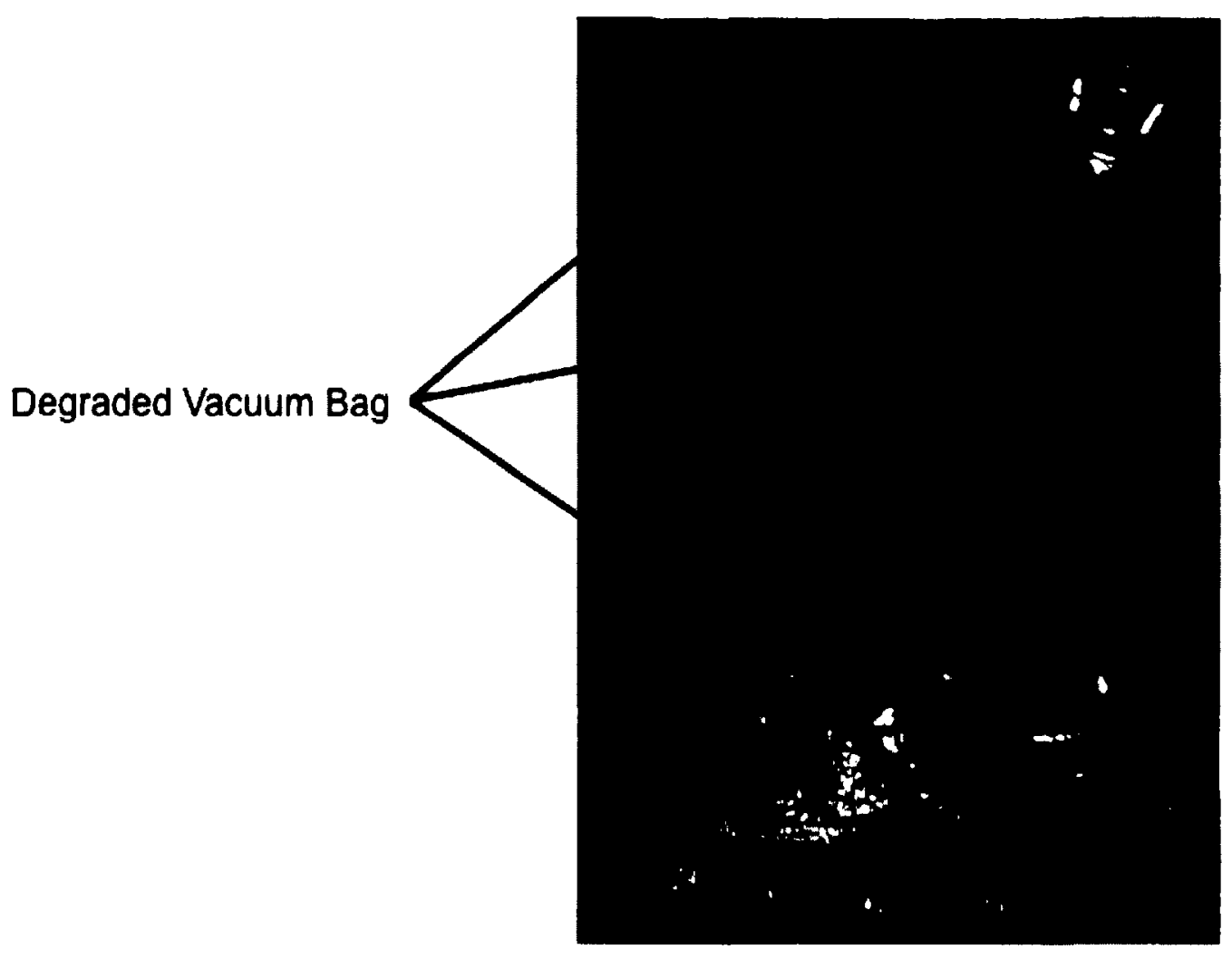

Figure 27: An example of vacuum bag degradation occurring during processing

The surface finish of the resulting laminate was extremely rough, with areas of very large crevasses and relatively dry fibres. Also, macro voids are visible on the cut edges of laminate. 
Images of the cross section of PPG baseline trial 1 are shown in Figure 28. Large voids were visible throughout the laminate, and also the surfaces appear extremely rough and uneven, as expected.

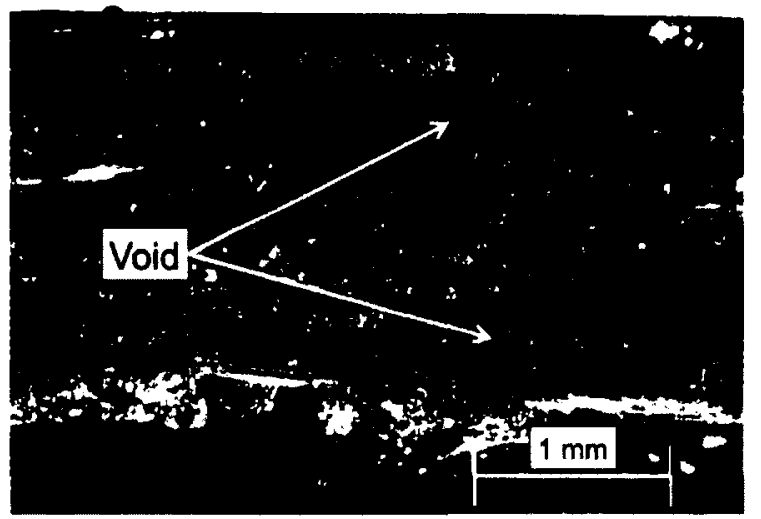

(a)

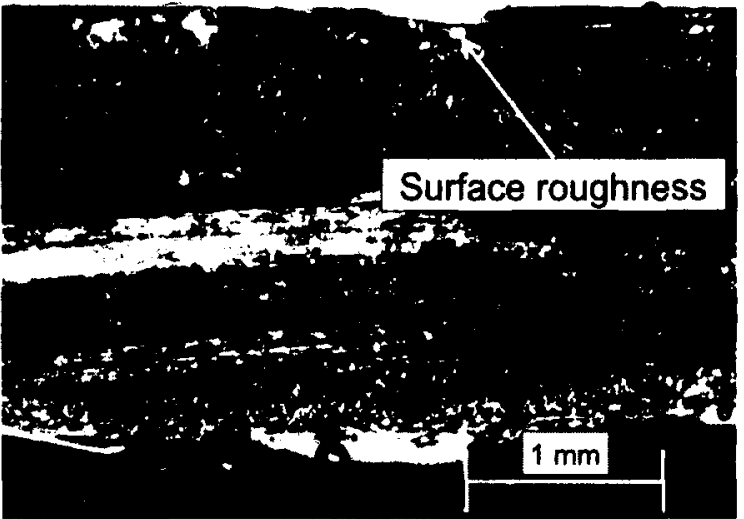

(b)

Figure 28: Cross section images of PPG B1

\subsubsection{PPG B2}

Due to the break in the vacuum bag during PPG baseline trial 1, the baseline laminate was reattempted with the same processing parameters (shown in Table 14). To reduce the chances of a leak in the tacky tape seal around the edges of the tool plate, 2 inch wide flashbreaker tape was used to tape closed the edges of the tool plate, further sealing the vacuum bag from potential leaks. 
Table 14: Processing parameters and thickness data for PPG B2

\begin{tabular}{|r|l|}
\hline Temperature Ramp Rate & $5^{\circ} \mathrm{C} / \mathrm{min}$ \\
\hline Soak Temperature & $180^{\circ} \mathrm{C}\left(355^{\circ} \mathrm{F}\right)$ \\
\hline Soak Time & $15 \mathrm{~min}$ \\
\hline Autoclave Pressure & $586 \mathrm{kPa}(85 \mathrm{psi})$ \\
\hline Consolidation & $1.8 \mathrm{~mm}(0.071 \mathrm{in})$ \\
\hline Laminate Thickness & $1.7 \mathrm{~mm}(0.069 \mathrm{in})$ \\
\hline Thickness Standard Deviation & $0.20 \mathrm{~mm}(0.008 \mathrm{in})$ \\
\hline
\end{tabular}

When removed from the autoclave, vacuum bag degradation similar to that of the previous trial was observed, but to a lesser degree (see Figure 27). Also, the vacuum seal of the bag was not broken.

The resulting laminate appeared to be of good quality, with no surface blemishes (i.e. roughness or dimples as observed on previous vacuum consolidated panels). Also, the final laminate thickness of $1.7 \mathrm{~mm}(0.069 \mathrm{in})$ indicates that approximately $0.3 \mathrm{~mm}-$ $0.4 \mathrm{~mm}(0.010-0.015 \mathrm{in})$ of additional consolidation is achieved with the addition of $586 \mathrm{kPa}(85 \mathrm{psi})$ of positive autoclave pressure.

Images of the cross section of PPG baseline trial 2 are shown in Figure 29. No significant internal void content has been observed for this laminate. 


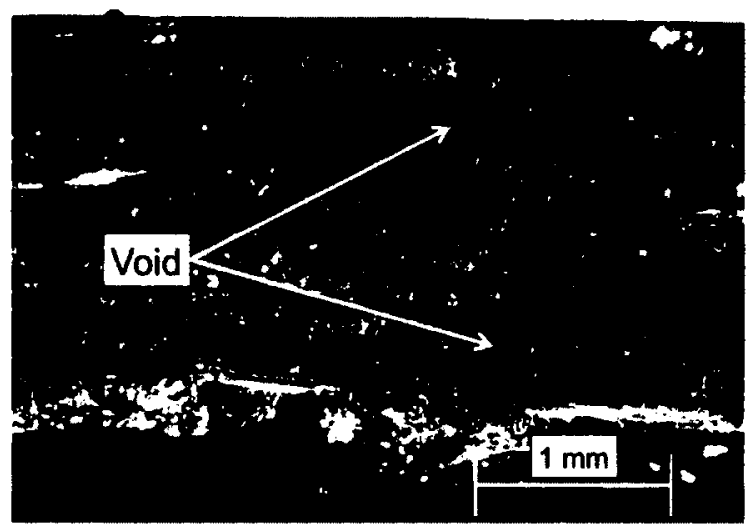

(a)

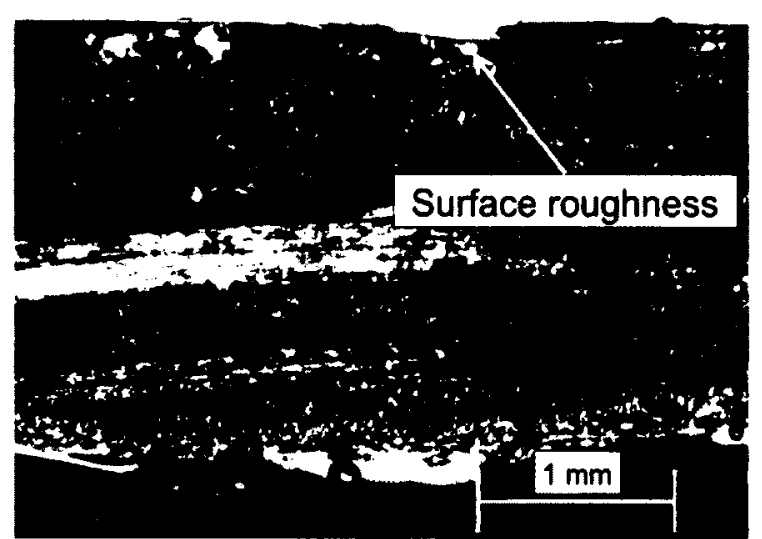

(b)

Figure 29: Cross section images of PPG B2

\subsubsection{Commingled Polyamide-6/Carbon}

The following sections describe the manufacturing trials performed during the process development exercise for the $\mathrm{NC}$ material type. The vacuum bagging procedure and materials used for these trials are described in section 3.2.

Although it was determined that the thickness shims used in previous manufacturing trials had no effect on the final laminate thickness because they were too thin, they were not removed from the vacuum bag lay-up due to their beneficial effect of reducing the amount of breather cloth becoming wedged under the caul plate during processing. Thicker shims could have been used to limit the final laminate thickness; however determining the total amount of 'free consolidation' (consolidation without obstruction from thickness shims) was of interest since an appropriate final laminate thickness was not known. The various processing parameters used for the NC processing trials are shown in Table 15. 
Table 15: Processing parameters for NC manufacturing trials

\begin{tabular}{|c|c|c|c|}
\hline Trial & $\begin{array}{c}\text { Temperature Ramp Rate, } \\
{ }^{\circ} \mathrm{C} / \mathrm{min}\end{array}$ & $\begin{array}{c}\text { Soak Temperature, } \\
{ }^{\circ} \mathrm{C}\left({ }^{\circ} \mathrm{F}\right)\end{array}$ & $\begin{array}{c}\text { Soak Time, } \\
\text { min }\end{array}$ \\
\hline T1 & 2.2 & $230(450)$ & 60 \\
\hline T2 & 2.2 & $190(374)$ & 60 \\
\hline T3 & 2.2 & $195(380)$ & 80 \\
\hline T4 & 2.2 & $195(380)$ & 80 \\
\hline BT1 & 5.0 & $190(374)$ & 60 \\
\hline BT2 & 5.0 & $195(380)$ & 60 \\
\hline
\end{tabular}

\subsubsection{NC T1}

Very little is known about the exact chemistry of the polyamide used in the NC material supplied by the NRC-IMI (as discussed in section 3.1.2). Most significantly, the type of polyamide used in the NC material is uncertain. From literature (NRC Material Data Sheet [date unknown]), it can be seen that the various types of polyamide have significantly different physical properties (i.e. $T_{m}$ ). For this reason, a starting point for the manufacturing trials described in this section was not as obvious as the PPG manufacturing trials described in section 3.4.1. For the initial trial, a high temperature cycle was performed to ensure the $T_{m}$ was achieved. The processing parameters used for NC trial 1 are shown in Table 16.

Table 16: Processing parameters and thickness data for NC T1

\begin{tabular}{|r|l|}
\hline Temperature Ramp Rate & $2.2^{\circ} \mathrm{C} / \mathrm{min}$ \\
\hline Soak Temperature & $230^{\circ} \mathrm{C}\left(450^{\circ} \mathrm{F}\right)$ \\
\hline Soak Time & $60 \mathrm{~min}$ \\
\hline Consolidation & $3.0 \mathrm{~mm}(0.117 \mathrm{in})$ \\
\hline Laminate Thickness & $2.6 \mathrm{~mm}(0.103 \mathrm{in})$ \\
\hline Thickness Standard Deviation & $0.10 \mathrm{~mm}(0.004 \mathrm{in})$ \\
\hline
\end{tabular}


To accommodate a high temperature run, a number of vacuum bagging materials had to be substituted for higher temperature rated alternatives. The vacuum bag material was substituted for high temperature Kapton film, the cotton breather cloth was substituted for 2 plies of a light fibreglass material, and all flashbreaker tape was replaced with Kapton tape.

From the consolidation data collected with the Kuda displacement sensors, it was clear that laminate consolidation commenced at approximately $180^{\circ} \mathrm{C}\left(355^{\circ} \mathrm{F}\right)$, indicating the onset of the resin melt as shown in Figure 30. It should be noted that abnormal consolidation behaviour before the onset of the polymer melt is due to temperature effects on the Kuda displacement sensors. These effects will be discussed further in section 3.5.1. 


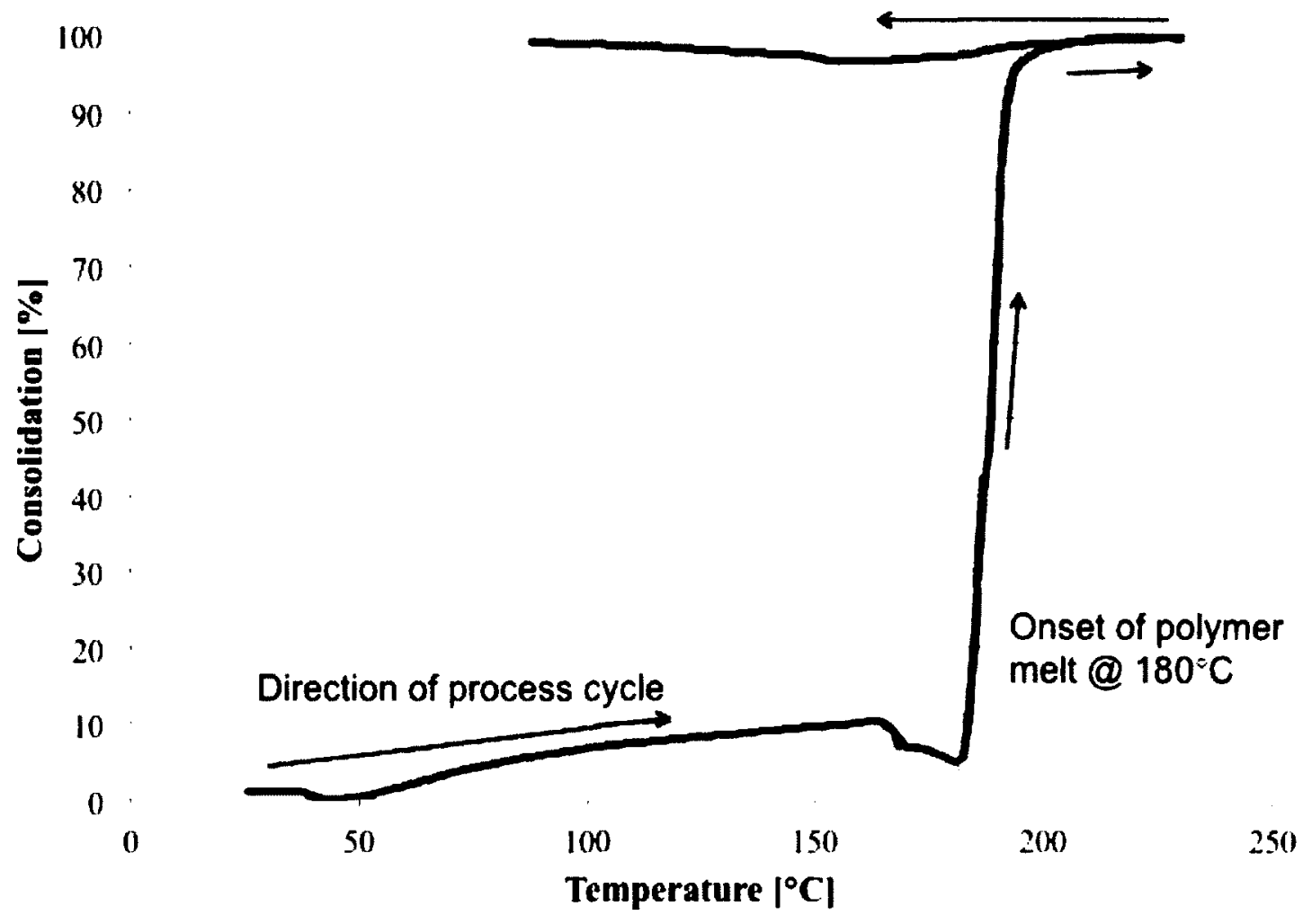

Figure 30: Raw consolidation data for NC T1 showing the onset of the resin melt at approximately $180^{\circ} \mathrm{C}$.

The laminate resulting from NC trial 1 was very rough on the surface. Large dimples and channels were present throughout both surfaces, indicating a less than ideal panel quality. Additionally, large macro voids are visible on the cut surfaces of the laminate. Images of the laminate cross section are shown in Figure 31. Large voids can be seen throughout the images. A common place for voids to form in this laminate was found to be between adjacent tows of material as seen in Figure 31(a). Unlike the previous images for the PPG material, the individual transverse tows of material are very distinct in this laminate, indicating insufficient consolidation for optimal mechanical performance. 


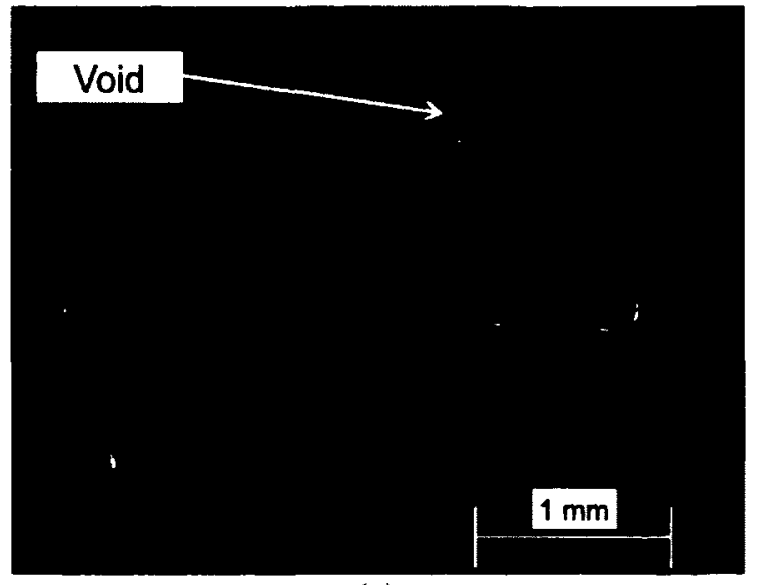

(a)

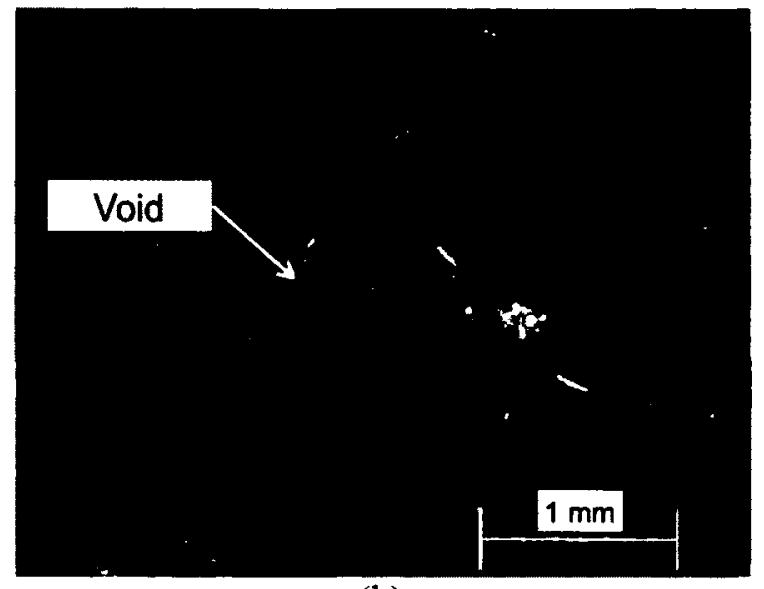

(b)

Figure 31: Cross section images of NC T1

\subsubsection{NC T2}

The processing parameters used for $\mathrm{NC}$ trial 2 are shown in Table 17. Based on the consolidation data collected for $\mathrm{NC}$ trial 1 (shown in Figure 30), a processing temperature of $190^{\circ} \mathrm{C}\left(374^{\circ} \mathrm{F}\right)$ was selected to ensure the laminate reached a temperature above the estimated melting temperature of $180^{\circ} \mathrm{C}\left(355^{\circ} \mathrm{F}\right)$. A soak time of $60 \mathrm{~min}$ was selected to ensure sufficient time for full consolidation to occur. Although it is clear that the majority of the consolidation occurs within 10-15 min of the laminate reaching its melting temperature (by analyzing the consolidation data), a longer processing cycle has been used to ensure the entire laminate consolidation range was captured.

Table 17: Processing parameters and thickness data for NC T2

\begin{tabular}{|r|l|}
\hline Temperature Ramp Rate & $2.2^{\circ} \mathrm{C} / \mathrm{min}$ \\
\hline Soak Temperature & $190^{\circ} \mathrm{C}\left(374^{\circ} \mathrm{F}\right)$ \\
\hline Soak Time & $60 \mathrm{~min}$ \\
\hline Consolidation & $3.1 \mathrm{~mm}(0.123 \mathrm{in})$ \\
\hline Laminate Thickness & $2.46 \mathrm{~mm}(0.097 \mathrm{in})$ \\
\hline
\end{tabular}


The resulting laminate greatly resembled NC trial 1 ; however size of the dimples and channels on the surface of the laminate was slightly less. Macro voids were also observed on the cut surface of this laminate. Cross sectional images of NC trial 2 are shown in Figure 32. Similar to the previous trial, surface roughness and voids were observed in the cross sectional images. Also, the transverse tows of material were again very distinct from each other, indicating incomplete laminate consolidation.

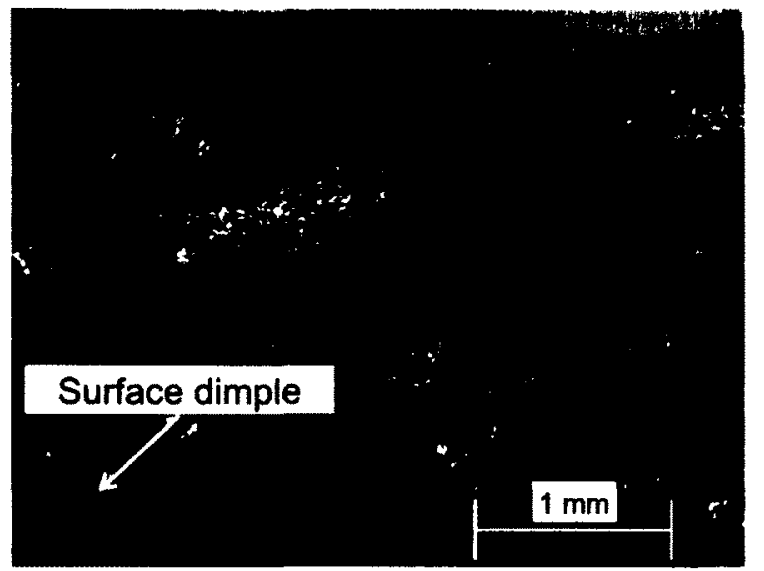

(a)

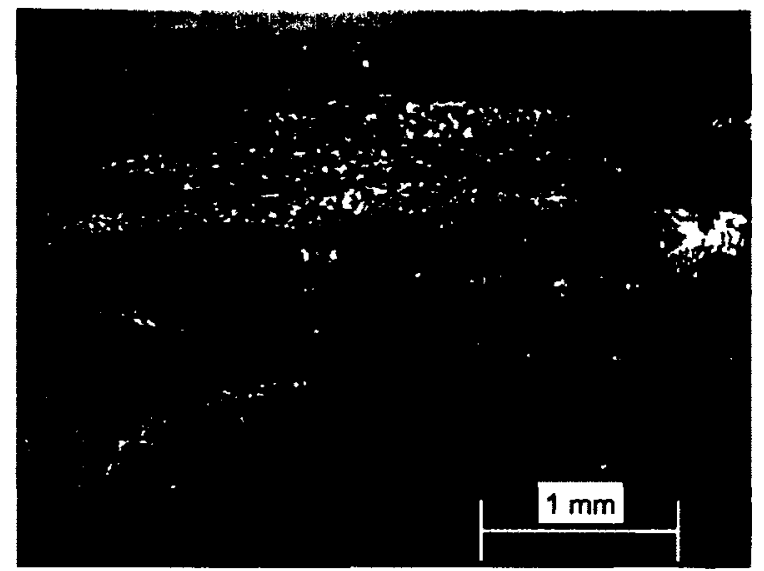

(b)

Figure 32: Cross section images of NC T2

\subsubsection{NC T3}

The processing parameters used for NC trial 2 are shown in Table 18. To investigate whether the quality of the laminate could be improved by increasing the processing temperature, a soak temperature of $195^{\circ} \mathrm{C}\left(380^{\circ} \mathrm{F}\right)$ coupled with an 80 minute soak time were selected for this trial. 
Table 18: Processing parameters and thickness data for NC T3

\begin{tabular}{|r|l|}
\hline Temperature Ramp Rate & $2.2^{\circ} \mathrm{C} / \mathrm{min}$ \\
\hline Soak Temperature & $195^{\circ} \mathrm{C}\left(380^{\circ} \mathrm{F}\right)$ \\
\hline Soak Time & $80 \mathrm{~min}$ \\
\hline Consolidation & $3.2 \mathrm{~mm}(0.127 \mathrm{in})$ \\
\hline Laminate Thickness & $2.4 \mathrm{~mm}(0.096 \mathrm{in})$ \\
\hline Thickness Standard Deviation & $0.102 \mathrm{~mm}(0.004 \mathrm{in})$ \\
\hline
\end{tabular}

When examining the vacuum bag post cure, a significant amount of breather cloth was found to be wedged under the caul plate. It was unclear whether the wedged breather cloth inhibited the panel consolidation. For this reason a second trial with the same processing parameters was performed (NC trial 4).

The resulting laminate showed a slight improvement in surface finish over NC trial 2. The amount of dimples and channels in the surface was much less, and the depth of these features was also reduced. A small number of macro voids were observed on the cut surfaces of the laminate, less than both previous trials.

Cross sectional images of NC trial 3 are shown in Figure 33. Similar to the previous trials, the transverse tows of material appear very distinct from each other. In some locations there are large pockets filled with only resin (void of carbon fibre). These features indicate that sufficient temperature was reached to melt the nylon resin, however insufficient pressure was supplied to optimally consolidate the laminate. 


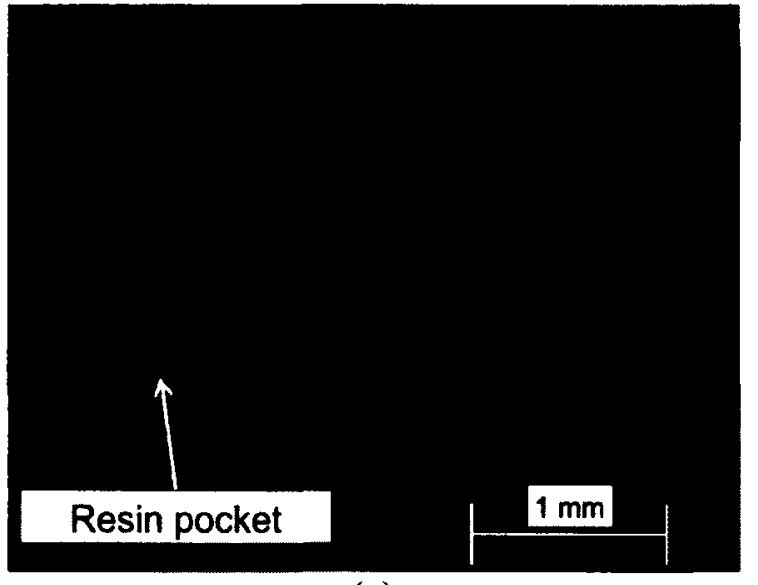

(a)

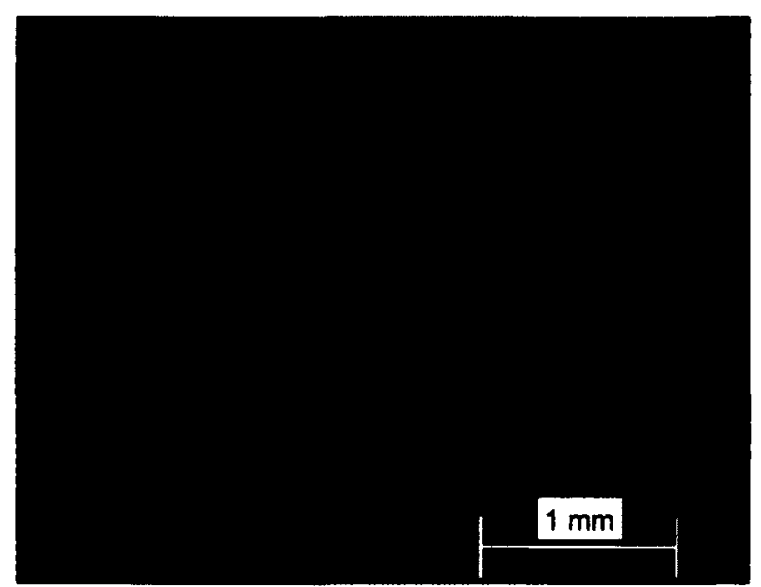

(b)

Figure 33: Cross section images of NC T3

\subsubsection{NC T4}

The processing parameters used for NC trial 4 are shown in Table 19. No changes were made from the previous trial; the main goal of this trial was to confirm that the breather being wedged under the caul plate had no effect on the laminate consolidation in the previous trial.

Table 19: Processing parameters and thickness data for NC T4

\begin{tabular}{|r|l|}
\hline Temperature Ramp Rate & $2.2^{\circ} \mathrm{C} / \mathrm{min}$ \\
\hline Soak Temperature & $195^{\circ} \mathrm{C}\left(380^{\circ} \mathrm{F}\right)$ \\
\hline Soak Time & $80 \mathrm{~min}$ \\
\hline Consolidation & $3.1 \mathrm{~mm}(0.122 \mathrm{in})$ \\
\hline Laminate Thickness & $2.5 \mathrm{~mm}(0.098 \mathrm{in})$ \\
\hline Thickness Standard Deviation & $0.13 \mathrm{~mm}(0.005 \mathrm{in})$ \\
\hline
\end{tabular}

No breather cloth was found to be wedged under the caul plate after this trial. The resulting panel showed no appreciable increase in surface finish quality over the 
previous trial. The surface roughness on NC trial 4 was identical to that found on NC trial 3.

Cross sectional images of NC trial 4 are shown in Figure 34. Both voids and resin pockets can be seen, similar to the previous trial. From these results it can be concluded that increasing the processing temperature from $190^{\circ} \mathrm{C}\left(374^{\circ} \mathrm{F}\right)$ to $195^{\circ} \mathrm{C}\left(380^{\circ} \mathrm{F}\right)$, and increasing the soak time from 60 minutes to 80 minutes did not have a significant effect on the laminate quality.

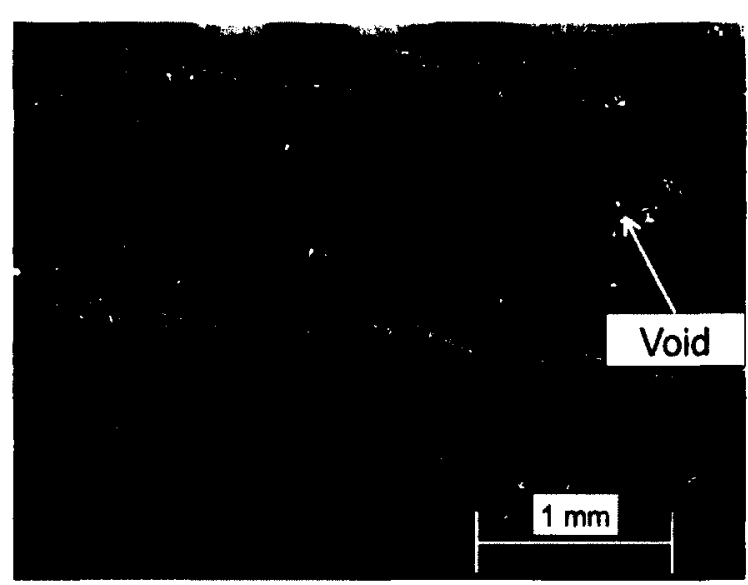

(a)

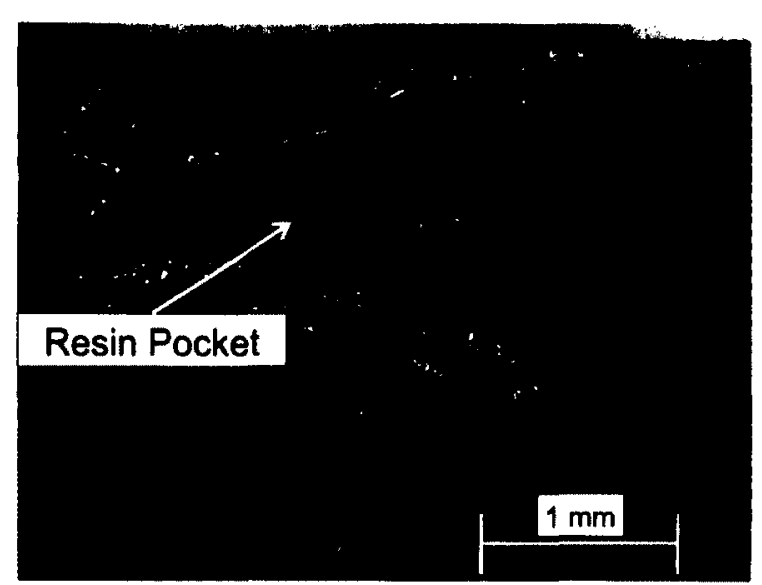

(b)

Figure 34: Cross section images of NC T4

\subsubsection{NC B 1}

To determine the ideal manufacturing quality (or the baseline laminate quality) for the $\mathrm{NC}$ material, a 4-ply laminate was manufactured in the autoclave located at the NRC-IAR in Ottawa, Ontario, Canada. The processing parameters used for this laminate are shown in Table 20. To achieve an ideal manufacturing quality, $190^{\circ} \mathrm{C}\left(374^{\circ} \mathrm{F}\right)$ and $60 \mathrm{~min}$ were selected for the soak temperature and soak time, ensuring that sufficient time and temperature were provided to reach $100 \%$ consolidation. An autoclave pressure of 
$586 \mathrm{kPa}(85 \mathrm{psi})$ was selected based previous experience with thermosetting cure cycles, and recommendations from NRC Technical Officer Brian Moyes.

Table 20: Processing parameters and thickness data for NC B1

\begin{tabular}{|r|l|}
\hline Temperature Ramp Rate & $5^{\circ} \mathrm{C} / \mathrm{min}$ \\
\hline Soak Temperature & $190^{\circ} \mathrm{C}\left(374^{\circ} \mathrm{F}\right)$ \\
\hline Soak Time & $60 \mathrm{~min}$ \\
\hline Autoclave Pressure & $586 \mathrm{kPa}(85 \mathrm{psi})$ \\
\hline Consolidation & $3.3 \mathrm{~mm}(0.130 \mathrm{in})$ \\
\hline Laminate Thickness & $2.3 \mathrm{~mm}(0.090 \mathrm{in})$ \\
\hline Thickness Standard Deviation & $0.10 \mathrm{~mm}(0.004 \mathrm{in})$ \\
\hline
\end{tabular}

Similair to PPG baseline trial 1, the vacuum bag used for this trial was found to have a leak when removed from the autoclave. Despite this, the quality of the resulting laminate was better than all previous trials with the NC material. A small amount of dimples and channels were still present on the surface of this laminate.

Cross sectional images of $\mathrm{NC}$ baseline trial 1 are shown in Figure 35. A small amount of voids were observed in NC baseline trial 1. Because the seal of the vacuum bag was found to be broken, this was an expected result due to the loss of driving pressure. 


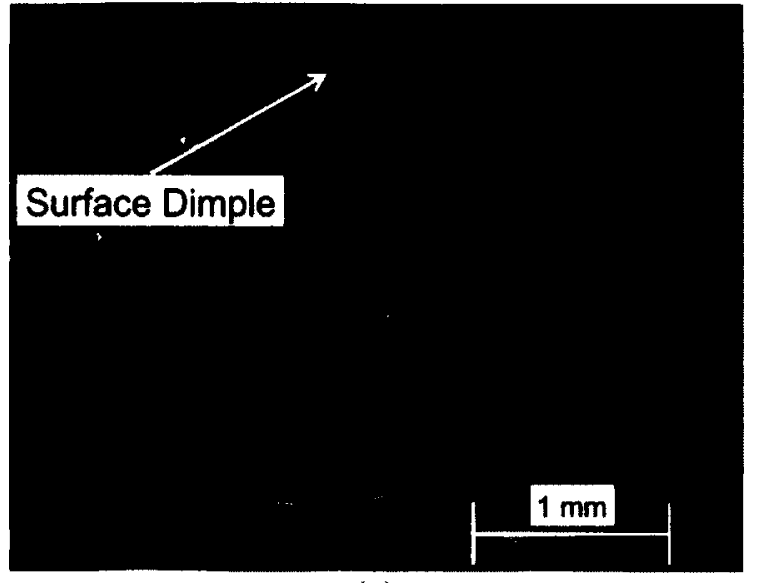

(a)

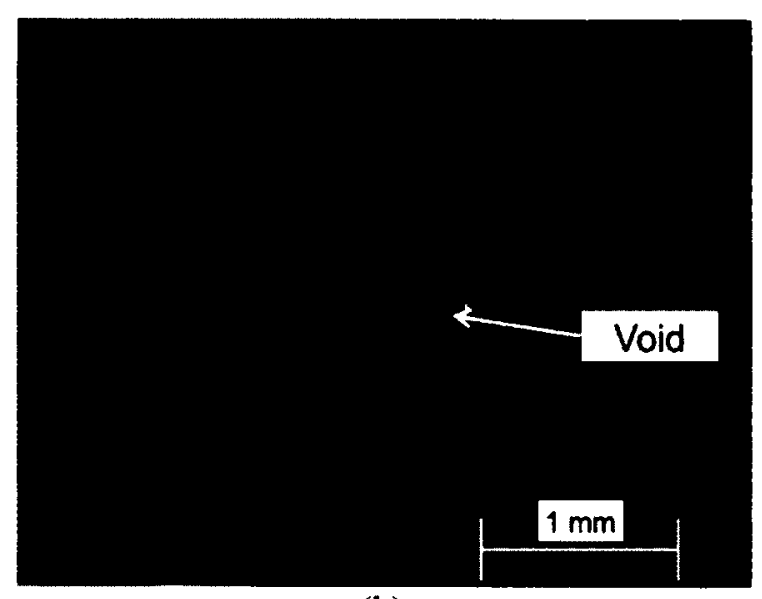

(b)

Figure 35: Cross section images of NC B1

\subsubsection{NC B2}

The processing parameters used for NC baseline trial 2 are shown in Table 21. Due to the break in the seal of the vacuum bag in the previous trial, a second panel was manufactured using the same processing parameters. Extra care was taken to ensure no leaks in the vacuum bag seal occurred in this trial; 2 inch wide flashbreaker tape was used as a second seal around the edge of the vacuum bag to help prevent leaks.

Table 21: Processing parameters and thickness data for NC B2

\begin{tabular}{|r|l|}
\hline Temperature Ramp Rate & $5^{\circ} \mathrm{C} / \mathrm{min}$ \\
\hline Soak Temperature & $195^{\circ} \mathrm{C}\left(380^{\circ} \mathrm{F}\right)$ \\
\hline Soak Time & $60 \mathrm{~min}$ \\
\hline Autoclave Pressure & $586 \mathrm{kPa}(85 \mathrm{psi})$ \\
\hline Consolidation & $3.3 \mathrm{~mm}(0.131 \mathrm{in})$ \\
\hline Laminate Thickness & $2.3 \mathrm{~mm}(0.089 \mathrm{in})$ \\
\hline Thickness Standard Deviation & $0.15 \mathrm{~mm}(0.006 \mathrm{in})$ \\
\hline
\end{tabular}


When removed from the autoclave, no problems with the vacuum bag were observed. The resulting laminate showed significant improvement in surface finish quality over the previous NC trials. No dimples or channels were observed in the surface of this laminate.

Cross sectional images of NC baseline trial 2 are shown in Figure 36. No voids or pockets of resin were observed in $\mathrm{NC}$ baseline trial 2. The transverse tows of the material show a much more homogeneous cross section, indicating a much improved consolidation quality. Also, adjacent tows of material look much less distinct than previous trials; in some cases adjacent tows could not be discerned from each other.

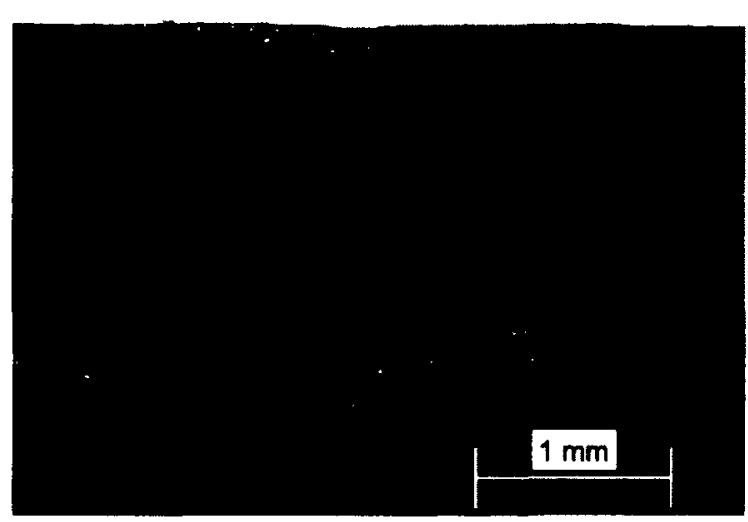

(a)

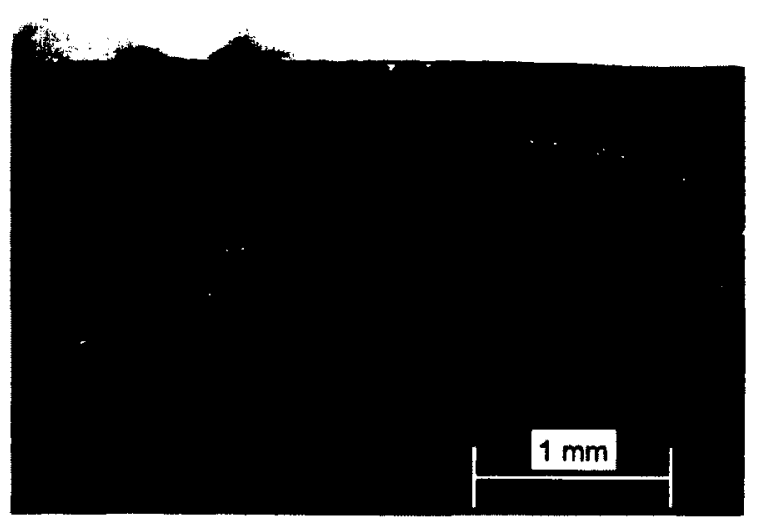

(b)

Figure 36: Cross section images of NC B2

\subsection{Laminate Consolidation Measurements}

During laminate processing, the amount of through-thickness consolidation (or compaction) was measured, in situ, using the non-contact displacement sensors described in section 3.3. Understanding the manner in which the commingled preform responds to heating is important when attempting to optimize the manufacturing process. By 
measuring the laminate consolidation, it becomes clearer what the required processing temperature, pressure and time are required for a given material to reach a fully consolidated state with the target fibre volume fraction and minimum void content. When these variables are known, the most economical and efficient process can be employed to manufacture parts.

A consolidation study on commingled polyethylene terephthalate (PET) composites was performed by ljaz et al. (2006) in which the compaction of laminates was measured by means of a linear variable differential transducer (LVDT) placed in contact with the part. When measuring consolidation in a non-idealized production scenario (i.e. typical vacuum bag and oven processing), it was concluded that two sources of error were affecting the measurements: (a) LVDT interaction with the vacuum bag surrounding the part, and (b) thermal effects on the LVDT hardware. By employing a non-contact sensor in the present work, the first of these sources of error has been eliminated; however, as is discussed in the next section, thermal effects did prove to be significant.

Typical consolidation measurements are shown in Figure 37 and Figure 38 for the PPG and NC materials respectively. Similar to what was observed by ljaz et al. for commingled PET composites, the consolidation of both the PPG and NC composites occurs in two distinct steps. To use the terminology proposed by Ijaz et al. (2006), the two processes are termed "Process A" and "Process B".

Process $\mathrm{A}$, occurring at a temperature above the $T_{g}$ of the material, is characterized by laminate debulking, and softening of the polymer fibres. The contribution of process $\mathrm{A}$ to the total laminate consolidation varies between the commingled PPG and NC materials. For the PPG material, Process A accounts for 
approximately $13 \%$ of the total consolidation, and for the NC material, Process A accounts for approximately $6 \%$ of the total consolidation. A contributing factor to this difference is the relative coarseness of the two dry commingled materials. The PPG material is woven more loosely than the NC material. Also, the individual tows of commingled NC are bundled very tightly, whereas the PPG tows are bundled loosely, allowing them to flatten out more readily with the application of heat and pressure.

Process B is characterized by melting of the polymer fibres in the commingled material. This is clear in both the PPG and NC consolidation plots, as the onset of Process B occurs at temperatures slightly above the respective $T_{m}$ (approximately $155^{\circ} \mathrm{C}$ $\left(311^{\circ} \mathrm{F}\right)$ and $170^{\circ} \mathrm{C}\left(338^{\circ} \mathrm{F}\right)$ for the PPG and $\mathrm{NC}$ material respectively, as measured by dynamic scanning calorimetry (see section 4.2). At these temperatures, the rate of consolidation increases sharply, bringing the laminates to near $100 \%$ of the achievable consolidation in less than 5 minutes after the onset of melting. Figure 37 shows that for the PPG material, the final $5 \%$ of consolidation occurs over a period of about 50 minutes whereas Figure 38 shows that the NC material reaches $100 \%$ of the achievable consolidation about 5 minutes after the onset of the polymer melt. This comparison indicates that very rapid processing cycles are more feasible with the NC blend than with the PPG material, given the constraints of vacuum consolidation. 


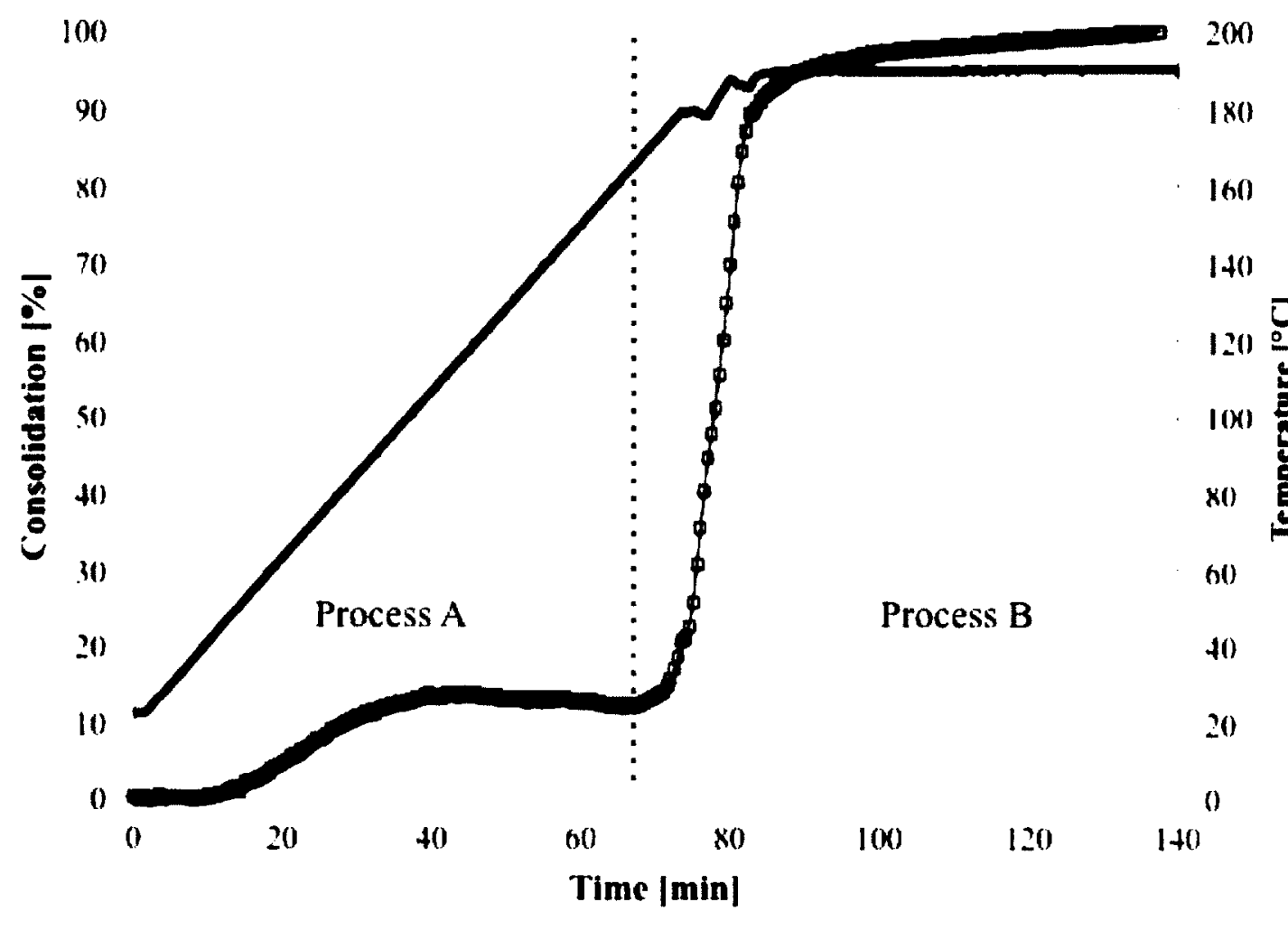

Figure 37: A typical consolidation plot for a PPG laminate

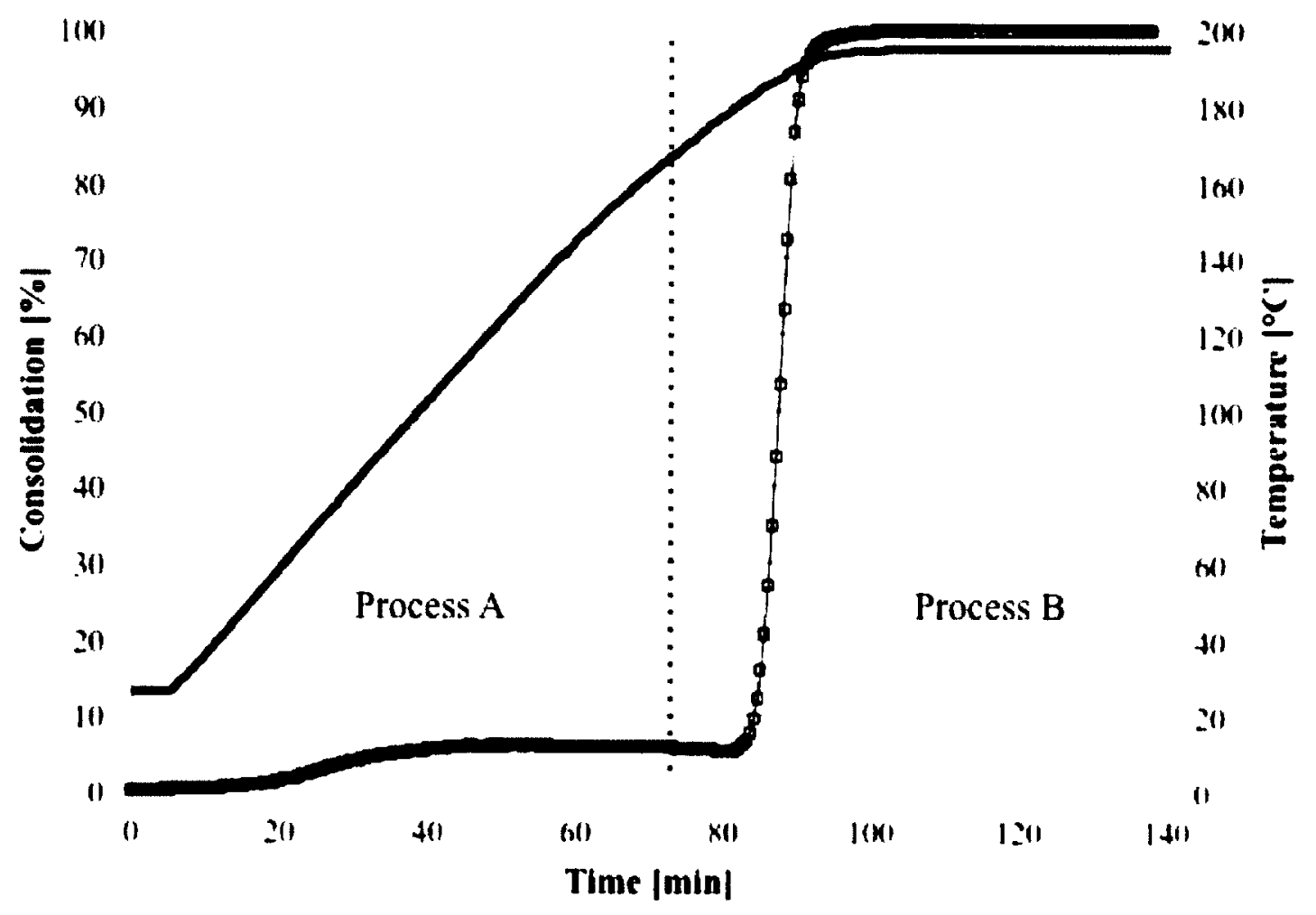

Figure 38: A typical consolidation plot for a NC laminate 


\subsubsection{Thermal Effects on the Kuda Displacement Sensors}

When initially analyzing the raw data collected from the Kuda non-contact displacement sensors, unexpected variations in laminate thickness were observed. Based on prior experience of researchers at NRC-IAR with these sensors, it was recommended that a "dry run" calibration trial be conducted. This exercise involved attaching a fixed metallic target to the sensors (as shown schematically in Figure 39), and collecting measurements as they were exposed to a temperature ramp from ambient to the processing temperatures used in this research (to a maximum of $235^{\circ} \mathrm{C}\left(455^{\circ} \mathrm{F}\right)$ ). A non-conductive offset spacer was placed between the sensor head and the metallic target to ensure the target was within the sensor's measurement range. The intent of this test was to simulate the actual consolidation trials without the composite material in the oven to identify possible hysteresis or temperature sensitivity effects in the sensors. The resulting plot from this trial is shown in Figure 40. From this figure, it is clear that a significant temperature induced error is present. Furthermore, the hysteresis in the measurements shows that the error differs depending on the direction of the temperature ramp rate. For sensor one, the maximum displacement error is approximately $-5 \%$ of the measurement range $(5 \mathrm{~mm}$ $(0.200 \mathrm{in}))$, and for sensor two the maximum displacement error is approximately $+5 \%$ of the measurement range. In absolute terms, the error is approximately $\pm 0.3 \mathrm{~mm}(0.010 \mathrm{in})$, or about $12.5 \%$ of the final thickness of a $2 \mathrm{~mm}(0.080 \mathrm{in})$ thick laminate.

To account for the thermally induced error in these measurements, a correction factor was applied to the raw data as a function of the oven temperature at every time step. The correction factors used are shown in Figure 41. It was determined that the only relevant errors produced by the sensors were those during the temperature ramp up since 
it is assumed that the laminate is fully consolidated before the temperature is ramped back down, and therefore the thickness measurements become static and not of concern after the soak time has expired. For this reason, only half of each hysteresis curve as highlighted in Figure 41 is considered for the purposes of correcting the sensor data for the consolidation trials.

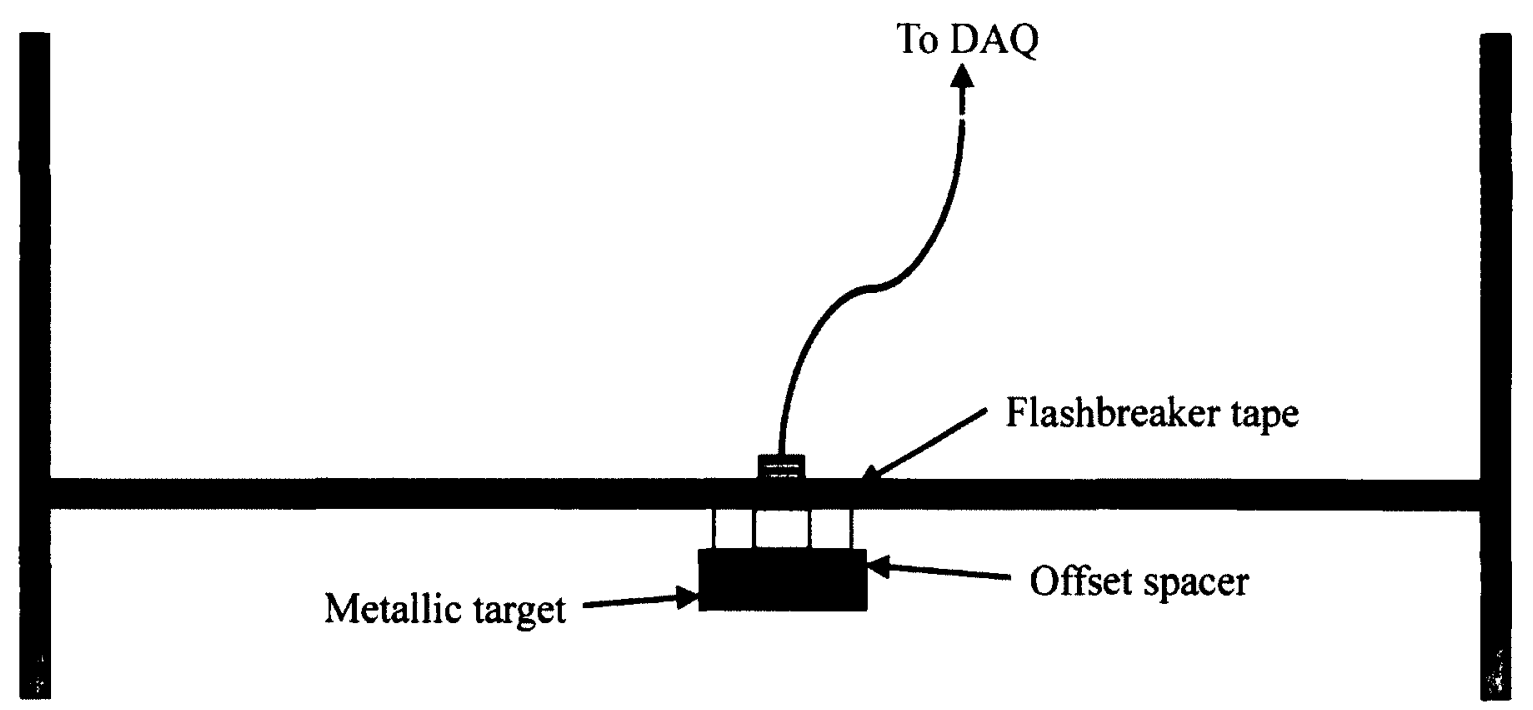

Figure 39: Schematic of a non-contact displacement sensor with a fixed target and offset spacer attached 


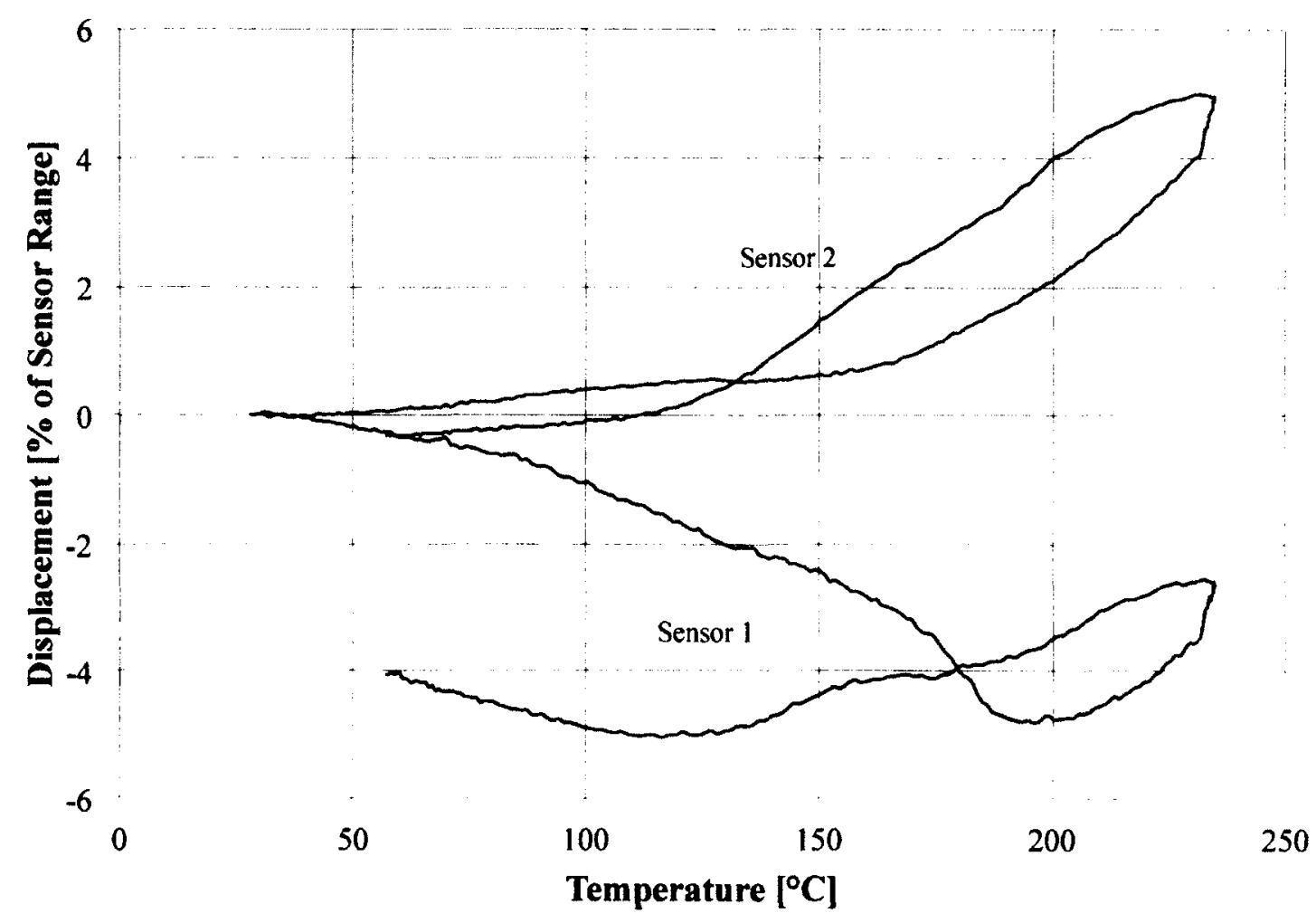

Figure 40: Dry run displacement measurements taken with a fixed target attached to the sensors

6

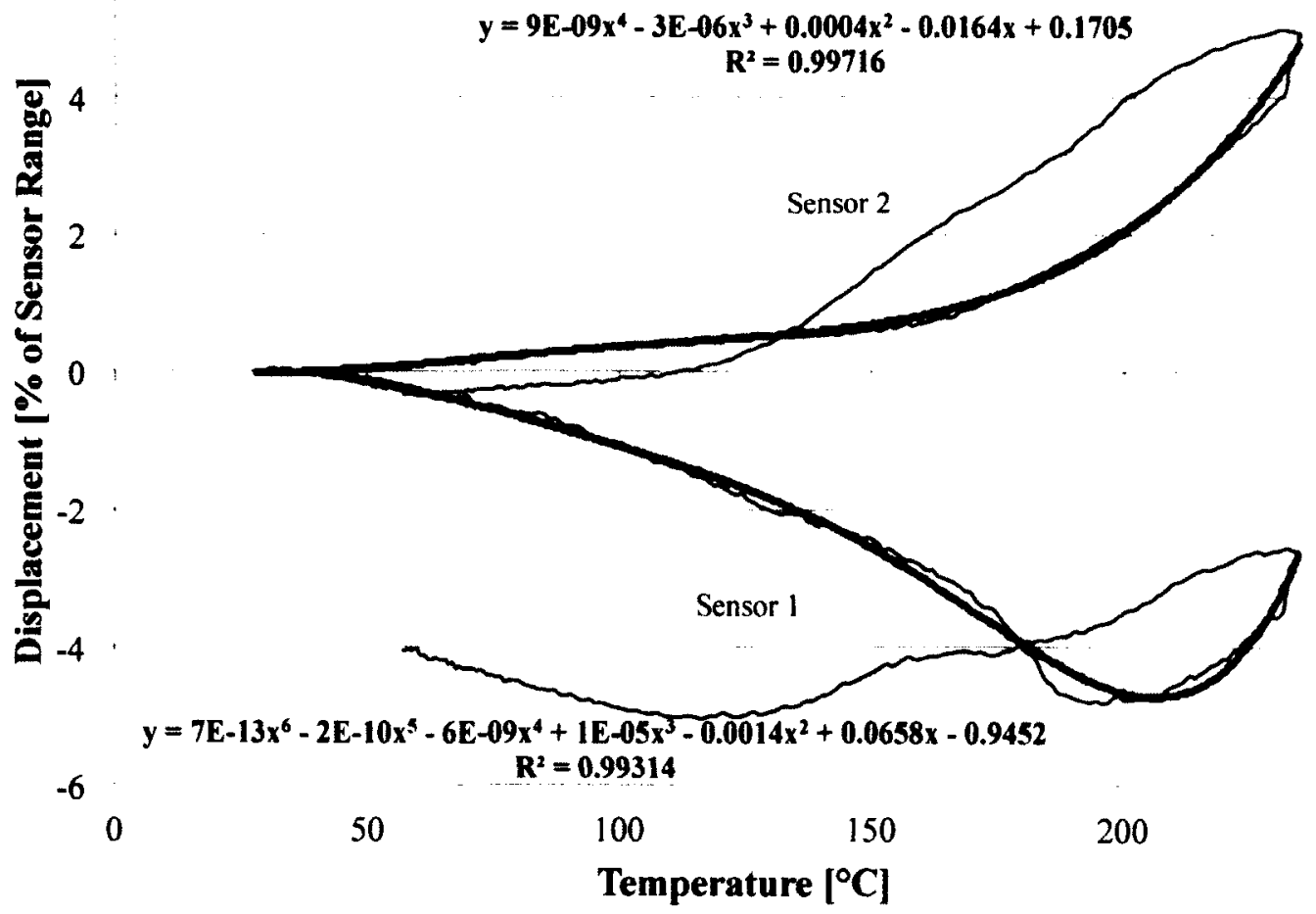

250

Figure 41: Kuda displacement sensor correction factors 


\subsection{Material Characterization}

Knowledge of thermal effects on mechanical and physical properties of a material is essential when considering the design of a suitable manufacturing process. In terms of polymeric materials, the glass transition temperature $\left(T_{\mathrm{g}}\right)$ and the melting temperature $\left(T_{m}\right)$ are of interest. These temperatures typically define a material's (and thus a part's) safe operating temperature range, and also play a primary role in the definition of an efficient processing cycle (in terms of cost and part quality). Depending on the material type and application, the $T_{g}$ can indicate either the maximum or minimum safe operating temperature, while the $T_{m}$ indicates the temperature that must be reached or exceeded to ensure sufficiently low resin viscosity to impregnate reinforcing fibres.

The following sections describe two test methods that are used to determine $T_{g}$ and $T_{m}$ for the thermoplastic polymer materials studied in this work: dynamic mechanical analysis (DMA) and differential scanning calorimetry (DSC).

\subsection{Dynamic Mechanical Analysis}

Dynamic mechanical analysis is a test method in which a sample's modulus (stiffness) and energy dissipation (damping) over a range of temperatures is determined (TA Instruments, 2007). These properties can also be referred to as the viscoelastic properties of the sample. This is achieved by exposing a test sample to cyclic stress (or strain) while ramping up the temperature over a range that spans the $T_{g}$, and in some cases the $T_{m}$. During this time the strain (or stress) is recorded. 
Numerous methods of determining the $T_{g}$ from DMA data are available, each providing a different result. Three of the possible methods are as follows (see Figure 42) (TA Instruments, 2007):

1. $E^{\prime}$ Onset - This value occurs at the point where the storage modulus ( $\left.E^{\prime}\right)$ begins to decrease significantly. It is typically the lowest $T_{g}$ value of the three discussed here. This value corresponds to the temperature at which mechanical failure can be expected to occur.

2. E" Peak - This value occurs at the peak of the loss modulus (E") curve, immediately before a sharp decrease occurs. It is typically the middle $T_{g}$ value of the three discussed here. This value corresponds to the temperature where physical property changes occur due to molecular motion of the polymer.

3. Tan $\delta$ Peak - This value occurs at the peak of the loss tangent $(\tan \delta)$ curve, and typically corresponds to the highest $T_{g}$ value of the three discussed here. This value corresponds to the midpoint between the brittle/glassy state and the ductile/rubbery state of the polymer. 


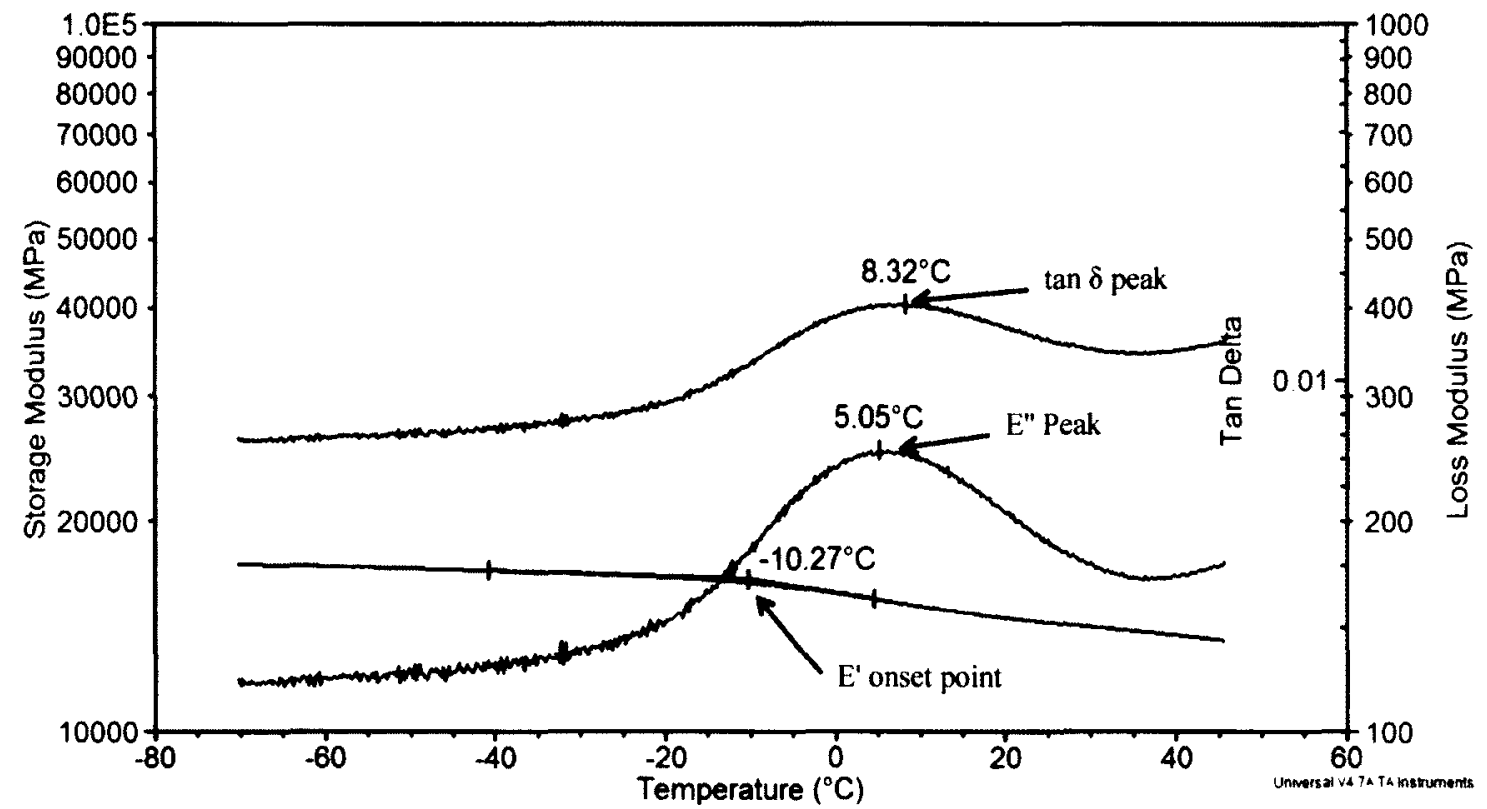

Figure 42: An example DMA plot demonstrating three methods of determining $T_{g}$

Two additional methods of determining $T_{g}$ from DMA are E" onset and $\tan \delta$ onset (corresponding to the point at which these curves sharply increase). The results of various methods of determining $T_{g}$ can vary significantly due to the different effects temperature can have of elasticity and viscosity, therefore it is important to note the means by which a value was determined (Perkin Elmer Inc., 2007). Storage modulus, loss modulus and loss tangent are discussed in next section.

When the material being examined is not completely amorphous (as is the case in this work), the glass transition can be much less pronounced. This can be seen in Figure 42 for instance. The E' curve shows a very shallow reduction in storage modulus, indicating crystalline content. If the coupon being tested had been of the amorphous type, a much sharper decrease in the $E^{\prime}$ curve would be expected. This phenomenon is due to the fact that local molecular order (or crystallinity) provides resistance to molecular chain mobility that is associated with $T_{g}$. Therefore, materials comprised of more amorphous 
regions will exhibit a sharper decrease in storage modulus due to increased molecular chain mobility. Conversely, materials containing mostly crystalline content will be more resistant to molecular chain movements, and therefore the storage modulus curve will remain more flat (as is the case in Figure 42). This quality of the $E^{\prime}$ curve makes it particularly difficult to achieve a reproducible glass transition temperature using the graphical method for the materials tested here. By choosing slightly different tangent points on the plot, the resulting $T_{g}$ can vary by up to $\pm 5^{\circ} \mathrm{C}$.

The glass transition temperature is an important material characteristic in terms of defining a component's safe temperature operating range. As an example, polypropylene is very brittle below its $T_{g}$, and relatively tough above its $T_{g}$. For this reason, if a component were designed using the PPG material studied here, and toughness was a primary design objective, $T_{g}$ would be considered the minimum operating temperature of that component to ensure sufficient toughness to meet the design objective.

\subsubsection{Viscoelasticity}

Polymers fall into the category of viscoelastic materials, indicating that their properties lie between those of an ideal solid and an ideal liquid. When an ideal solid (i.e. one that follows Hooke's law of elasticity) is strained cyclically (as in a DMA test), it can be shown that the stress response is in phase with the applied strain. Assuming:

$$
\varepsilon(t)=\varepsilon_{0} \sin (\omega t)
$$

where $\varepsilon$ is strain, $\omega$ is frequency and $t$ is time. The stress at any time can be expressed through application of Hooke's law as follows: 


$$
\sigma(t)=E \varepsilon(t)=E \varepsilon_{0} \sin (\omega t)=\sigma_{0} \sin (\omega t)
$$

where $\sigma$ is stress, and $E$ is Young's Modulus. When considering an ideal liquid on the other hand, the shear stress at any time is proportional to the rate of shear strain. It can be shown that this results in a $90^{\circ}$ phase lag between the applied shear strain $(\gamma)$, and the shear stress response $(\tau)$. Assuming:

$$
\gamma(t)=\gamma_{0} \sin (\omega t)
$$

The shear stress at any time can be expressed through application of Newton's law of viscosity $(\eta)$ as follows:

$$
\tau(t)=\eta \frac{d}{d t} \gamma(t)=\eta \gamma_{0} \omega \cos (\omega t)=\eta \gamma_{0} \omega \sin \left(\omega t+\frac{\pi}{2}\right)
$$

The $90^{\circ}$ phase lag between stress response for the ideal solid and the ideal liquid indicates that for a viscoelastic material, having properties between the two ideal materials, will have a phase lag somewhere between 0 and $90^{\circ}$. Therefore by applying a sinusoidal strain to a test coupon and measuring the magnitude and phase angle of the stress response, the modulus and proportion of elastic to viscous behaviour can be determined (Menczel et al., 2009).

Results from DMA testing are commonly presented in the form of a complex modulus, or the ratio of sinusoidal stress to strain. In complex notation, the complex modulus can be expressed as:

$$
E^{*}=E^{\prime}+i E^{\prime \prime}
$$

where

$$
E^{\prime}=\frac{\sigma_{0}}{\varepsilon_{0}} \cos (\delta)
$$




$$
E^{\prime \prime}=\frac{\sigma_{0}}{\varepsilon_{0}} \sin (\delta)
$$

The value $E^{\prime}$ is the storage modulus and is relative to stiffness. This value reflects the proportion of elastic response observed in the test coupon and the amount of recoverable strain energy. $E^{\prime \prime}$ is the loss modulus and is relative to viscous damping. This value reflects the proportion of viscous response observed in the test coupon, and the amount of energy lost to heat dissipation.

A third value of interest is the loss tangent $(\tan \delta)$. This value is defined as the ratio of E' to E', and can be expressed as

$$
\frac{E^{\prime \prime}}{E^{\prime}}=\frac{\sin (\delta)}{\cos (\delta)}=\tan (\delta)
$$

This value ranges from 0 for an ideal solid to infinity for an ideal liquid. In terms of the previously mentioned definitions of $E^{\prime}$ and $E^{\prime \prime}$, the loss tangent represents the ratio of energy lost to heat dissipation to the recoverable strain energy (Ferry, 1980).

\subsubsection{DMA Apparatus}

For this work, a three point bending fixture mounted in a TA Instruments Q800 dynamic mechanical analyzer (Figure 43) was used to perform DMA experiments as per ASTM D7026 Standard Test Method for Glass Transition Temperature (DMA $T_{g}$ ) of Polymer Matrix Composites by Dynamic Mechanical Analysis (DMA) (ASTM International, 2011). A schematic of the DMA operation is provided in Figure 44. The measurement ranges and sensitivities of this apparatus are provided in Table 22. 


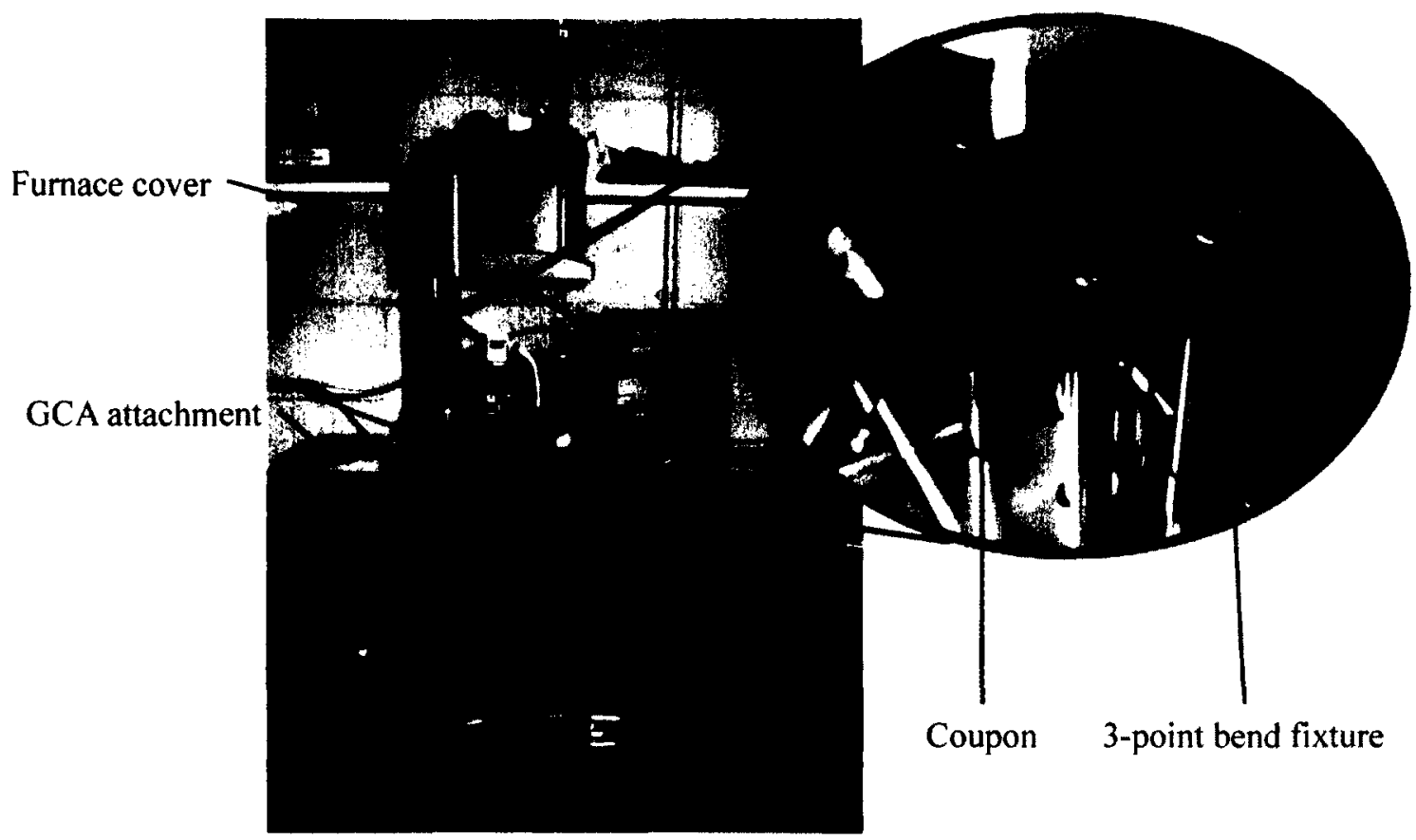

Figure 43: TA Instruments Q800 Dynamic Mechanical Analyzer (located at McGill University, Montreal Canada) with a test coupon installed in the three-point bend fixture.

\section{Furnace}

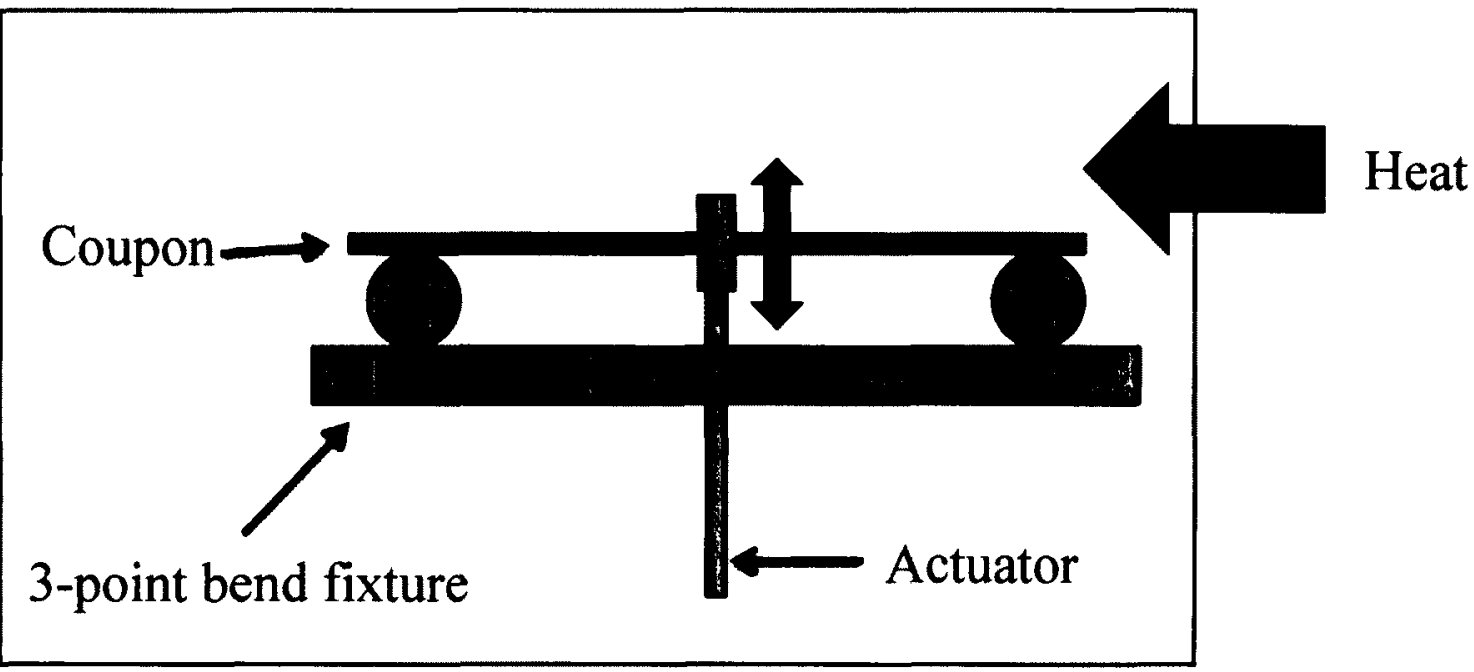

Figure 44: Schematic of the TA Instruments Q800 DMA with a three-point bend fixture 
Table 22: Specifications for the TA Instruments Q800 Dynamic Mechanical Analyzer (TA Instruments, 2011)

\begin{tabular}{|l|l|}
\hline Force Capability & $0.0001-18 \mathrm{~N}$ \\
\hline Force Resolution & $0.00001 \mathrm{~N}$ \\
\hline Strain Resolution & $1 \mathrm{~nm}$ \\
\hline Frequency Range & $0.01-200 \mathrm{~Hz}$ \\
\hline Temperature Range & $-150-600^{\circ} \mathrm{C}$ \\
\hline Heating Rate & $0.1-20^{\circ} \mathrm{C} / \mathrm{min}$ \\
\hline Cooling Rate & $0.1-10^{\circ} \mathrm{C} / \mathrm{min}$ \\
\hline Isothermal Stability & $\pm 0.1^{\circ} \mathrm{C}$ \\
\hline Modulus Precision & $\pm 1 \%$ \\
\hline
\end{tabular}

From the reviewed literature, it was found that the glass transition temperatures of nylon and polypropylene are approximately $35^{\circ} \mathrm{C}\left(95^{\circ} \mathrm{F}\right)$ and $-20^{\circ} \mathrm{C}\left(-4^{\circ} \mathrm{F}\right)$ respectively (depending on their exact chemistry) (NRC Data Sheet [date unknown]). For this reason, the gas cooling accessory (GCA) was used to achieve an initial temperature of $-70^{\circ} \mathrm{C}$ $\left(-94^{\circ} \mathrm{F}\right)$. The test parameters for these tests are shown in Table 23.

Table 23: Dynamic mechanical analysis test parameters

\begin{tabular}{|l|l|}
\hline Initial Temperature & $-70^{\circ} \mathrm{C}\left(-94^{\circ} \mathrm{F}\right)$ \\
\hline Final Temperature & $50^{\circ} \mathrm{C}\left(122^{\circ} \mathrm{F}\right)$ \\
\hline Ramp Rate & $5^{\circ} \mathrm{C} / \mathrm{min}$ \\
\hline Strain Amplitude & $0.05 \%$ \\
\hline Preload & $0.01 \mathrm{~N}(0.02 \mathrm{lbs})$ \\
\hline Frequency & $1 \mathrm{~Hz}$ \\
\hline
\end{tabular}


The frequency at which a test is performed can also have a significant effect on the results. It has been found that for each decade change in test frequency, the measured $T_{g}$ can shift by $5-7^{\circ} \mathrm{C}$ (Perking Elmer, 2007). The principle of time-temperature superposition best illustrates this principle. The Williams-Landel-Ferry model states that time (or the frequency of load application) and temperature can be interchanged under certain conditions (Perkin Elmer, 2008). This indicates that increasing the frequency of stress or strain application on a material has the same effect as increasing the temperature of a material in terms of viscoelastic properties. This principle is often used to determine the effect of loads at frequencies that are unable to be tested conveniently. By testing a material's viscoelastic properties over a limited frequency range but at a wide range of temperatures, the viscoelastic properties can be calculated by converting the testing temperatures into equivalent frequencies, thus arriving at test results that span a wide range of frequencies. The opposite is also true: by testing a material's viscoelastic properties over a wide range of frequencies, the material's response to a wide range of temperatures over a limited range of frequencies can be determined.

\subsubsection{Dynamic Mechanical Analysis Coupon Preparation}

DMA coupons were water jet cut from the manufactured panels by Hydrotech Cutting Inc. in Ottawa, Canada to avoid any adverse temperature effects caused by traditional abrasive cutting methods such as machining or diamond saw cutting. The standard ASTM D7028 does not specify a coupon size for these experiments, but rather the test fixture dimensions of the specific DMA unit dictate the test coupon size. In this case, test coupons were cut to $10 \mathrm{~mm}(0.39 \mathrm{in})$ length and $2 \mathrm{~mm}(0.08 \mathrm{in})$ width. The coupon 
thickness varied according to the specific panel from which it was cut. The majority of coupons ranged between $2 \mathrm{~mm}(0.08 \mathrm{in})-2.5 \mathrm{~mm}(0.10 \mathrm{in})$ in thickness.

Due to equipment availability limitations, only one coupon from each manufacturing trial was tested. Although the results from such a small number of coupons are not statistically valid, this work provides a starting point from which preliminary design decisions can be made.

\subsubsection{Dynamic Mechanical Analysis Test Results}

The results of the DMA experiments are shown in Figure 45 and Figure 46 for the PPG blend and the NC blend respectively. For reference, the processing parameters of each processing trial have been summarized in Table 24 and Table 25. A complete set of DMA plots is available in Appendix A. 


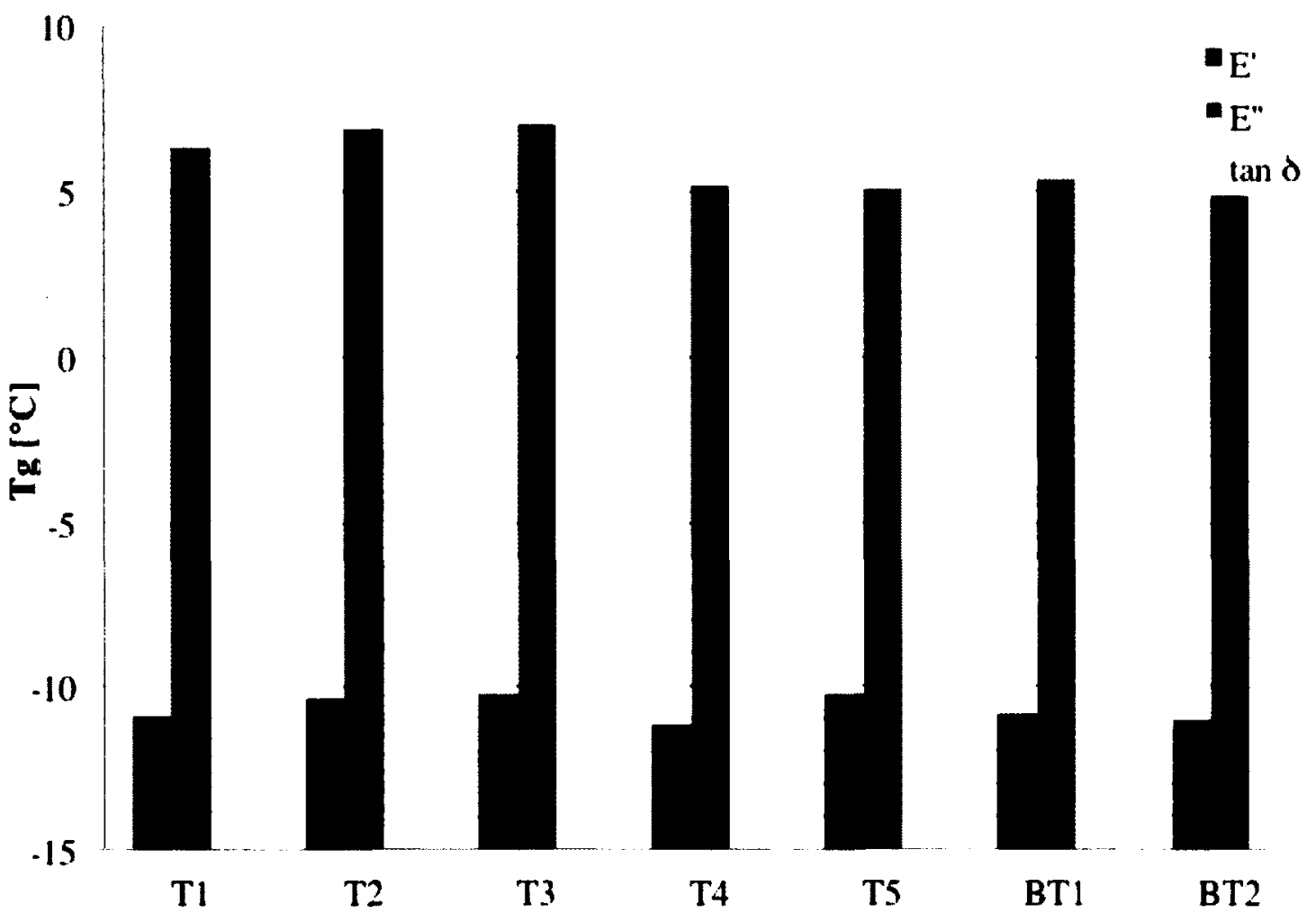

Figure 45: DMA results for the polypropylene/glass (PPG) blend

Table 24: Processing parameters for PPG processing trials

\begin{tabular}{|c|c|c|c|}
\hline Trial & $\begin{array}{c}\text { Temperature Ramp Rate, } \\
{ }^{\circ} \mathbf{C} / \mathbf{m i n}\end{array}$ & $\begin{array}{c}\text { Soak Temperature, } \\
{ }^{\circ} \mathbf{C}\left({ }^{\circ} \mathbf{F}\right)\end{array}$ & $\begin{array}{c}\text { Soak Time } \\
{[\mathbf{m i n}]}\end{array}$ \\
\hline T1 & 2.2 & $180(355)$ & 15 \\
\hline T2 & 2.2 & $180(355)$ & 25 \\
\hline T3 & 2.2 & $180(355)$ & 25 \\
\hline T4 & 2.2 & $175(347)$ & 120 \\
\hline T5 & 2.2 & $190(374)$ & 60 \\
\hline BT1 & 5.0 & $190(374)$ & 60 \\
\hline BT2 & 5.0 & $180(355)$ & 15 \\
\hline
\end{tabular}




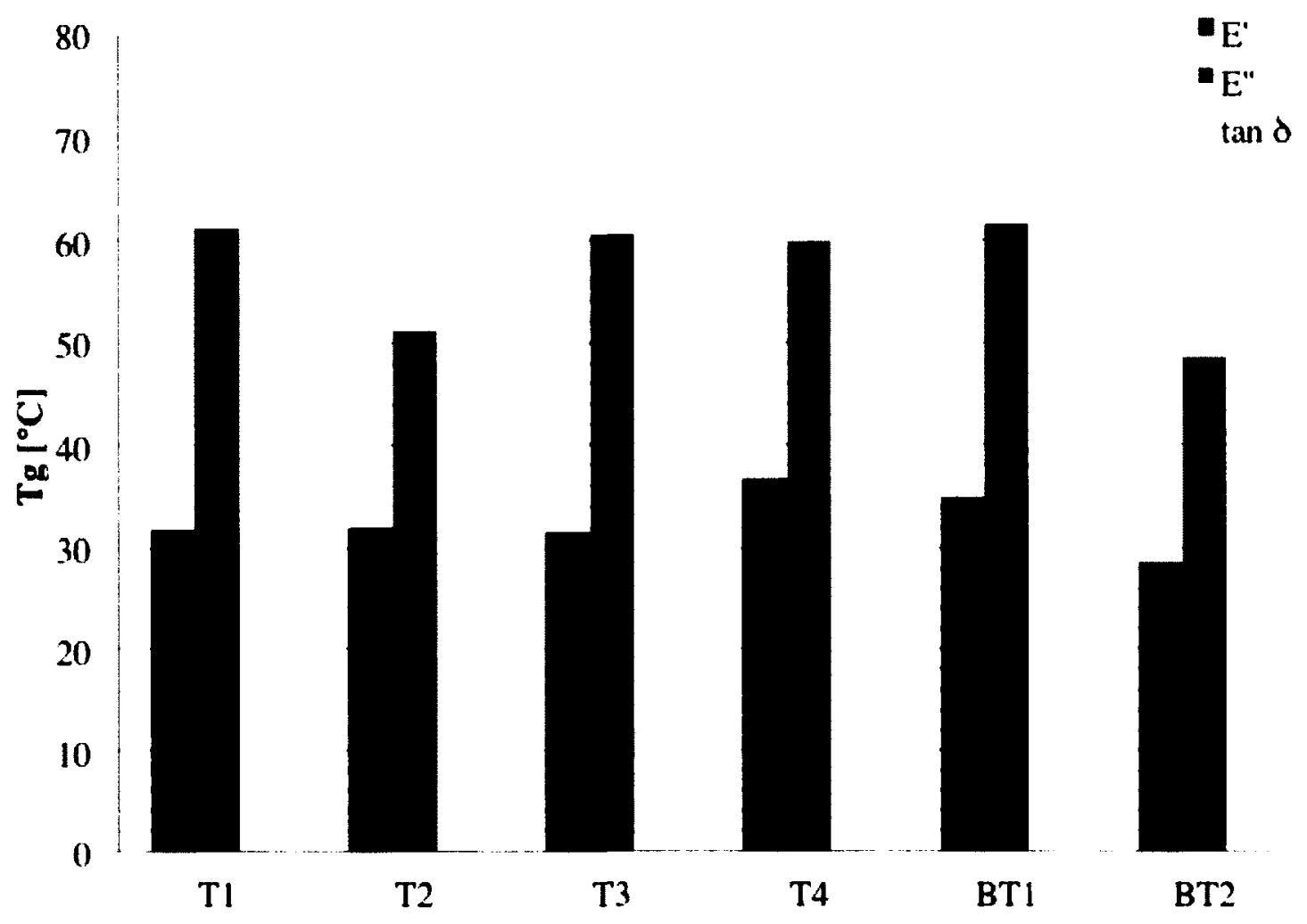

Figure 46: DMA results for the nylon/carbon (NC) blend

Table 25: Processing parameters for NC processing trials

\begin{tabular}{|c|c|c|c|}
\hline Trial & $\begin{array}{c}\text { Temperature Ramp Rate, } \\
{ }^{\circ} \mathrm{C} / \mathrm{min}\end{array}$ & $\begin{array}{c}\text { Soak Temperature, } \\
{ }^{\circ} \mathrm{C}\left({ }^{\circ} \mathrm{F}\right)\end{array}$ & $\begin{array}{c}\text { Soak Time, } \\
\text { min }\end{array}$ \\
\hline $\mathrm{T} 1$ & 2.2 & $230(450)$ & 60 \\
\hline $\mathrm{T} 2$ & 2.2 & $190(374)$ & 60 \\
\hline $\mathrm{T} 3$ & 2.2 & $195(380)$ & 80 \\
\hline $\mathrm{T} 4$ & 2.2 & $195(380)$ & 80 \\
\hline BT1 & 5.0 & $190(374)$ & 60 \\
\hline BT2 & 5.0 & $195(380)$ & 60 \\
\hline
\end{tabular}

The data for the PPG coupons of the same measurements method show consistent results. The average $T_{\mathrm{g}}$ for the PPG coupons using the $\mathrm{E}^{\prime}, \mathrm{E}^{\prime \prime}$ and $\tan \delta$ methods are $10.7^{\circ} \mathrm{C}\left(13^{\circ} \mathrm{F}\right), 5.8^{\circ} \mathrm{C}\left(42^{\circ} \mathrm{F}\right)$ and $6.7^{\circ} \mathrm{C}\left(44^{\circ} \mathrm{F}\right)$ respectively. The varying processing parameters did not have any significant effect on the $T_{g}$. As was expected, the $\mathrm{E}^{\prime}$ measurements produced significantly different $T_{g}$ values than those obtained from the E" 
and $\tan \delta$ methods. If designing a load bearing component, $-10.7^{\circ} \mathrm{C}\left(13^{\circ} \mathrm{F}\right)$ should be taken as the $T_{g}$ for this material type. In terms of service temperature, this value would typically be considered the lower limit for this material since temperatures below this value polypropylene becomes brittle, and its toughness is greatly reduced (Perkin Elmer, 2007). For many materials used in structural applications, the $T_{g}$ is considered the maximum operating temperature since above the $T_{g}$, a transition from occurs from stiff and glassy to more ductile and rubber like. Further testing should be carried out in the future to produce more statistically significant results to verify that these results are valid.

The results of the NC coupons show less consistent results than those manufactured from the PPG blend. The average $T_{g}$ for the NC coupons using the E', E" and $\tan \delta$ methods are $32.6^{\circ} \mathrm{C}\left(91^{\circ} \mathrm{F}\right), 57.2^{\circ} \mathrm{C}\left(135^{\circ} \mathrm{F}\right)$ and $64.8^{\circ} \mathrm{C}\left(149^{\circ} \mathrm{F}\right)$ respectively. This is a significant variation between each measurement method. Additionally, the results obtained using the same measurement method vary significantly, even between coupons that were manufactured using identical processes. A factor contributing to this result is the inconsistent and significant void content observed in the NC panels. Since DMA relies on stress and strain measurements, large and/or abundant voids can impact the results greatly. To illustrate this, consider the following rule of mixtures calculation for elastic modulus assuming zero void content:

$$
E_{1}=E_{f} V_{f}+E_{m} V_{m}
$$

where $E_{l}$ is the elastic modulus in the longitudinal direction, $V_{f}$ and $V_{m}$ are the volume fractions of the fibres and matrix (the ratio of the constituent material's volume to the total volume of the coupon), and $E_{f}$ and $E_{m}$ are the elastic modulus of the constituent fibre and matrix materials. When voids are introduced into the coupon, they occupy some 
volume; therefore for the same absolute amount of fibres and matrix in a coupon, $V_{f}$ and $V_{m}$ will decrease accordingly. When substituted into equation 9 , it is shown the elastic modulus of the composite will decrease accordingly, and proportional to the void content. For this reason, a conservative approach should be taken when considering these results for design purposes. Further testing should be carried out in the future to produce more statistically significant results to verify these results are valid.

\subsection{Differential Scanning Calorimetry}

Differential scanning calorimetry (DSC) is a test method that measures heat flow of a test sample relative to a control sample over a range of temperatures. When the test sample undergoes physical or chemical changes due to temperature change, variations in the magnitude and direction of heat flow are recorded, and can be used to determine thermal properties of the sample (i.e. $T_{g}$ and $T_{m}$ ), and also information about the degree of crystallinity of the polymer.

The method to graphically determine $T_{\mathrm{g}}$ and $T_{m}$ from DSC data is shown in Figure 47. Intersecting tangent lines are used to determine the $T_{g}$, similar to the DMA method outlined in the previous section (see Figure 42). In the case of the PPG and NC material studied here, the $T_{g}$ transition did not appear on the DSC plot, and therefore it will not be reported. The $T_{m}$ is determined by integrating the area under the melt peak, as shown in Figure 47. Similarly, the heat of crystallization can be determined by integrating the area under the crystallization peak, as shown in Figure 47. By comparing the heat of crystallization with a reference heat corresponding to $100 \%$ crystallinity, the percent crystallinity of the coupon can be determined. 


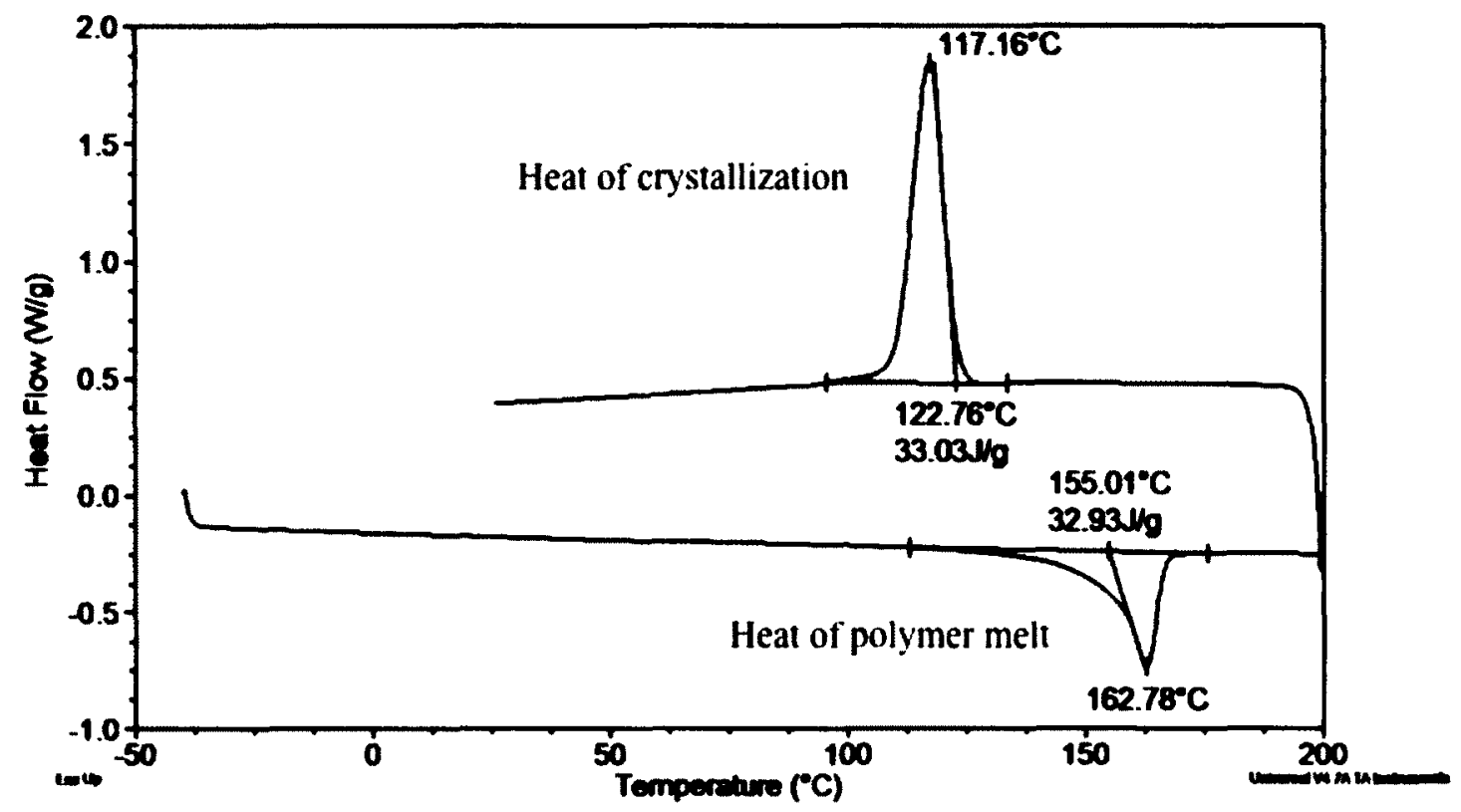

Figure 47: An example of a DSC plot for the PPG blend with the heat of melt and crystallization labeled.

\subsubsection{DSC Apparatus}

For this work, a TA Instruments a Q2000 Differential Scanning Calorimeter at McGill University in Montreal, Canada was used (shown in Figure 48) according to ASTM D3418-08 Standard Test Method for Transition Temperatures and Enthalpies of Fusion and Crystallization of Polymers by Differential Scanning Calorimetry (ASTM International, 2011). A schematic of the TA Instruments Q2000 DSC is shown in Figure 49. The specifications for the TA Instruments Q2000 DSC are shown in Table 26. 


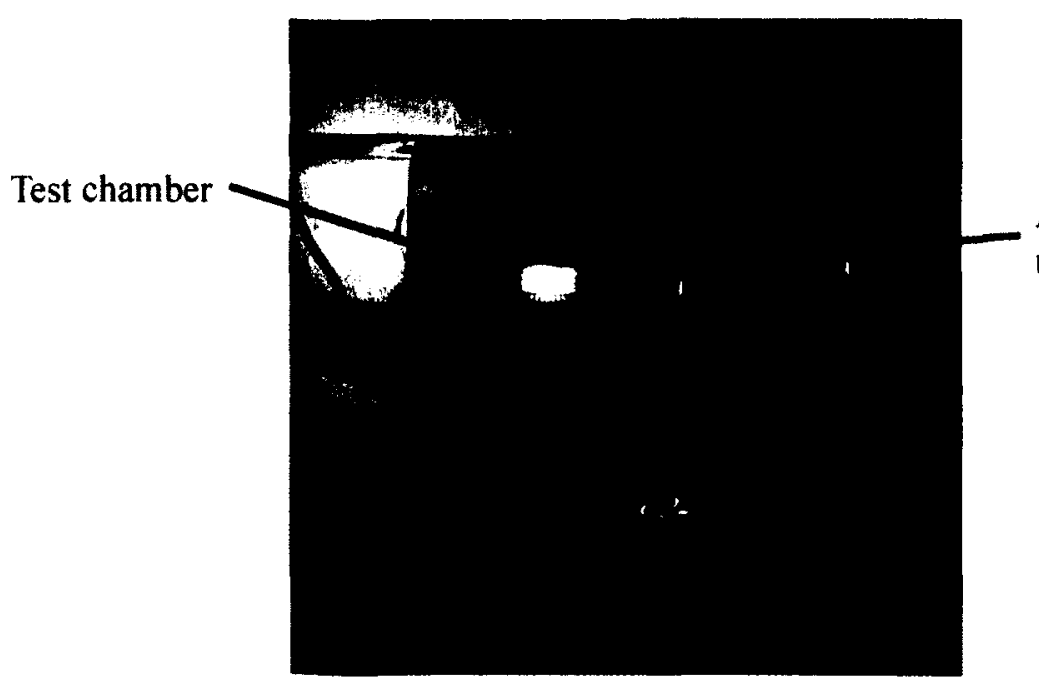

Automated chamber loading mechanism

Figure 48: TA Instruments Q2000 Dynamic Scanning Calorimeter (located at McGill University, Montreal Canada)

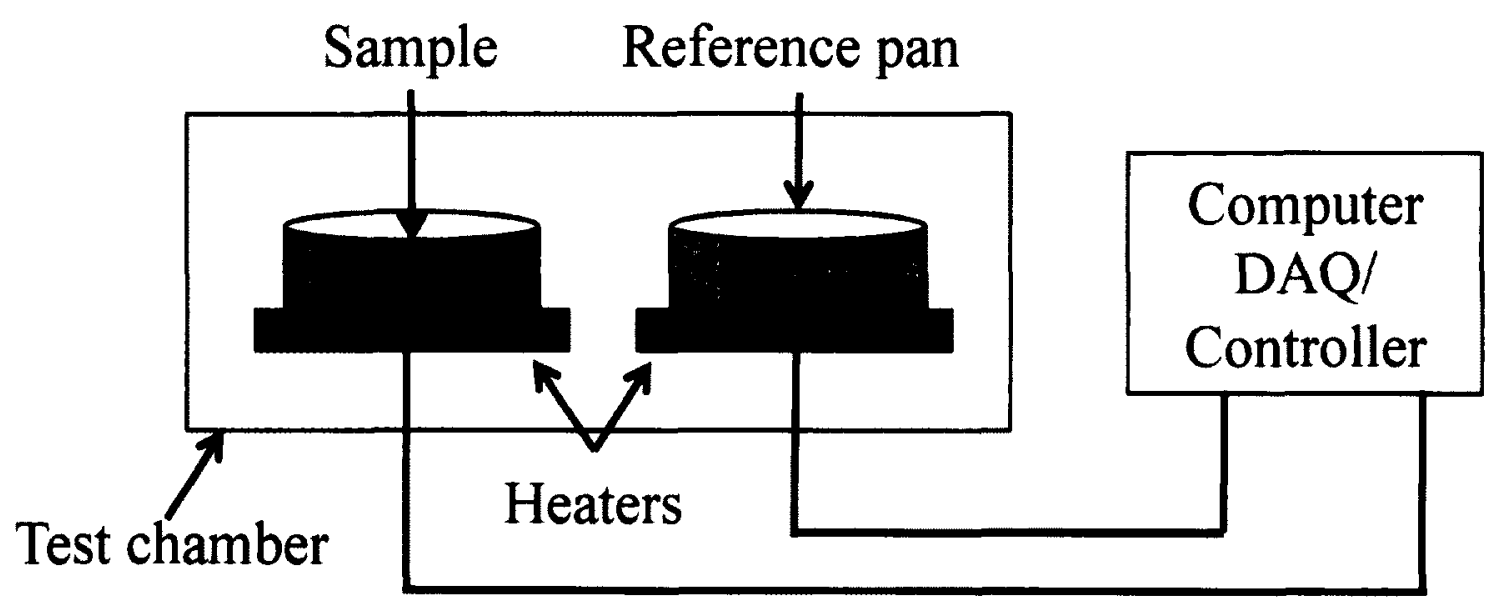

Figure 49: Schematic of a dynamic scanning calorimeter

Table 26: Specifications for the TA Instruments Q2000 Dynamic Scanning Calorimeter

\begin{tabular}{|l|l|}
\hline Temperature range (with GCA) & $-180-725^{\circ} \mathrm{C}$ \\
\hline Temperature accuracy & $\pm 0.1^{\circ} \mathrm{C}$ \\
\hline Calorimetric accuracy & $\pm 0.1^{\circ} \mathrm{C}$ \\
\hline Sensitivity & $0.2 \mu \mathrm{W}$ \\
\hline
\end{tabular}


The test parameters used for these experiments are shown in Table 27. Similar to the DMA experiments discussed in section 4.1 , the gas cooling accessory (GCA) was used to reach the required minimum temperatures.

Table 27: Differential scanning calorimetry test parameters.

\begin{tabular}{|l|l|}
\hline Initial Temperature & $-40^{\circ} \mathrm{C}\left(-40^{\circ} \mathrm{F}\right)$ \\
\hline Isothermal time at initial temperature & 4 minutes \\
\hline Maximum Temperature & $200^{\circ} \mathrm{C}\left(392^{\circ} \mathrm{F}\right)$ \\
\hline Ramp Up Rate & $10^{\circ} \mathrm{C} / \mathrm{min}$ \\
\hline Ramp Down Rate & $20^{\circ} \mathrm{C} / \mathrm{min}$ \\
\hline
\end{tabular}

\subsubsection{DSC Coupon Preparation}

A razor blade was used to cut small amounts of material from the test panels. Approximately 5-10 mg of material from each panel was cut, and encapsulated in an aluminum test pan. A crimping tool was used to ensure intimate contact between the test pan and the encapsulated specimen. This intimate contact is essential to ensure the heat flow reaches the encapsulated specimen.

\subsubsection{DSC Test Results}

The melt temperature, $T_{m}$, and heat of crystallization results of the DSC tests on the PPG coupons are shown in Figure 50 and Figure 51. The $T_{m}$ and heat of crystallization results of the DSC tests on the NC coupons is shown in Figure 52 and Figure 53. A complete set of DSC plots is available in Appendix B. 
165

160

$\bar{\Xi}_{E}^{\bar{O}} 155$

150

145

140

135

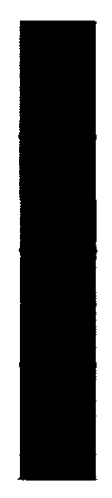

TI

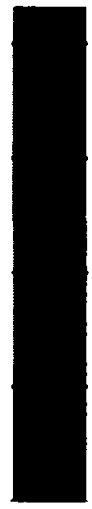

T2

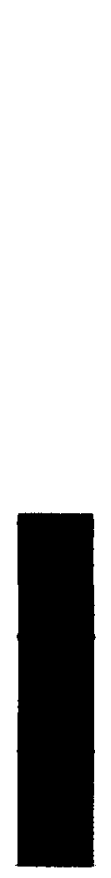

T3

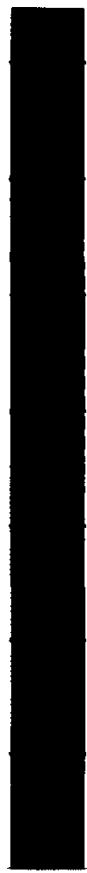

T4

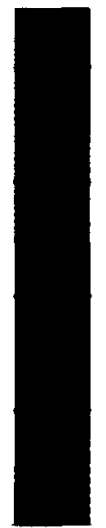

T5

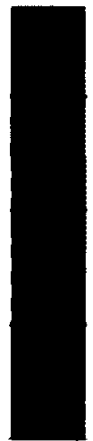

B1

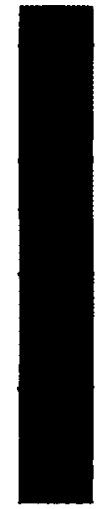

B2

Figure 50: DSC test results for the PPG coupons showing $T_{m}$

50

45

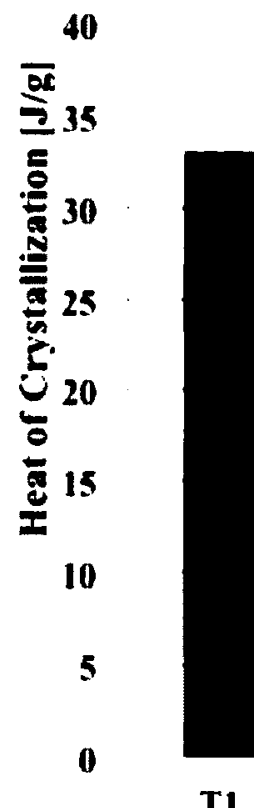

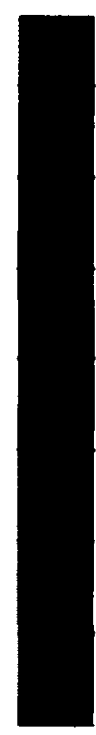

T2

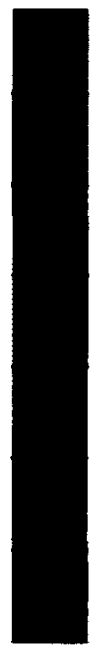

T3

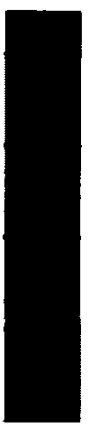

T4

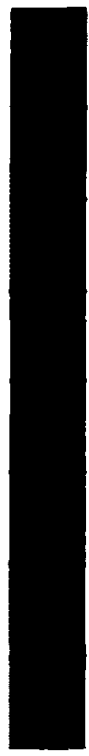

T5

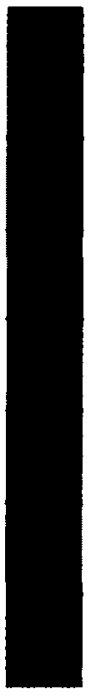

B1

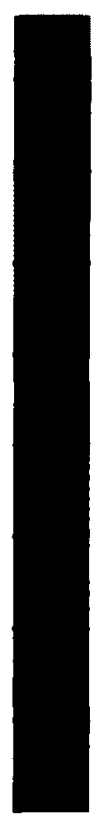

B2

Figure 51: DSC test results for the PPG coupons showing heat of crystallization 


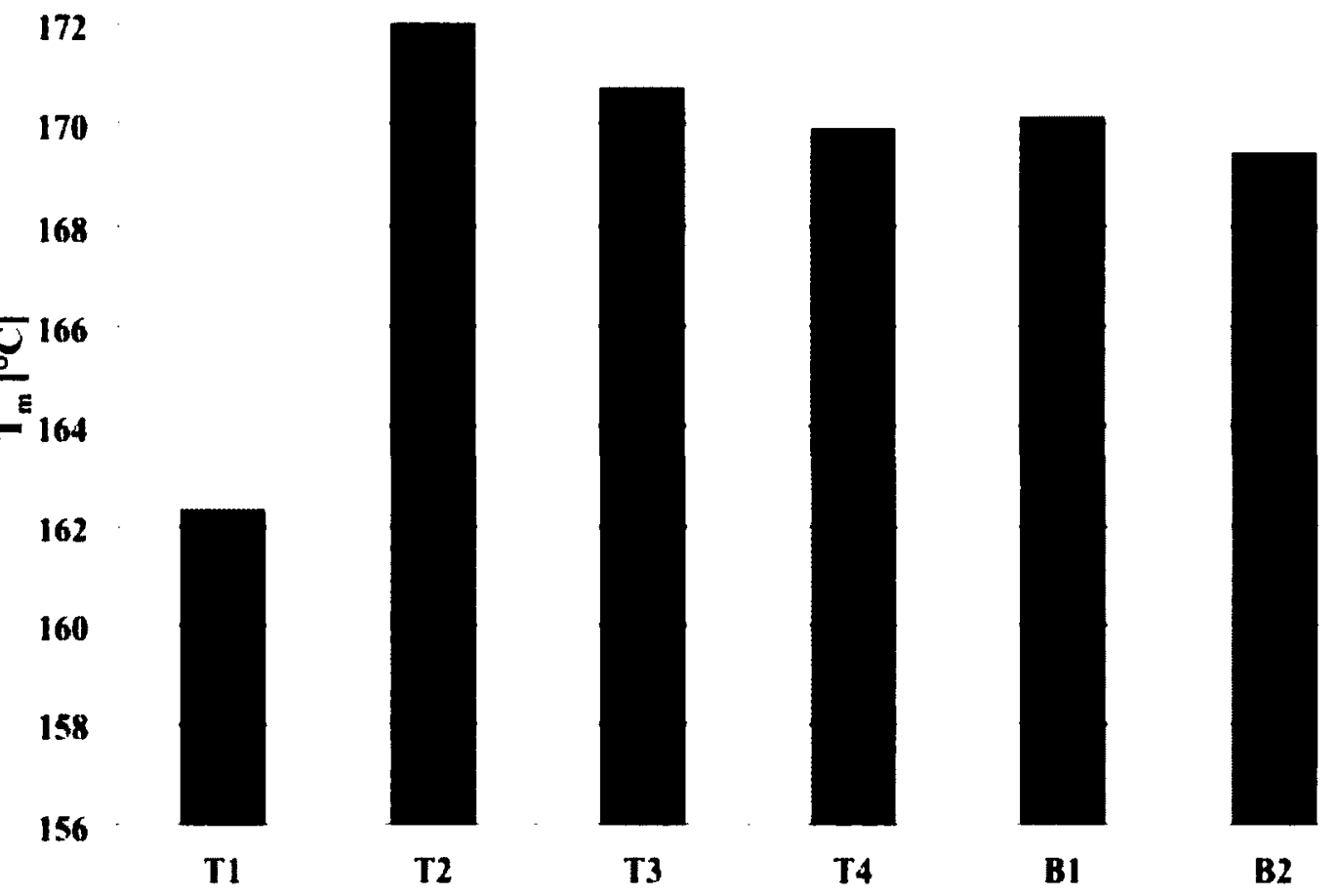

Figure 52: DSC test results for the NC coupons showing $T_{m}$ 25

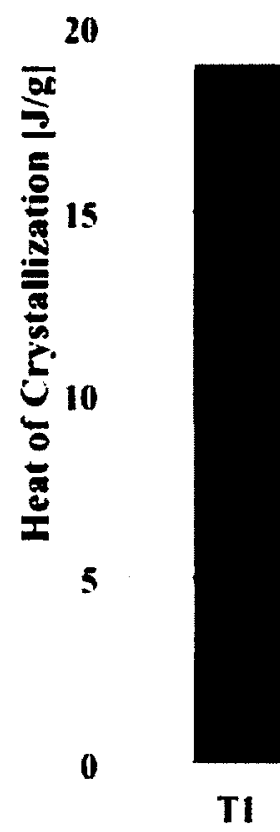

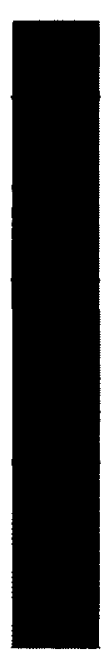

T2

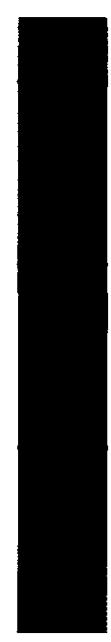

T3

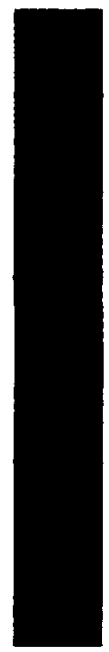

T4

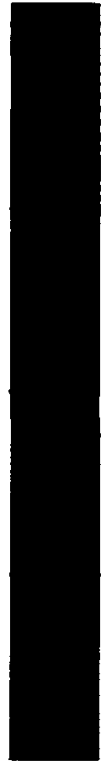

B1

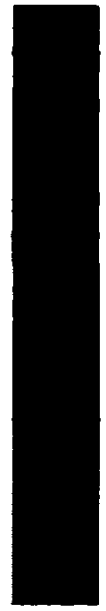

B2

Figure 53: DSC test results for the NC coupons showing heat of crystallization 
The mean $T_{m}$ for the PPG coupons was found to be $155^{\circ} \mathrm{C}\left(311^{\circ} \mathrm{F}\right)$ (standard deviation of $2.6^{\circ} \mathrm{C}$ ) when you exclude the outlying result of $172^{\circ} \mathrm{C}\left(342^{\circ} \mathrm{F}\right.$ ) for T4 (as identified by the modified Z-score method). This unusually high $T_{m}$ result for T4 (DSC plot shown in Figure 54) is characteristic of an annealing effect that occurs when certain polymers are exposed to temperatures at or above $T_{m}$ for an extended period of time (in this case $175^{\circ} \mathrm{C}\left(347^{\circ} \mathrm{F}\right)$ for 120 minutes)(Pae et al., 1968). In Figure 54, it is clear that the $T_{m}$ transition is unique relative to the other test coupons shown in Appendix B. In the PPG T4 plot, the melting transition occurs in two steps rather than a single step. At a molecular level, the annealing results in a thickening of crystals. This phenomenon has been described by Kojima (1968). In his study, Kojima found that by exposing crystallized polypropylene to $160^{\circ} \mathrm{C}\left(320^{\circ} \mathrm{F}\right)$ for 60 minutes, the laminar thickness of the crystals increased from $100 \AA$ to $350 \AA$. It has been reported that the result of this growth is an increase in $T_{m}$ of the polymer, since it is directly related to crystal thickness (Pae $e t$ al., 1968) (2011 Aug 24 private communication with D. Maillard; unreferenced, see "Notes"). As a trade-off, Figure 51 shows that the heat of crystallization of T4 is $41 \%$ lower $(22 \mathrm{~J} / \mathrm{g})$ than the mean of the other coupons $(38 \mathrm{~J} / \mathrm{g})$. This indicates that although an increase in $T_{m}$ was gained, a number of other properties such as stiffness, toughness and barrier resistance (resistance to gas transfer into the polymer) are compromised. One factor influencing the slight variation in the results of the other 6 tests is the varying fibre content in the test samples. Since such small samples are required to execute a DSC trial (5-10 mg), it was very difficult to control the amount of glass being cut from each of the test panels introducing a possible source of error. 


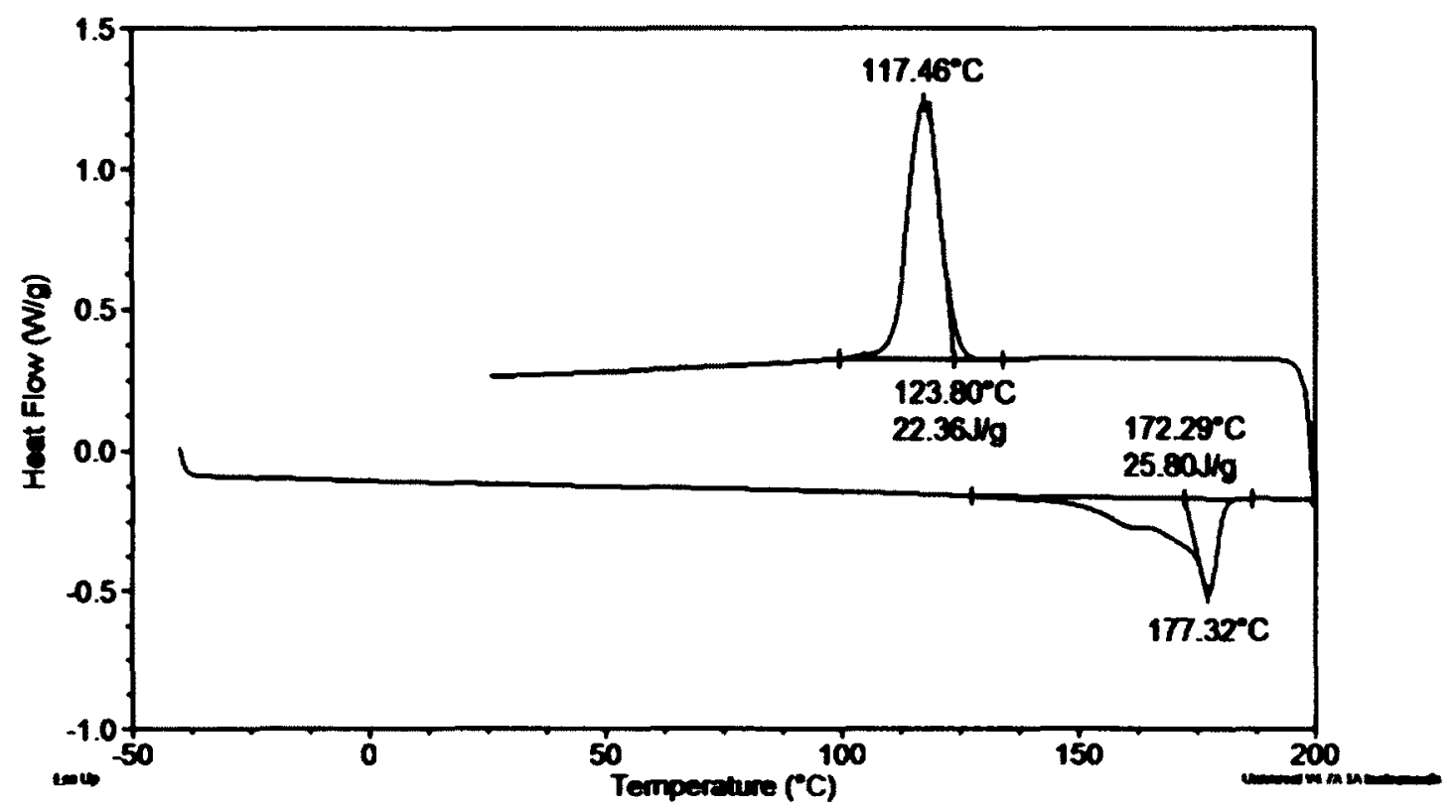

Figure 54: DSC plot for PPG T4

The NC DSC tests resulted in a mean $T_{m}$ of $171^{\circ} \mathrm{C}\left(340^{\circ} \mathrm{F}\right)$ (standard deviation of $0.98^{\circ} \mathrm{C}$ ) when the outlying result of $162^{\circ} \mathrm{C}\left(324^{\circ} \mathrm{F}\right)$ for $\mathrm{T} 1$ is excluded (T1 was determined to be an outlier by use of the modified Z-score method). In contrast to the PPG results where an annealing phenomenon is observed for $\mathrm{T} 4$ due to extended processing time near $T_{m}, \mathrm{~T} 1$ of the $\mathrm{NC}$ material was exposed to a processing temperature of $230^{\circ} \mathrm{C}\left(450^{\circ} \mathrm{F}\right)$ for 60 minutes, which is $60^{\circ} \mathrm{C}\left(110^{\circ} \mathrm{F}\right)$ higher than the resulting mean $T_{m}$ for the other trials. At this temperature, degradation is likely to have occurred resulting in a $10^{\circ} \mathrm{C}$ reduction in $T_{m}$ for this coupon. Despite this reduction in $T m, \mathrm{~T} 1$ shows a higher heat of crystallization $(18.9 \mathrm{~J} / \mathrm{g})$ than the $\mathrm{NC}$ mean $(17.8 \mathrm{~J} / \mathrm{g})$. These results indicate that the narrow band of processing temperatures and soak times used to manufacture the NC panels had no effect on the crystalline content of the polymer. Also, exposure to processing temperatures significantly higher than $T_{m}$ could reduce the $T_{m}$ of the final part. 
Again, it should be noted that only one coupon from each trial was tested, and therefore a more comprehensive test matrix should be developed in the future to further confirm these results. 


\subsection{Mechanical Testing}

Static tensile testing on coupons cut from trial panels was performed in order to evaluate the effects of the various processing parameters on the mechanical properties of the PPG and NC materials. These tests were performed according to ASTM D3039: Standard Test Method for Tensile Properties of Polymer Matrix Composite Materials (ASTM International, 2011). One of the primary reasons for conducting this test was so that a quantitative comparison could be made between the tensile properties of the materials studied here, and the tensile properties of the epoxy/carbon fibre material system previously studied (and currently being used) at Carleton University.

\subsection{Coupon Preparation}

Tensile coupons were water jet cut at Hydrotech Cutting Inc. in Ottawa, Canada. An example of a water jet cut edge is shown in Figure 55, and the laminate cutting template is shown schematically in Figure 56. Other common abrasive cutting methods (i.e. a diamond saw, CNC machining) were not used due to thermal heating effects on the coupon edges. Adverse effects on both the fibres (tearing) and matrix (melting) of the material were observed when attempting to cut the coupons by abrasive means. 


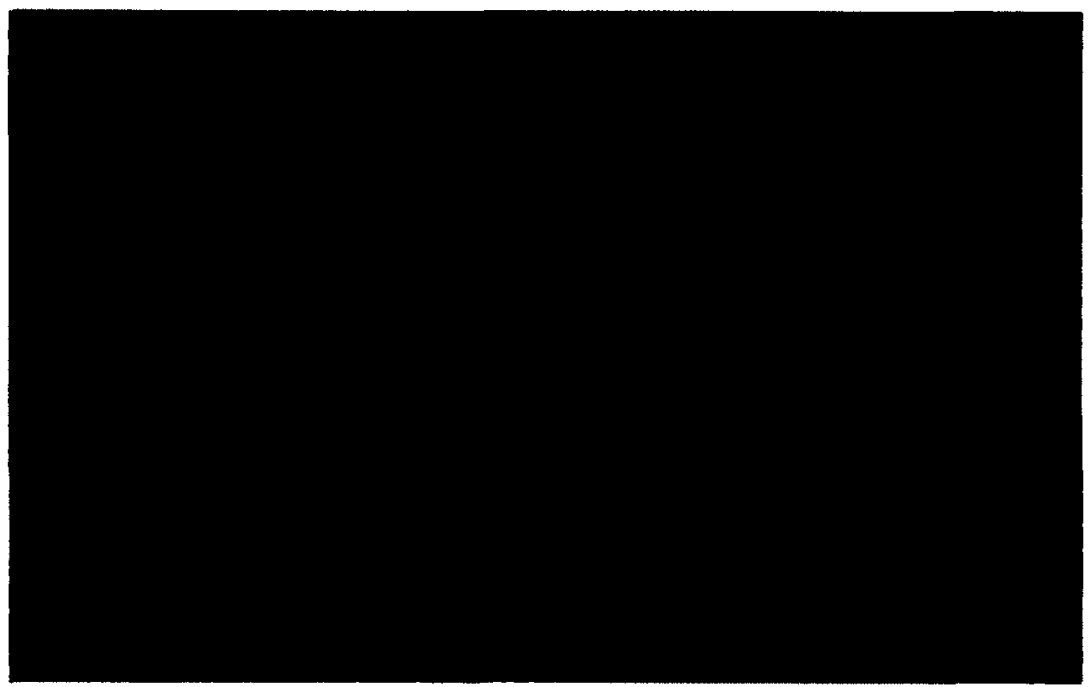

Figure 55: An example of a water jet cut edge of a tensile coupon

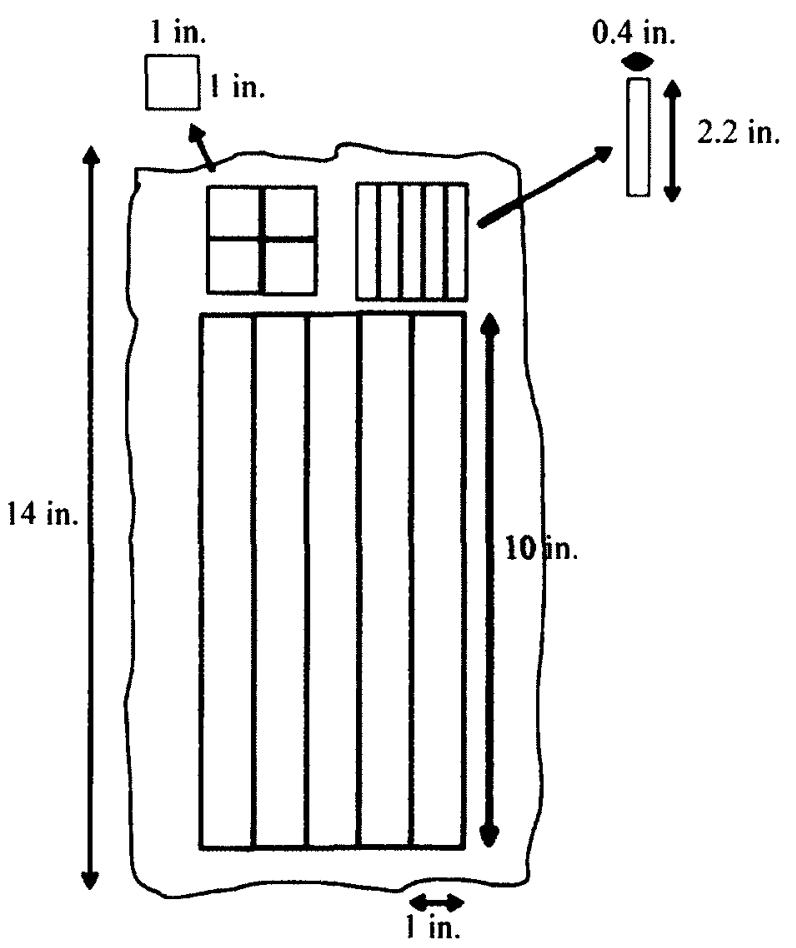

Figure 56: Cutting template used to cut test coupons from the laminates manufactured in this work. Tensile coupons (10 in $\times 1$ in), DMA coupons ( 2.2 in $\times 0.4$ in) and optical microscopy coupons ( 1 in $x$ 1 in) are shown

As specified in ASTM D3039, the coupons were cut to dimensions of $25.4 \mathrm{~mm}$ (1 in) wide and $254 \mathrm{~mm}$ (10 in) in length. The thickness of the coupons varied, 
depending on the final thickness of the panel from which they were cut. The thicknesses of the PPG and NC coupons are shown in Table 28 and Table 29 respectively.

Table 28: PPG tensile coupon thickness data

\begin{tabular}{|c|c|c|c|c|c|c|c|}
\hline & T1 & T2 & T3 & T4 & T5 & B1 & B2 \\
\hline $\begin{array}{c}\text { Average coupon } \\
\text { thickness [in] }\end{array}$ & 0.081 & 0.085 & 0.082 & 0.084 & 0.081 & 0.089 & 0.070 \\
\hline
\end{tabular}

Table 29: NC tensile coupon thickness data

\begin{tabular}{|c|c|c|c|c|c|c|}
\hline & T1 & T2 & T3 & T4 & B1 & B2 \\
\hline $\begin{array}{c}\text { Average coupon } \\
\text { thickness [in] }\end{array}$ & 0.101 & 0.097 & 0.096 & 0.098 & 0.090 & 0.089 \\
\hline
\end{tabular}

\subsection{Test Set-up}

Tensile testing was performed using a servo-hydraulic Material Testing System (MTS) 810 test frame with a $100 \mathrm{kN}(22500 \mathrm{lbs})$ load cell, and serrated wedge type grips. The tests were conducted in displacement control, with a constant crosshead displacement rate of $2 \mathrm{~mm} / \mathrm{min}(0.05 \mathrm{in} / \mathrm{min})$. The test set-up is shown in Figure 57. An MTS 634.12E-24 extensometer was used to measure coupon strain during testing. This extensometer has a range of $-10-50 \%$, and an accuracy of $0.25 \%$. The calibration of this instrument was verified on 29 April 2011. 


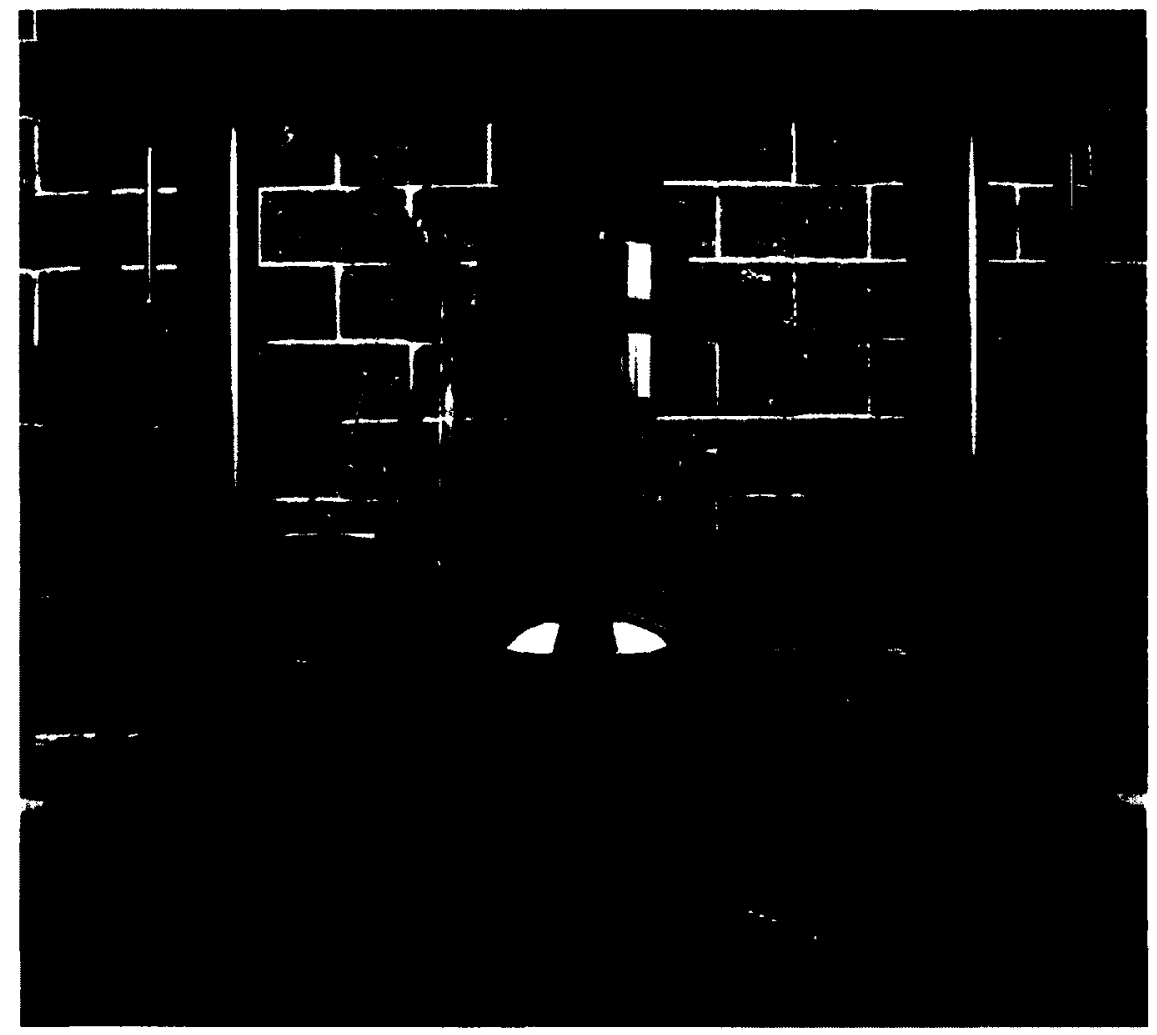

Figure 57: MTS test frame with a tensile coupon installed in the grips

A test matrix was originally designed in order to evaluate the both the tensile modulus and ultimate tensile strength of both material types. During preliminary coupon testing, it was found that failure occurred at the grips (see Figure 58), producing a result that is not indicative of the true ultimate tensile strength of the material. For this reason, aluminum tabs were prepared to alleviate the stress concentration produced by the grips. The aluminum tabs measured $25.4 \mathrm{~mm}(1 \mathrm{in})$ wide and $57 \mathrm{~mm}(2.25 \mathrm{in})$. The bonding surfaces of the coupons and the tabs were roughened using light grit sandpaper, and all surfaces were wiped clean with isopropanol. The adhesive used for bonding of the tabs was Hysol EA9430, a commonly used two-part room temperature-cure paste adhesive. 


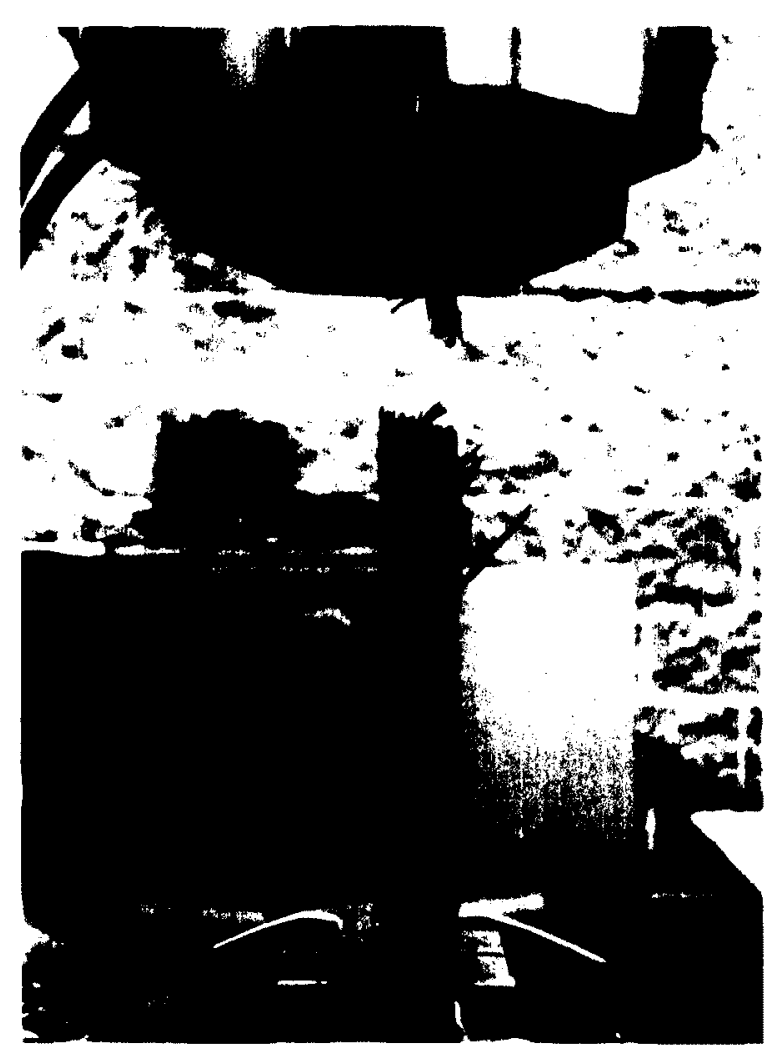

Figure 58: A tensile test coupon failed at the grips

The first batch of coupons tested also highlighted an issue with the MTS test frame hydraulic system. Cyclic displacement behaviour was noted in the stress vs. strain plot in what should have been a displacement-controlled test. When the test data was analyzed, it was clear that a non-linear strain rate was being applied to the test coupons, as shown in Figure 59. It was determined that the hydraulic accumulator of the test frame had become saturated and was no longer smoothing the applied hydraulic pressure pulsations. In this application, the hydraulic accumulator stores hydraulic energy (pressure) that is used when the hydraulic pump cannot accommodate the demands of the test frame's control system. To maintain a constant displacement rate, many hydraulic load demand changes occur every second, however the response time of the pump is insufficient to meet these quickly changing demands. For this reason, an accumulator is 
used to improve the response time of the system, and effectively smooth the displacement rate of the test frame crosshead. The laboratory technicians at Carleton University repaired this issue so that testing could continue.

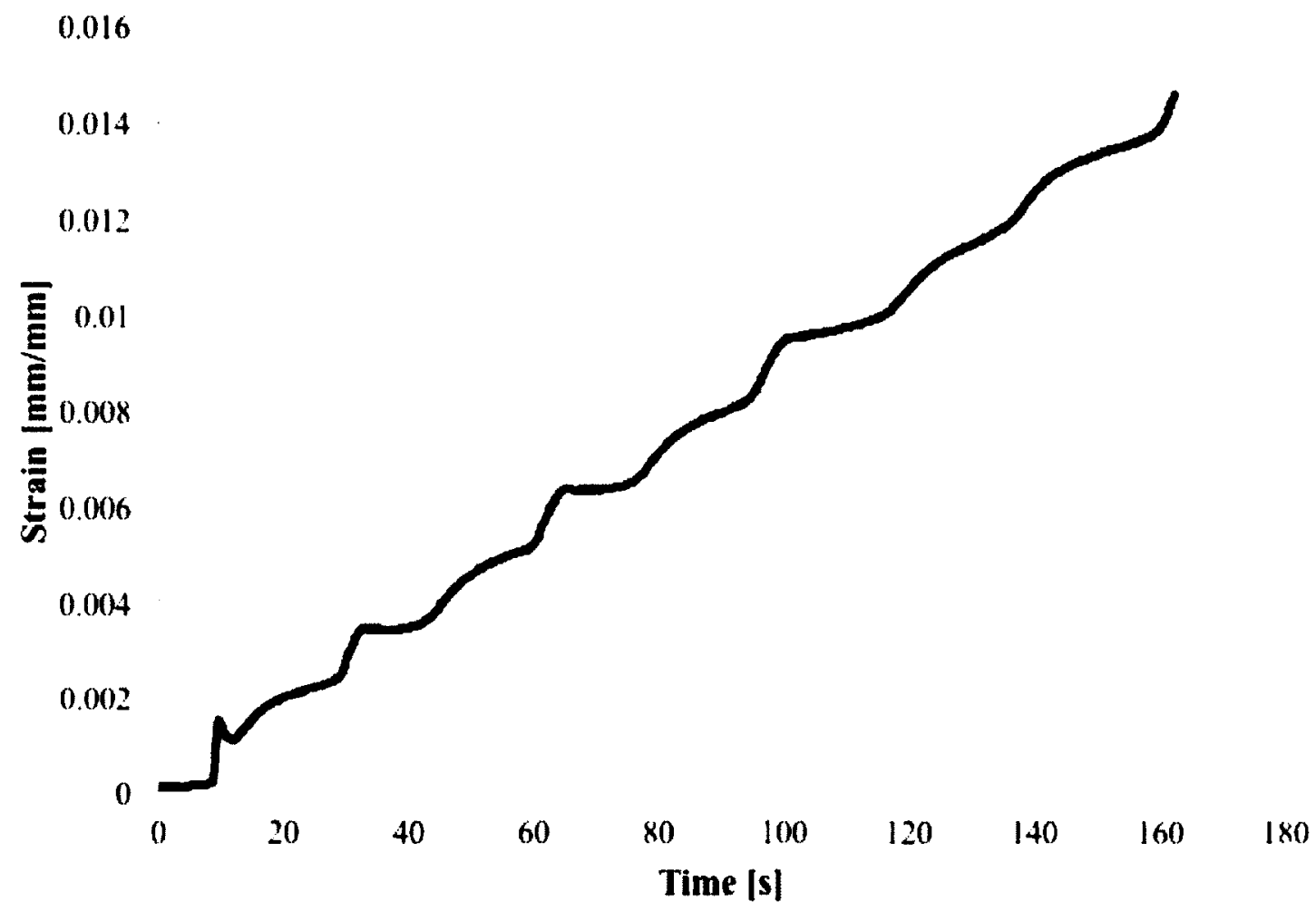

Figure 59: Strain vs. time plot of an initial tensile test showing a variable strain rate due to accumulator saturation in the MTS test frame.

During the initial tests of the tabbed coupons, approximately $50 \%$ of the tabs disbonded from the coupons during testing, resulting in coupon slippage. Two possible reasons for the disbonding are substrate/adhesive incompatibility and inadequate surface preparation.

In terms of substrate/adhesive compatibility issues, it has been found that relative to thermosetting polymers, thermoplastics have poorer wettability, and significantly reduced adhesion to epoxy based adhesives (Kadokian et al., 1988). Due to this complication, it 
was decided that the tensile coupons would be tested for their tensile modulus only, and not for ultimate tensile strength (i.e. not to failure).

\subsection{Polypropylene/E-glass Results}

The results of the tensile tests performed on the PPG coupons are shown in Figure 60. The error bars above each bar in Figure 60 represent one interval of standard deviation. The number of coupons tested from each panel is shown in Table 30. As specified in ASTM D3039, the tensile chord modulus of elasticity method was used to extract the tensile modulus from the test data. This method specifies a strain range of $0.001-0.003 \varepsilon$ to be used when calculating the tensile modulus for all tests where $0.006 \varepsilon$ is exceeded. In the case where $0.006 \varepsilon$ was not reached, the range of $25-50 \%$ of the recorded strain was used to determine the tensile modulus.

One of the primary factors affecting the tensile modulus of a composite material is the fibre volume content, $V_{f}$. Since each coupon is made from the same commingled fabric, one can assume that a decrease in coupon thickness will correspond to an increase in fibre volume content. This concept can be illustrated by application of the rule of mixtures. The fibre volume fraction can be calculated as:

$$
V_{f}=\frac{v_{f}}{v_{T}}
$$

and

$$
v_{T}=v_{f}+v_{m}
$$

where $v_{T}$ is the total volume of the coupon in question and $v_{f}$ and $v_{m}$ are the volumes of the constituent fibres and matrix. For a given quantity of dry, unprocessed commingled 
fabric, $v_{m}$ will be at its maximum possible value since during processing, the matrix will flow to some degree, and the laminate consolidation will force some matrix to bleed out of the part. However during part consolidation, the fibre bed that was present originally will not change in absolute terms, since the fibres do not flow. This implies that, in terms of proportions, the fibre volume fraction, $V_{f}$, stands to increase during laminate consolidation as the volume of matrix (and part thickness) decreases.

The degree of crystallinity of the polymer matrix in a composite material is a second factor that can change the modulus of the material. A higher degree of crystallinity (indicated by its heat of crystallization, as determined by the DSC results presented in section 4.2) corresponds to a more brittle material. For reference, the mean coupon thickness and heat of crystallinity for each PPG trial is shown in Table 31.

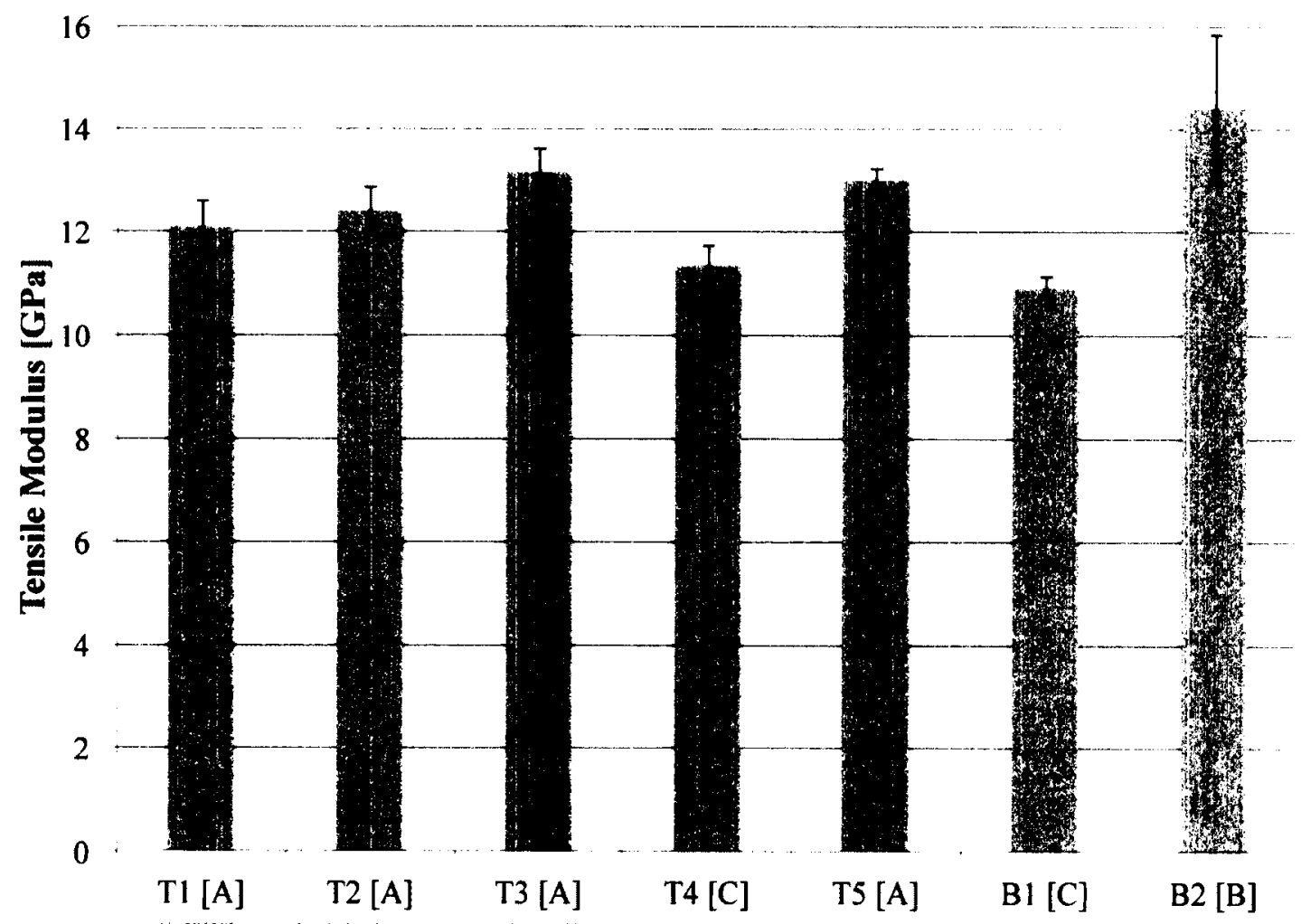

Figure 60: Tensile modulus results for the PPG coupons (processing group of each trial is shown in brackets) 
Table 30: Number of tensile coupons tested from each panel

\begin{tabular}{|c|c|c|c|c|c|c|c|}
\hline & T1 & T2 & T3 & T4 & T5 & B1 & B2 \\
\hline $\begin{array}{c}\text { No. of coupons } \\
\text { tested }\end{array}$ & 5 & 5 & 5 & 4 & 5 & 4 & 5 \\
\hline
\end{tabular}

Table 31: Average coupon thickness and heat of crystallization for each PPG panel

\begin{tabular}{|c|c|c|c|c|c|c|c|}
\hline & T1 & T2 & T3 & T4 & T5 & B1 & B2 \\
\hline Processing Group* & A & A & A & C & A & C & B \\
\hline $\begin{array}{c}\text { Average coupon } \\
\text { thickness, mm (in) }\end{array}$ & $\begin{array}{c}2.0 \\
(0.081)\end{array}$ & $\begin{array}{c}2.2 \\
(0.085)\end{array}$ & $\begin{array}{c}2.1 \\
(0.082)\end{array}$ & $\begin{array}{c}2.2 \\
(0.084)\end{array}$ & $\begin{array}{c}2.0 \\
(0.081)\end{array}$ & $\begin{array}{c}2.3 \\
(0.089)\end{array}$ & $\begin{array}{c}1.8 \\
(0.070)\end{array}$ \\
\hline $\begin{array}{c}\text { Heat of } \\
\text { crystallization, J/g }\end{array}$ & 33.03 & 38.79 & 34.67 & 22.36 & 40.37 & 37.08 & 43.50 \\
\hline $\begin{array}{c}\text { Tensile Modulus, } \\
\text { GPa }\end{array}$ & 12.08 & 12.41 & 13.18 & 11.35 & 13.01 & 12.02 & 14.40 \\
\hline $\begin{array}{c}\text { Standard } \\
\text { Deviation, GPa }\end{array}$ & 0.50 & 0.43 & 0.43 & 0.37 & 0.19 & 0.21 & 1.44 \\
\hline $\begin{array}{c}\text { Coefficient of } \\
\text { Variation (CV), \% }\end{array}$ & 4.14 & 3.50 & 3.28 & 3.26 & 1.45 & 1.89 & 9.99 \\
\hline
\end{tabular}

*Processing group is discussed in the next paragraphs

The batches of coupons tested can be combined into three groups corresponding to their respective processing conditions. When examining the differences in the tensile modulus between the different groups of coupons it is possible to attribute these differences to the process conditions.
A. Typical vacuum consolidated coupons (T1, T2, T3, T5)
B. Typical autoclave processed coupons (B2)
C. Coupons affected by irregular processing (T4, B1)

The first group that has been identified, A, "typical vacuum consolidated coupons", show a consistent tensile modulus (average of $12.67 \mathrm{GPa}$ (1837 ksi), standard deviation of $0.14 \mathrm{GPa})$. Trials $\mathrm{T} 1-\mathrm{T} 3$ underwent almost identical processes $\left(180^{\circ} \mathrm{C}\left(355^{\circ} \mathrm{F}\right), 15-25\right.$ minutes), while $\mathrm{T} 5$ was processed at a higher temperature, and for a longer period of time $\left(190^{\circ} \mathrm{C}\left(374^{\circ} \mathrm{F}\right), 60\right.$ minutes). When correlating these results to the heat of crystallization 
(shown in Figure 61), it can be concluded that the degree of crystallinity of these coupons had little effect on the modulus. This is illustrated when comparing T3 and T5 results. The difference in average coupon thickness of these two groups is only $0.025 \mathrm{~mm}$ ( $0.001 \mathrm{in}$ ), however the heat of crystallization (and therefore degree of crystallinity) of T5 is $16 \%$ higher than that of T3. Despite this, the average tensile modulus of the T3 and T5 coupons was found to be negligibly different $(13.177 \mathrm{GPa}(1911 \mathrm{ksi})$ and $13.008 \mathrm{GPa}$ (1887 ksi) respectively).

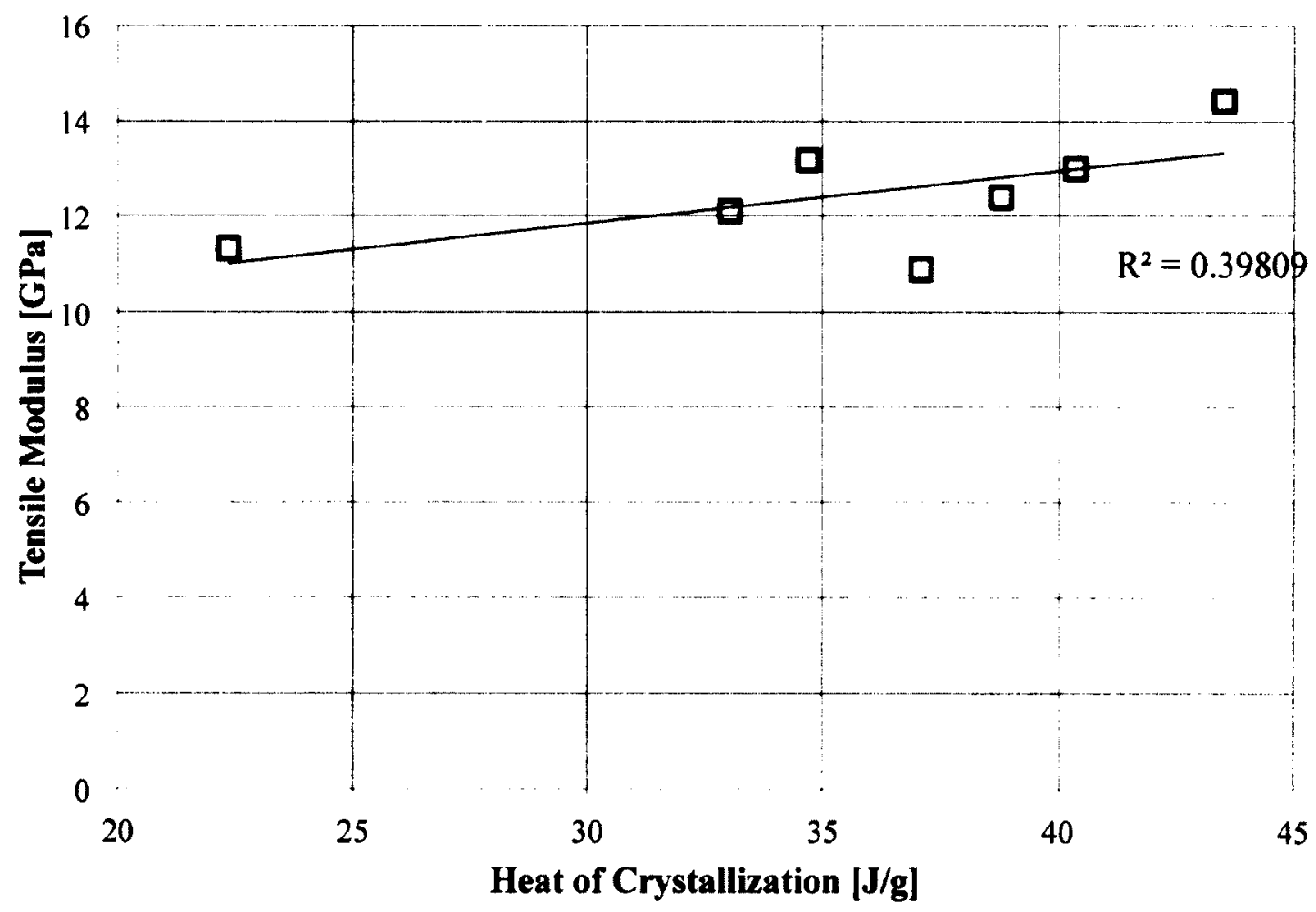

Figure 61: Tensile modulus vs. heat of crystallization for the PPG material showing a weak correlation between the two properties

The second group of results identified, B, "typical autoclave processed coupons (B2)", show a distinctly higher modulus than all other coupons that were tested. When comparing the average coupon thickness and heat of crystallization of $\mathrm{B} 2$, it is no 
surprise that this group of coupons resulted in the highest tensile modulus as it showed the lowest average coupon thickness (i.e. highest fibre volume fraction) and the highest heat of crystallization. It should also be noted that this group of coupons showed the highest standard deviation in its tensile modulus results. This can be attributed to the various thickness gradients that resulted from the autoclave processing. The increased pressure provided by the autoclave process caused the panel thickness at the edges to be significantly smaller than the thickness at the center of the panel. The bending of the caul plate under pressure causes this effect, as shown in Figure 62. The coupon thickness measurements for all five PPG - B2 coupons are shown in Table 32, and Figure 63 shows the locations at which thickness measurements were taken. These large thickness gradients imply that the local coupon fibre volume fraction varies significantly, hence the large standard deviation observed in the tensile modulus results.

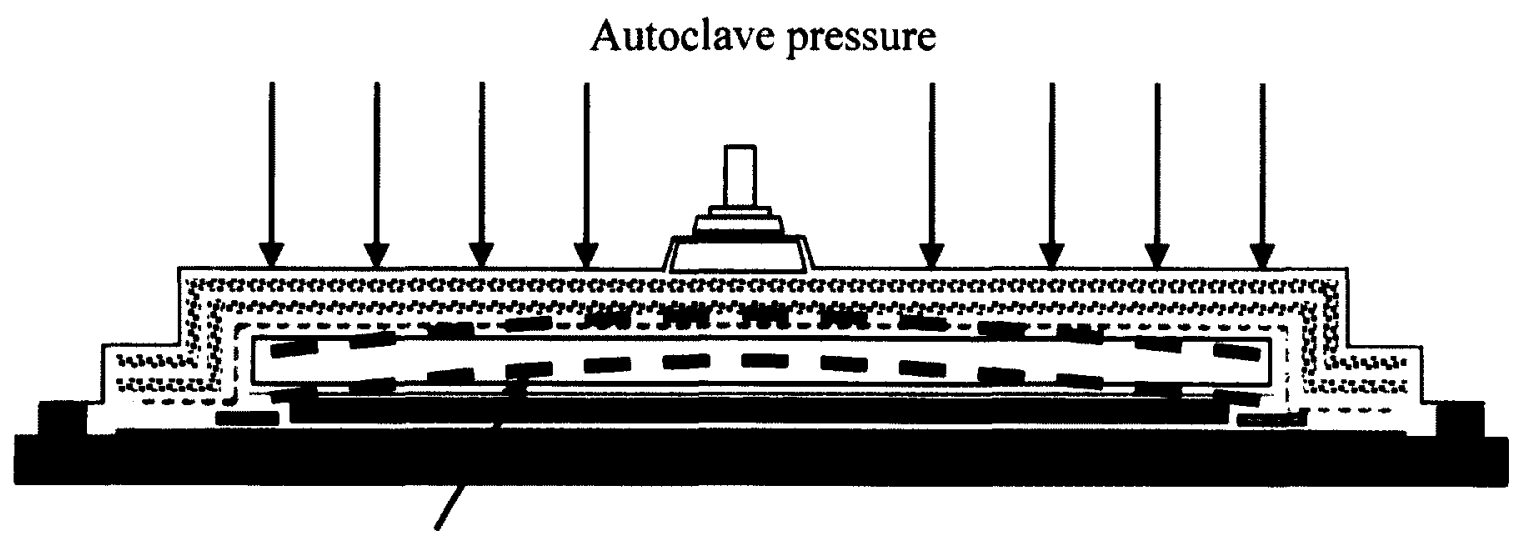

Caul plate bending under pressure

Figure 62: Schematic of the caul plate bending under pressure applied during autoclave processing 
Table 32: Coupon thickness measurements for PPG B2

\begin{tabular}{|c|c|c|c|c|c|}
\hline Location & $\begin{array}{c}\text { B2 - 1, } \\
\text { mm (in) }\end{array}$ & $\begin{array}{c}\text { B2 - 2, } \\
\text { mm (in) }\end{array}$ & $\begin{array}{c}\text { B2 - 3, } \\
\text { mm (in) }\end{array}$ & $\begin{array}{c}\text { B2 - 4, } \\
\text { mm (in) }\end{array}$ & $\begin{array}{c}\text { B2 - 5, } \\
\text { mm (in) }\end{array}$ \\
\hline $\mathbf{1}$ & $1.3(0.053)$ & $1.4(0.057)$ & $1.5(0.059)$ & $1.5(0.059)$ & $1.4(0.057)$ \\
\hline $\mathbf{2}$ & $1.7(0.066)$ & $1.8(0.069)$ & $1.8(0.072)$ & $1.8(0.073)$ & $1.8(0.069)$ \\
\hline $\mathbf{3}$ & $1.9(0.073)$ & $1.9(0.076)$ & $2.0(0.078)$ & $2.0(0.079)$ & $2.0(0.078)$ \\
\hline $\mathbf{4}$ & $1.8(0.070)$ & $1.9(0.074)$ & $1.9(0.076)$ & $1.9(0.076)$ & $1.9(0.075)$ \\
\hline
\end{tabular}

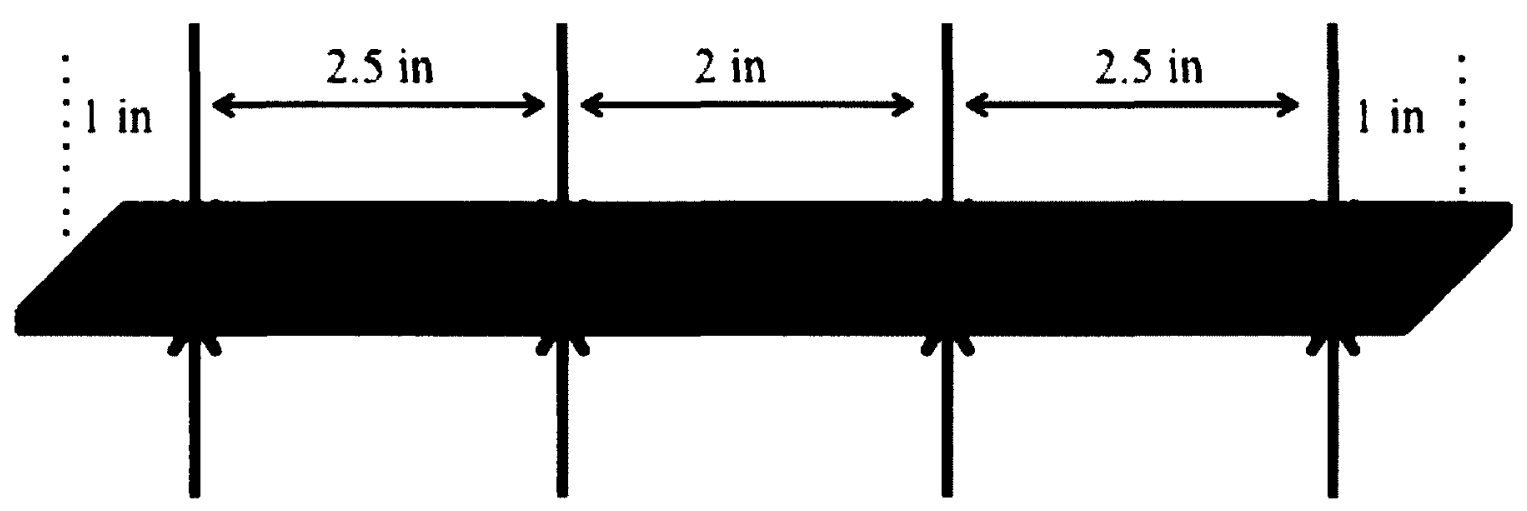

Figure 63: Schematic of a tensile test coupon showing the location of each thickness measurement

The third group of results that are identified, C, "coupons affected by irregular processing", shows a lower tensile modulus than that of the previous two groups. In the case of $\mathrm{T} 4$, the process is considered irregular due to the excessively long soak time ( 120 minutes) at $175^{\circ} \mathrm{C}\left(347^{\circ} \mathrm{F}\right)$. In section 4.2 .3 , it was shown that this processing time resulted in a heat of crystallization that is $32-49 \%$ lower than the other PPG coupons that were tested. The result of this is reduced crystallinity is a less brittle material. The tensile coupons from panel $\mathrm{Bl}$ are considered irregular due to the broken seal in the vacuum bag that occurred during processing. The broken seal reduced the effective consolidation pressure to zero, resulting in a panel with a high void content void filled panel. This was noted when examining the cross sectional images of this panel in section 3.4.1.6, and can also be assumed based on the average panel thickness data presented in Table 31. 


\subsection{Nylon/Carbon Results}

The results of the tensile tests performed on the NC coupons are shown in Figure 64. The error bars above each bar in Figure 64 represent one interval of standard deviation. The number of coupons tested from each panel is shown in Table 33. As was discussed in the previous section, fibre volume fraction and degree of crystallinity are two factors that can greatly influence the tensile modulus of a composite material. For reference, average coupon thickness and average heat of crystallization data for each group of test coupons is provided in Table 34 .

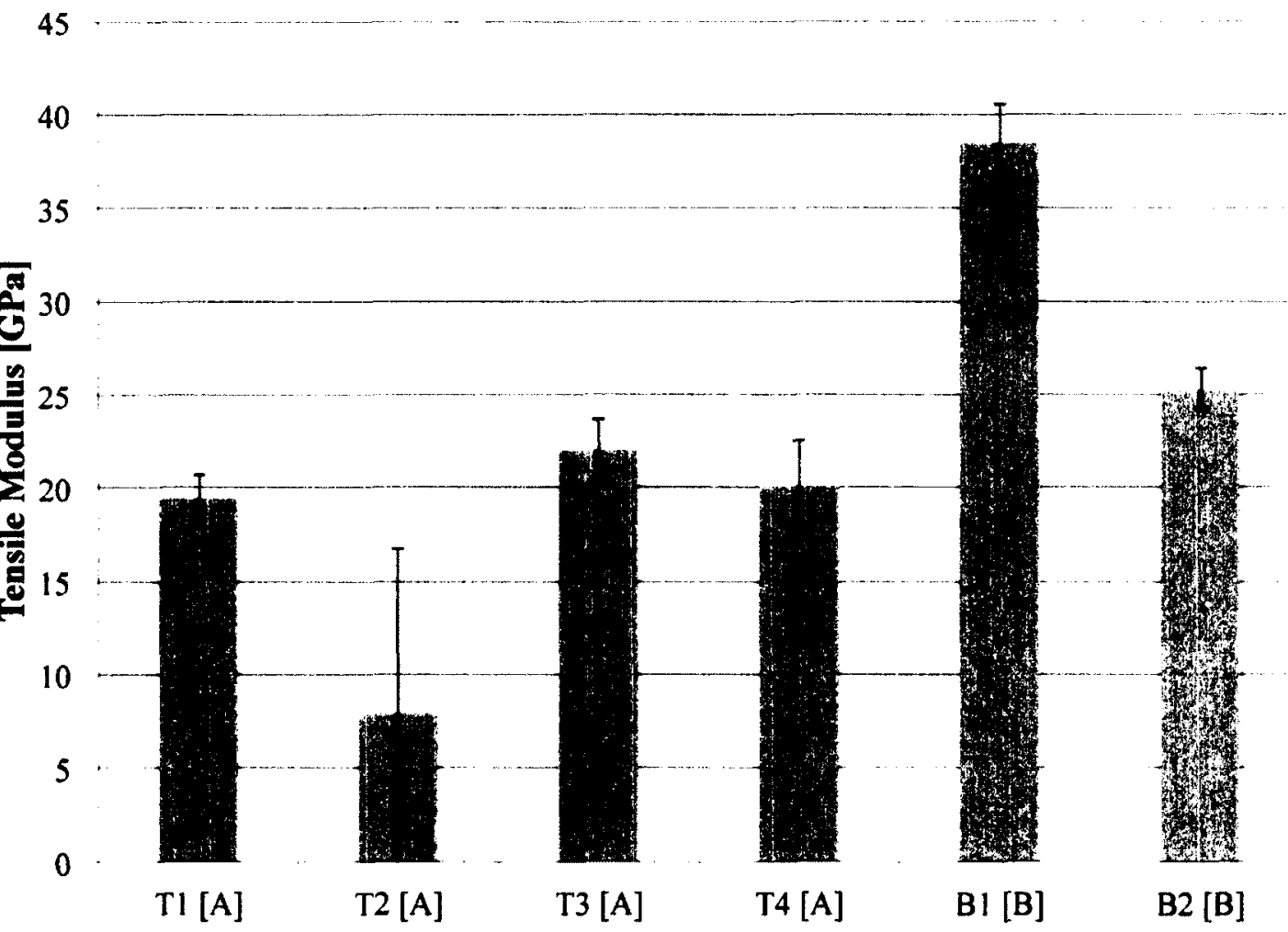

Figure 64: Tensile modulus results for the NC coupons

Table 33: Number of tensile coupons tested from each NC panel

\begin{tabular}{|c|c|c|c|c|c|c|}
\hline & T1 & T2 & T3 & T4 & B1 & B2 \\
\hline $\begin{array}{c}\text { No. of coupons } \\
\text { tested }\end{array}$ & 5 & 4 & 5 & 5 & 5 & 5 \\
\hline
\end{tabular}


Table 34: Average coupon thickness and heat of crystallization for each NC panel

\begin{tabular}{|c|c|c|c|c|c|c|}
\hline & T1 & T2 & T3 & T4 & B1 & B2 \\
\hline Processing Group & $\mathbf{A}$ & $\mathbf{A}$ & $\mathbf{A}$ & $\mathbf{A}$ & $\mathbf{B}$ & $\mathbf{B}$ \\
\hline $\begin{array}{c}\text { Average coupon } \\
\text { thickness [in] }\end{array}$ & 0.101 & 0.097 & 0.096 & 0.098 & 0.090 & 0.089 \\
\hline $\begin{array}{c}\text { Heat of } \\
\text { crystallization } \\
{[\mathbf{J} / \mathbf{g}]}\end{array}$ & 18.97 & 17.09 & 16.70 & 17.33 & 20.54 & 16.30 \\
\hline $\begin{array}{c}\text { Tensile Modul us } \\
{[\text { GPa] }}\end{array}$ & 19.51 & 7.99 & 22.11 & 20.04 & 38.60 & 23.34 \\
\hline $\begin{array}{c}\text { Standard Deviation } \\
{[\text { GPa] }}\end{array}$ & 1.16 & 0.04 & 1.55 & 2.55 & 1.93 & 1.11 \\
\hline $\begin{array}{c}\text { Coefficient of } \\
\text { Variation [\%] }\end{array}$ & 5.95 & 0.54 & 7.02 & 12.70 & 5.01 & 4.36 \\
\hline
\end{tabular}

It makes sense to analyze the $\mathrm{NC}$ tensile modulus results in two groups:
A. Vacuum consolidated panel results (T1-T4),
B. Autoclave processed panel results (B1-B2).

Other than for group T2, the vacuum consolidated panels showed consistent tensile modulus results of approximately $20 \mathrm{GPa}(2900 \mathrm{ksi})$. T2 showed results inconsistent with the other vacuum consolidated coupons. The tensile modulus results for all four T2 coupons that were tested are shown in Table 35.

Table 35: Tensile modulus of each coupon from T2

\begin{tabular}{|c|c|}
\hline Coupon & Tensile Modulus [GPa] \\
\hline T2 -1 & 3.331 \\
\hline T2 -2 & 3.320 \\
\hline T2 -3 & 3.400 \\
\hline T2 -4 & 21.92 \\
\hline
\end{tabular}

From the data shown in Table 35, it is clear that there is a significant discrepancy between coupons $1-3$, and coupon 4 . Figure 65 shows the stress vs. strain plot for $\mathrm{T} 2-1$, 
and Figure 66 shows the stress vs. strain plot for T2 - 4. In Figure 65, it is clear that there is no distinct linear region in the stress vs. strain plot. In Figure 66, there is a clear linear region up to approximately $0.004 \varepsilon$, at which point the coupon begins to yield. The result from coupon $\mathrm{T} 2-4$ is similar to those of the other vacuum consolidated trials ( $\mathrm{T} 1$, $\mathrm{T} 3, \mathrm{~T} 4)$. Since the processing history of $\mathrm{T} 2$ is similar to that of $\mathrm{T} 3$ and $\mathrm{T} 4$, it can be speculated that the result from coupon T2 $-4(21.917 \mathrm{GPa})$ is indicative of the true tensile modulus of panel T2, however further tests are required to confirm this hypothesis. The reason for the significantly lower values from coupons 1-3 is unknown. When compared to coupons from the other trials, coupon T2-4 is the only coupon to show a distinct linear region followed by an apparent yielding region. The heat of crystallization of the panels T1-T4 were all similar, therefore it is not believed that the degree of crystallinity influenced these results. 


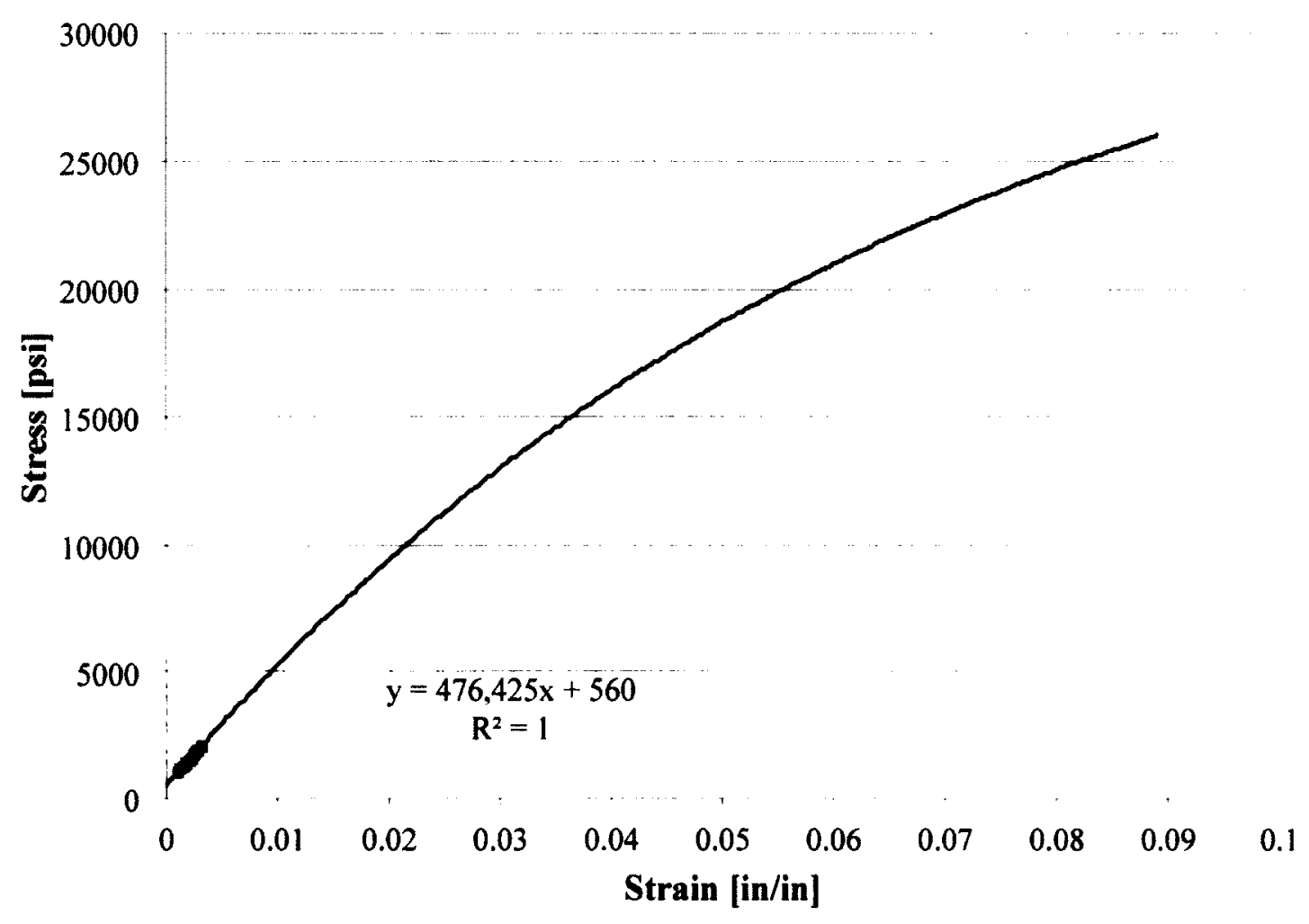

Figure 65: Stress vs. strain plot for NC-T2-2

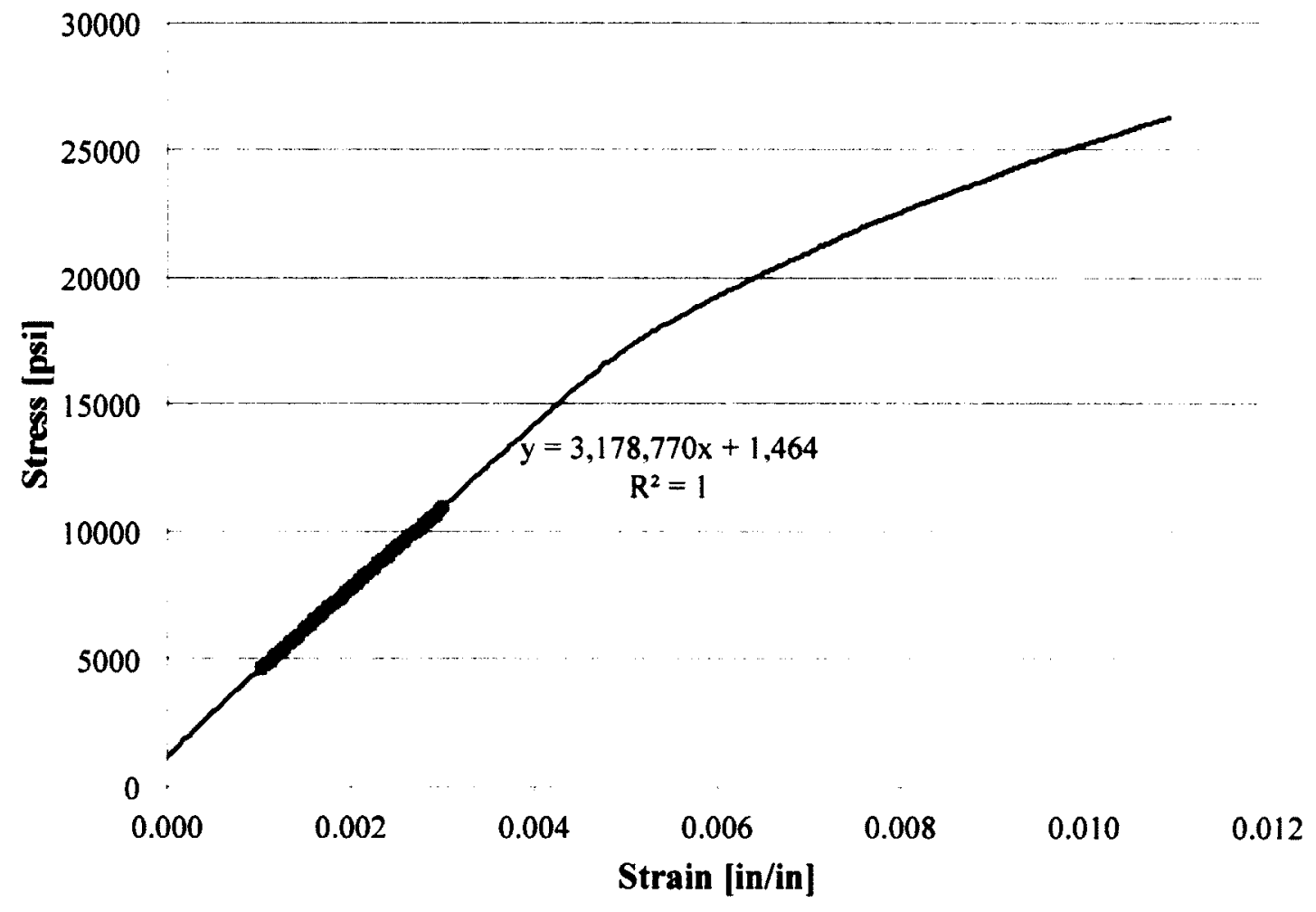

Figure 66: Stress vs. strain plot for NC-T2-4 
The coupons from the autoclave processed panels (B1 and B2) showed significantly different results. The average coupon thickness of the two groups of coupons showed only a $0.025 \mathrm{~mm}(0.001 \mathrm{in})$ difference; therefore it is not believed that the fibre volume fraction contributed significantly to this difference. The heat of crystallization of the coupons from panel B1 is $26 \%$ higher than that of panel $\mathrm{B} 2$. This higher heat of crystallization indicates a higher degree of crystallinity, and therefore a stiffer panel. The coupons from both autoclave-processed panels show a higher tensile modulus than any of the vacuum processed panels. This is due to the higher fibre volume fraction (lower laminate thickness) of the autoclave processed panels relative to the vacuum consolidated panels. 


\subsection{Consolidation Modelling}

The ability to predict the consolidation behaviour of a specific material given varying processing parameters is extremely valuable when designing manufacturing processes. For this reason, a consolidation model has been implemented for use with the PPG and $\mathrm{NC}$ materials studied in this work.

When selecting a modeling approach, a number of factors were considered. First, the amount of material data available for the PPG and NC materials was found to be a limiting factor. A number of physics-based models based mainly on Darcy's Law have been developed, including those cited here (van West, 1991)(Klinkmuller, 1995 and Ye, 1995). A common requirement among these physics-based models is rheology data. As was noted in sections 3.1 , very little information was available for the PPG or the NC materials. Furthermore, samples of neat resin were not available to perform the necessary experiments to collect rheology data. In a commercial production environment, this limitation could be equally as prevalent. Experiments to collect rheological data require specialized equipment that are costly, and the cost of hiring laboratory to conduct this research could be equally as limiting for a small company where cost is a primary concern.

The empirical modeling approach proposed by ljaz et al. (2006) was an attractive option, as it only required consolidation data in order to define the model parameters. Additionally, the manner in which the consolidation model treats each of the two independent consolidation processes separately (process A and process B, as discussed in 3.5) allows it to represent a wide range of consolidation behaviours, and hence a wide range of commingled material types without additional experimentation to determine 
their physical characteristics (other than consolidation experiments). For these reasons, the model proposed by Ijaz et al. has been adapted for the PPG and NC materials studied here. Goal of this model implementation exercise is to provide a first estimate of consolidation behaviour given a thermal processing input, allowing for rapid visualization of laminate consolidation resulting from various processing cycles without the need to perform experimental measurements.

\subsection{Consolidation Model Mathematics}

The derivation of the consolidation model proposed by Ijaz et al. is based on the assumption that the rate of either Process A or Process $\mathrm{B}$, (where $X$ is the normalized degree of consolidation), is proportional to a rate constant, $K$, as a function of temperature, and a function of the degree of consolidation, $F$ :

$$
\frac{d X}{d t}=K(T) F(X)
$$

It is assumed that the rate constant $K$ follows the Arrenhuis law, a common expression for a thermally activated rate constant:

$$
K(T)=\exp (-B / T)
$$

where $T$ is temperature, and $B$ is a material specific empirical constant that represents the activation energy of the process. The $F(X)$ term in equation (10) is borrowed from a thermoset cure model derived by Kamal and Sourour (1973) in which the rate of cure of a thermosetting polymer is expressed as a function of the degree of cure and temperature as follows:

$$
\frac{d X}{d t}=A[\exp (-B / T)] X^{n}(1-X)^{m}
$$


where $A, B, n$ and $m$ are empirically determined constants, $T$ is temperature, and $X$ is degree of cure. The term $(1-X)^{m}$ is used to describe the declining rate of cure as the curing reaction progresses in this model. In terms of laminate consolidation, a similar phenomenon occurs where the rate of consolidation decrease due to increasing resistance to resin flow as the lamina are compacted during processing. The Kamal and Sourour relationship also employs the Arrenhuis law to describe the thermally activated rate of cure.

By applying the concepts developed by Kamal and Sourour for thermoset curing to the proposed equation for rate of consolidation of a commingled thermoplastic composite, one can express the rate of consolidation as a function of the degree of consolidation using the same relationship:

$$
F(X)=\mathrm{A}(1-X)^{m}
$$

where $A$ and $m$ are empirically determined material specific constants. The $X^{n}$ term in equation (12) was found to be unnecessary when describing laminate consolidation rates since a value of $n=0$ produced good correlation with experimental data for all processing scenarios and materials. For this reason, Ijaz et al. (2006) dropped the term from their consolidation model. With the relationships for both $K(T)$ and $F(X)$ known, equation (10) can now be expressed, for each process, in terms of empirical constants $A_{A}, B_{A}, m_{A}, A_{B}$, $B_{B}$ and $m_{B}$ :

$$
\begin{aligned}
& \frac{d X_{A}}{d t}=A_{A}\left[\exp \left(-B_{A} / T\right)\right]\left(1-X_{A}\right)^{m} \\
& \frac{d X_{B}}{d t}=A_{B}\left[\exp \left(-B_{B} / T\right)\right]\left(1-X_{B}\right)^{m}
\end{aligned}
$$


Finally, the relative contribution of each process to the total laminate consolidation is expressed as:

$$
X=\mathrm{f} X_{A}+(1-\mathrm{f}) X_{B}
$$

where $f$ is the percentage of the total consolidation provided by Process A.

Although the empirical constants do not have a direct physical meaning, the effect of varying each constant is summarized in Table 36. Through comparison with consolidation test data (Figure 37 and Figure 38), the empirical constants for PPG and NC were determined, and are presented in Table 37.

Table 36: Effect of varying each constant in the consolidation model

\begin{tabular}{|l|l|}
\hline Constant & Effect \\
\hline $\mathrm{A}$ & Defines the slope of the process transient \\
\hline $\mathrm{B}$ & Defines the temperature of process onset \\
\hline $\mathrm{m}$ & $\begin{array}{l}\text { Defines the sharpness of process transitions } \\
\text { (corners of the process transient) }\end{array}$ \\
\hline $\mathrm{f}$ & $\begin{array}{l}\text { Relative contribution of process } \mathrm{A} \text { to total } \\
\text { consolidation }\end{array}$ \\
\hline
\end{tabular}

Table 37: Consolidation model parameters for PPG, NC, and PET/Glass (ljaz, 2006)

\begin{tabular}{|c|c|c|c|c|c|c|c|}
\hline Material & $\mathbf{F}$ & $\mathbf{A}_{\mathbf{A}}$ & $\mathbf{B}_{\mathbf{A}}$ & $\mathbf{m}_{\mathbf{A}}$ & $\mathbf{A}_{\mathbf{B}}$ & $\mathbf{B}_{\mathbf{B}}$ & $\mathbf{m}_{\mathbf{B}}$ \\
\hline PPG & 0.16 & $10 \times 10^{27}$ & 22000 & 7 & $5 \times 10^{36}$ & 40000 & 2.5 \\
\hline NC & 0.06 & $15 \times 10^{27}$ & 24000 & 5 & $10 \times 10^{38}$ & 44200 & 0.9 \\
\hline PET/Glass & 0.40 & $4 \times 10^{27}$ & 22000 & 9.5 & $3.2 \times 10^{36}$ & 45000 & 3.0 \\
\hline
\end{tabular}

\subsection{Consolidation Model Results}

The consolidation model output plots are compared to experimental data in Figure 67 and Figure 68. Close correlation has been achieved between the calculated and experimental consolidation data. In the case of the PA6/carbon laminate, "Process B" shows a slight 
discrepancy between the experimental and calculated results. The initiation of the polymer melt occurs very suddenly in this case, producing a difficult scenario to model. In the case of the PP/E-glass laminate, the melt occurs more gradually, and thus a better correlation resulted.

The accuracy of the model output at different heating rates cannot be assessed since validation cases were not performed. The maximum achievable heating rate in the convection oven used for this work is $2.2^{\circ} \mathrm{C} / \mathrm{min}$, therefore higher heating rates could not be investigated.

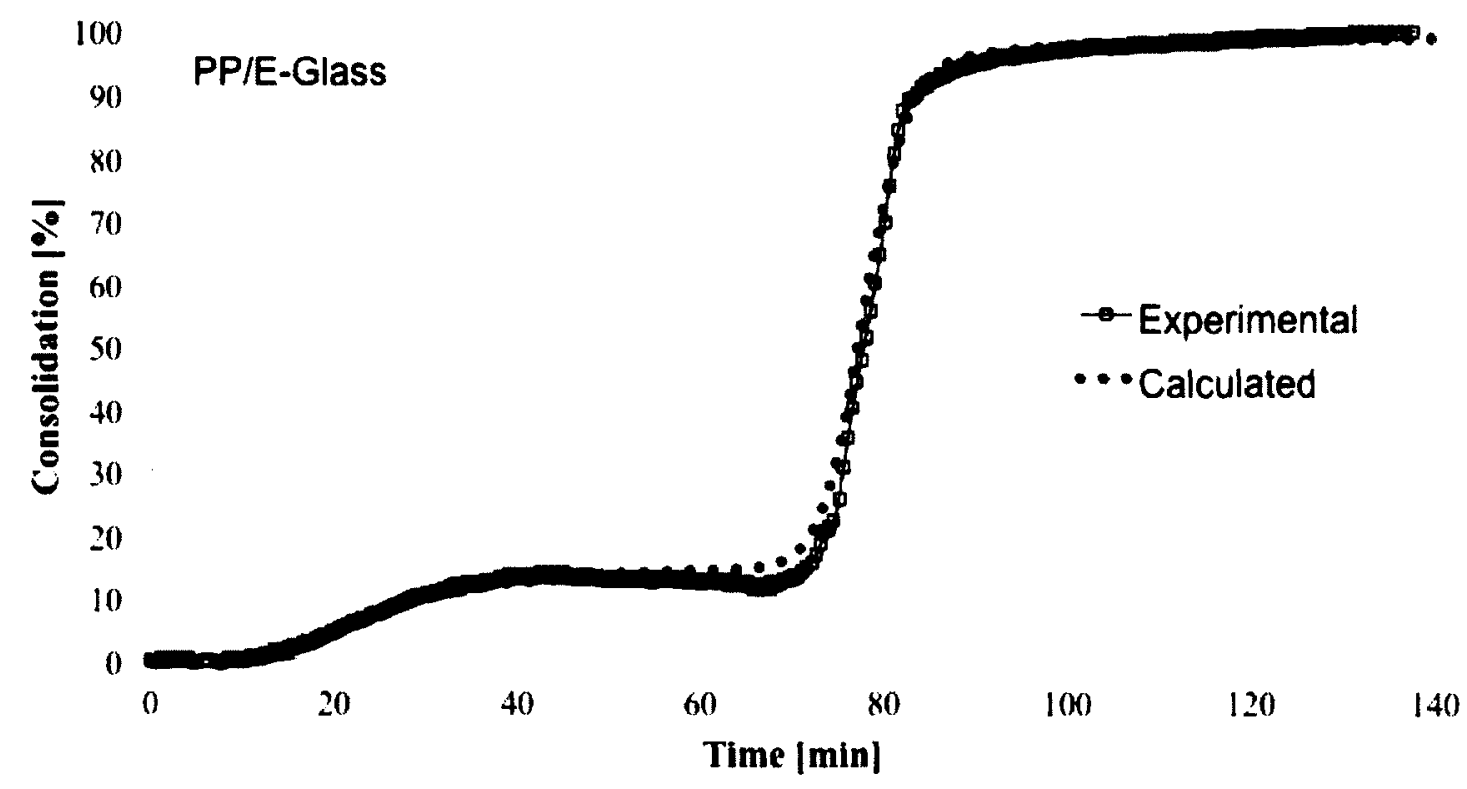

Figure 67: Consolidation model output compared to experimental consolidation data for PPG 


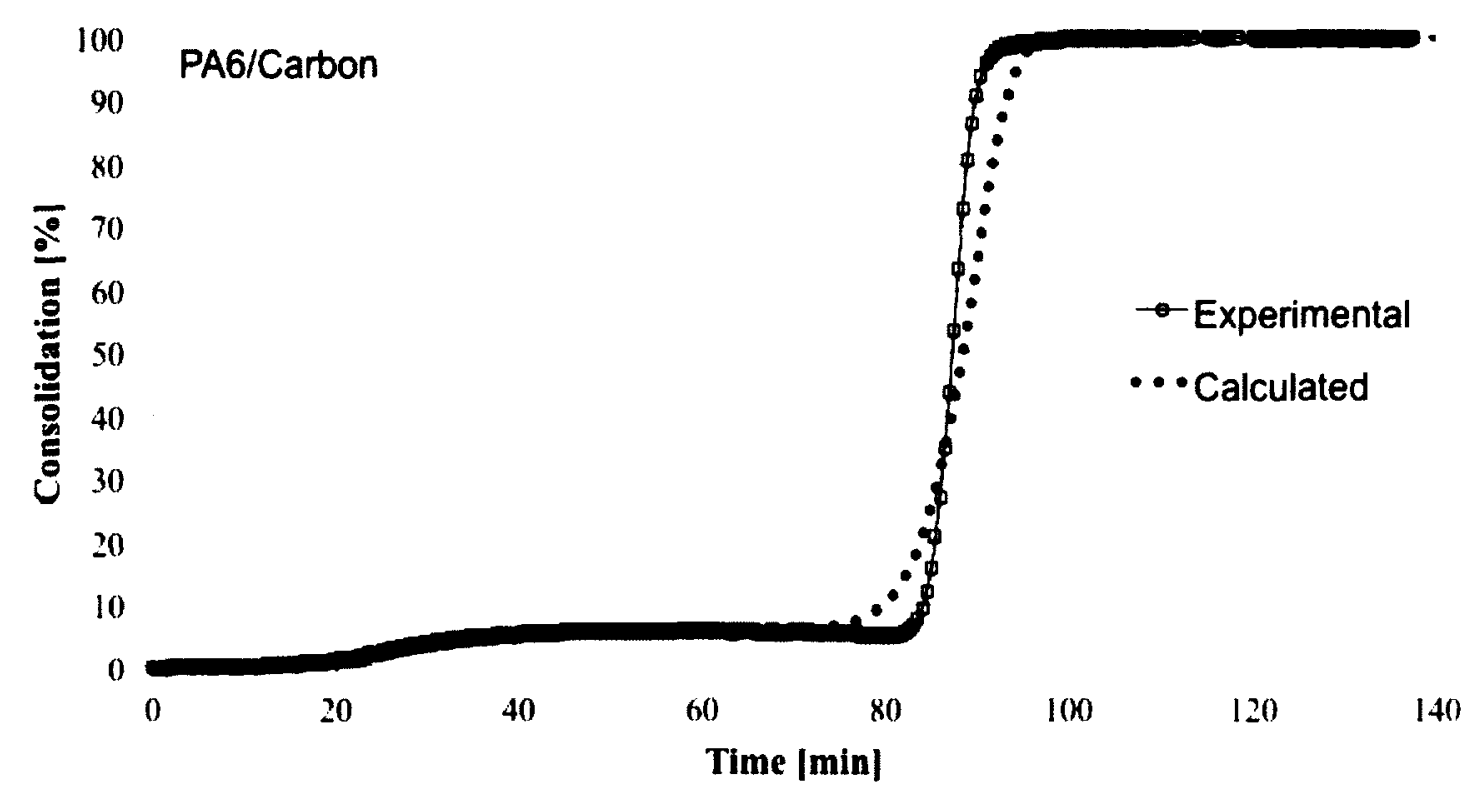

Figure 68: Consolidation model output compared to experimental consolidation data for NC

\subsection{Consolidation Model Coding}

The main purpose of the consolidation model code is to perform the required calculations outlined in section 6.1 and produce consolidation vs. time predictions for various temperature profile inputs. By writing this Matlab program, various processing scenarios can be visualized quickly and conveniently. The Matlab code used to implement the laminate consolidation model discussed in the previous section is shown in Appendix C. The code is divided into six main segments as follows:

1. Definition of Process Parameters

2. Simulation Time Parameters

3. Simulation Temperature Parameters

4. Initialization of Variables

5. Main Calculation Loop

6. Plotting 
A block diagram of this procedure is shown in Figure 69. Each segment of code will be discussed in the following sections. A full list of Matlab variables used in this code is provided in Appendix D.

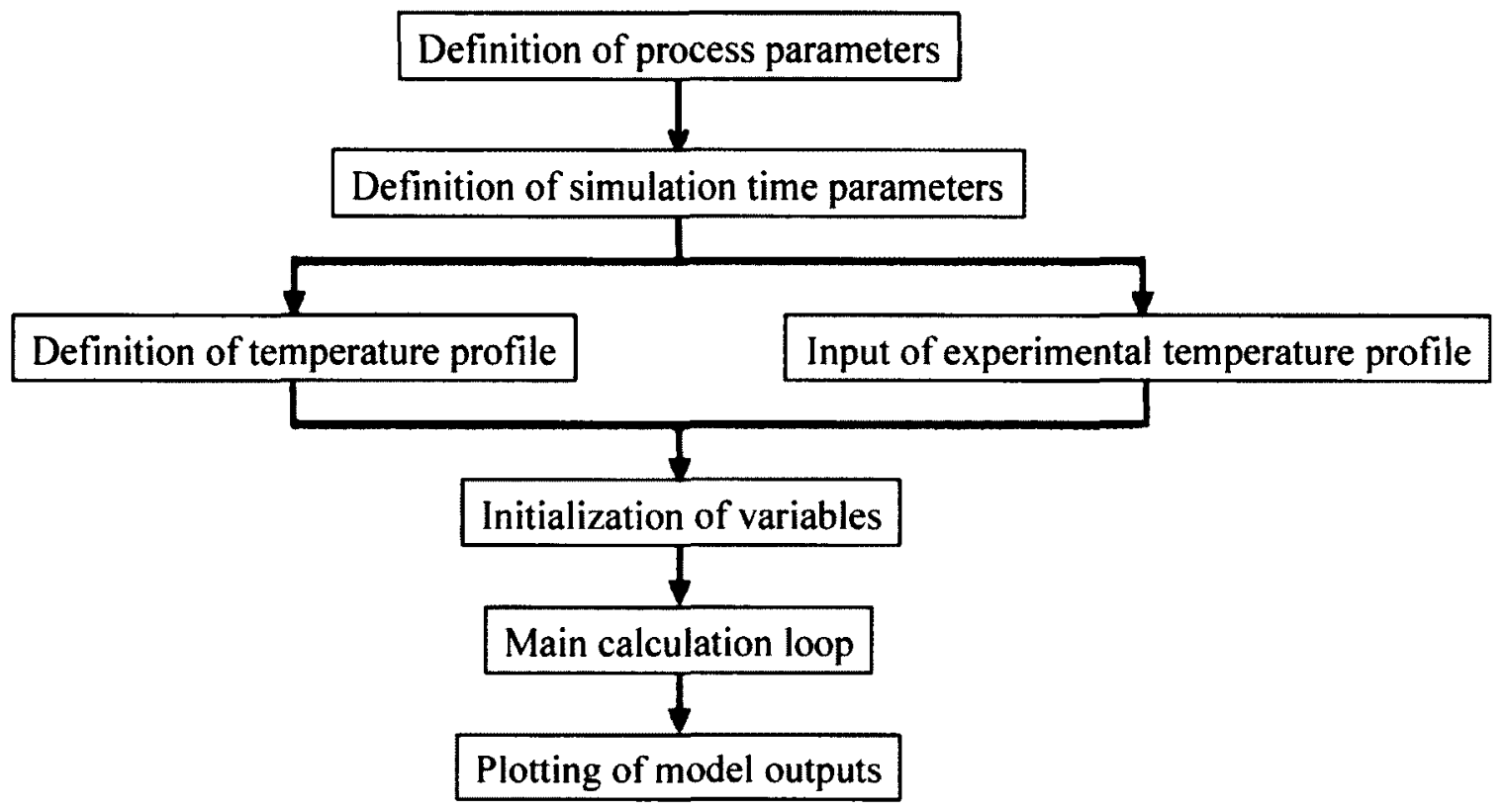

Figure 69: Block diagram of the consolidation model code execution

\subsubsection{Definition of Process Parameters}

This segment of code is where the empirical constants of the model are defined. These constants are material specific, and are listed in Table 37. The code provided in Appendix $\mathrm{C}$ has values coded for PPG, NC and PET. A material type can be selected by commenting out all lines of code corresponding to the unwanted material types, leaving only the desired material parameters. A line of code can be commented out by inserting a "\%" at the beginning of the line. 


\subsubsection{Simulation Time Parameters}

This segment of code is used to define the length of the simulation (in seconds), and also the sampling rate in $\mathrm{Hz}$ (or the number of data points desired per second).

\subsubsection{Simulation Temperature Parameters}

This segment of code is used to define the temperature profile of the manufacturing process to be simulated. The processing soak temperature (in Kelvin), the heating rate (in $\mathrm{K} / \mathrm{s}$ ) and the initial material temperature (in Kelvin) are defined here. It should be noted that no temperature ramp down or soak time is specified as it is not simulated. This modeling approach assumes that the laminate reaches full consolidation during the soak period, and therefore once the soak temperature is reached, it is held constant for the duration of the simulation.

An alternative method of defining the temperature profile of the manufacturing process is to input real temperature data collected during a consolidation trial. By double clicking on the variable $T$ in the variable browser in Matlab, temperature data collected during processing can be copy and pasted directly into Matlab from Excel. This method of defining the temperature profile can potentially provide a more accurate representation of laminate consolidation, and should be used if test data is being compared with the model output.

\subsubsection{Initialization of Variables}

This segment of code initializes the main consolidation variables (sets the arrays to the required size) in order to minimize simulation running time. 


\subsubsection{Main Loop}

The main loop of the simulation performs all the main calculations to determine the degree of consolidation of the laminate. This process is as follows:

1. The temperature profile is updated to the current time step if an experimental thermal profile has not been input. In the code provided in Appendix $\mathrm{C}$, the lines of code corresponding to this step are commented out. If experimental data is not to be used, these lines should be uncommented.

2. The rate of consolidation for the current time step is calculated for each process. Accommodation is made for the first time step to ensure a numerical error does not occur.

3. The rate of consolidation for each process is integrated (i.e. multiplied by the length of the time step), and added to the previously accumulated consolidation. When the main loop has completed, the arrays of $X_{A}$ and $X_{B}$ are used to compute the final consolidation curve as is shown in equation 16.

\subsubsection{Plotting the Simulation}

This segment of code uses the basic Matlab plotting functions to produce plots of the temperature profile used, the total consolidation $(X)$ vs. time, the consolidation due to Process A and B $\left(X_{A}\right.$ and $\left.X_{B}\right)$ vs. time, and the rate of Process A and B vs. time. Any of these plots can be suppressed by commenting out the relevant lines of code. 


\subsection{Conclusion}

Based on the manufacturing trials performed on the commingled PPG material, PPG is a viable option for the manufacturing of UAV components. Based on optical microscopy of the laminate cross sections, a negligible void content was achieved. Since the measured $T_{g}$ of this material ranged from $-11^{\circ} \mathrm{C}\left(12^{\circ} \mathrm{F}\right)$ to $7^{\circ} \mathrm{C}\left(45^{\circ} \mathrm{F}\right)$, applications where stiffness is a primary design driver require additional analysis to determine the suitability of this material.

The NC material on the other hand did not result in satisfactory laminate quality. Large macro voids were present throughout all of the vacuum consolidated laminates. Also, large concentrations of resin and unimpregnated fibres were observed in all vacuum consolidated panels. The autoclave processed laminates resulted in good laminate quality, with a negligible void content and fairly homogenous cross sections. This indicates that vacuum pressure in insufficient to properly consolidate this material type. With an investigation into alternative processing methods for the $\mathrm{NC}$ material, there is potential to incorporate this material into an aerospace component where damage tolerance is desirable (such as the payload bay hatches on the GeoSurv II UAV).

Dynamic mechanical analysis was performed to characterize the glass transition temperature range of both material types. As previously mentioned, the PPG material underwent glass transition between $-11^{\circ} \mathrm{C}\left(12^{\circ} \mathrm{F}\right)$ and $7^{\circ} \mathrm{C}\left(45^{\circ} \mathrm{F}\right)$. Varying the processing parameters had no apparent effect on the $T_{g}$ of the resulting laminates. For the $\mathrm{NC}$ material, the glass transition temperature range was found to be approximately $33^{\circ} \mathrm{C}$ $\left(91^{\circ} \mathrm{F}\right)$ to $65^{\circ} \mathrm{C}\left(149^{\circ} \mathrm{F}\right)$. Large variations in the results, even between laminates 
manufactured with identical processes, make it difficult to conclude the effect of varying processing parameters

Differential scanning calorimetry was also performed to determine the melting temperature and the heat of crystallization of the PPG and NC materials. For the PPG material, it was found that exposing the material to temperatures about its melting temperature for an extended period of time can significantly increase its melting temperature while significantly debiting its heat of crystallization, and thus crystallinity. For the NC material, it was found that exposing the material to temperatures significantly higher than its melting temperature can reduce its $T_{m}$. Varying the processing parameters for this material had no significant effect on the heat of crystallization, and thus crystallinity.

The tensile modulus data collected from the tensile testing of both materials showed a correlation between laminate thickness (indirectly, fibre volume fraction) and stiffness, as predicted by the rule of mixtures. This phenomenon is best illustrated by the relatively high modulus results produced by the autoclave-processed laminates of both material types.

Finally, the consolidation model developed by ljaz et al. was successfully implemented in MATLAB to predict the consolidation behaviour of both material types. Material constants for use in the consolidation model were determined by fitting model outputs to real consolidation data collected during the manufacturing trials. Good agreement was achieved between the calculated and experimental results for both material types. 


\subsection{Future Work}

Since this is the first research project to be performed on thermoplastic composites at Carleton University, the scope of possible future work is extremely broad. This research has shown that commingled material is a viable option for low cost manufacturing, and therefore future research on this material type is warranted. The focus of future work should first be to identify the many polymer/reinforcement combinations available as commingled precursors. From there, an ideal combination for specific applications could be determined.

In terms of fundamental material characterization, a more extensive test matrix should be developed to study the effect of processing parameters on more mechanical properties including ultimate tensile strength, shear strength, and shear modulus. Additionally, to assess the potential improvement thermoplastic matrix composites offer in the realm of impact damage resistance, impact tests, and strength after impact tests would provide valuable data to this end.

A next step towards manufacturing UAV components is determining consolidation behaviour of 2-D and 3-D curvatures, as this will be critical for the manufacturing of final aircraft components. Since Carleton has been developing small to medium sized UAVs, sharp corners and rounds are commonplace on these aircraft. An adequate method of dealing with this geometry will be required.

\subsection{Contributions}

A new area of research has been established at Carleton University in the field of composite materials processing. The viability of vacuum consolidation of commingled 
thermoplastic composites has been investigated and reported in this thesis, as well as in Canadian Aeronautics and Space Institute AERO 2011 conference proceedings (Chiasson et al., 2011). The effect of various vacuum consolidation process parameters has been assessed in terms of qualitative void content observations, physical properties and tensile modulus. A consolidation model proposed by ljaz et al. (2006) has been implemented and shown to agree well with experimental consolidation measurements. 


\section{References}

Ahrens, M., Mallickm V., Parfrey, K. 1998. Robotic Based Thermoplastic Fibre Placement Process. Proceedings of the 1998 IEEE International Conference on Robotics \& Automation. Leuven, Belgium, 16-20 May 1998.

ASTM International. 2011. ASTM D30390 - Standard Test Method for Tensile Properties of Polymer Matrix Composite Materials. American Society for Testing and Materials. West Conshohocken, PA, USA.

ASTM International. 2011. ASTM D3418 - 08 Standard Test Method for Transition Temperatures and Enthalpies of Fusion and Crystallization of Polymers by Differential Scanning Calorimetry (DSC). American Society for Testing and Materials. West Conshohocken, PA, USA.

ASTM International. 2011. ASTM D7028 - Standard Test Method for Glass Transition Temperature (DMA Tg) of polymer Matrix Composites by Dynamic Mechanical Analysis (DMA). American Society for Testing and Materials. West Conshohocken, PA, USA.

Beauclaire, N. 2001. Airbus on the leading edge in composites [Internet]. Interavia Business \& Technology. [Cited 28 July 2009] Available from:

http://www.articlearchives.com/chemicals/plastics-rubber-industry-resinsthermoplastics/328701-1.html

Bokulich, F. 2001. Thermoplastic Use on Airbus Aircraft. Aerospace Engineering, SAE International. 12(2).

Cakmak, M., Dutta, A. 1991. Instrumented thermoforming of advanced thermoplastic composites. II: Dynamics of double curvature part formation and structure development from PEEK/carbon fiber prepreg tapes. Polymer Composites, 12:338 353.

Chalwa, K. K. 1998. Fibrous Materials. Cambridge, England. Cambridge University Press.

Chiasson, M., Laliberté, J. 2011. Low Cost Processing of Commingled Thermoplastic Composites. CASI Aero 2011 Conference Proceedings.

Desbiens, A. L. 2003. Justification de la s'election du IM7/APC-2 dans la structure du Space Station Remote Manipulator System. Universite de Sherbrooke, Faculte de Genie - Genie Mecanique. 
Devlin, B.J., Williams, M.D., Quinn, J.A., Gibson, A.G. 1991. Pultrusion of unidirectional composites with thermoplastic matrices. Composites Manufacturing. 2(3-4):203-207.

Djokic, D., Johnston, A., Rogers, A., Lee-Sullican, P., Mrad, N. 2001. Residual stress development during the composite patch bonding process: measurement and modeling. Composites Part A 33(2002):277-288.

Dutta, A., Niemeyer, M. and Cakmak, M. 1991. Thermoforming of advanced thermoplastic composites. I: Single curvature parts. Polymer Composites. 12:257272.

Eire Composites. [Date Unknown]. Thermoplastic Composites Explained [Internet]. Eire Composites [Cited 2 October 2011]. Available from: http://www.eirecomposites.com/Thermoplastic_Composites_Explained.asp

El Kadi, H., Denault, J. 2001. Effects of Processing Conditions on the Mechanical Behavior of Carbon-Fiber-Reinforced PEEK. Journal of Thermoplastic Composite Materials. 14(1)34-53.

Ferry, J. D. 1980. Viscoelastic Properties of Polymers. $3^{\text {rd }}$ Edition. New Jersey, USA: Jon Wiley and Sond Inc.

Harntess, T., Husman, G., Koenig, J., Dyksterhouse, J. 2001. The Characterization of Low Cost Fibre Reinforced Thermoplastic Composites Produced by the DRIFT Process. Composites: Part A. 32(2001):1155-1160.

Hexcell Corporation. 2007 [Internet]. HexTow AS4 Carbon Fiber Product Data. [Cited 18 August 2009]. Available from:

http://www.hexcel.com/Products/Downloads/Carbon+Fiber+Data+Sheets.htm?ds=Co ntinuous

Hexcel Corporation. 2007. [Internet]. HexTow IM6 Carbon Fiber Product Data. [Cited 18 August 2009]. Available from:

http://www.hexcel.com/Products/Downloads/Carbon+Fiber+Data + Sheets.htm?ds=Co ntinuous

Hexcel Corporation. 2007 [Internet]. HexTow IM7 (5000) Carbon Fiber Product Data. [Cited 18 August 2009]. Available from:

http://www.hexcel.com/Products/Downloads/Carbon+Fiber+Data+Sheets.htm?ds=Co ntinuous

High Performance Composites. 2006. [Internet]. Thermoplastic Composites Gain Leading Edge On The A380. [Cited 17 June 2009]. Available from: http://www.compositesworld.com/articles/thermoplastic-composites-gain-leadingedge-on-the-a380.aspx 
Hutchins, J. G. 1992. Thermoplastic Applications in Helicopter Components. AHS 48th Annual Forum. Washington D.C.: American Helicopter Society.

IAR-NRC. (n.d.). Thermoplastic Material Data.

Ijaz M., Robinson M., Wright P.N,H., Gibson A.G. 2006. Vacuum Consolidation of Commingled Thermoplastic Matrix Composites. Journal of Composite Materials 41(2):243-262.

Iyer, S. R., Drzal, L. T. 1990. Manufacture of Powder-Impregnated Thermoplastic Composites. Journal of Thermoplastic Composite Materials. 3(4):325-355.

Kadokian, G.K.A., Kinloch, A.J., 1988. Surface pretreatment and adhesion of thermoplastic fibre-composites. Journal of Materials Science Letters 7. P. 625-627.

Kamal, M.R., Sourour, S. 1973. Kinetics and Thermal Characterization of Thermoset Cure, Polymer Engineering \& Science, 13(1): 59-64.

Kaman Instrumentation Kuda Harware Manual. 2001. Kaman Aerospace Corportation Measuring and Memory Systems. Middletown, CT, USA.

Klinkmuller, V., Um, M. K., Steffens, M., Friedrich, K., Kim, B. S. 1995. A new model for Impregnation Mechanism in Different GF/PP Commingled Yarns, Applied Composite Materials, 1(5): 351-371.

Kojima, M. 1968. Annealing of polypropylene lamellar crystals. Journal of Polymer Science Part A-2: Polymer Physics, 6:1938-1942

Laliberté, J., Mahendran, M., Djokic, D., Li, C., Kratz, J. 2007. Effect of ProcessInduced Residual Stresses on Mechanical Properties and Fatigue Crack Initiation in Fibre Metal Laminates. $24^{\text {th }}$ ICAF Symposium. Naples, 16-18 May.

Larock, J.A., Hahn, H.T., Evans, D.J. 1989. Pultrusion Processes for Thermoplastic Composites. Journal of Thermoplastic Composite Materials. 2(3):216-229.

Lauke, B., Friedrich, K. 1993. Evaluation of processing parameters of thermoplastic composites fabricated by filament winding. Composites Manufacturing , 4(2):93101.

Menczel, J. D., Prime, R. B. 2008. Thermal Analysis of Polymers: Fundamentals and Applications, Hoboken, NJ, USA: John Wiley \& Sons, Inc.

Michaels, K. 2007. Aerospace composites market will quadruple by 2026 . Composites World [Internet]. [Cited 1 August 2011]. Available from: http://www.compositesworld.com/columns/market-trends-aerospace-compositesmarket-will-quadruple-by-2026 
Moran, B., Adams, B., Follo, B., Salem, D. 2009. Weight Reduction and Cost Savings using Hybrid Composites containing High Modulus Polypropylene Fiber. American Composites Manufacturers Association, Composites and Polycon 2009.

Muzzy, J. D. 2000. Thermoplastics-Properties. Comprehensive Composite Materials. Elsevier Science Ltd.

Offringa, A. 2005. Thermoplastics in Aerospace, New Products through Innovative Technology. SAMPE Journal , 47(6):19-27.

Offringa, A., Davies, C. R. 1996. Gulfstream V Floors - Primary Aircraft Structure in Advanced Thermoplastics. Journal of Advanced Materials. 27 (2):2-7.

Owens Corning. 2009. [Internet]. Twintex Thermoplastic Composite Solutions Vacuum Moulding Manual. Available from: http://www.twintex.com/

Pae, K.D., Sauer, J.A. 1968. Effects of thermal history on isotactic polypropylene. Journal of Applied Polymer Science. 12(8):1901-1919.

Peltonen, P., Lahteenkorva, K., Paakkonen, E.J., Jarvela, P.K., Tormala, P. 1992. The Influence of Melt Impregnation Parameters on the Degree of Impregnation of a Polypropylene/Glass Fibre Prepreg. Journal of Thermoplastic Composite Materials. 5(4):318.

Perkin Elmer Inc. 2007. [Internet] Dynamic Mechanical Analysis Basics: Part 2 Thermoplastic Transitions and Properties. [Cited 15 October 2011]. Available from: http://www.perkinelmer.com/CMSResources/Images/4474546GDE_IntroductionToDMA.pdf

Perkin Elmer. 2008. Introduction to Dynamic Mechanical Analysis, A Beginners Guide. [Internet]. Waltham, MA, USA. [Cited 10 September 2011]. Available from: http://www.perkinelmer.com/CMSResources/Images/4474546GDE_IntroductionToDMA.pdf

Perkin Elmer. 2008. Part 2: Thermoplastic Transitions and Properties. [Internet]. Waltham, MA, USA. [Cited 10 September 2011]. Available from: http://www.perkinelmer.com/CMSResources/Images/4474546GDE_IntroductionToDMA.pdf

Salek, M. H. 2005. Effect of Processing Parameters on the Mechanical Properties of Carbon/PEKK Thermoplastic Composite Materials. Montreal, QC. Concordia University.

Shuart, M. J., Johnston, N. J., Dexter, H. B., Marchello, J. M., Grenoble, R. W. 1998. Automated Fabrication Technologies for High Performance Polymer Composites. Technical Report. Nasa Langley. 
Sichina, W. J. 2000. [Internet] DSC as Problem Solving Tool: Measurement of Percent Crystallinity of Thermoplastics. [Cited 28 Novemeber 2011]. Available from:

http://www.perkinelmer.com/Content/applicationnotes/app_thermalcrystallinitytherm oplastics.pdf

Svensson, N., Shishoo, R., Gilchrist, M. 1998. Manufacturing of Thermoplastic Composites from Commingled Yarns-A Review. Journal of Thermoplastic Composite Materials. 11(1):22-56.

TA Instruments. 2007. Measurement of the Glass Transition Temperature Using Dynamic Mechanical Analysis. Thermal Analysis \& Rheology Application Library. Version 4.0.

TA Instruments. 2011. [Internet] Q800 Specifications. [Cited 5 December 2011]. Available from: $\mathrm{http} / / \mathrm{www}$.tainstruments.com/product.aspx?siteid=11\&id=25\&n=1

Toray Carbon Fibers America. 2008. [Internet]. Torayca T300 Data Sheet. [Cited 18 August 2009] Available from http://www.toraycfa.com/standardmodulus.html

Total Plastics Inc. 2010. [Internet]. Look to Aerospace for Material Innovations of Tomorrow [Cited 10 August 2011]. Available from:

http://www.totalplastics.com/news/read/92

Twintex. 2011. [Internet]. Owens Corning [cited 1 Sept 2010] Available from: http://www.twintex.com/

Vaidya, U.K., Chawla, K.K. 2008. Processing of fibre reinforced thermoplastic composites. International Materials Reviews. 53(4):185-218.

Van West, B.P., Pipes, R.B., Advani, S.G. 1991. The Consolidation of Commingled Thermoplastic Fabrics, Polymer Composites, 12(6): 417-427.

Vitlip, M. L. 1991. Design and Manufacture of an Advanced Horizontal Stabilator for the AH-64A. 47th Annual Forum of the American Helicopter Society. Phoenix, Arizona.

Vodermayer, A.M., Kaerger, J.C., Hinrichsen, G. 1993 Manufacture of high performance fibre-reinforced thermoplastics by aqueous powder impregnation, Composites Manufacturing. 4(3):123-132

Wakeman, M.D., Rudd, C.D., Cain, T.A., Brooks, R., Long, A.C. 2000. Compression moulding of glass and polypropylene composites for optimised macroand micro-mechanical properties. 4: Technology demonstrator - a door cassette structure. Composites Science and Technology 60(200):1901-1918. 
Ye, L., Friedrich, K., Kastel, J. 1995. Consolidation of GF/PP Commingled Yarn Composites, Applied Composite Materials, 1(6): 415-429.

Younossi, O., Kennedy, M., Graser, J. C. 2001. Military Airframe Costs. RAND Corporation.

Yousefpour, A., Hojjati, M., Immarigeon, J.P, 2004. Fusion Bonding/Welding of Thermoplastic Composites. Journal of Thermoplastic Composite Materials , 17(4):303-341. 


\section{Notes}

Unpublished electronic correspondence referenced in section 4.2.3:

From: Maillard, Damien

Sent: August-24-11 9:59 AM

To: Boucher, David

Subject: RE: DSC Data Analysis

$\mathrm{Hi}$,

I just took a look on the two DSC thermographs. I agree that PPG1 is exactly what I would expect from polypropylene, and that PPG4 is more surprising. But, this kind of modification is often observed for other polymers (especially PLA). From what I know it could come from two things. First, a phase transition in the crystalline phase (alpha to beta for example). The second possibility would be the result of a annealing of the sample. If the sample is maintained at a temperature very close to the $\operatorname{Tm} 0$, you could observe a thickening of the crystals. As the Tm is directly connected to the crystal thickness, this thickening will rise the $\mathrm{Tm}$. In some situation, this thickening (or even the phase transition) can occur directly during the DSC scan (in PLA for example). In this case, an "event" (thickening or transition) exotherm is superposed on the melting endotherm, and the new endotherm appears at higher temperature. My advice would be to perform a modulated DSC on the sample to separate those possibly superposed endotherms and exotherms. In the mean time, it would be nice to check the effect of the thermal history. I red that the panel stayed longer ( $2 \mathrm{~h}$ ) in temperature (close to the Tm probably), this could easily explain this annealing/thickening behaviour.

Best regards,

Damien Maillard 

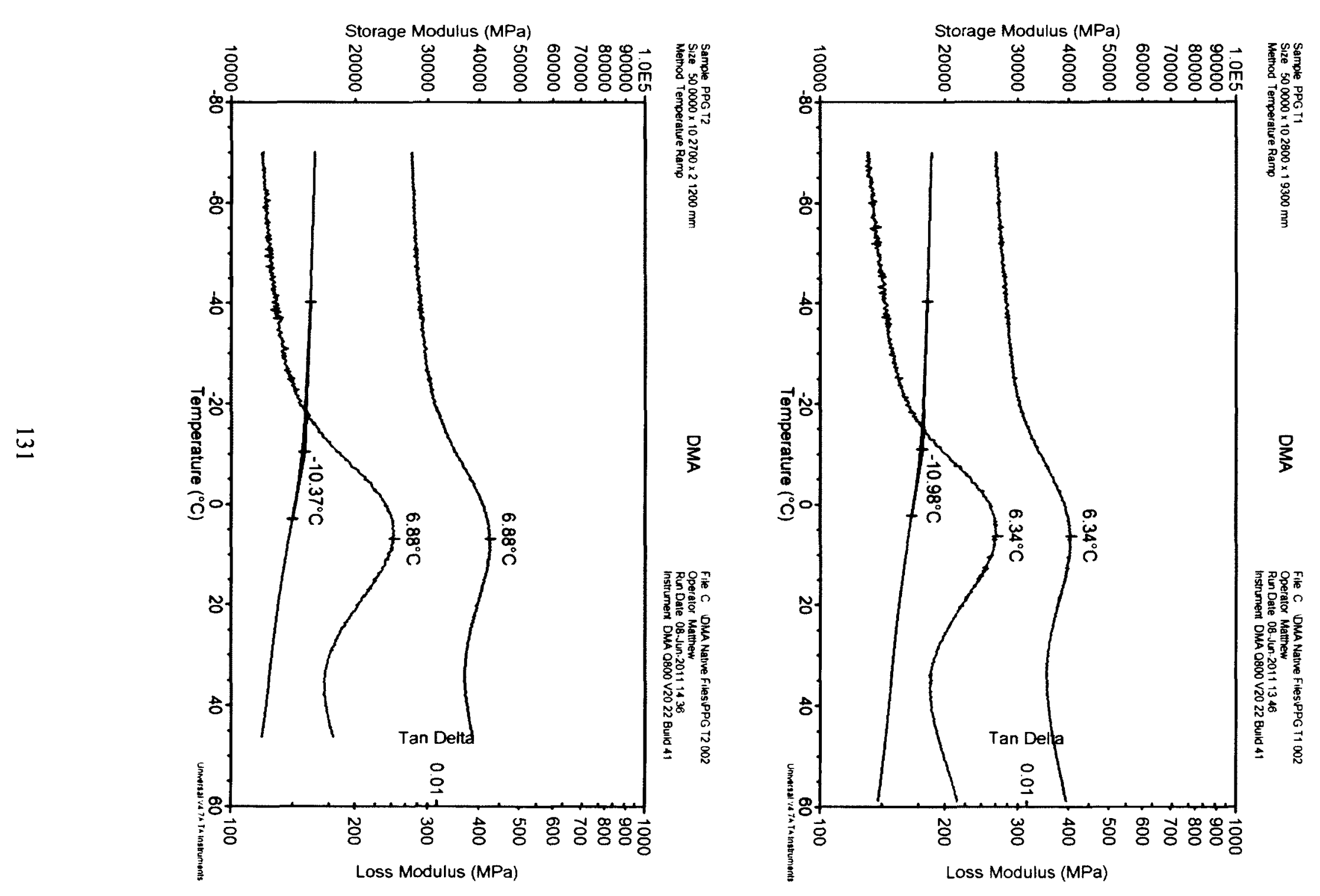

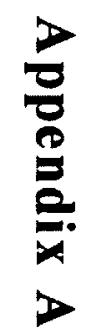



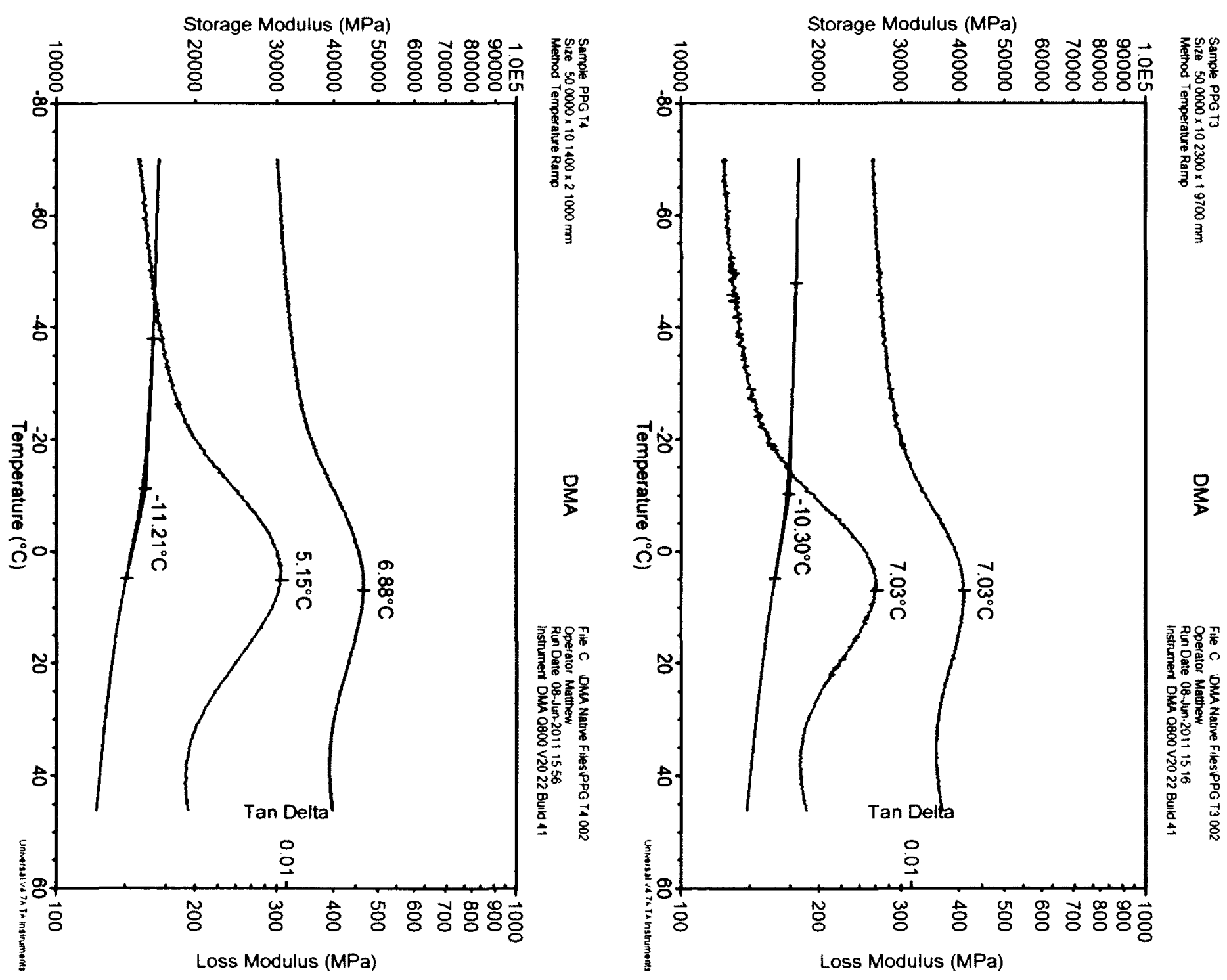


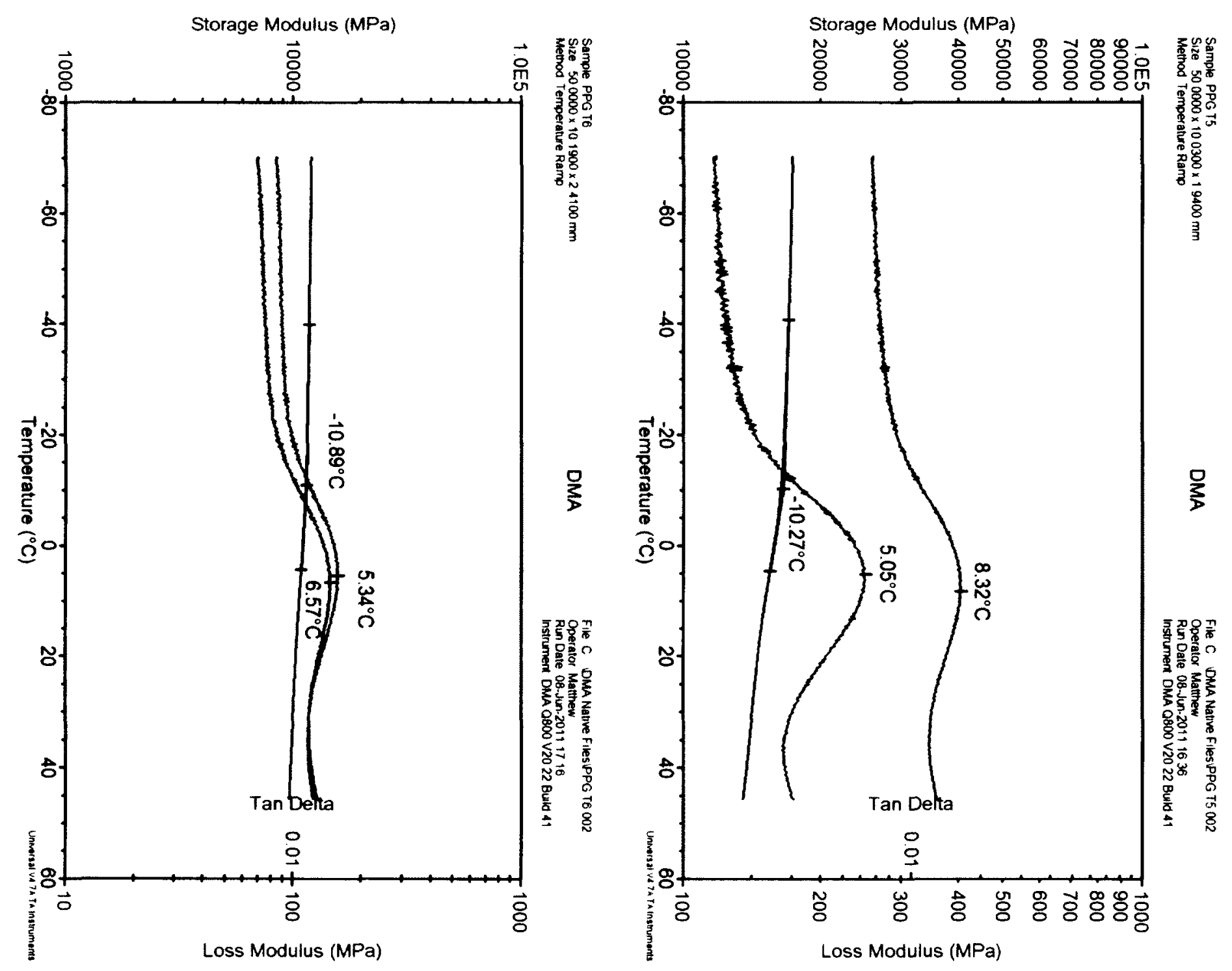



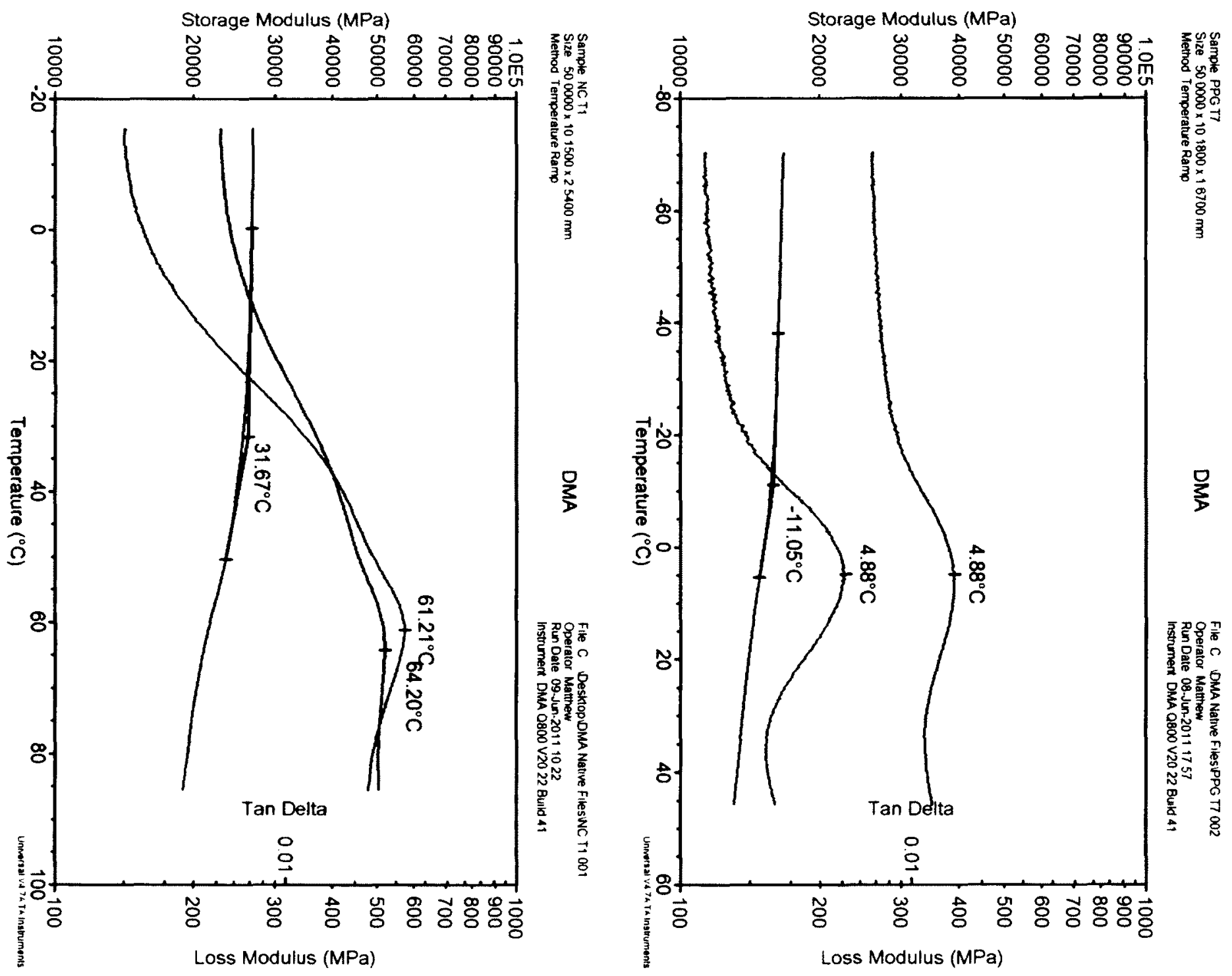

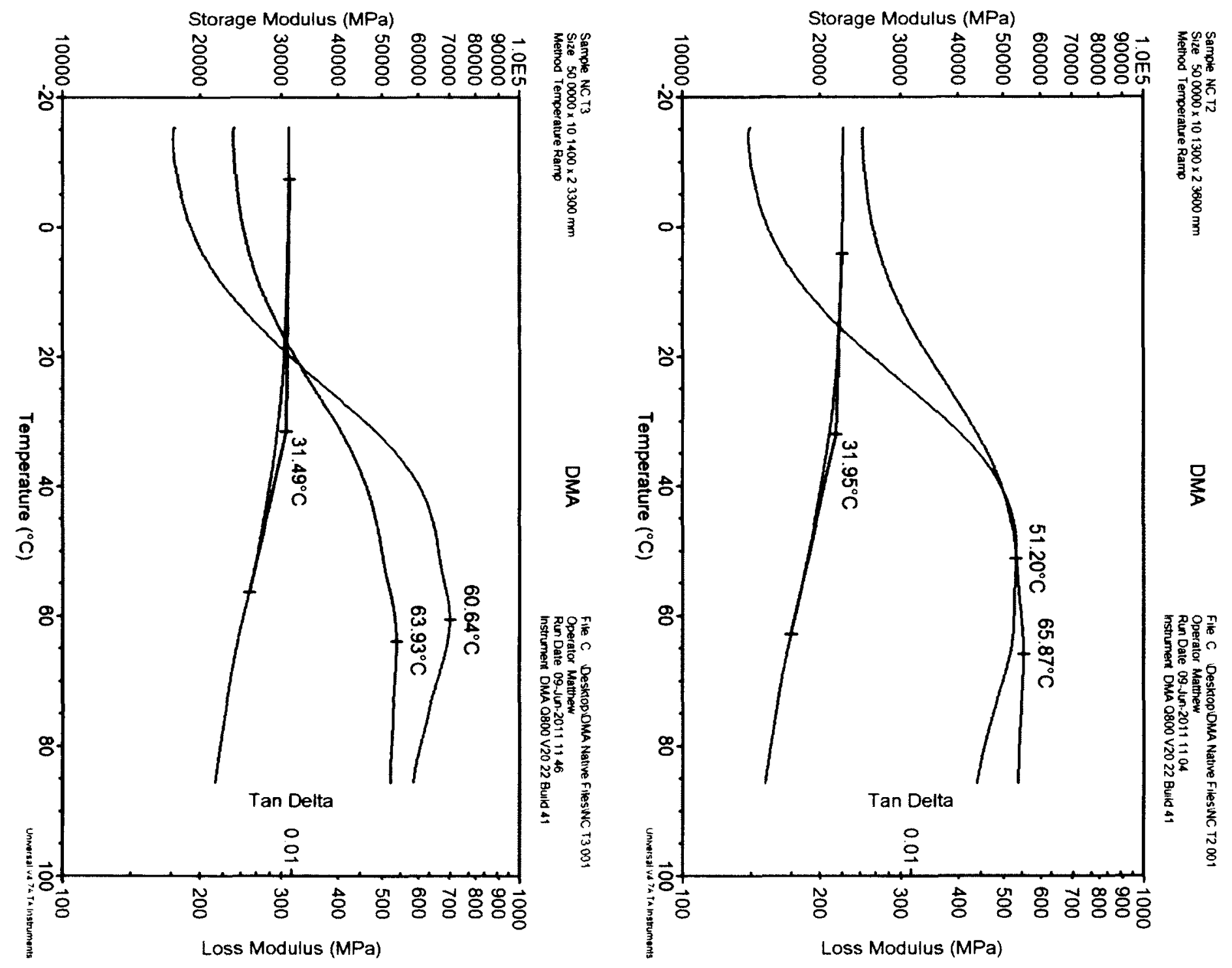

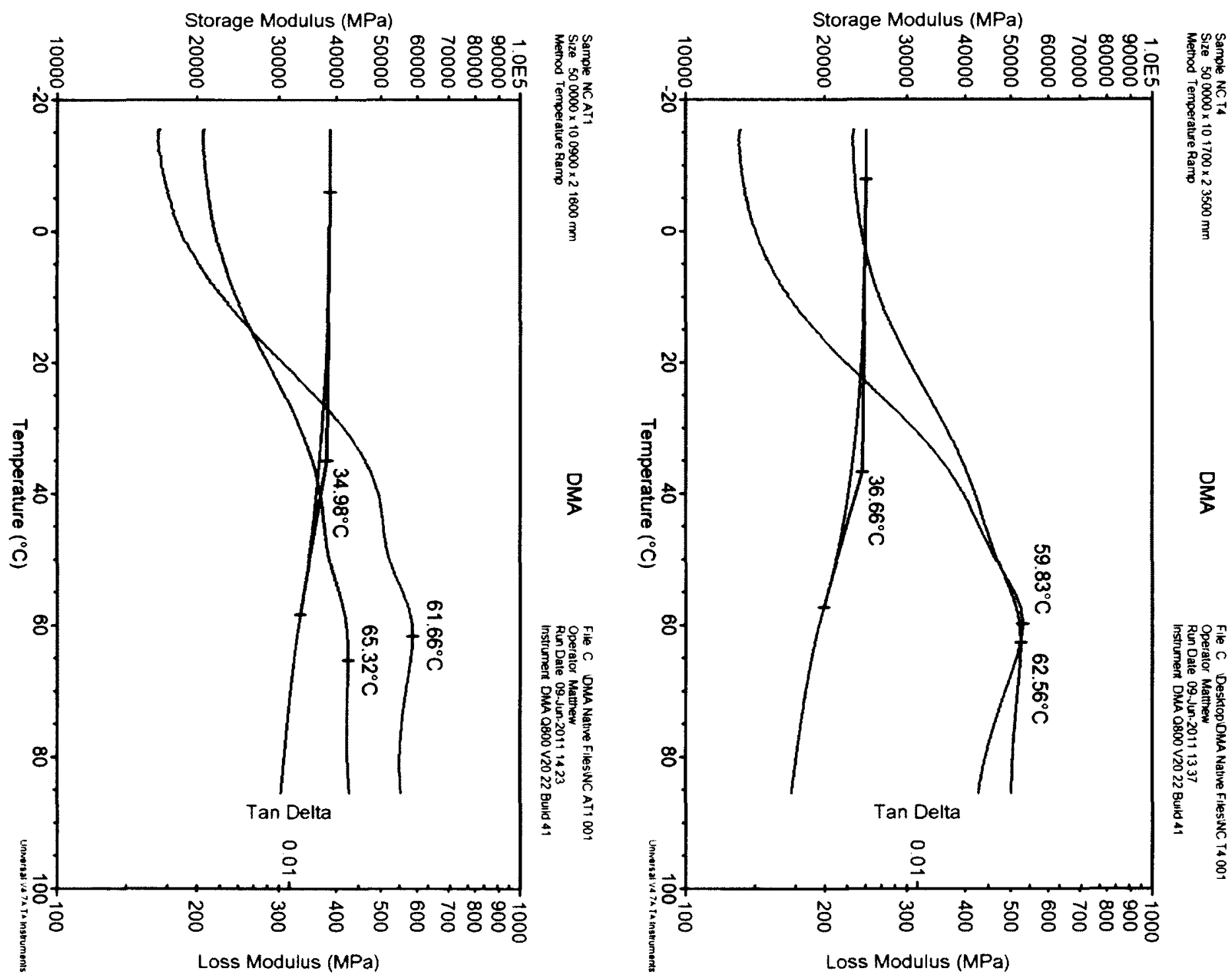


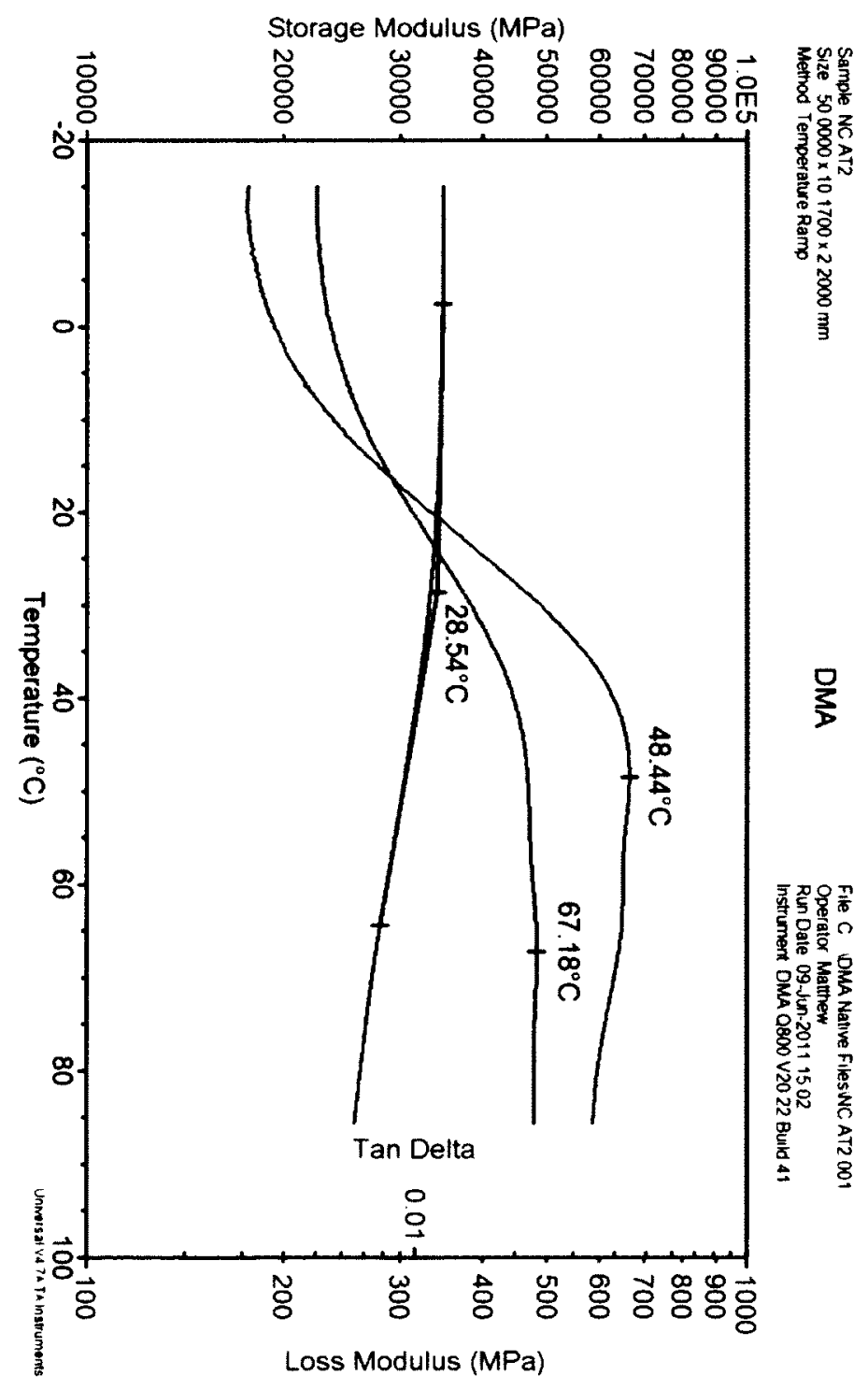




\section{Appendix B}

PPG T1

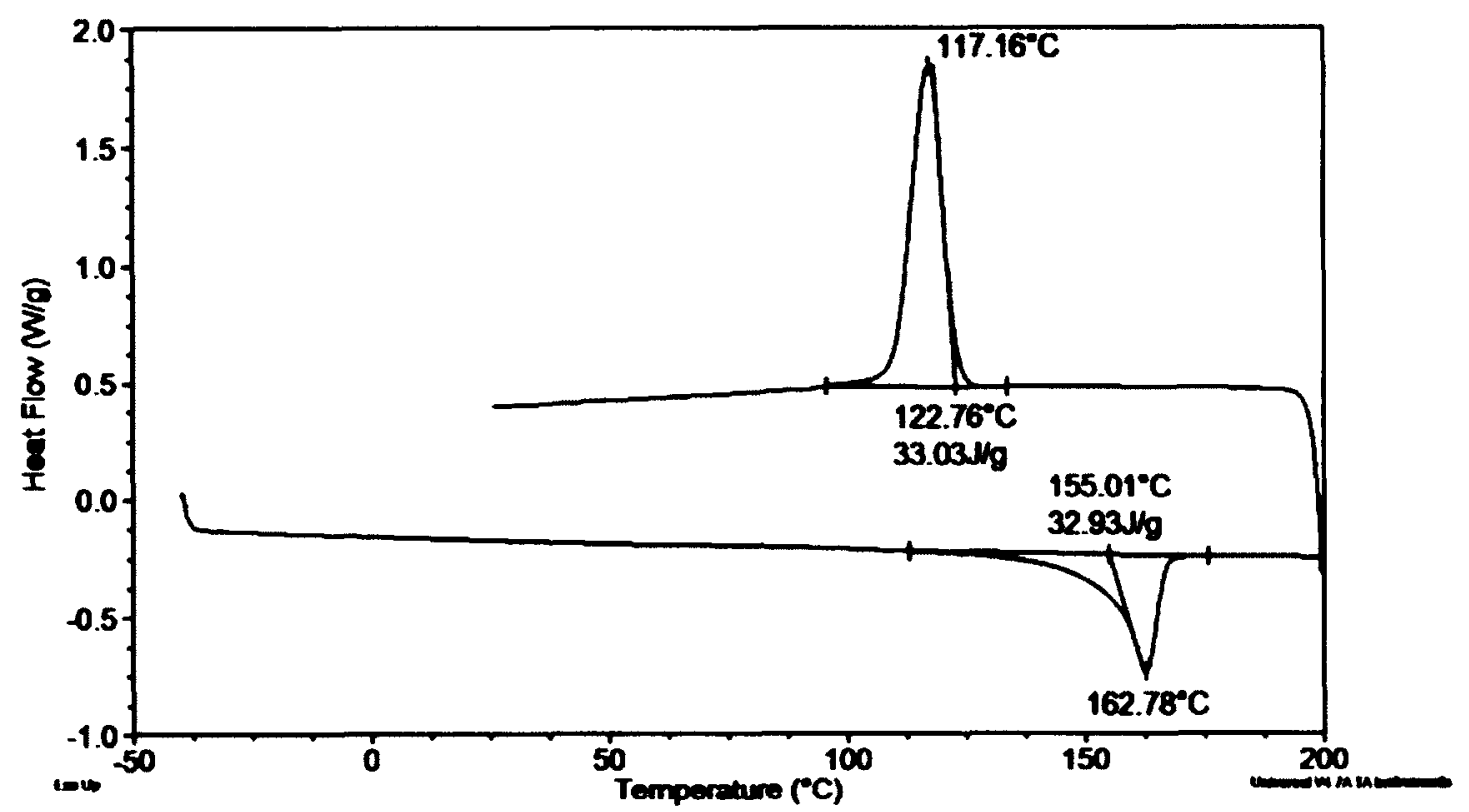

PPG T2

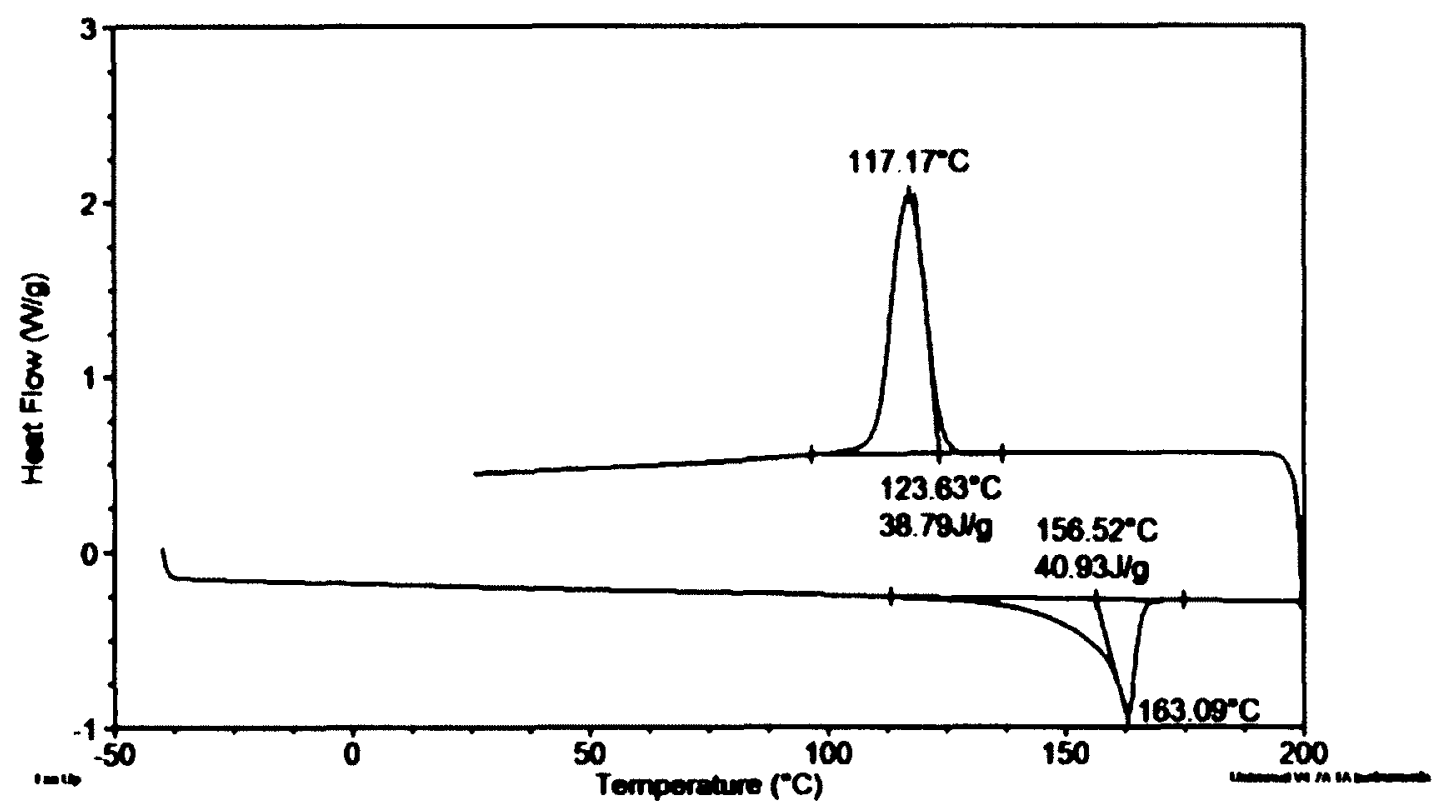


PPG T3

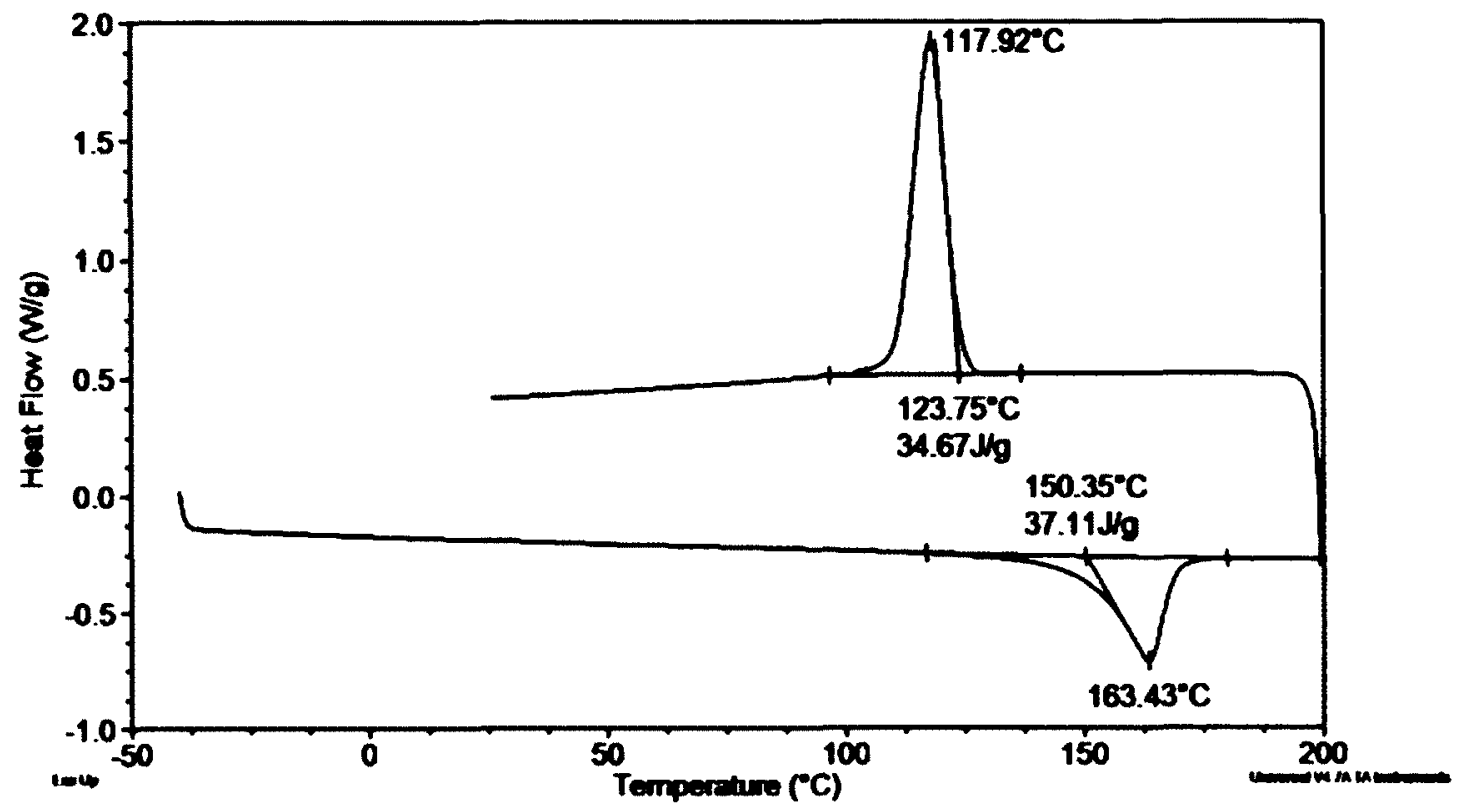

PPG T4

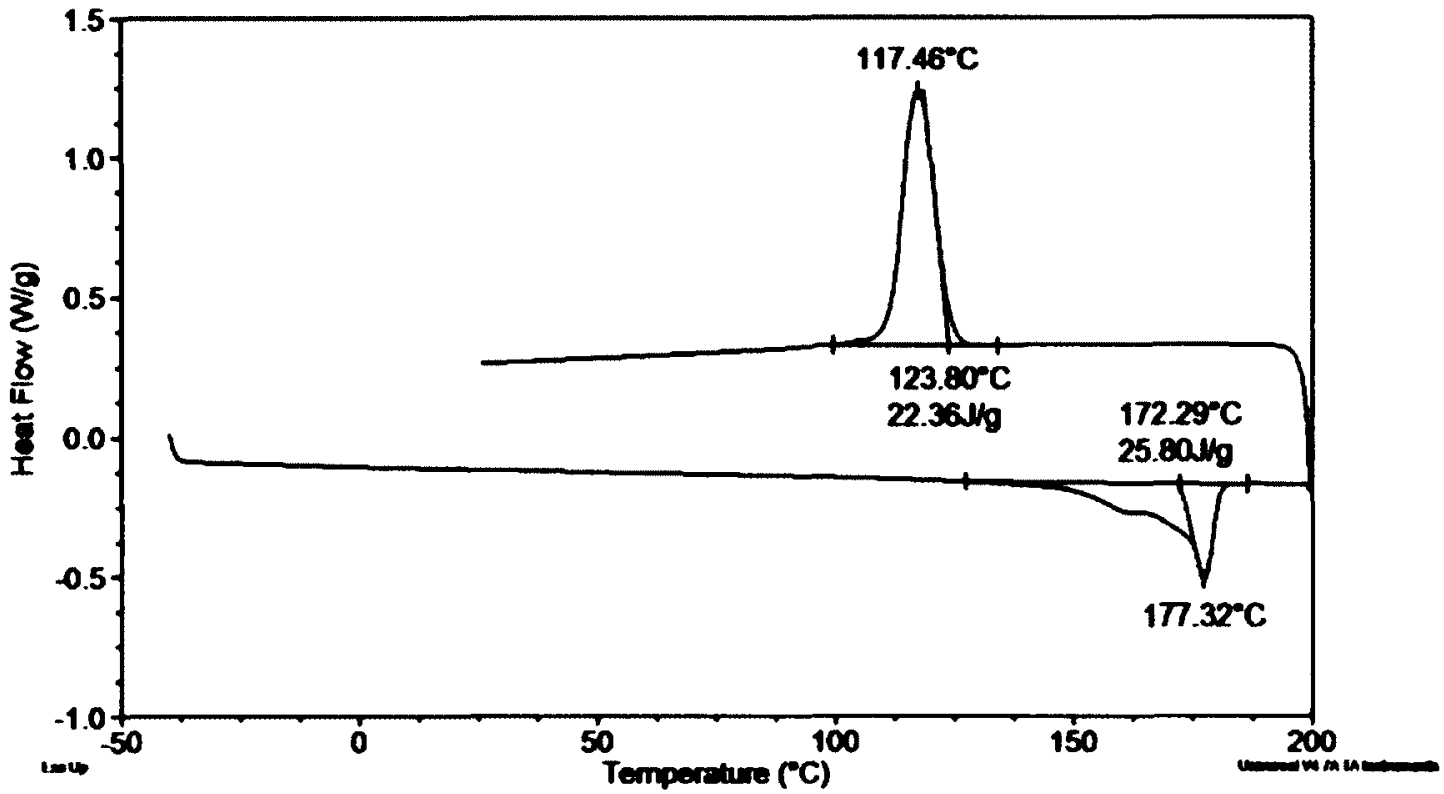




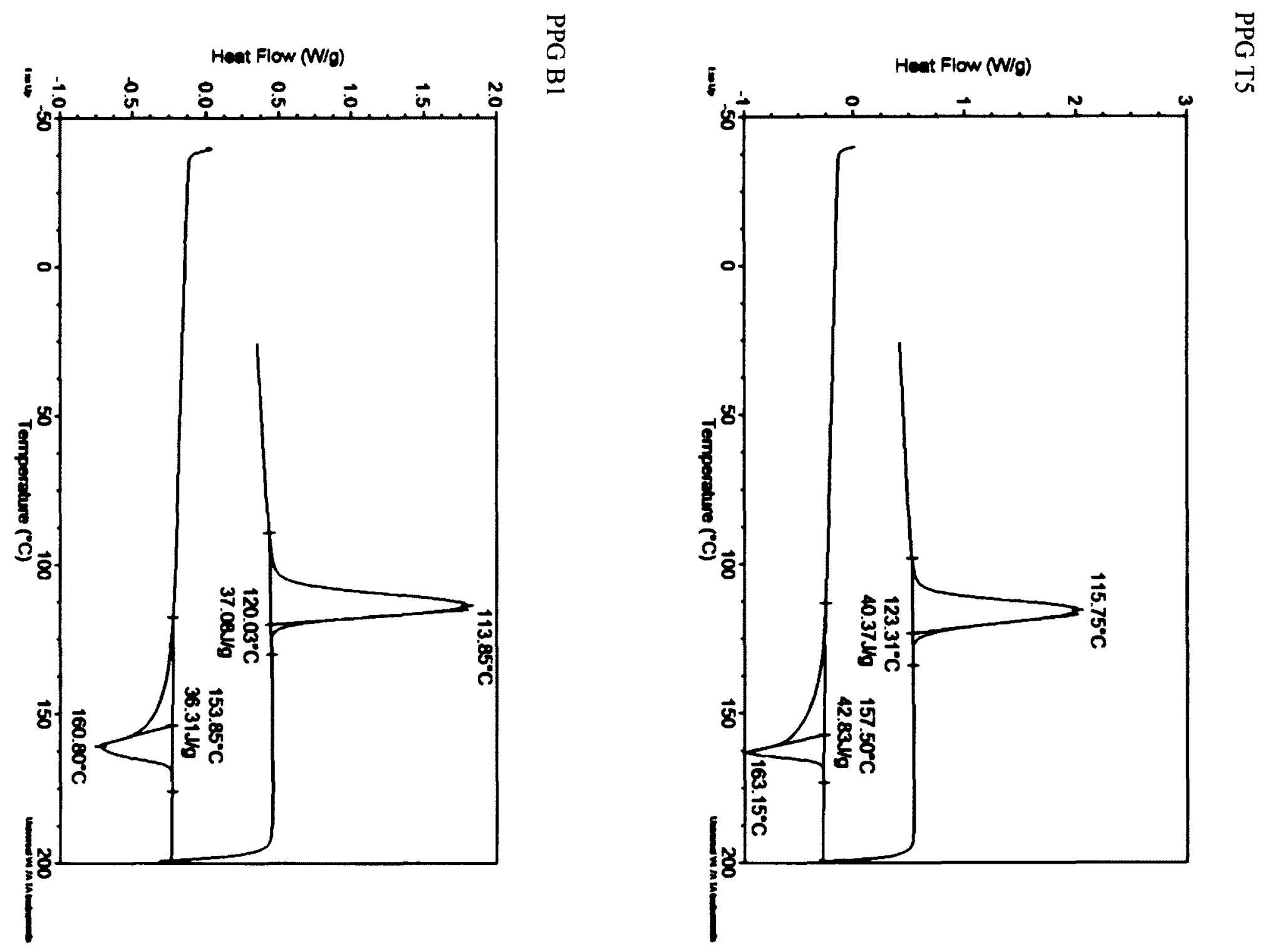



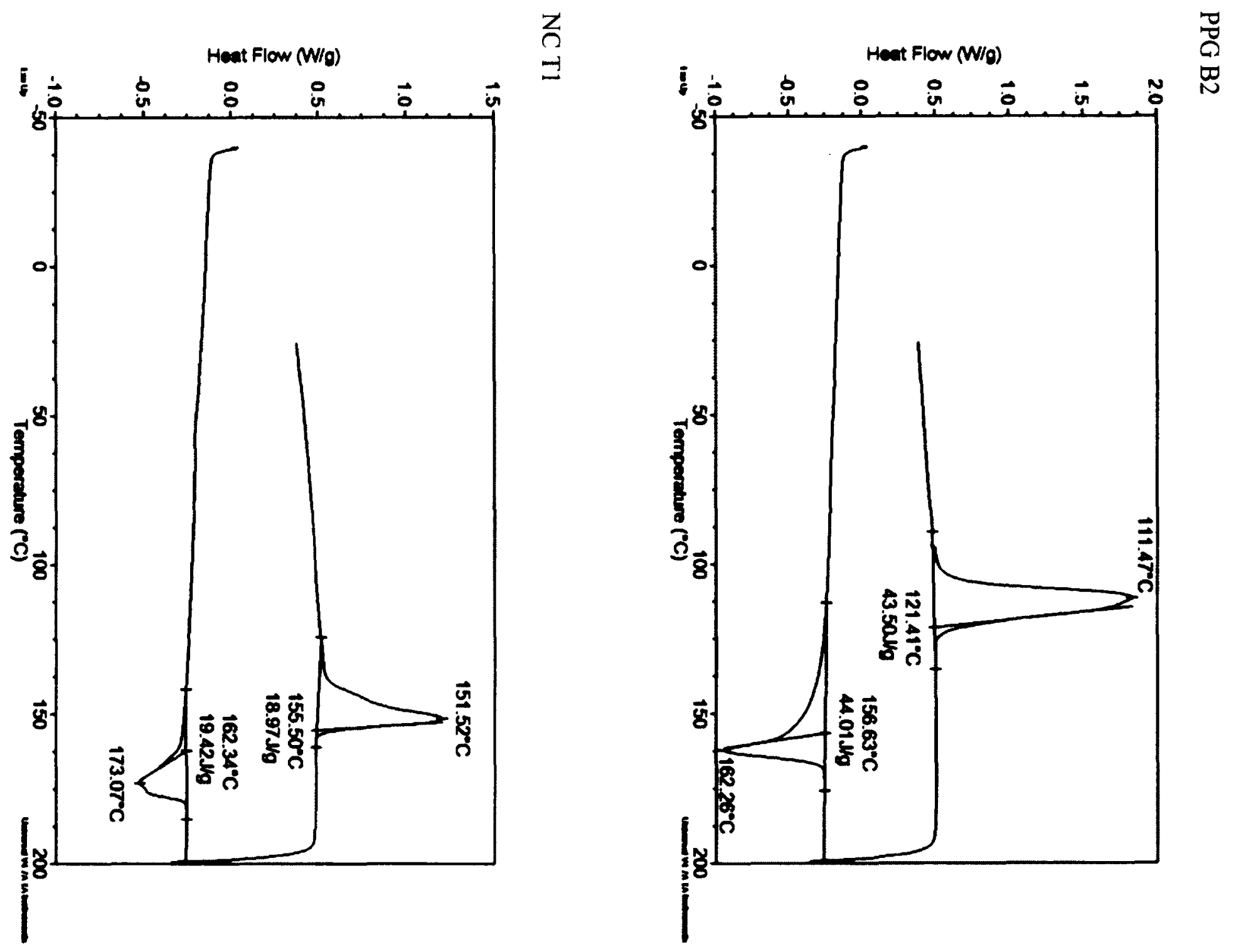


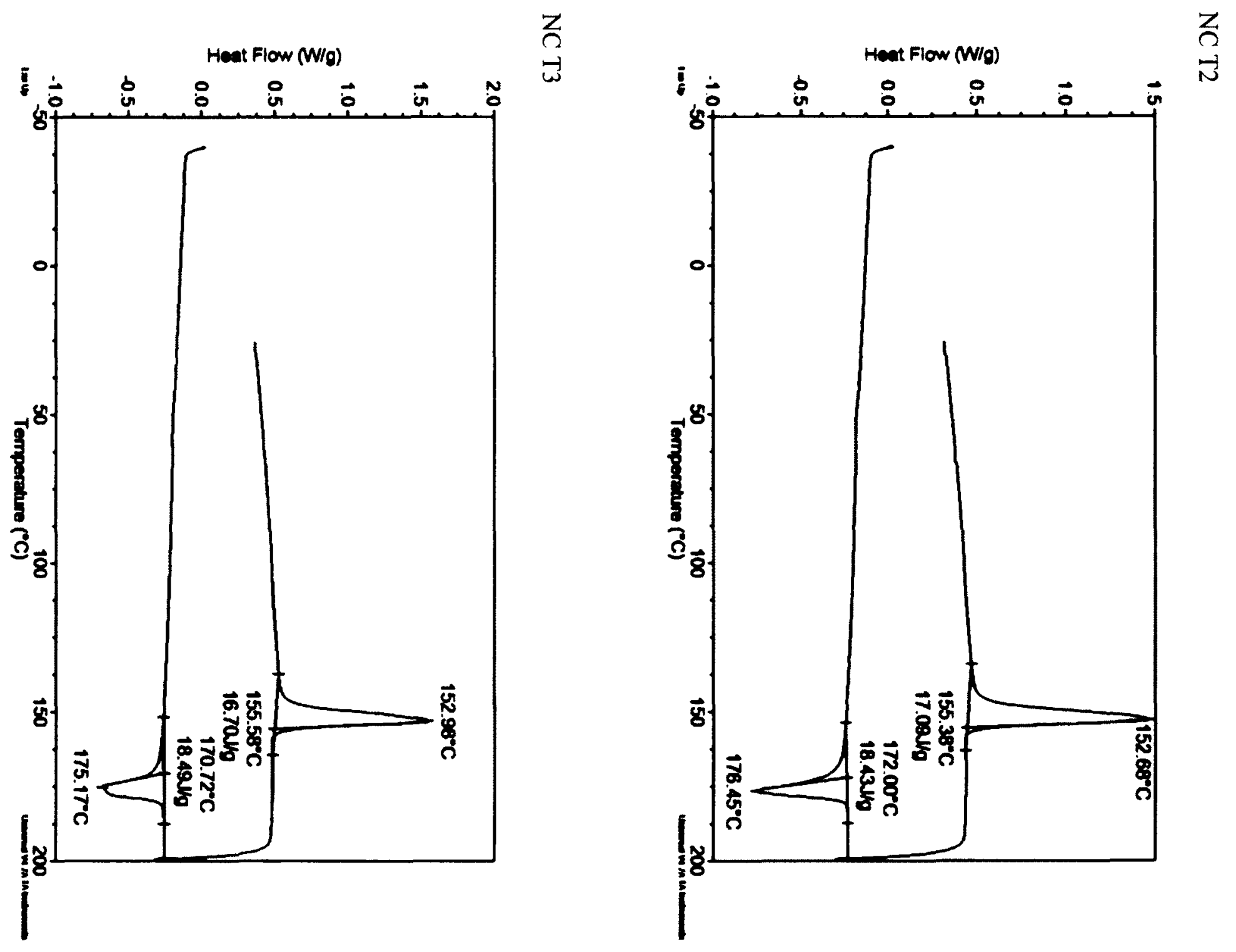


NC T4

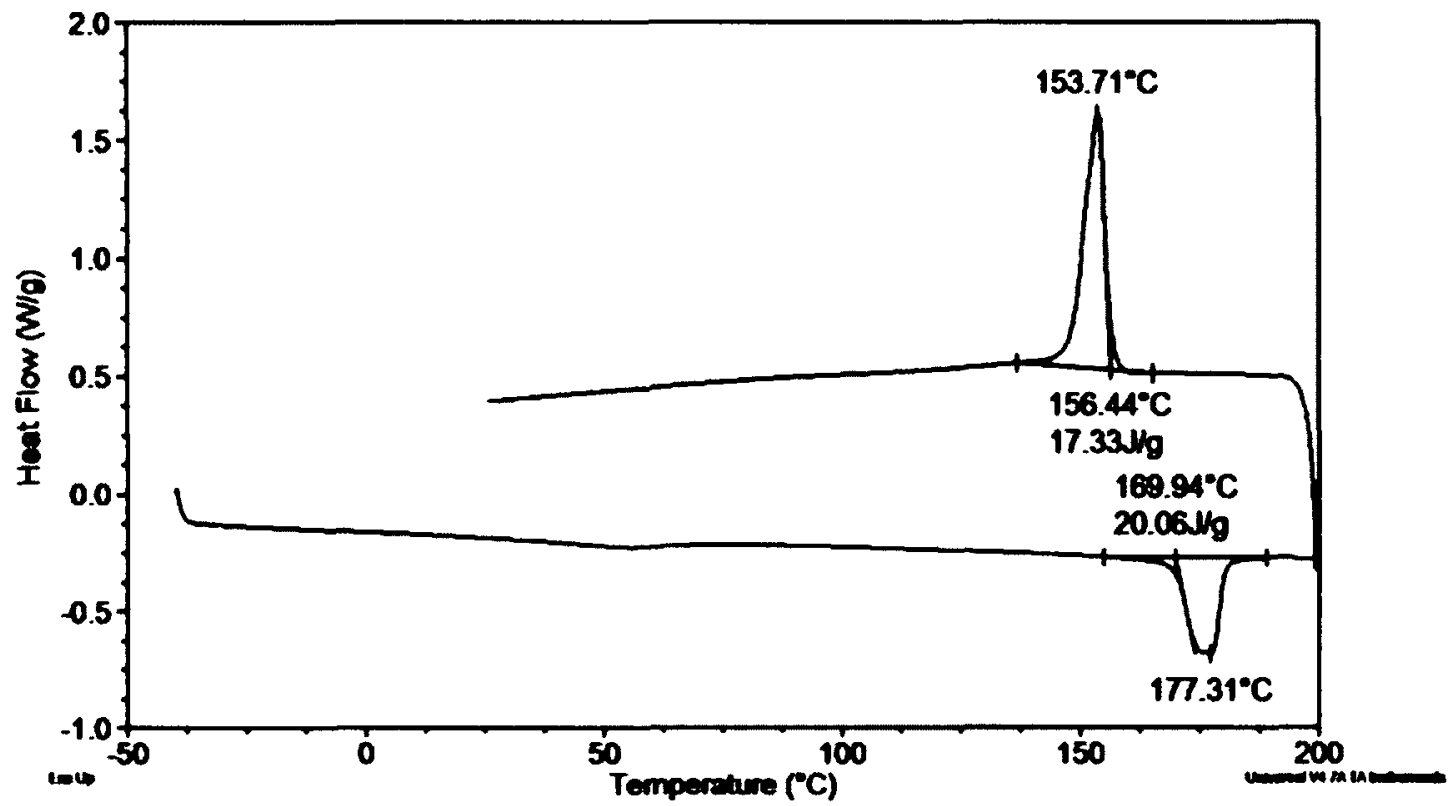

NC B1

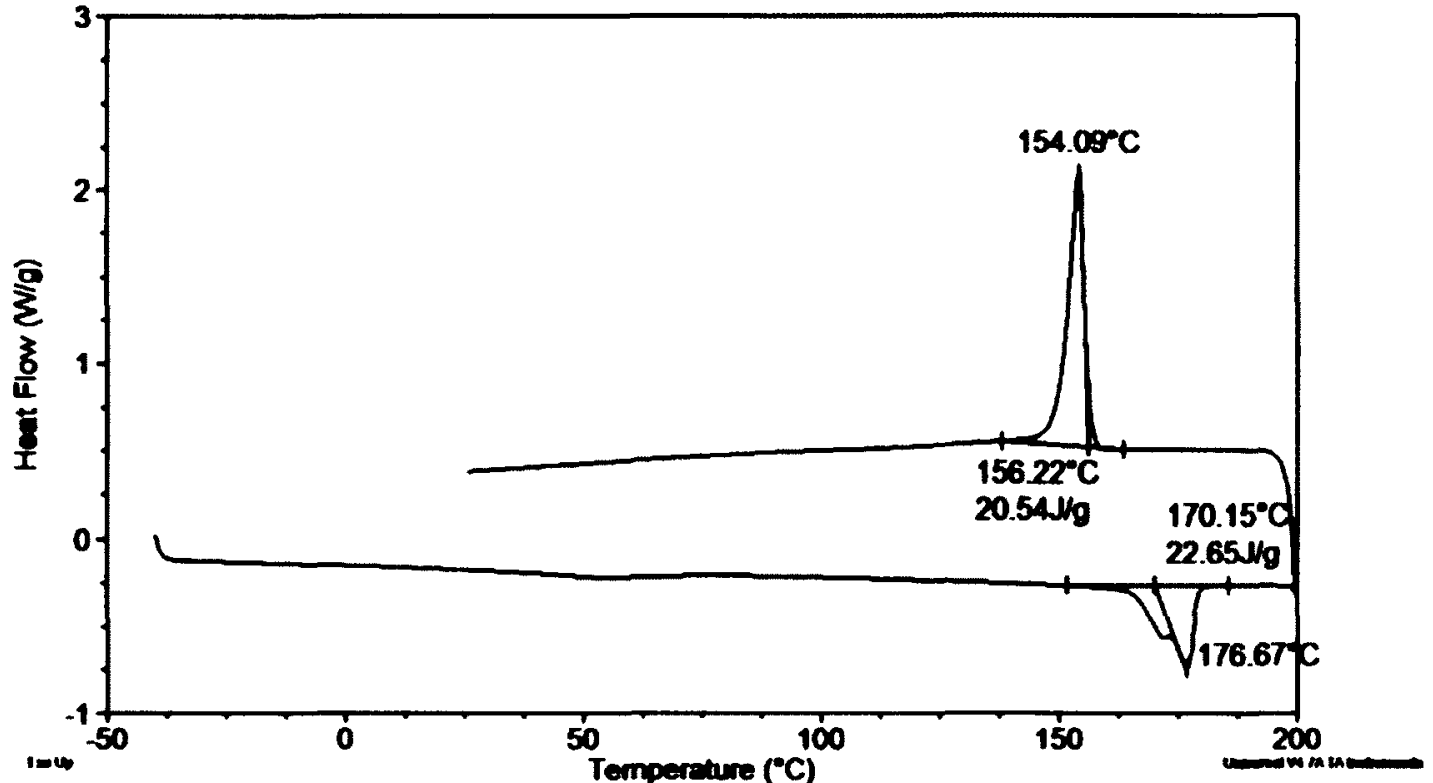




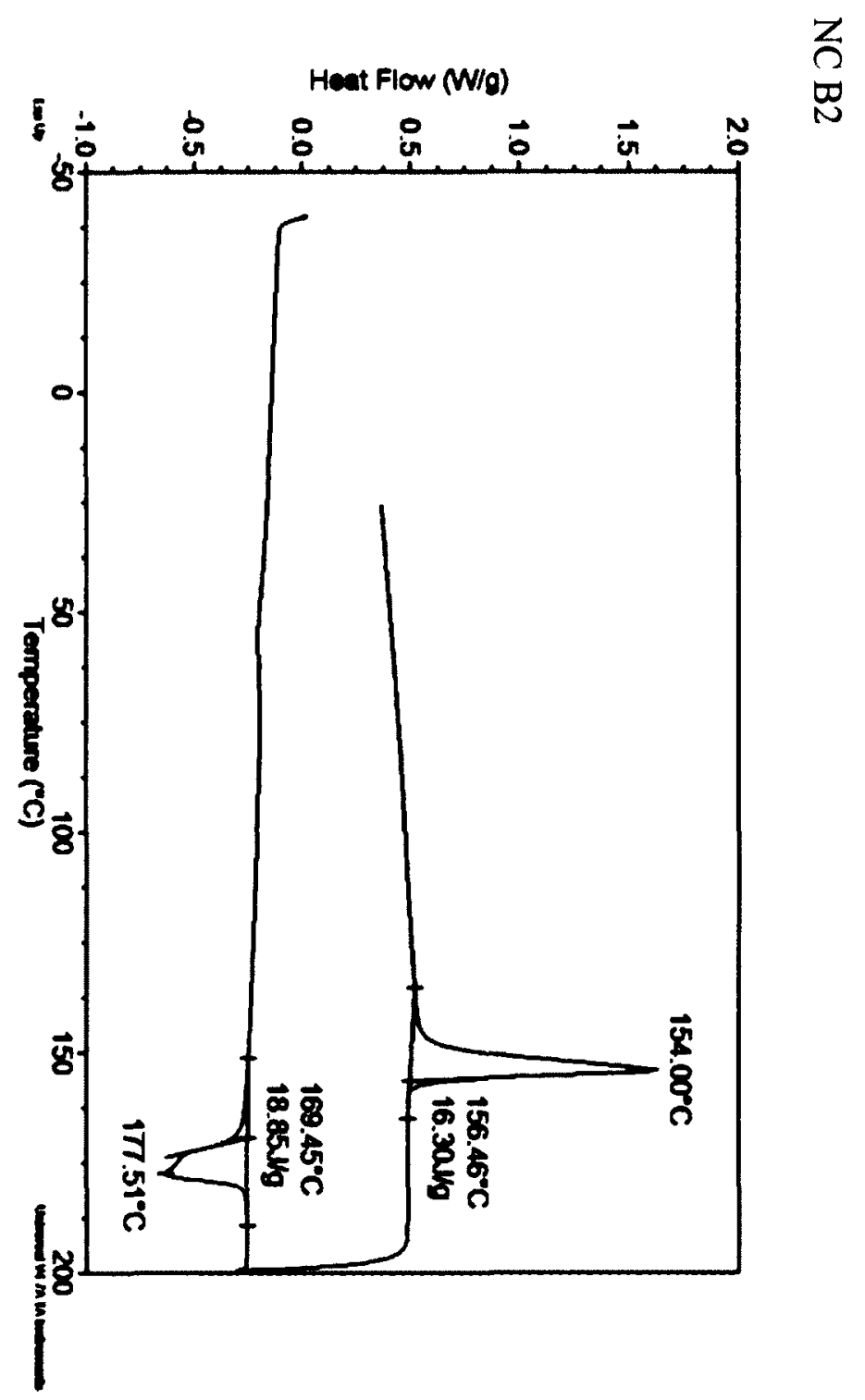




\section{Appendix $\mathbf{C}$}

$\%$ Consolidation Model adapted from "Vacuum Consolidation of Commingled $\%$ Composites" by M. ljaz et al.

\% Coded by Matthew Chiasson

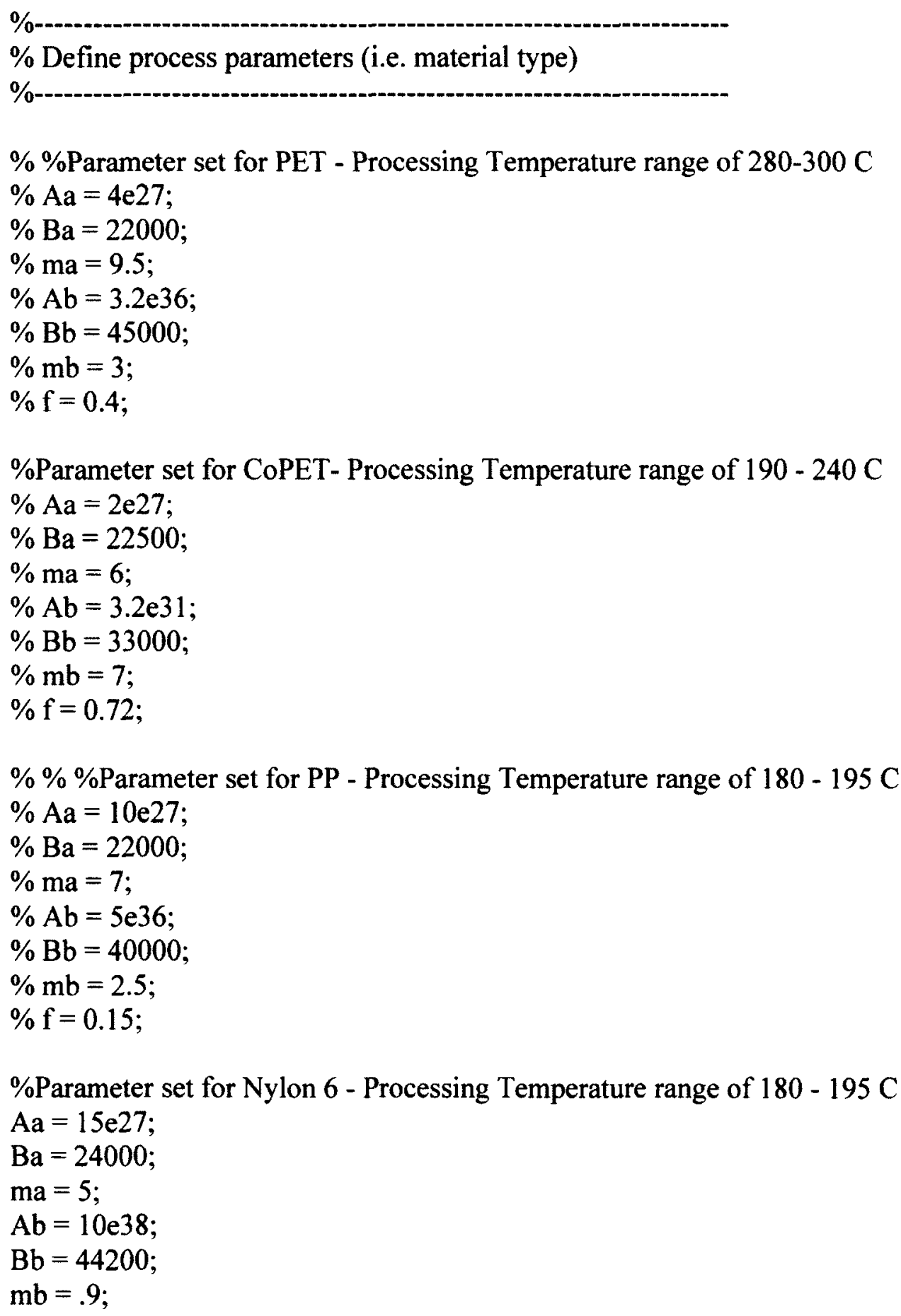


$f=0.06$

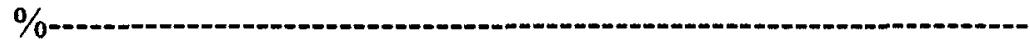

$\%$ Simulation Time Parameters

$\%$

\%Length of simulation in seconds

$t \_\max =194.5^{*} 60$;

\%Sampling rate in $\mathrm{Hz}$

freq $=1 / 30$

$\%$ Define number of time steps

t_steps = t_max*freq;

$\%$

$\%$ Simulation Temperature Parameters

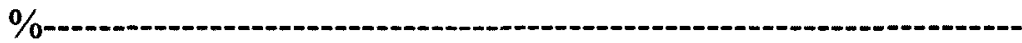

\%Define the maximum processing temperature (in C, converted to $\mathrm{K}$ )

$T_{\text {_max }}=273+195$;

$\%$ Define the heating rate $\mathrm{C}$ or $\mathrm{K}$ per second

$T_{-}$rate $=2.2 / 60$

\%Initial material temperature (Probably room temperature)in Kelvin $T_{\text {_init }}=273+25.8$;

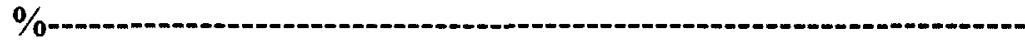

$\%$ Initialize variables for speed

\%

$\% \% \%$ COMMENT OUT TEMPERATURE INITIALIZATION AND PROFILE CREATION IF USING ACTUAL OVEN DATA

$\% \mathrm{~T}=$ zeros $\left(\mathrm{t} \_\right.$steps, 1$)$;

$\mathrm{dXa}=$ zeros(t_steps, 1$)$;

$\mathrm{Xa}=$ zeros $(\mathrm{t}$ _steps, 1$)$;

$\mathrm{dXb}=$ zeros(t_steps, 1$)$

$\mathrm{Xb}=$ zeros(t_steps, 1$)$;

$\mathrm{X}=$ zeros $\left(\mathrm{t} \_\right.$steps, 1$)$;

$\mathrm{t} 1=$ zeros $\left(\mathrm{t} \_\right.$steps, 1$)$;

t2 = zeros(t_steps, 1); 


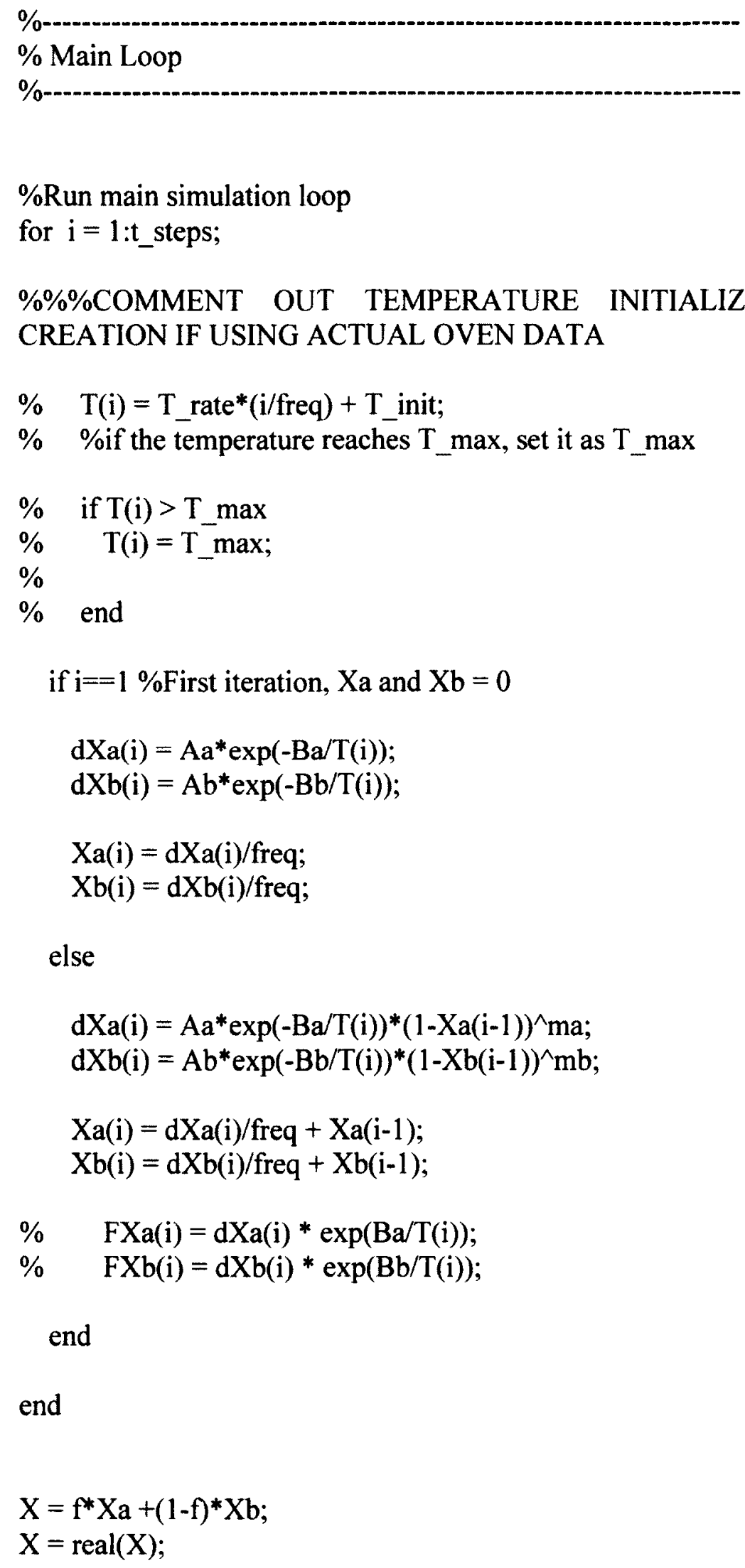




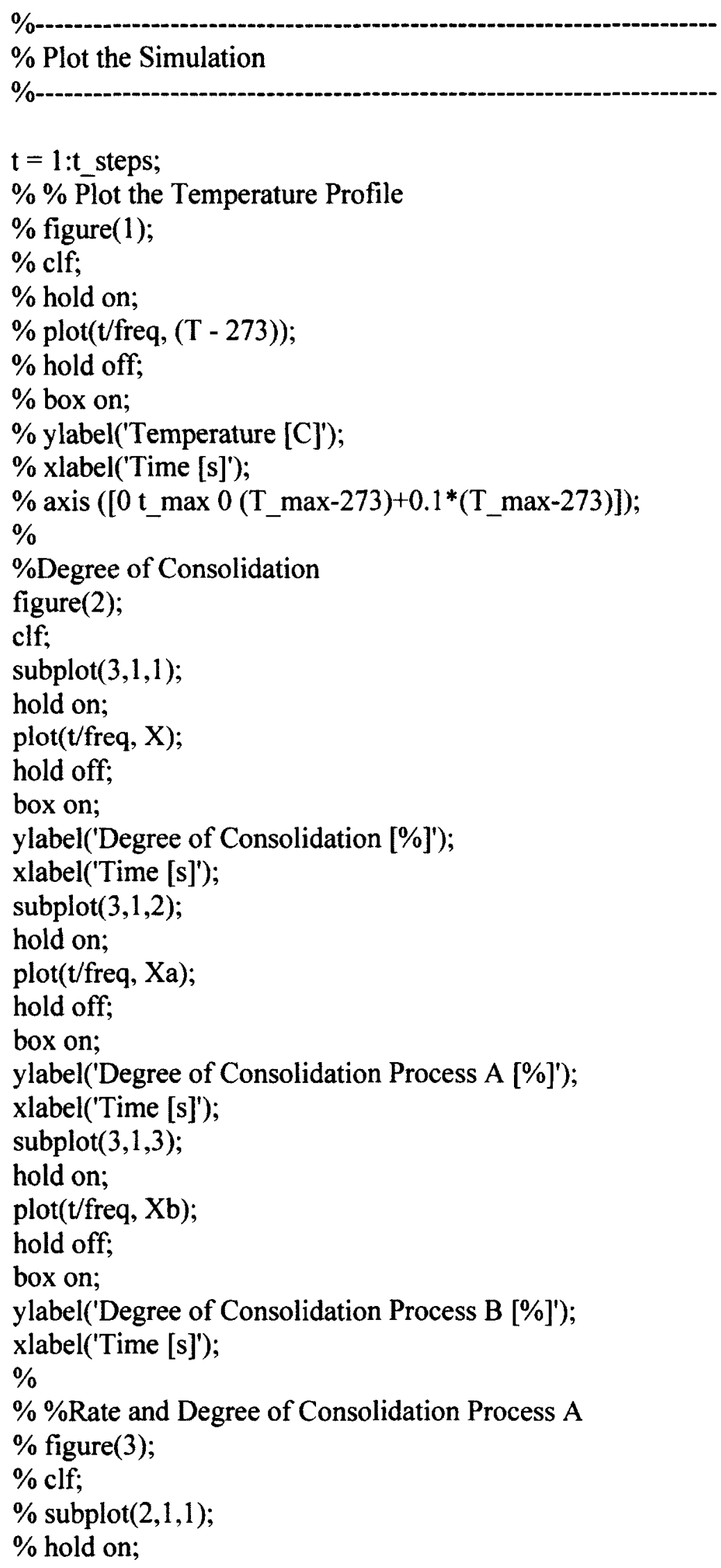


$\%$ plot(t/freq, dXa);

$\%$ hold off;

$\%$ box on;

$\%$ ylabel('Rate of Consolidation A [\%]');

$\%$ xlabel('Time [s]');

$\%$ subplot $(2,1,2)$

$\%$ hold on;

$\% \operatorname{plot}(\mathrm{t} / \mathrm{freq}, \mathrm{Xa})$;

$\%$ hold off;

$\%$ box on;

$\%$ ylabel('Degree of Consolidation Process A [\%]');

$\%$ xlabel('Time [s]');

$\%$

$\% \%$ Rate and Degree of Consolidation Process B

$\%$ figure(4);

$\%$ clf;

$\%$ subplot $(2,1,1)$

$\%$ hold on;

$\%$ plot $(\mathrm{t} / \mathrm{freq}, \mathrm{dXb})$;

$\%$ hold off;

$\%$ box on;

$\%$ ylabel('Rate of Consolidation B [\%]');

$\%$ xlabel('Time [s]');

$\%$ subplot $(2,1,2)$

$\%$ hold on;

$\% \operatorname{plot}(\mathrm{t} /$ freq, $\mathrm{Xb})$

$\%$ hold off;

$\%$ box on;

$\%$ ylabel('Degree of Consolidation Process B [\%]');

$\%$ xlabel('Time [s]'); 


\section{Appendix D}

\begin{tabular}{|c|c|c|}
\hline Variable Name & Description & Unit \\
\hline $\mathrm{t}$ max & Total length of simulation & $\mathrm{s}$ \\
\hline Freq & Sampling rate & $\mathrm{Hz}$ \\
\hline $\mathrm{t}$ steps & Number of time steps & $\mathrm{K}$ \\
\hline $\mathrm{T}$ max & Processing soak temperature & $\mathrm{K} / \mathrm{s}$ \\
\hline $\mathrm{T}$ rate & Temperature ramp up rate & $\mathrm{K}$ \\
\hline $\mathrm{T}$ init & Initial laminate temperature & $\mathrm{K}$ \\
\hline $\mathrm{T}(\mathrm{i})$ & $\begin{array}{c}\text { Process temperature at time } \\
\text { step } \mathrm{i}\end{array}$ & $\% / \mathrm{s}$ \\
\hline $\mathrm{dXa}$ & Rate of process A & $\%$ \\
\hline $\mathrm{Xa}$ & $\begin{array}{c}\text { Normalized degree of process } \\
\text { A completion }\end{array}$ & $\% / \mathrm{s}$ \\
\hline $\mathrm{dXb}$ & Rate of process B & $\%$ \\
\hline $\mathrm{Xb}$ & $\begin{array}{c}\text { Normalized degree of process } \\
\text { B completion }\end{array}$ & $\begin{array}{c}\text { Normalized degree of } \\
\text { consolidation }\end{array}$ \\
\hline $\mathrm{X}$ & &
\end{tabular}

